WILBERT DEMETRIO ALVAREZ LUPACA

\title{
DESAFIOS E OPORTUNIDADES DA GERAÇÃO EÓLICA E TERMELÉTRICA A GÁS NATURAL NO SISTEMA ELÉTRICO PERUANO
}

São Paulo 
WILBERT DEMETRIO ALVAREZ LUPACA

\section{DESAFIOS E OPORTUNIDADES DA GERAÇÃO EÓLICA E TERMELÉTRICA A GÁS NATURAL NO SISTEMA ELÉTRICO PERUANO}

Dissertação apresentada à Escola Politécnica da Universidade de São Paulo para obtenção de título de Mestre em Engenharia Elétrica

Área de concentração:

Sistemas de Potência

Orientadora:

Prof ${ }^{a}$. Dra . Eliane A. F. A. Fadigas

São Paulo 
AUTORIZO A REPRODUÇÃO E DIVULGAÇÃO TOTAL OU PARCIAL DESTE TRABALHO, POR QUALQUER MEIO CONVENCIONAL OU ELETRÔNICO PARA FINS DE ESTUDO E PESQUISA, DESDE QUE CITADA A FONTE.

Este exemplar foi revisado e alterado em relação à versão original, sob responsabilidade única do autor e com a anuência de seu orientador.

São Paulo, 04 de abril de 2012.

Assinatura do autor

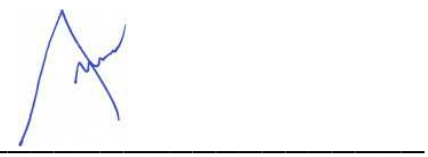

Assinatura do orientador

\section{FICHA CATALOGRÁFICA}

Alvarez Lupaca, Wilbert Demetrio.

Desafios e oportunidades da geração eólica e termelétrica a gás natural no sistema elétrico Peruano / W.D. Alvarez Lupaca. - ed. rev. -- São Paulo, 2012. $194 \mathrm{p}$.

Dissertação (Mestrado) - Escola Politécnica da Universidade de São Paulo. Departamento de Engenharia de Energia e Automação Elétricas.

1. Energia eólica - Peru 2. Energia termelétrica - Peru 3. Gás natural - Peru I. Universidade de São Paulo. Escola Politécnica. Departamento de Engenharia de Energia e Automação Elétricas II. t. 


\section{FOLHA DE APROVAÇÃO}

Wilbert Demetrio Alvarez Lupaca

Desafios e Oportunidades da Geração Eólica e Termelétrica a Gás Natural no Sistema Elétrico Peruano

Dissertação apresentada à Escola
Politécnica da Universidade de São Paulo
para obtenção de título de Mestre em
Engenharia Elétrica
Área de concentração: Sistemas de Potência

Aprovado em:

Banca Examinadora

Prof ${ }^{a}$. Draㅡ. Eliane Aparecida Faria Amaral Fadigas Instituição: PEA-USP

Assinatura:

Prof.Dr. Dorel Soares Ramos Instituição: PEA-USP

Assinatura:

Prof. Dr. Edmilson Moutinho dos Santos Instituição: IEE-USP

Assinatura: 
DEDICATÓRIA

À Deus e minha família 


\section{AGRADECIMENTOS}

A minha orientadora Profa. Dra. Eliane Aparecida Faria Amaral Fadigas, pela paciência, sugestões e apoio transmitido no desenvolvimento do presente trabalho.

Aos meus pais Juan Luis e Genara e irmão Fredy, pelo incentivo, motivação e força que ao longo da minha vida me permitiram chegar até aqui. E em especial a minha mãe que sempre esteve estimulando meu desenvolvimento profissional.

Ao Prof. Dr. Dorel Soares Ramos, pela inspiração, contribuição, paciência e objetividade nas avaliações.

Aos amigos e colegas Luiz Marcos, Bernardette, Lizeth, Roberto, Teddy, Elmer Lenin, Omar, Elvis, Carlos Alberto, Norman, Wilingthon, Pablo, Carlos, Javier e muitos outros que me apoiaram incondicionalmente, com o intercambio de experiências, revisão e comentários.

Ao Prof. Dr. Edmilson Moutinho dos Santos pelo estimulo, avaliações objetivas e inspiração.

Ao meu grande amigo Edward Alvarez pelas valiosas dicas, sugestões e contribuições que muito contribuíram para a realização desta dissertação.

À CAPES pelo suporte financeiro.

E a todos aqueles que direta ou indiretamente contribuíram para este trabalho. 


\section{RESUMO}

Vários países ao redor do mundo têm procurado cada vez mais diversificar suas matrizes elétricas com o objetivo de diminuir a dependência de combustíveis fósseis e reduzir as emissões dos gases responsáveis pelo agravamento do efeito estufa na atmosfera. Com isso, tem crescido a participação de algumas fontes renováveis de energia que, até duas décadas atrás, não ocupavam lugar de destaque na matriz elétrica mundial, como por exemplo, a energia eólica. O gás natural, embora seja um recurso fóssil, é considerado menos poluente e este tem substituído os derivados de petróleo em várias aplicações, entre elas na geração de eletricidade. O Peru, no intuito de atender a sua demanda crescente por eletricidade, vem buscando novas alternativas energéticas, como por exemplo, a energia eólica e, em maior escala, a termeletricidade com o uso do gás natural, cuja disponibilidade aumentou consideravelmente após o início da exploração das jazidas de Camisea.

O presente trabalho tem o objetivo de avaliar, tanto em um cenário de curto prazo como de longo prazo, o impacto de uma maior inserção da energia eólica e a expansão das térmicas a gás natural na operação econômica do sistema hidrotérmico Peruano. Esta avaliação é realizada com base na análise das seguintes figuras de mérito: custo marginal de operação (CMO), custo de operação do sistema, deslocamento de geração térmica e perfil de despacho de geração das unidades geradoras $(\mathrm{MWh})$. Foram realizadas simulações do sistema elétrico peruano "com" e "sem" participação da geração eólica e a partir dos resultados obtidos, efetuou-se uma análise comparativa com base nos cenários propostos. Para efetuar as simulações foi utilizada a ferramenta computacional denominada PERSEO. Este programa, utilizado pelo setor Elétrico Peruano, permite simular o sistema hidrotérmico com característica de representação de um sistema multireservatorio, multi-nodal e multi-cenário utilizando programação dinâmica estocástica. O trabalho também apresenta as principais características do Setor Elétrico Peruano enfocando sua evolução, desafios e plano de expansão, onde, com base neste se elaborou as simulações propostas. Os resultados obtidos com a inserção da geração eólica, baseados nas premissas e cenários propostos, foram considerados positivos. Houve uma diminuição média anual de $18 \%$ nos custos marginais de operação, o que representa uma diminuição nos custos de operação em torno de US\$ 28 milhões ao ano, ou seja, 4\% do total. Com relação à geração 
térmica a gás natural, o impacto da maior inserção desta no sistema também foi positivo, com redução dos custos de operação do sistema e deslocamento de geração térmica mais poluente (óleo combustível e carvão mineral). Adicionalmente efetuou-se uma análise do potencial de complementaridade da geração eólica e hídrica e do plano de expansão da geração hídrica com exportação de energia elétrica para o Brasil.

Palavras-chave: Geração eólica. Térmica a gás natural. Sistema elétrico peruano. Despacho econômico. 


\section{ABSTRACT}

Several countries around the world have increasingly sought to diversify their electrical matrix in order to reduce dependence on fossil fuels and reduce emissions of gases responsible for worsening greenhouse effect in the atmosphere. As a result, has grown the participation of some renewable energy sources that until two decades ago did not occupied a prominent place in the world energy matrix, such as wind power. The Natural gas, although it is a fossil resource, is considered less pollutant and it has replaced petroleum products in various applications among them in the generation of electricity. The Peru, in order to meet its growing demand for electricity, has been seeking new alternatives between them wind power, and on a larger scale, thermoelectricity with the use of natural gas whose availability has increased considerably since the beginning of the exploitation of the fields of Camisea.

This study has the objective of evaluate, both in a short-term outlook and long-term the impact of a greater insertion of wind energy and expansion of natural gas thermal on the economic operation of the hydrothermal Peruvian system. This evaluation is performed based on the analysis of the following arguments of merit: the marginal cost of operation (CMO), cost of system operation, displacement of thermal generation and profile and generation dispatch of generating units (MWh). Simulations of Peruvian electric system "with" and "without" participation of wind generation were realized and from the results obtained, it was performed a comparative analysis based on the proposed scenarios. To effectuate the simulations, it was used a computational tool called PERSEO. This program, used by the Peruvian electricity sector, allows simulating the hydrothermal system with features of a representation of system multi-reservoir, multi-nodal and multi-scenario using stochastic dynamic programming. The study also presents the main characteristics of the Peruvian Electric Sector focusing on its evolution, challenges and expansion plan, where, based on this proposal were elaborated the simulations. The results obtained with the insertion the wind generation, based on premises and proposed scenarios, were considered positive. There was an average annual decline of $18 \%$ in the marginal costs of operation, which represents a decrease in operating costs around U.S. $\$ 28$ million a year, i.e. $4 \%$ of the total. With respect to natural gas thermal generation, the impact of greater insertion of this in the system was also 
positive, with reduction the cost system operation and displacement of more polluting thermal generation (fuel oil and coal). Additionally it was performed an analysis of the complementarity potential of generation wind and hydro and of the plan for expansion of hydro power with electrical energy export to Brazil.

Keywords: Wind generation. Thermal natural gas. Peruvian electric system. Economic dispatch. 


\section{LISTA DE FIGURAS}

Figura 1 - Os primeiros dez países com maior capacidade eólica instalada a 2010 .6

Figura 2 - Evolução das turbinas eólicas nos últimos 25 anos. .7

Figura 3 - Projeções da participação por fonte energética na geração mundial de eletricidade 13

Figura 4 - Esquema do setor elétrico peruano. 19

Figura 5 - Funções dos órgãos institucionais do setor elétrico. .24

Figura 6 - Organização do setor elétrico peruano. .25

Figura 7 - Evolução do crescimento do PIB e da produção. 28

Figura 8 - Evolução da potencia efetiva, demanda máxima e reserva (2001 - 2010) do SEIN. .30

Figura 9 - Porcentagem de participação por fonte energética na potência efetiva do SEIN em 2010. 31

Figura 10 - Produção de energia por tipo de geração no SEIN 2010 ........................32

Figura 11 - Produção de energia por fonte de energia no SEIN 2010 .....................33

Figura 12 - Produção de energia por empresas no SEIN 2010 ..............................33

Figura 13 - Mapa do sistema elétrico interligado nacional peruano (SEIN), 2011 ....36

Figura 14 - Evolução das vendas de eletricidade no SEIN. ....................................39

Figura 15 - Evolução da máxima demanda do SEIN............................................41

Figura 16 - Projeção da demanda de energia do SEIN (2009 - 2019) .....................41

Figura 17 - Projeção da demanda por potência do SEIN (2009 - 2019) ................. 42

Figura 18 - Transações de energia no setor elétrico peruano ...............................45

Figura 19 - Produção de energia e custos marginais médias mensais do SEIN. .....53

Figura 20 - Localização geográfica das hidrelétricas da Amazônia Peruana. ..........70

Figura 21 - Localização geográfica da futura interligação elétrica Peru - Brasil .......75

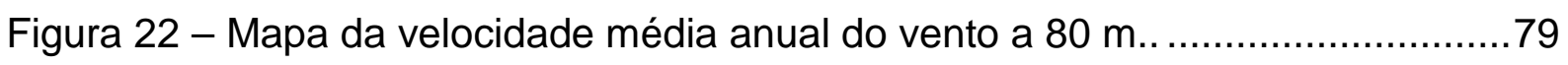

Figura 23 - Complementaridade da geração eólica - hidrelétrica ...........................81

Figura 24 - Estrutura geral da remuneração da geração RER ……..........................84

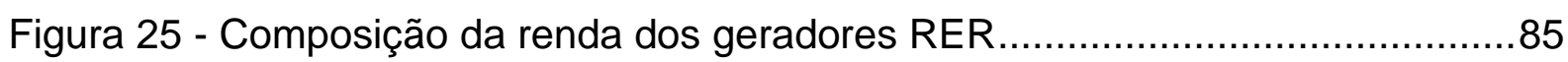

Figura 26 - Estrutura da remuneração dos geradores RER sem ingresso garantido 86

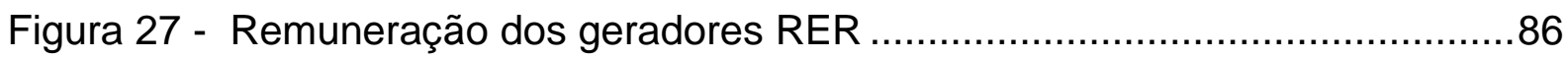

Figura 28 - Localização de projetos eólicos em estudos .......................................90 
Figura 29 - Localização e participação das jazidas de gás natural no Perul.............93

Figura 30 - Mapa do gasoduto de transporte de gás natural (Camisea - Lima).......95

Figura 31 - Evolução de consumo de gás natural no setor elétrico...........................98

Figura 32 - Plano de expansão de gasodutos no Peru. .........................................99

Figura 33 - Oferta máxima garantida de gás natural de Camisea.........................100

Figura 34 - Projeção do preço do GN de Camisea em referencia internacional......102

Figura 35 - Evolução da participação porcentual do GN na produção de energia do SEIN (GW.h.)

Figura 36 - Distribuição da potência efetiva por tipo de fonte energética do SEIN..105 Figura 37 - Balanço energético de potência - demanda do SEIN para o período 2010 $-2019$ 106

Figura 38 - Potência efetiva termelétrica por tipo de tecnologia no SEIN..............107

Figura 39 - Potência efetiva com geração termelétrica no SEIN. .........................108

Figura 40 - Evolução da produção termelétrica de gás natural na matriz elétrica ...109 Figura 41 - VPL por milhão investido (US\$) e preços de energia no SEIN. ...........114

Figura 42 - TIR por milhão investido (US\$) e preços de energia no SEIN. ............115

Figura 43 - Impacto do gás natural no custo de longo prazo da eletricidade do SEIN.

Figura 44 - Preço do gás natural $x$ investimento em hidrelétrica..........................119

Figura 45 - Processo de decisão em sistemas hidrotérmicos..............................123

Figura 46 - Custos associados à operação dos reservatórios..............................124

Figura 47 - Visão geral da metodologia.....................................................130

Figura 48 - Esquema Funcional do Modelo PERSEO ........................................136

Figura 49 - Energia sem geração eólica no curto prazo. ........................................144

Figura 50 - Produção de energia por tipo de fonte no curto prazo. .......................144

Figura 51 - Energia com geração eólica no curto prazo. .....................................145

Figura 52 - Produção de energia por tipo de fonte no curto prazo. ......................146

Figura 53 - Custo marginal de operação no curto prazo. ......................................147

Figura 54 - Custo marginal médio anual no curto prazo......................................148

Figura 55 - Evolução do custo de operação no curto prazo. ................................149

Figura 56 - Custo de operação no curto prazo. ................................................149

Figura 57 - Deslocamento da geração térmica no curto prazo. ..............................151

Figura 58 - Complementaridade hídrica - eólica no curto prazo. ...........................152

Figura 59 - Energia sem geração eólica no longo prazo. ....................................154 
Figura 60 - Produção de energia por tipo de fonte no longo prazo........................155

Figura 61 - Produção de energia por tipo de fonte no longo prazo.......................157

Figura 62 - Custo marginal de operação no longo prazo....................................158

Figura 63 - Custo marginal médio anual do SEIN no longo prazo..........................158

Figura 64 - Evolução do custo de operação no longo prazo. ...............................159

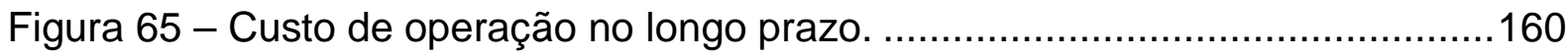

Figura 66 - Deslocamento da geração térmica no longo prazo. ............................161

Figura 67 - Complementaridade hídrica - eólica no longo prazo. .........................162

Figura 68 - Custo marginal de operação do SEIN. ...........................................164

Figura 69 - Custo marginal de operação com e sem exportação SEIN....................165

Figura 70 - Custo de operação com e sem exportação SEIN................................165 


\section{LISTA DE TABELAS}

Tabela 1 - Principais empresas elétricas do mercado elétrico peruano. 28

Tabela 2 - Potência efetiva, demanda máxima e reserva - SEIN (2001- 2010) (MW). 30

Tabela 3 - Potência firme e potência efetiva do SEIN em 2010 (MW)......................31

Tabela 4 - Venda de energia em (GWh) por setores econômicos do SEIN ..............40

Tabela 5 - Potencial hidrelétrico amazônico peruano comprometido ao Brasil ..........70

Tabela 6 - Reservas de gás natural no Peru em (tpc) .......................................95

Tabela 7 - Composição das reservas de gás natural de Camisea. ..........................96

Tabela 8 - Consumidores do gás natural de Camisea. .......................................97

Tabela 9 - Produção termelétrica por tipo de tecnologia no SEIN 2009.................109

Tabela 10 - Pressupostos de cálculo para 1 MW de potência instalda no SEIN...112

Tabela 11 - Dados de cálculo adicionais de (LCOE) .........................................113

Tabela 12 - Custo total nivelado de eletricidade por tipo de fonte no SEIN. ..........113

Tabela 13 - VPL por milhão investido (US\$) por fonte energética no SEIN. ..........114

Tabela 14 - TIR por milhão investido (US\$) por fonte energética no SEIN ............115

Tabela 15 - Custo nivelado de eletricidade com preço Henry Hub de GN no SEIN.

Tabela 16 - VPL e TIR por fonte energética com preço Henry Hub de GN no SEIN. 


\section{LISTA DE QUADROS}

Quadro 1 - Potência instalada do setor elétrico peruano (2009 - 2010) em MW.....29

Quadro 2 - Prazos de contrato de energia no setor elétrico peruano........................61

Quadro 3 - Sistema de preços no setor elétrico peruano. ......................................62

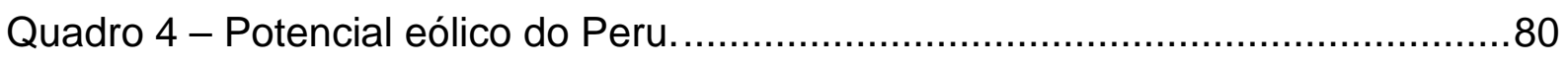

Quadro 5 - Usinas eólicas em estudo na zona norte do SEIN.................................88

Quadro 6 - Usinas eólicas em estudo na zona centro sul do SEIN. .........................88

Quadro 7 - Usinas eólicas em estudo na zona sul do SEIN. ..................................89

Quadro 8 - Usinas eólicas vencedoras do primeiro leilão RER do SEIN...................91

Quadro 9 - Usina eólica vencedora do segundo leilão RER do SEIN. .....................92

Quadro 10 - Critérios de investimento e custos de projetos de geração no SEIN. .120

Quadro 11 - Programação da operação do SEIN..............................................126

Quadro 12 - Arquivos de entrada no modelo PERSEO.......................................137

Quadro 13 - Projeção da demanda no período $(2011$ - 2020)..............................138

Quadro 14 - Programa de obras de projetos hidrelétricos $(2011$ - 2020)..............139

Quadro 15 - Programa de obras de projetos termelétricos $(2011$ - 2020) . ............140

Quadro 16 - Programa de obras de projetos RER $(2011$ - 2020).......................140

Quadro 17 - Projetos hidrelétricos da Amazônia para exportação ao Brasil. ..........141

Quadro 18 - Plano de obras de transmissão SEIN $(2011$ - 2020).........................141

Quadro 19 - Participação de energia por tipo de fonte no curto prazo (GWh).......146

Quadro 20 - Deslocamento de geração térmica no curto prazo. ...........................150

Quadro 21 - Participação da termelétrica a gás natural no curto prazo...................153

Quadro 22 - Participação de energia por tipo de fonte no longo prazo (\%)............154

Quadro 23 - Produção de energia por tipo de fonte no longo prazo (GWh)..........156

Quadro 24 - Participação de energia por tipo de fonte no longo prazo (GWh).......156

Quadro 25 - Deslocamento de geração térmica no longo prazo. ...........................160

Quadro 26 - Produção do SEIN por tipo de fonte no longo prazo (GWh)..............163 


\section{LISTA DE ABREVIATURAS E SIGLAS}

ADINELSA Empresa de Administración de Infraestructura Eléctrica (Peru).

AIPSA

Agro Industrial Paramonga S.A.

AT

Alta Tensão, igual ou superior a $30 \mathrm{kV}$ até $100 \mathrm{kV}$.

BT Baixa tensão, menores de $1 \mathrm{kV}$.

BNDES

Banco Nacional do Desenvolvimento Econômico e Social do Brasil.

$\mathrm{CMO}$ Custo Marginal de Operação.

COES Comitê de Operação Econômica do Sistema.

CELEPSA Compañía Eléctrica El Platanal S.A.

CNEL La Corporación Nacional de Electricidad (Equador).

EAT Extra-alta tensão, superior a $100 \mathrm{kV}$

EIA International Energy Agency.

EEPSA Empresa Elétrica Piura S.A.

EPE Empresa de Pesquisa Energética (Brasil)

ETEVENSA Empresa de Geração Termelétrica Ventanilla S.A.

EDEGEL Empresa de Geração de Lima S.A.

ENERSUR Empresa de Energía del Sur S.A.

E. Santa Rosa Empresa Elétrica Santa Rosa.

E. Santa Cruz Empresa Elétrica Santa Cruz.

FONAFE Fondo Nacional de Financiamiento de la Actividad Empresarial del Estado (Peru).

GRP Garantía de Red Principal de Camisea.

GEPSA Generadora de Energía del Perú S.A.

HRSG Heat Recovery Steam Generators.

LCE Lei de Concessões Elétricas.

MEM Ministério de Energia y Minas (Peru).

MINAM Ministério de Ambiente (Peru).

MMPCD Milhões de Pés Cúbicos Diários.

MT Media Tensão, maiores a $1 \mathrm{kV}$ e inferiores a $30 \mathrm{kV}$.

NTCSE Norma Técnica de Calidad de Servicios Eléctricos (Peru).

ONS Operador Nacional do Sistema Elétrico Brasileiro.

OSINERGMIN Organismo Supervisor do Investimento em Energia e Mineração. 
PCHs Pequenas Centrais Hidrelétricas.

PROINFA Programa de Incentivo às Fontes Alternativas.

PPT

Primeiro Plano de Transmissão.

PIB

Produto Interno Bruto.

RER

Recursos Energéticos Renováveis.

SEIN

Sistema Elétrico Interligado Nacional.

SNMPE Sociedade Nacional de Mineração, Petróleo e Energia.

SPT

Sistema Principal de Transmissão.

SST

Sistema Secundário de Transmissão.

SGT

Sistema Garantido de Transmissão.

SCT

Sistema Complementário de Transmissão.

S.M. Corona Sociedade Minera Corona.

SDF Energía Sudamericana de Fibras Energía S.A.C.

SINERSA Sindicato Energético S.A.

VAD Valor Agregado de Distribuição. 


\section{SUMÁRIO}

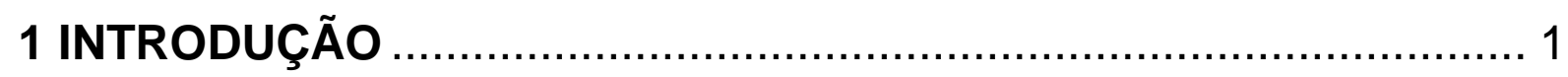

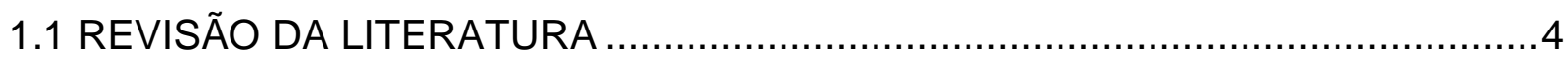

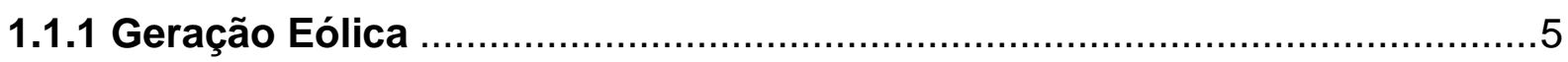

1.1.2 Geração Termelétrica a Gás Natural ..................................................12

2 SISTEMA ELÉTRICO PERUANO .............................................. 15

2.1 MODELO ATUAL DO SETOR ELETRICO PERUANO …................................15

2.2 MARCO NORMATIVO DO SETOR ELÉTRICO PERUANO …...........................21

2.3 ÓRGÃOS INSTITUCIONAIS DO SETOR ELÉTRICO PERUANO .......................23

2.4 CARACTERISTICAS DO SETOR ELÉTRICO PERUANO.................................27

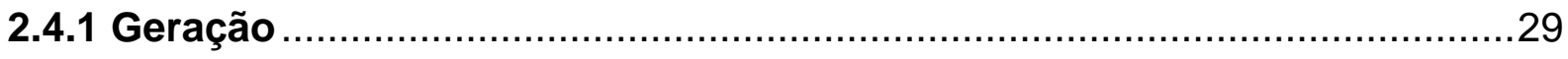

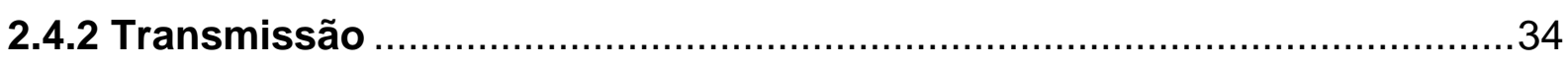

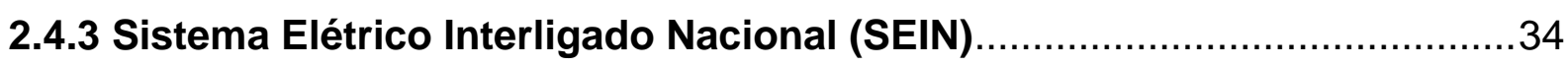

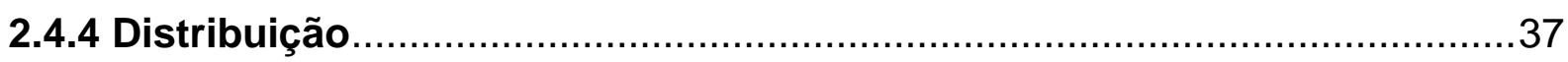

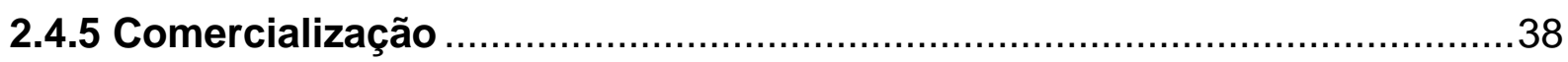

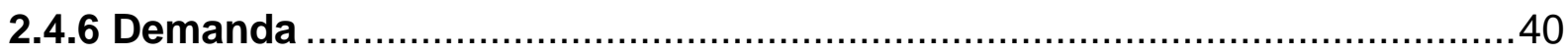

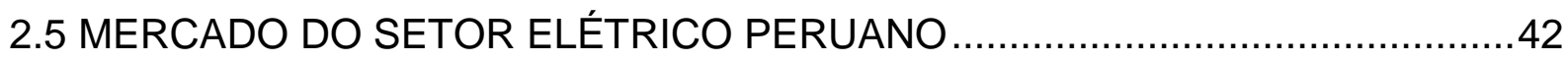

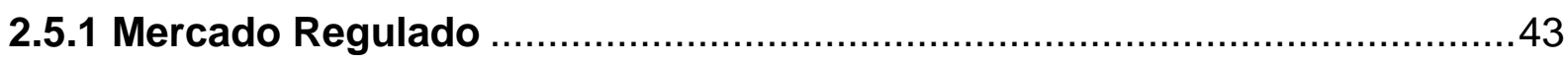

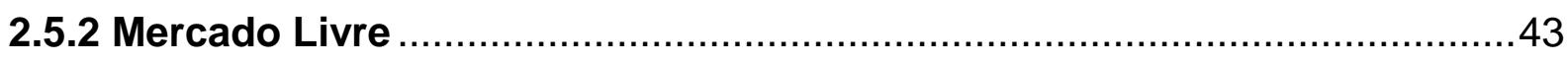

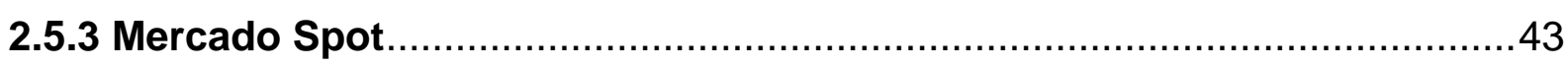

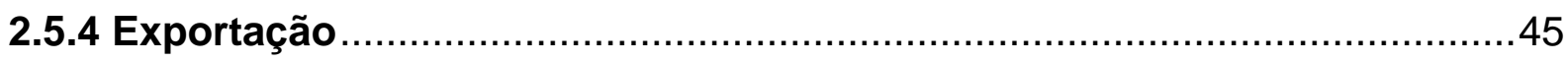

2.6 FIXAÇÃO DE TARIFAS NO SETOR ELÉTRICO PERUANO ............................47

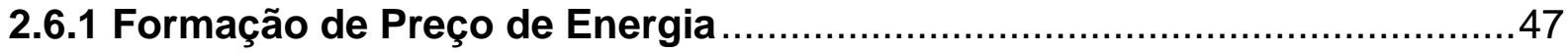

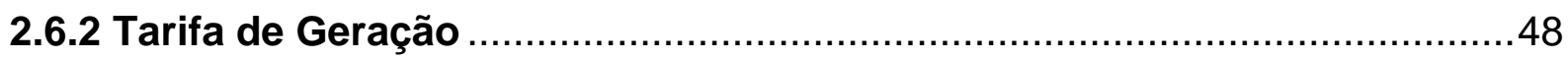

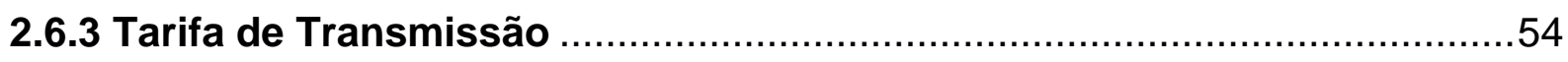

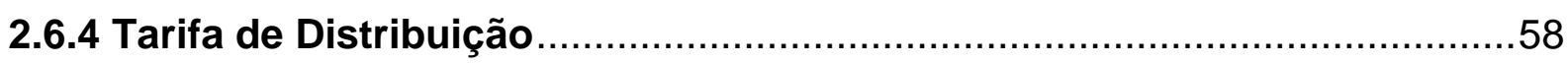

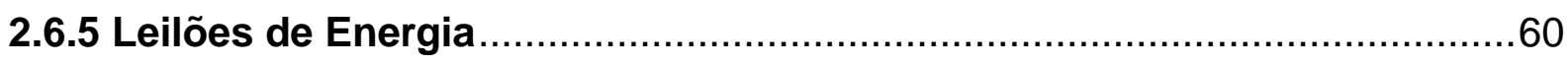

2.7 CRITERIOS DE PLANEJAMENTO DA EXPANSÃO DO SEIN ...........................63

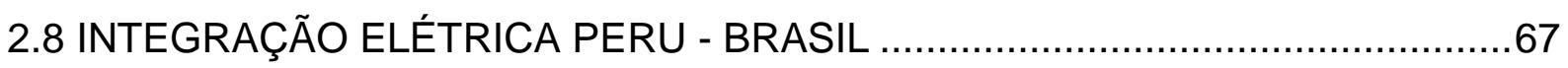

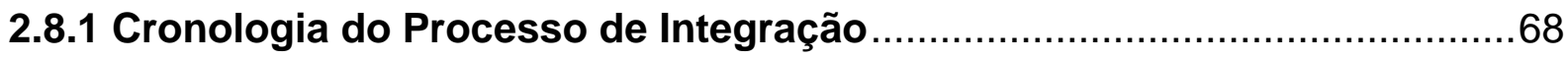

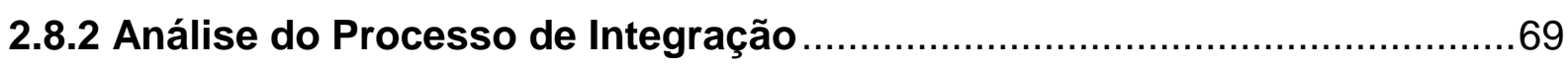

2.8.3 Interligação Elétrica Peru - Brasil .......................................................73 
3 GERAÇÃO EÓLICA E TERMELÉTRICA A GN NO PERU .............. 77

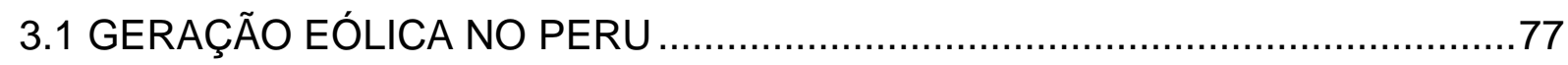

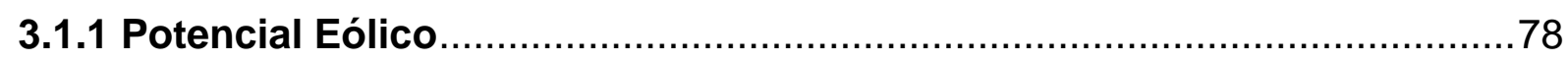

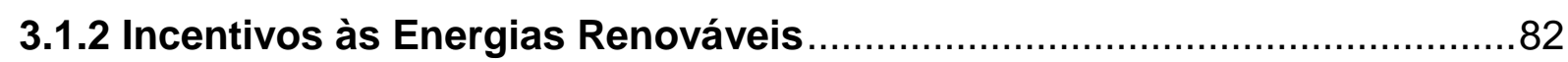

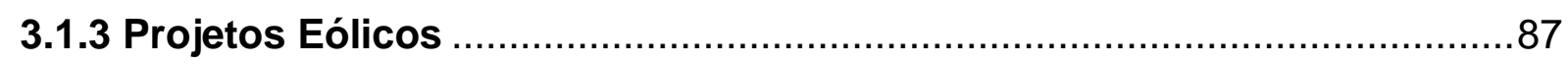

3.1.4 Leilões e Capacidade Contratada de Energia Eólica …............................90

3.2 GERAÇÃO TERMELÉTRICA A GÁS NATURAL NO PERU .............................92

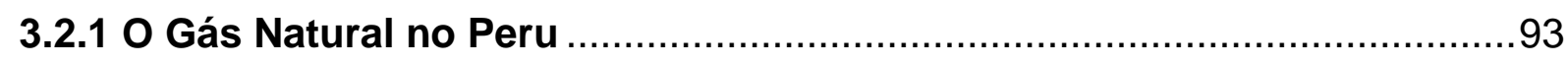

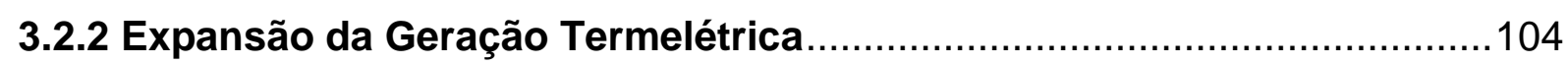

3.2.3 Características das Usinas a Gás Natural ..........................................107

3.2.4 Competitividade das Termelétricas a Gás Natural ...............................110

4 DESCRIÇÃO DA METODOLOGIA E MODELO UTILIZADO .......... 122

4.1 ASPECTOS DA OPERAÇÃO DO SISTEMA HIDROTÉRMICO PERUANO .....122

4.2 METODOLOGIA E MODELO UTILIZADO …...............................................127

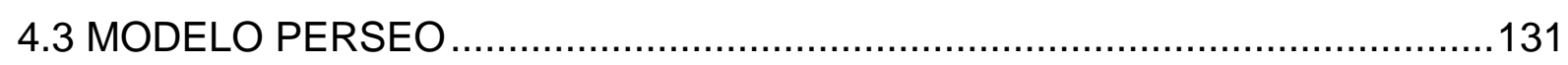

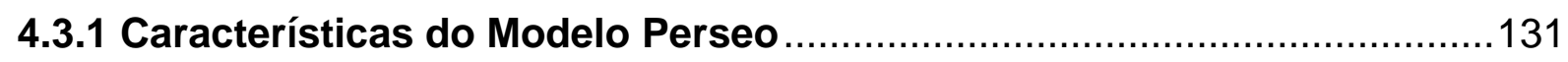

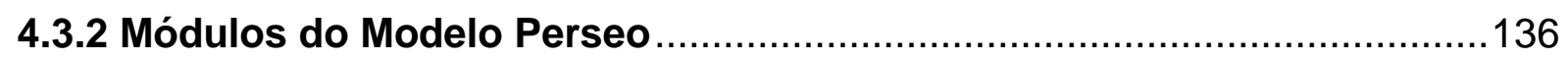

4.4 CONSIDERAÇÕES DOS DADOS DE ENTRADA .....................................137

5 IMPACTOS NO SISTEMA HIDROTERMICO PERUANO .............. 143

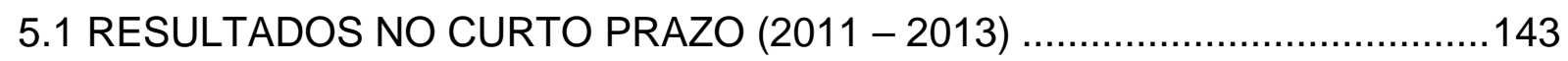

5.1.1 Expansão de Referência sem Energia Eólica ........................................143

5.1.2 Expansão com Inserção de Energia Eólica............................................145

5.1.3 Impacto no Custo Marginal de Operação (CMO) …..............................147

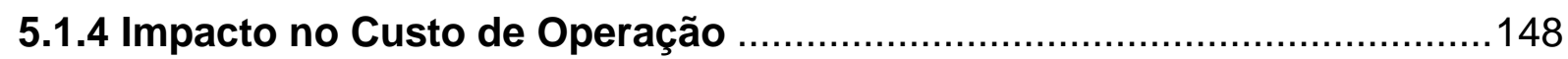

5.1.5 Impacto na Geração Termelétrica .....................................................150

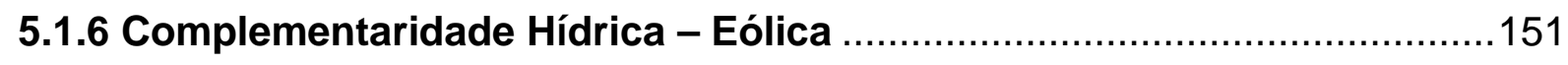

5.1.7 Expansão da Geração Termelétrica a Gás Natural.................................152

5.2 RESULTADOS NO LONGO PRAZO (2014 - 2020) ...................................153

5.2.1 Expansão de Referência sem Energia Eólica .........................................153

5.2.2 Expansão com Inserção de Energia Eólica..........................................155

5.2.3 Impacto no Custo Marginal de Operação (CMO) ……..........................157

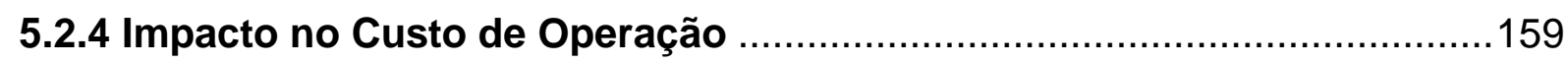

5.2.5 Impacto na Geração Termelétrica .....................................................160 
5.2.6 Complementaridade Hídrica - Eólica ............................................. 161

5.2.7 Expansão da Geração Termelétrica a Gás Natural...............................162

5.2.8 Proposta para a Inserção da Energia Eólica no SEIN ............................163

5.3 EXPANSÃO COM EXPORTAÇÃO DE 50\% DE UHEs AMAZÔNIA .................163

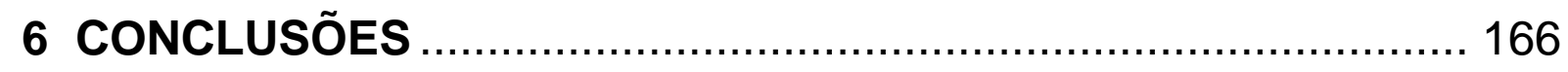

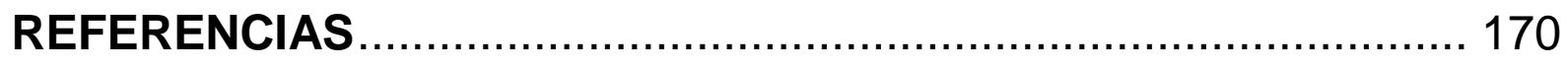

ANEXO A: Metodologia do Modelo Perseo.............................. 182 


\section{INTRODUÇÃO}

Novos paradigmas de expansão e uso das fontes de energia, como a gestão, o uso sustentável e eficiente dos recursos energéticos, mediante a participação de fontes renováveis de energia, bem como a exploração da complementaridade entre fontes intermitentes e renováveis em complemento às fontes de energia tradicionais, vem alterando a matriz energética dos países desenvolvidos e em desenvolvimento, tornando-a mais limpa e sustentável, com menor custo ambiental e social.

A geração eólica como fonte renovável de energia e as termelétricas a gás natural, fonte não renovável de energia, são as que mais vêm sendo exploradas nos últimos anos, mesmo que o custo ainda elevado da geração eólica esteja diminuindo e ganhando competitividade. A vantagem da disponibilidade de recursos, como as reservas de gás natural, permitem a países como Peru e Brasil, por exemplo, que possuem grandes quantidades desses recursos energéticos, buscar um aproveitamento de forma mais eficiente e sustentável.

Esses países vêm enfrentando novos desafios, principalmente no aproveitamento eficiente da geração eólica de maior escala e o gás natural na geração elétrica em sistemas de geração de energia de origem predominantemente hidráulica.

No que tange à geração eólica, os desafios são os mesmos enfrentados por países europeus como Espanha, Portugal, Alemanha, Dinamarca, entre outros, os Estados Unidos e China, ou seja, o de inserir uma fonte intermitente no sistema elétrico de potencia.

Um dos desafios que apresenta a energia eólica é a complexidade da previsão futura dos ventos, o que implica numa maior incerteza no planejamento e operação dos sistemas elétricos, já que não é possível "armazenar o vento" na sua forma natural para firmar energia.

No entanto, de forma antagônica, em Portugal, na região de Coimbra, já temos um exemplo no qual a energia eólica produzida em maior volume durante o período da madrugada, momento em que a demanda por energia é baixa e os ventos são mais intensos, bombas hidráulicas são acionadas no reservatório de 
Raiva, para bombear a água ao outro reservatório localizado $12 \mathrm{~km}$ rio acima, em Aguieiro, armazenando, desta forma a energia eólica na forma de energia potencial.

Cada país e região tem diferentes condições e características do recurso eólico e seu aproveitamento depende de sua viabilidade econômica e técnica, entre outros fatores. Além disso, políticas adotadas pelos governos de cada país é que determinam sua exploração, como no caso peruano, que no curto prazo possibilitará o ingresso em operação comercial de parques eólicos de até 142 MW de capacidade, interligados ao sistema elétrico em 2012.

A inserção da geração eólica no sistema hidrotérmico peruano permitirá diversificar melhor a matriz elétrica peruana, tendo a hidreletricidade e termeletricidade como as maiores fontes de geração, e a energia eólica como fonte complementar.

No caso peruano, a expansão de seu sistema elétrico foi baseada na construção de usinas termelétricas a gás natural, originado pela disponibilidade do combustível. O aproveitamento deste combustível na geração de energia elétrica permitiu benefícios diretos na economia do país, com diminuição de gastos com diesel e óleo combustível nas termelétricas.

A inserção da geração eólica e termelétrica a gás natural gera questões importantes sobre seus impactos no sistema hidrotérmico peruano, tanto na operação econômica do sistema, no deslocamento de despacho das térmicas a diesel e a óleo combustível, no custo futuro da energia do sistema, quanto no planejamento da operação e na interação de cada fonte energética na matriz elétrica no cenário futuro, no qual a integração elétrica Peru - Brasil também deve ser levada em consideração.

As experiências e avanços significativos relativos à inserção de energia eólica em sistemas hidrotérmicos ao redor do mundo podem dar uma idéia do leque de potencialidades e desafios a serem enfrentados na integração aos sistemas elétricos, bem como em sua operação e planejamento.

O objetivo geral deste trabalho é avaliar os desafios e oportunidades da inserção da geração eólica e a expansão das termelétricas a gás natural no sistema hidrotérmico peruano, com foco na operação econômica, através do estudo e da descrição das principais características do setor, sua situação atual e perspectivas futuras destes recursos no fornecimento de energia elétrica.

Como objetivo específico nos cenários de curto e longo prazo, o trabalho 
propõe avaliar os impactos da inserção da geração eólica e das termelétricas a gás natural no custo marginal de operação do sistema elétrico peruano. Neste estudo, empregou-se o modelo matemático de simulação denominado Perseo ${ }^{1}$. O seu uso possibilitou a determinação dos custos futuros de energia nestes cenários levando em conta os programas de planejamento oficial do setor elétrico peruano.

Pretende-se assim, contribuir com informações que permitam ilustrar e avaliar as mudanças provocadas pela inserção destas fontes energéticas neste novo cenário, no qual a integração com o Brasil também deverá ter um grande impacto.

O trabalho procura, além disso, tornar-se mais uma referência ou literatura no tratamento da inserção da geração eólica e termelétrica a gás natural em sistemas hidrotérmicos, com destaque nos desafios e oportunidades da implantação, gestão operacional e planejamento de sua expansão.

No intuito de atingir os objetivos propostos, manteve-se o foco nas referências bibliográficas dos últimos dez anos, e utilizou-se a metodologia de revisão e pesquisa bibliográfica, análise e valoração das informações dos dados do setor elétrico peruano, com ênfase na expansão, operação e planejamento do sistema, além de estudos de experiências de integração da geração eólica a sistemas elétricos e suas interações com outras fontes, tais como, as termelétricas a gás natural, a hidroeletricidade, e os impactos na operação e planejamento de seus sistemas.

A partir da coleta e análise desses dados, elaborou-se a sistematização das informações, para se identificar os desafios, oportunidades e impactos da inserção em maior escala da geração eólica e termelétrica a gás natural no sistema hidrotérmico peruano.

O presente trabalho está estruturado da seguinte forma:

Capítulo 1: Introdução

Capítulo 2: Sistema Elétrico Peruano - estrutura e organização do setor elétrico peruano, participação dos principais órgãos institucionais, processo de integração elétrica binacional Peru - Brasil, e suas principais características atuais.

Capítulo 3: Geração Eólica e Termelétrica a GN no Peru - abordagem e descrição da atual situação da participação eólica e térmica a gás natural na geração de energia elétrica no mercado peruano.

\footnotetext{
${ }^{1}$ Modelo de despacho econômico utilizado pelo órgão regulador e pelas empresas geradoras do mercado elétrico peruano.
} 
Capítulo 4: Descrição da Metodologia e Modelo Utilizado - descrição da metodologia e do modelo matemático de simulação, ambos utilizados no estudo.

Capítulo 5: Impactos no Sistema Hidrotérmico Peruano - análise dos impactos da inserção da geração eólica e termelétrica a gás natural no sistema hidrotérmico peruano, com base nos resultados obtidos das simulações efetuadas no modelo Perseo, bem como a proposta de alternativas deste tipo de inserção em sistemas hidrotérmicos.

Capítulo 6: Conclusão - síntese dos aspectos tratados e propostos, análise conclusiva e sugestões para trabalhos futuros.

\subsection{REVISÃO DA LITERATURA}

No contexto energético mundial, dentre diversos temas relevantes que fazem parte de políticas energéticas e dão visão de futuro, podemos citar: o aproveitamento eficiente da energia, a inserção cada vez maior de fontes renováveis, por exemplo, a eólica, e a preocupação com o meio ambiente; isto tudo no sentido de cobrir as expectativas de desenvolvimento sustentável de cada país.

É notória a preocupação dos países em ter como meta a gestão eficiente da energia, principalmente no abastecimento seguro de suas demandas futuras, a variabilidade dos preços de petróleo e gás, e as mudanças climáticas.

Segundo a PSR ABEEólica (2009), no caso da segurança energética, uma das principais preocupações é a interrupção do suprimento de petróleo e gás natural devido a problemas geopolíticos ocasionados pela localização das reservas em regiões conturbadas. É o que ocorreu, por exemplo, no leste europeu, no inverno de 2005/2006 com a interrupção do suprimento de gás da Rússia para a Ucrânia e a suspensão do fornecimento para a União Européia em janeiro de 2009.

Outra preocupação importante é a grande variação dos preços destes combustíveis fósseis. As oscilações de preço resultam de um equilíbrio bastante estreito entre oferta e a demanda, além da ação coordenada de países produtores, que controlam em média $90 \%$ as reservas de petróleo e gás do mundo.

As mudanças climáticas e sua relação direta com a emissão antropogênica de gases de efeito estufa (GEE) e seus impactos negativos em nosso 
planeta, tais como, oscilações extremas de chuvas e secas, derretimento das geleiras na Ásia e América Latina, são temas que vêm sendo intensamente discutidos por governos e instituções multilaterais.

\subsubsection{Geração Eólica}

As mudanças climáticas, a diminuição das reservas de gás e petróleo, e a busca dos países por suprimento de recursos energéticos cada vez mais limpos, vêm incentivando uma maior participação da geração eólica na matriz elétrica mundial, o que fez com que a geração eólica apresentasse o maior índice de crescimento nos últimos anos. Tal crescimento traz consigo muitos benefícios, embora também, muitos sejam os desafios em sua implantação e operação.

Os países da União Europeia (UE) e Estados Unidos (EUA), foram até alguns anos atrás, os principais impulsionadores da energia eólica. No entanto, em 2010 a China, instalou 16,5 GW de nova capacidade, cerca de metade do total mundial instalado durante esse ano, passando a ser o país com a maior capacidade instalada. Estima-se que atingirá $200 \mathrm{GW}$ até 2020. Este crescimento origina-se principalmente no desenvolvimento econômico do país asiático que atingiu a 42,3 GW, superando o EUA, ou seja $21,8 \%$ de um total global de mais de $194 \mathrm{GW}$ de capacidade instalada ao final de 2010, como é apresentado na figura 1, (GWEC, 2010). 
OS TOP DEZ PAÍSES COM MAIOR CAPACIDADE EÓLICA INSTALADA EM 2010

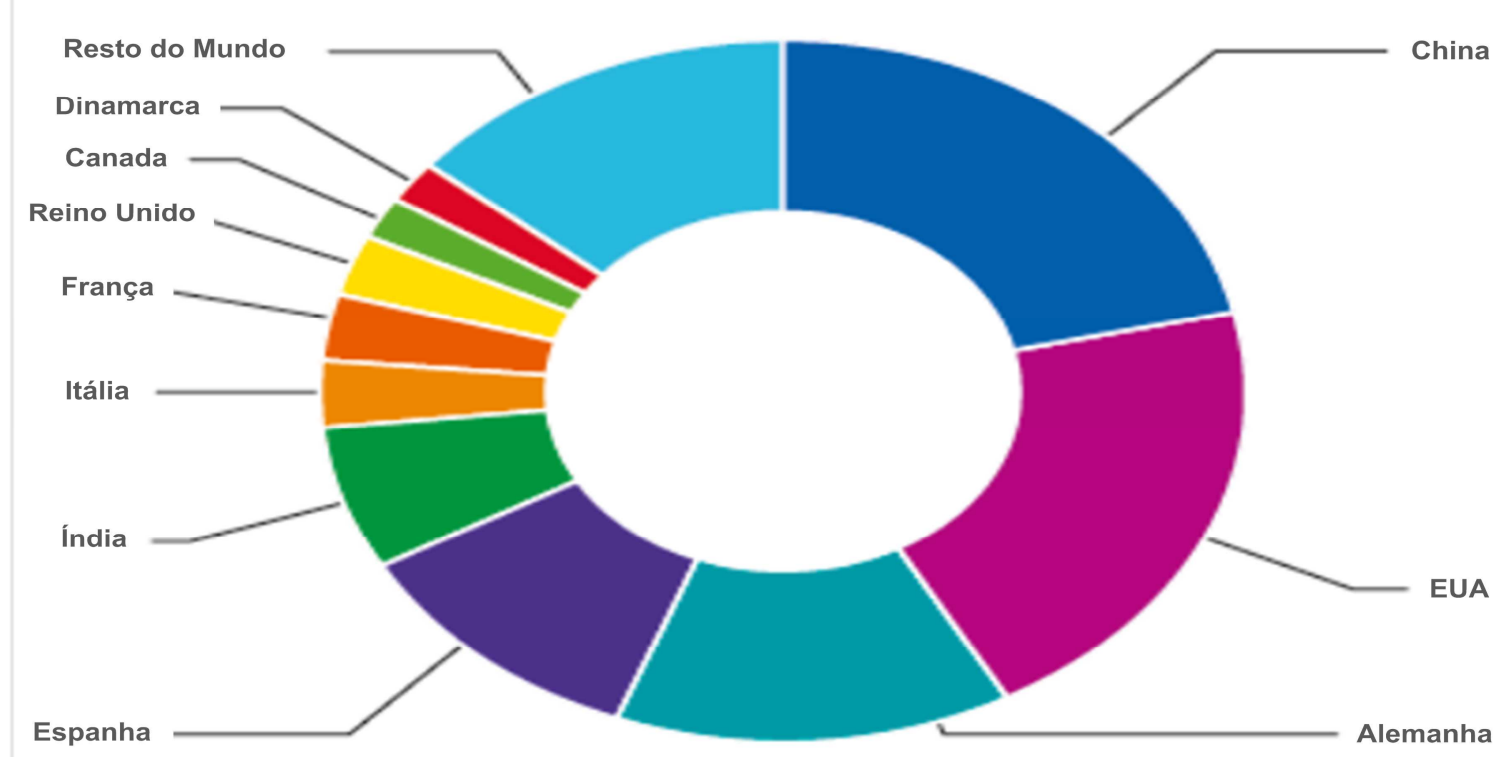

\begin{tabular}{rrr} 
País & MW & $\%$ \\
\hline China & 42,287 & 21.8 \\
EUA & 40,180 & 20.7 \\
Alemanha & 27,214 & 14.0 \\
Espanha & 20,676 & 10.6 \\
Índia & 13,065 & 6.7 \\
Itália & 5,797 & 3.0 \\
França & 5,660 & 2.9 \\
Reino Unido & 5,204 & 2.7 \\
Canada & 4,009 & 2.1 \\
Dinamarca & 3,752 & 1.9 \\
Resto do Mundo & 26,546 & 13.7 \\
Total TOP 10 & 16,844 & $\mathbf{8 6 . 3}$ \\
\hline Total Mundial & 194,390 & 100
\end{tabular}

Figura 1 - Os primeiros dez países com maior capacidade eólica instalada a 2010.

Fonte: (GWEC, 2011a).

As estimativas e projeções realizadas pela GWEC (2010), sobre a expansão da geração eólica para o cenário de curto prazo até 2014 , indicam uma capacidade instalada de $400 \mathrm{GW}$, dobrando a atual capacidade instalada mundial, 0 que mostra que a energia eólica é, cada vez mais, a tecnologia energética escolhida pelos países desenvolvidos e emergentes, como a China, Índia, dentre outros. 
O crescimento da geração eólica vem acompanhado do desenvolvimento de novos e melhores aerogeradores com potências cada vez maiores, destacando se, nas últimas duas décadas, como a fonte que mais tecnologias desenvolveu no aumento da potência, desempenho e confiabilidade de suas máquinas, o que permitiu à energia eólica conquistar cada vez mais espaços na geração de energia elétrica visando a complementação energética às fontes convencionais. (FERREIRA, 2008).

O comércio de aerogeradores no mundo desenvolveu-se rapidamente em tecnologia e tamanhos durante os últimos 25 anos. A figura 2 mostra 0 impressionante desenvolvimento do tamanho e da potência de aerogeradores desde 1985.

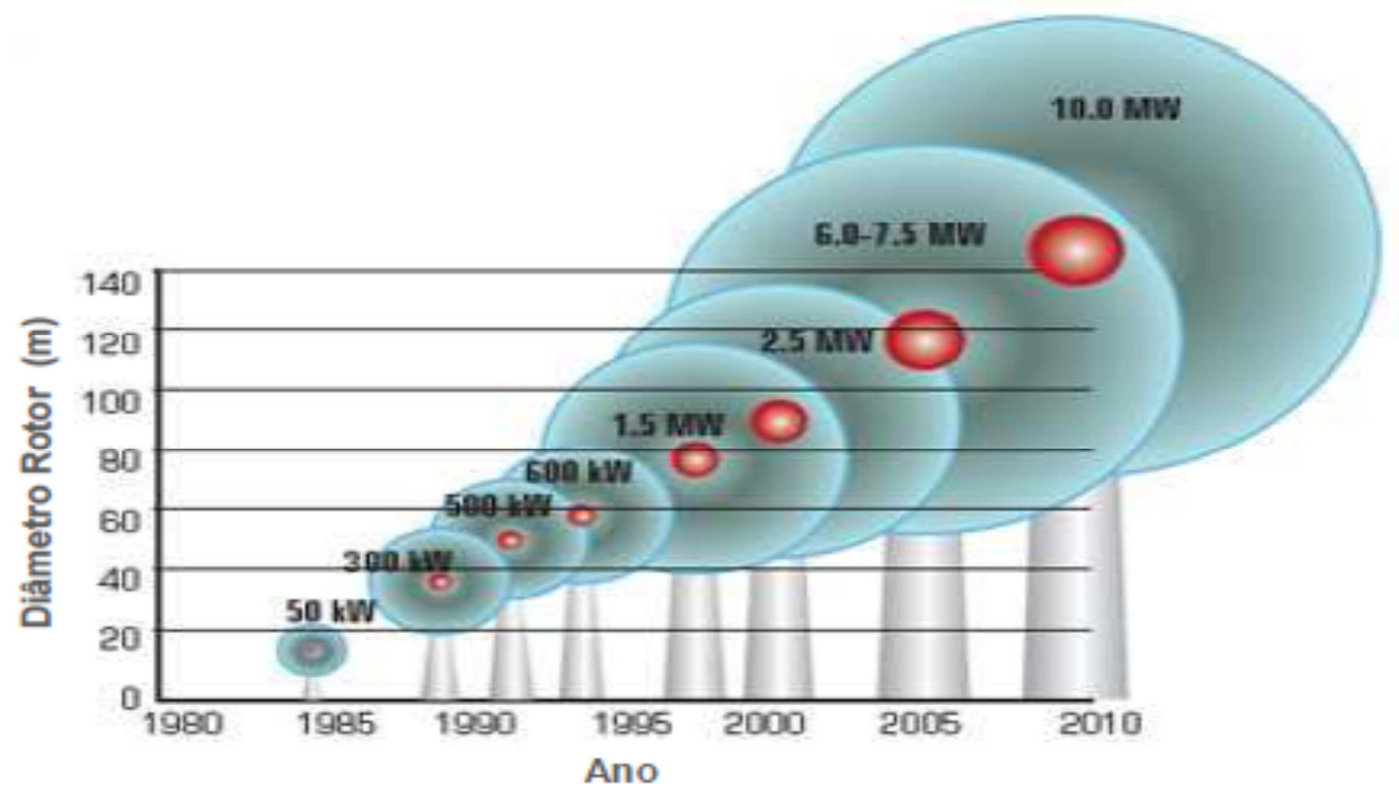

Figura 2 - Evolução das turbinas eólicas nos últimos 25 anos.

Fonte: Clipper Windpower.

Os aerogeradores podem ser divididos em três categorias de acordo a sua capacidade, ou seja, em função de sua potência: em pequeno, médio e grande porte. Os de pequeno porte têm capacidade de gerar até $50 \mathrm{~kW}$ e são ideais para abastecer residências rurais e fazendas em localidades remotas, onde o custo de uma rede de transmissão é excessivamente alto. Os equipamentos de médio porte têm capacidade entre 50 kW e 500 kW e são usadas tanto em residências quanto por usinas eólicas conectadas à rede de menor capacidade de potência. Já os equipamentos de grande porte têm capacidades superiores a $500 \mathrm{~kW}$, e são utilizados em parques eólicos conectados às redes de distribuição e transmissão. 
$\mathrm{Na}$ inserção da geração eólica em sistemas hidrotérmicos, o Brasil vem ganhando destaque. Em 2002, criou o Programa de Incentivo às Fontes Alternativas de Energia Elétrica - PROINFA, com o objetivo de incentivar e aumentar o uso de fontes renováveis de energia como a energia eólica, térmicas a biomassa e pequenas centrais hidrelétricas $\left(\mathrm{PCHs}^{2}\right)$ no sistema elétrico brasileiro, além de incentivar o crescimento de sua indústria nacional. Com incentivos como a garantia de compra da energia gerada por vinte anos e de financiamento de até $80 \%$ do empreendimento pelo Banco Nacional do Desenvolvimento (BNDES), programa dividido em duas etapas, onde a primeira consiste na implantação de $3300 \mathrm{MW}$ de capacidade, distribuídos igualmente entre as fontes participantes, no caso da geração eólica esta-se finalizando a instalação de 1400 MW de plantas eólicas espalhadas pelo país.

Uma das vantagens atrativas para a inserção da geração eólica, por exemplo no caso brasileiro, é seu grande potencial eólico, que em função de sua localização geográfica é complementar à geração hidrelétrica e termelétrica a biomassa, sendo hoje uma das fontes energéticas com maior atratividade no mercado elétrico brasileiro. (PORRUA, et al. 2010).

Além da complementaridade geográfica dos recursos energéticos no sistema hidrotérmico brasileiro, há uma sinergia significativa entre estas fontes. Por um lado, a capacidade de modulação (aumento/redução) da produção de energia hidrelétrica viabiliza a integração da energia gerada por fontes sazonais/variáveis como a bioeletricidade, (cuja produção de energia se concentra na época da safra de cana de açúcar) e a energia eólica (que produz energia ao longo de todo o ano, mas com fatores de sazonalidade e flutuações a cada mês). Segundo a PSR (2009) quando a produção de energia eólica e/ou bioeletricidade aumenta, reduz-se a geração das usinas hidrelétricas e vice-versa.

Guedes e Cavalcanti (2010), propõem um estudo de inserção de 620 MW médios anuais de geração eólica no sistema hidrotérmico brasileiro de 2012 até 2017, com simulações em horizontes de médio e longo prazo, sob condições oficiais previstas e sob certas premissas, onde os resultados apontaram impactos favoráveis no custo de operação econômica do sistema hidrotérmico brasileiro, com redução de aproximadamente seis bilhões de reais. Em um cenário com atrasos nas obras de

\footnotetext{
${ }^{2}$ Empreendimentos hidrelétricos com potência superior a $1 \mathrm{MW}$ e igual ou inferior a $30 \mathrm{MW}$, com área total de reservatório igual ou inferior a $3,0 \mathrm{~km}^{2}$.
} 
geração hidrelétrica, se observa também as reduções no Custo Marginal de Operação (CMO), em todo o período de análise de 2012 até 2017, com redução dos custos nos submercados de $35 \%$ no Sudeste, $40 \%$ no Norte, $45 \%$ no Sul e $50 \%$ no Nordeste.

Tais resultados das simulações mostram, que a geração eólica pode vir a ser a fonte renovável de energia de maior crescimento e expansão no sistema hidrotérmico brasileiro, apresentando ganhos significativos nos custos de energia gerada no mercado elétrico brasileiro, deslocando a geração térmica a gás, carvão e/ou óleo diesel, entre outras, pelo fato de ser complementar às hidrologias nas hidroelétricas e, pelo fato, dos novos empreendimentos hidrelétricos serem usinas a fio d'água.

Outro estudo feito por PSR (2009) simula a inserção da geração eólica no sistema hidrotérmico brasileiro com a seguinte premisa: "O cenário de expansão com desenvolvimento da energia eólica considera a contratação de 400 MW médios de energia firme por ano (cerca de 1000 MW de capacidade instalada), durante dez anos (2011 a 2020). Em 2011 e 2012 a geração eólica seria adicionada como reserva para o sistema ${ }^{3}$, totalizando 800 MW médios. De 2013 a 2020, os 3200 MW médios restantes seriam contratados pelos consumidores, ou seja, comporiam seu portfólio de contratos". Após a simulação, o estudo apresenta resultados, onde se observa que a inserção da geração eólica traz vários benefícios para o sistema, entre os quais se destaca a redução dos custos operativos das termelétricas $(1,4$ bilhões de Reais por ano, em média) e a redução acumulada de emissões de CO2 de 100 MtCO2 o que equivale a 12,5 MtCO2 por ano, em média.

Atualmente no Brasil, os bons ventos e a forte disputa entre os fornecedores internacionais de equipamentos aceleram a implantação dos parques eólicos. Com a crise na economia mundial, especialmente com a retração dos investimentos dos EUA e Europa em energia eólica, o Brasil atraiu recursos financeiros consideráveis de grandes fabricantes de equipamentos de aerogeração e dos produtores independentes de energia, o que proporcionou uma incrível redução dos custos da energia gerada e sua implantação.

Segundo levantamento da ABEEólica, esse potencial vem ampliando a disputa do mercado, como mostra a participação da capacidade instalada de quase 
$6 \mathrm{GW}$ prevista para 2013. Atraindo oito grandes fabricantes globais Impsa (18,5\%), Wobben/Enercon (18,1\%), GE (15,4\%), Vestas (14,9\%), Suzlon (13,6\%), Gamesa $(5,6 \%)$, Alstom $(4,7 \%)$, Siemens $(3,1 \%)$ e outros $6 \%$ ainda sem contrato.

Estes proporcionam uma grande oportunidade de diminuir os custos da energia gerada das eólicas, com destaque nos leilões de energia A-3 e reserva 2011 realizados recentemente pelo EPE (Empresa de Pesquisa Energética ), onde o patamar de custo alcançado pela energia eólica, que ofereceu os menores preços do leilão, foi de $R \$ 96,49 / M W h$, (ABEEólica, 2011).

Por outro lado, outros paises como Portugal, que querem aumentar a participação dos parques eólicos em seus sistemas hidrotérmicos, tiveram dificuldades na implantação desta fonte, principalmente pela localização dos recursos eólicos, as incertezas e variabilidade da presença dos ventos; e pela necessidade de fazer estudos e reforços em seus sistemas de transmissão nacionais e interligações internacionais.

Em Pinto et al. (2009) é mostrado que em Portugal, para os próximos anos, há metas de implantação de 7500 MW em energia eólica, o que constitui um grande desafio por seu sistema ser de pequena dimensão, com demanda de ponta de 9000 MW. Foi necessário o desenvolvimento prévio de um plano de expansão da rede de transporte dedicado exclusivamente para a recepção de montantes elevados de energias renováveis, associado a um processo de determinação de montantes máximos de potência a ser ligado em cada subestação, metodologia que foi aplicada de forma eficaz.

A integração de grandes quantidades de geração eólica é um desafio para os sistemas de energia. Por outro lado a variabilidade da energia eólica é reduzida quando se olha para um grande sistema interligado com uma produção de energia eólica geograficamente dispersa, como é apresentado no estudo feito por Holttinen (2004), no sistema elétrico dos países Nórdicos. No estudo se avalia os impactos da inserção da energia eólica de grande escala na operação econômica, na geração e transmissão do sistema elétrico Nórdico e sob o funcionamento do mercado e os preços da eletricidade.

Os resultados das simulações da operação do sistema elétrico Nórdico mostram que a energia eólica substituirá principalmente o carvão e incrementará os fluxos de transmissão entre as áreas dentro dos países Nórdicos, e destas para a Europa Central. Quanto, ao incremento da exigência de reserva para o sistema 
elétrico Nórdico, este é determinado pela combinação das variações de energia gerada em usinas eólicas com uma variação da demanda do sistema, combinado com a carga variável. A energia eólica não iria impôr grandes variações extras no sistema, atingindo uma penetração substancial. Estudo que analisa os impactos da inserção eólica do ponto de vista energético, mas que um complemento importante aínda será necessario representa-lo pelos estudos elétricos, posto que quando a geração eólica atinge grande participação, o atendimento aos criterios de performance elétrica torna-se imperativo e condiciona a viabilização prática da fonte.

A integração da geração eólica nos sistemas elétricos em condições aceitáveis de segurança apresenta alguns desafios tecnológicos decorrentes, por um lado, pela característica variável e não-programada da energia eólica e, por outro, pelo atual estado de arte das tecnologias das turbinas eólicas. Esta tecnologia é substancialmente diferente das usinas convencionais. Os primeiros parques empregavam turbinas de velocidade fixa com geradores assíncronos com rotor tipo "gaiola". Nos últimos anos a tendência dominante tem sido a instalação de turbinas eólicas de velocidade variável, com geradores assíncronos duplamente alimentados ou com geradores síncronos acoplado à rede através de conversores eletrônicos no estator, melhorando assim a segurança da operação das usinas, (QUINGATUÑA, 2009).

Para reduzir as incertezas associadas à operação dos projetos de geração eólica, foram desenvolvidos, e ainda estão sendo aprimorados, modelos de previsão de curto prazo de velocidade do vento. A geração eólica, por ser intermitente, requer previsões precisas de curto prazo de geração de energia elétrica e, consequentemente, modelos aptos a fazê-las, possibilitando a programação de um despacho adequado do sistema (SALLES, 2004).

Ainda hoje existem grandes limitações que afetam a implantação da geração eólica na rede, em função da variabilidade do vento e a imprecisão em sua predição, o que impacta o adequado funcionamento do sistema elétrico. A variabilidade do vento faz que a potência eólica gerada possa passar de um máximo de geração a um mínimo em poucas horas (MORENO, 2007). Além disso, a possibilidade de não se ter vento suficiente nas horas de ponta da demanda faz com que seja necessário dispor-se de geração de reserva elétrica suficiente em magnitude e em velocidade de resposta. Estas são algumas das características que 
geram desafios na operação dos sistemas elétricos com fontes eólicas, e que impactam os custos de operação do sistema.

A aprendizagem e experiência obtidas pelos países com a inserção das fontes eólicas nos sistemas elétricos interligados, bem como, a interação destas com outras formas de geração de energia, com destaque para as hidréletricas e termelétricas a gás natural, com o objetivo de buscar a eficiência econômica em um ambiente de livre mercado sob controle e supervisão do estado, estão sendo recentemente assimilados e adaptados ao setor elétrico peruano.

\subsubsection{Geração Termelétrica a Gás Natural}

A descoberta de novas jazidas de gás natural fez com que nos anos 70 e 80 fossem desenvolvidas tecnologias de aproveitamento mais eficientes deste recurso na geração de energia elétrica. O crescimento acelerado da demanda, 0 avanço tecnológico e preços mais competitivos, fizeram com que a geração termelétrica com motores de combustão interna, turbinas a gás e vapor, em usinas de ciclo simples e combinado crescesse de importância na matriz elétrica mundial. As turbinas a gás passaram a ser utilizadas em usinas termelétricas concorrendo com sucesso com as usinas com turbinas a vapor, tendo um crescimento significativo no mercado, devido a seu menor custo e às facilidades de instalação, operação e manutenção, (BRANCO, 2005).

Usinas termelétricas a gás natural implantadas em diferentes partes do mundo estão substituindo outros tipos de combustíveis mais poluentes e/ou complementando outros tipos de fontes de geração, em função de seus impactos positivos na diminuição da emissão de gases de efeito estufa e cuidado com o meio ambiente.

A figura 3 mostra as projeções de participação de cada fonte energética na geração de eletricidade mundial para 2035 feita pela Agência Internacional de Energia (EIA). Percebe-se que o gás natural continuará sendo um dos combustíveis mais importantes da matriz elétrica mundial, permanecendo como a segunda fonte mais importante, só atrás do carvão, que terá ainda uma maior participação. Por 
outro lado observa-se o rápido crescimento das energias renováveis, dentre elas a energia eólica de 2\% em 2007 a 7\% para 2035.

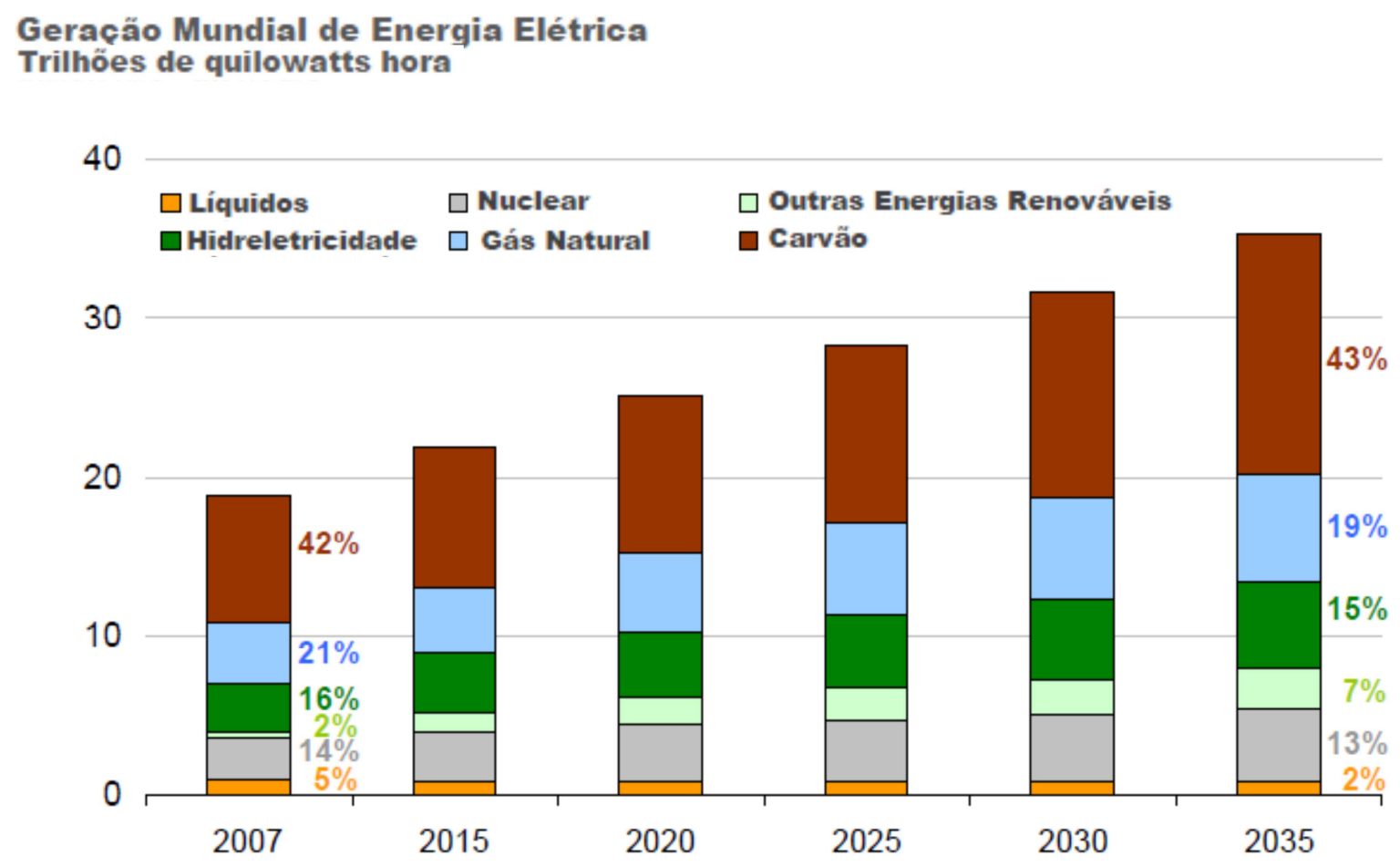

Figura 3 - Projeções da participação por fonte energética na geração mundial de eletricidade.

Fonte: (EIA, 2010)

As usinas termelétricas a gás natural compreendem basicamente a queima do gás na geração de energia em usinas de: ciclo simples, combinado, motor a combustão de ciclo Otto e Diesel; este último com destaque na substituição do diesel pelo gás natural, mediante adaptações na admissão do combustível nos motores, para o aproveitamento do gás natural.

Os motores de ciclo Diesel originalmente desenhados para o trabalho com óleo diesel, foram transformados para substituir o diesel pelo gás natural, pelo fato de oferecer maiores vantagens na combustão, emissão de gases de exaustão, custos mais baixos do combustível, bem como o prolongamento de vida útil dos motores.

Em 2004, no Peru com a construção do gasoduto que liga as jazidas de Camisea com a cidade de Lima, capital do Peru, houve uma expansão e aproveitamento do gás natural na geração de energia elétrica em novas e antigas usinas termelétricas, renovando algumas usinas que operavam com óleo diesel e 
passando agora a queimar gás natural, transformando assim, o sistema elétrico peruano num sistema hidrotérmico.

Nos últimos anos no Peru, decisões políticas vêm sendo tomadas no sentido da diversificação de sua matriz elétrica, com a inserção de novos aproveitamentos e incentivo às fontes renováveis não tradicionais, como a energia eólica, solar, biomassa e pequenas centrais hidrelétricas. Como resultado, foi implantado em fevereiro de 2010 o primeiro leilão de energia eólica, para o suprimento do mercado elétrico peruano, mediante a interligação ao sistema principal de transmissão.

Junto com os incentivos às energias renováveis ressalta-se que a geração térmica a gás natural nos últimos anos teve uma expansão significativa no mercado elétrico peruano, a partir da disponibilidade do gás, sendo atualmente a segunda fonte de geração elétrica mais importante do país. 


\section{SISTEMA ELÉTRICO PERUANO}

O desenvolvimento e a formação do setor elétrico peruano caracterizaram diferentes etapas de sua história, desde sua criação pela iniciativa privada nas primeiras usinas implantadas no país, passando pela estatização durante os anos setenta, até sua reestruturação e desenvolvimento atual. A expansão de sua capacidade instalada ocorreu inicialmente com usinas térmicas, posteriormente com usinas hidrelétricas, até atingir seu sistema atual hidrotérmico.

Em 1992 estabeleceu-se uma reforma institucional do setor elétrico peruano, um novo modelo, transformando o setor com a desverticalização das atividades elétricas de geração, transmissão, comercialização e distribuição em segmentos independentes além de uma nova estrutura tarifária (custos marginais). Nos anos seguintes houve o estabelecimento da operação centralizada e a criação de uma agência de regulação do setor.

Desde a reestruturação do setor elétrico peruano até a última década, o setor sofreu transformações importantes no contexto de sua política econômica e energética, fundamentando-se principalmente nas privatizações do setor e na abertura ao livre mercado; com isso o estado passou a ser o proprietário absoluto dos ativos no mercado elétrico, a atuar só como uma entidade que estabelece as normas gerais e concessões para a promoção do investimento privado, fiscalização do planejamento referencial do setor, deixando ao setor privado a responsabilidade de buscar a eficiência econômica no suprimento de energia elétrica para o mercado.

\subsection{MODELO ATUAL DO SETOR ELETRICO PERUANO}

O atual marco regulatório do setor elétrico peruano nasceu em 1992, com a promulgação da Lei $N^{\circ} 25844$, "Lei de Concessõ es Elétricas" (LCE) e sua posterior regulamentação. O marco geral definido por estas normas foi complementado, entre outros, com a Lei № 28832 "Lei para Assegurar o Desenvolvimento Eficiente da Geração Elétrica", a Lei antimonopólio e antioligopólio, 
que impôs condições prévias para a autorização de eventos de concentração econômica ou poder de mercado no setor, e a norma técnica de qualidade dos serviços elétricos, que estabelece entre outros aspectos a regulação da qualidade dos serviços elétricos, (OSINERG, 2005).

A LCE modificou a forma como estava organizada a indústria e estabeleceu um novo marco regulatório cujo objetivo geral era criar um sistema tarifário que fomentasse a eficiência econômica. O sistema deveria gerar os incentivos para que as empresas investissem num ambiente estável e com um sistema tarifário adequado. Isso permitiria incrementar a capacidade de geração e conseguir um incremento da cobertura do serviço elétrico no Peru.

Com respeito ao marco institucional, deixaram-se as funções de outorga de concessões, planejamento referencial e aprovação de normas sob responsabilidade do ministério do setor, enquanto a aplicação do esquema tarifário ficou a cargo da Gerência Adjunta de Regulação Tarifária (GART) do órgão regulador do sistema (Osinergmin).

Nesse sentido, o estado através do Ministério de Energia e Minas (MEM) tem o papel promotor de fixar as principais políticas energéticas, passando ao setor privado o papel da atuação principal nos assuntos relacionados à energia elétrica. Assim, o governo adota políticas energéticas que promovem 0 melhor aproveitamento de seus recursos energéticos, relativamente abundantes como a hidroeletricidade e o gás natural, substituindo os mais caros e mais poluidores, quais sejam, o diesel ou óleo combustível na geração de energia elétrica.

Entretanto, se tem adotado políticas voltadas à implantação de fontes renováveis de energia não tradicionais como a energia eólica, solar, geotérmicas e pequenas centrais hidrelétricas ( $\mathrm{PCHs}$ ), a promoção do uso eficiente da energia e as reformas necessárias que permitam a eficiência econômica no setor para o melhor desenvolvimento do mercado elétrico peruano.

Em dezembro de 1996, foi criado o Organismo Supervisor do Investimento Privado em Energia (OSINERG), através da Lei № 26734, que é um ente autônomo responsável pela fiscalização e supervisão da regulação, em matéria de qualidade, conservação do meio ambiente, eficiência e normatividade dos setores de eletricidade e hidrocarbonetos, bem como a fiscalização do cumprimento das obrigações contraídas nos contratos de concessão. É um organismo subordinado ao 
Ministério de Energia e Minas e deu início a suas funções em outubro de 1997. Posteriormente acrescentaram-se a suas funções, as de fiscalização da mineração, tendo atualmente a denominação de Osinergmin, (OSINERG, 2005).

Após as privatizações dos ativos de geração, transmissão e parte da distribuição pelo estado, foi feita a integração da infraestrutura elétrica do mercado elétrico peruano mediante a interligação entre os dois principais subsistemas elétricos do Peru, o sistema elétrico Centro-Norte com o sistema Sul, transformando em um único sistema elétrico interligado nacional (SEIN). Assim foi centralizada a operação do SEIN, mediante um único operador nacional do sistema, o Comitê de Operação Econômica do Sistema (COES).

A operação centralizada do sistema elétrico interligado nacional peruano (SEIN) é realizado pelo COES em tempo real. Encarregado da operação econômica e técnica do sistema, o COES tem por finalidade coordenar a operação de curto, médio e longo prazo do SEIN a custos mínimos, preservando a segurança do sistema, o melhor aproveitamento dos recursos energéticos, bem como planejar o desenvolvimento da transmissão do SEIN e administração do mercado de curto prazo.

As funções básicas do COES incluem: O planejamento da operação do sistema elétrico interligado, incluindo o controle do cumprimento dos programas de operação e a coordenação da manutenção maior das instalações; o cálculo dos custos marginais de curto prazo do sistema; cálculo da potência e energia firme de cada uma das unidades geradoras; a garantia a todos os integrantes sobre a venda de sua potência contratada até o limite de sua potência firme, e realiza as liquidações de potência e energia pelas diferenças que possam vir a ser geradas entre o despacho das usinas e seus compromissos contratuais, cumprindo princípios de segurança e eficiência econômica do sistema, além de atuar como o segmento de comercialização do mercado de curto prazo, (OSINERG, 2005).

$\mathrm{Na}$ atividade de geração estabeleceu-se a livre participação de qualquer investidor, possibilitando que qualquer agente, que possa cumprir certos requisitos (contar com contrato de concessão ou autorização, segundo seja o caso), possa competir ou ampliar sua capacidade no mercado de forma livre, o que permite que o segmento seja considerado potencialmente competitivo, com o benefício da econômica de escala e os custos globais mais eficientes no aproveitamento da 
energia, (ARISTONDO, 2009).

Desenharam-se então, para a geração de um sistema tarifário baseado em princípios marginalistas, os critérios do modelo "Peak Load Pricing" e de planejamento de investimentos aplicados ao setor elétrico num meio mais desregulado. Dessa forma os preços de geração de energia fixaram-se como a base do abastecimento da demanda a um mínimo custo, dados os custos variáveis auditados das usinas geradoras e o custo de investimento de uma usina de ponta eficiente. Estes preços são calculados com base em projeções da demanda e da oferta e, junto com os encargos por transmissão principal, constituem-se os "preços em barramento"”, que são usados como tarifas máximas nas transações entre geradores e distribuidoras para 0 atendimento dos consumidores cativos ${ }^{5}$, (OSINERG, 2005).

Por outro lado, a transmissão e distribuição são segmentos do setor que apresentam características de monopólio natural, atuando sob concessão especial e remunerados pelos agentes do sistema. Na distribuição existe a regulação e revisão de preços e tarifas, o que também permite gerar maior eficiência e ganhos de economia de escala.

A comercialização de energia elétrica no mercado elétrico peruano é realizada em dois níveis, no mercado livre e no mercado cativo, partindo do ponto em que a geração e a comercialização são segmentos competitivos; no mercado livre a comercialização é feita diretamente entre agentes geradores e consumidores livres, entre geradores e distribuidores ou entre distribuidores e consumidores livres. Por outro lado, no mercado cativo, a demanda é suprida em sua totalidade por empresas de distribuição, em função da localização da unidade consumidora na área de concessão da empresa.

O abastecimento do mercado atacadista realiza-se de forma centralizada mediante o órgão operador COES (formado pelas empresas geradoras, consumidores livres e transmissoras), encarregado de minimizar o custo de abastecimento da energia. Embora todas as transações passem por este órgão e não existam "contratos bilaterais físicos", permite-se a assinatura de "contratos financeiros" entre geradores e distribuidoras, ou clientes não regulados. O despacho

\footnotetext{
4 São os preços que os geradores cobram aos distribuidores para o abastecimento do mercado regulado, incluídos os custos de transmissão.

5 Segue adiante no trabalho, na seção 2.6.5 uma maior explicação dos leilões de energia do SEIN.
} 
é independente destes contratos, os geradores que não conseguem honrar ou cumprir os contratos de demanda de seus clientes devem comprar energia no mercado de curto prazo conhecido como mercado spot a "custo marginal instantâneo", (OSINERG, 2005), (NADIRA; MERRILL; ARTHUR, 2007).

A demanda do mercado elétrico peruano está organizada em dois grupos: o mercado regulado com demandas de potência menores a 0,2 MW atendidas pelas empresas de distribuição com tarifas reguladas pelo órgão regulador do setor; e os consumidores livres que têm demandas superiores a 0,2 MW de potência e que possuem liberdade para contratar e negociar as tarifas de energia no mercado diretamente com os agentes geradores ou com as empresas de distribuição, com contratos de livre determinação das partes, de quantidade e preço de venda de energia. Não obstante, os consumidores com demanda entre 0,2 MW e 2,5 MW têm liberdade de escolha entre os dois mercados, (SOWITEC, 2010).

A figura 4 apresenta a estrutura e composição básica do setor elétrico peruano após sua reestruturação. Sua organização em segmentos mostra as interações entre estes, formando a indústria da eletricidade.

\section{MINISTERIO DE ENERGIA Y MINAS}

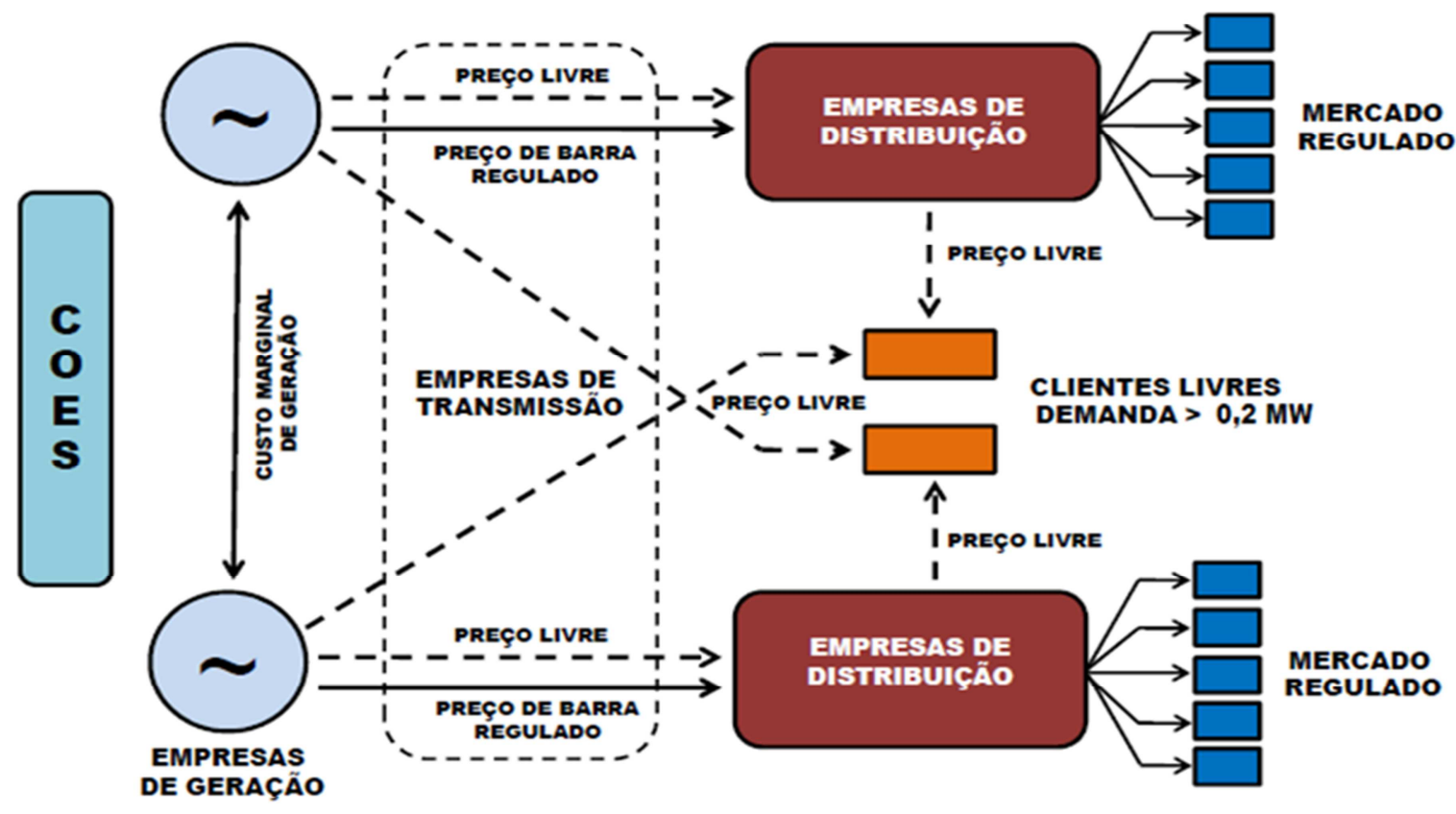

\section{OSINERGMIN}

Figura 4 - Esquema do setor elétrico peruano. 
A adoção de políticas energéticas na busca da diversificação da matriz elétrica peruana, o estabelecimento de políticas de uso eficiente de energia, o aproveitamento do gás natural de Camisea e o recente acordo de integração elétrica assinado entre os governos do Peru e Brasil, mostram algumas características gerais do contexto do setor elétrico peruano que não são tão diferentes das de outros países da região.

A abertura do setor elétrico peruano ao livre mercado e concorrência, com maior presença da participação privada em todos os segmentos da cadeia de valor da eletricidade nas últimas duas décadas, transformaram o setor numa nova estrutura, gerando uma gestão mais eficiente em termos econômicos; paralelamente o setor que tinha uma predominância da geração hidroelétrica agora passou a ter um sistema hidrotérmico, com forte participação da geração térmica a gás natural, e mais atualmente projetou-se a diversificação de sua matriz elétrica com a exploração de fontes renováveis não tradicionais de energia como a energia eólica, geotérmica, solar e biomassa.

Nos últimos cinco anos a demanda de eletricidade no Peru teve um crescimento médio anual de $8 \%$ devido, entre outros aspectos, ao intenso desenvolvimento das atividades de mineração e também das atividades manufatureiras. Influiu também a evolução positiva das condições macroeconômicas do país, demonstrando estabilidade ante as recentes crises econômicas internacionais. Tais condições permitiram ao país, no último quinquênio, crescimento dos investimentos no setor elétrico a uma taxa média anual de 27\%. Mesmo assim persiste a necessidade de assegurar a execução de novos projetos para poder assegurar o abastecimento de eletricidade no médio e longo prazo, (PERU MINISTERIO DE ENERGIA Y MINAS, 2010a).

Nesse sentido, estabeleceram-se normas e promoção de ações de cooperação internacional que permitiram: Assegurar a oferta de geração, reforçar o sistema elétrico, ampliar a cobertura elétrica, promover a concorrência no mercado elétrico e promover o uso sustentável e diverso dos recursos energéticos. Em síntese o setor elétrico desenvolveu aspectos como:

- Mecanismos de incentivo para o investimento elétrico;

- Promoção das energias renováveis para a geração elétrica;

- Uso eficiente do gás natural para geração elétrica;

- Segurança e cobertura da transmissão elétrica; 
- Cultura de eficiência energética e segurança elétrica aos usuários;

- Segurança e integração energética;

- Promoção do desenvolvimento elétrico preservando o meio ambiente.

\subsection{MARCO NORMATIVO DO SETOR ELÉTRICO PERUANO}

Os aspectos mais importantes da regulação do setor, emanados pelo poder público após a reestruturação e promulgação da LCE, definiu três atividades principais permitidas no setor elétrico peruano: A geração, transmissão e distribuição, além da comercialização; estas atividades podem ser levadas a cabo por empresas ou pessoas jurídicas, sendo as atividades de transmissão e distribuição consideradas como serviços públicos.

A normatividade geral das atividades no setor elétrico peruano é regida pela Lei de Concessões Elétricas (LCE), Lei № 25844, desde 1992, sendo complementada, desde 2006, com a Lei para Assegurar o Desenvolvimento Eficiente da Geração Elétrica (LADEGE), Lei №28832, com a finalidade de melhorar a sustentabilidade, eficiência e segurança energética do país, (PERU MINISTERIO DE ENERGIA Y MINAS, 2010a).

Dentro do marco das normas já mencionadas no setor, com o objetivo de gerar mecanismos de investimento e conceder benefícios tributários aos investidores, para melhorar a factibilidade econômica dos projetos, estas são melhoradas e complementadas pelas seguintes normas adicionais:

- Lei №1041 (junho de 2008), que melhora a normati vidade elétrica e promove o uso eficiente do gás natural;

- Lei №1002 (maio de 2008), Lei de promoção do inv estimento para a geração de eletricidade com o uso de energias renováveis não tradicionais (Lei RER), que concede vantagens competitivas aos projetos de geração com energias renováveis;

- DS № 027-2007-EM e DS № 010-2010-EM, que promove o investimento em transmissão; 
- Lei $\mathrm{N}^{\circ} 1058$ (junho de 2008), que estabelece o benefício da depreciação acelerada, até $20 \%$ anual, para o investimento em projetos hidrelétricos e outros recursos renováveis;

- Lei № 28876 (Junho de 2006), que estabelece a recuperação antecipada do imposto geral às vendas de eletricidade em empresas que utilizam recursos hidráulicos e energias renováveis.

Deve-se mencionar que os investidores têm o direito de celebrar contratos de estabilidade jurídica, estabilidade tributária e de livre disponibilidade de divisas. Assim mesmo, é possível viabilizar a implementação de projetos de infraestrutura pública ou de prestação de serviços públicos através da modalidade de associação público-privada que agiliza os processos de promoção do investimento privado.

Por outro lado a regulação do setor estabelece o procedimento das concessões para conseguir estabelecer, ou levar a cabo algumas das atividades permitidas e reconhecidas pela lei no setor elétrico. Precisa-se concessão definitiva para os seguintes casos, (SOWITEC, 2010):

- Na geração elétrica quando a capacidade instalada do empreendimento elétrico é superior a $20 \mathrm{MW}$;

- $\mathrm{Na}$ transmissão elétrica quando se requer o uso de bens de propriedade do estado, ou a imposição de faixa de servidão;

- Distribuição elétrica para fins públicos quando a demanda é superior a $0,5 \mathrm{MW}$;

- Na geração elétrica baseada em RER quando a capacidade instalada do empreendimento é superior a 0,5 MW.

No caso da implantação de usinas térmicas para geração elétrica com capacidade inferior a $20 \mathrm{MW}$ e superior a $0,5 \mathrm{MW}$ requer autorização, geralmente estes empreendimentos são de consumidores livres e produtores independentes.

É importante indicar que as empresas que desenvolvem atividades elétricas devem cumprir com os padrões técnicos nacionais que são:

- O Código Nacional de Eletricidade, Suprimento e Utilização, que determina os critérios técnicos de segurança para os operadores de instalações elétricas e usuários finais;

- Norma Técnica de Qualidade dos Serviços Elétricos (NTCSE), 
(Decreto supremo D.S. N020-97-EM de 1997), que es tabelece os níveis mínimos de qualidade dos serviços elétricos;

- Regulamento de Segurança e Saúde no Trabalho das Atividades Elétricas, que estabelece as condições de segurança e higiene ocupacional para toda a atividade elétrica.

Ademais, a regulação do setor elétrico é complementada por outras normas e decretos que organizam e governam as atividades elétricas; algumas das principais leis e normas que regulam o setor no momento são:

- Lei marco dos órgãos reguladores do Peru (Lei №2 7332, de 2000).

- Lei de promoção do uso eficiente da energia (Lei No 27345, de 2000).

- Norma técnica para a coordenação da operação dos sistemas interligados (Resolução Diretorial №014-2005-EM/D GE, 2005).

\section{3 ÓRGÃOS INSTITUCIONAIS DO SETOR ELÉTRICO PERUANO}

A reestruturação do setor elétrico peruano trouxe ao país novos paradigmas na evolução de seu mercado. Após as privatizações e desverticalização de sua estrutura mediante a Lei de Concessões Elétricas (LCE) foram criadas e definidas as funções das principais instituições do setor elétrico peruano, os que são encarregados pela promoção e direção da política energética, regulação, supervisão do setor, a operação centralizada, entre outras funções.

Sob um foco geral as principais funções das instituições do setor elétrico peruano são resumidas e mostradas no seguinte esquema da figura 5. 


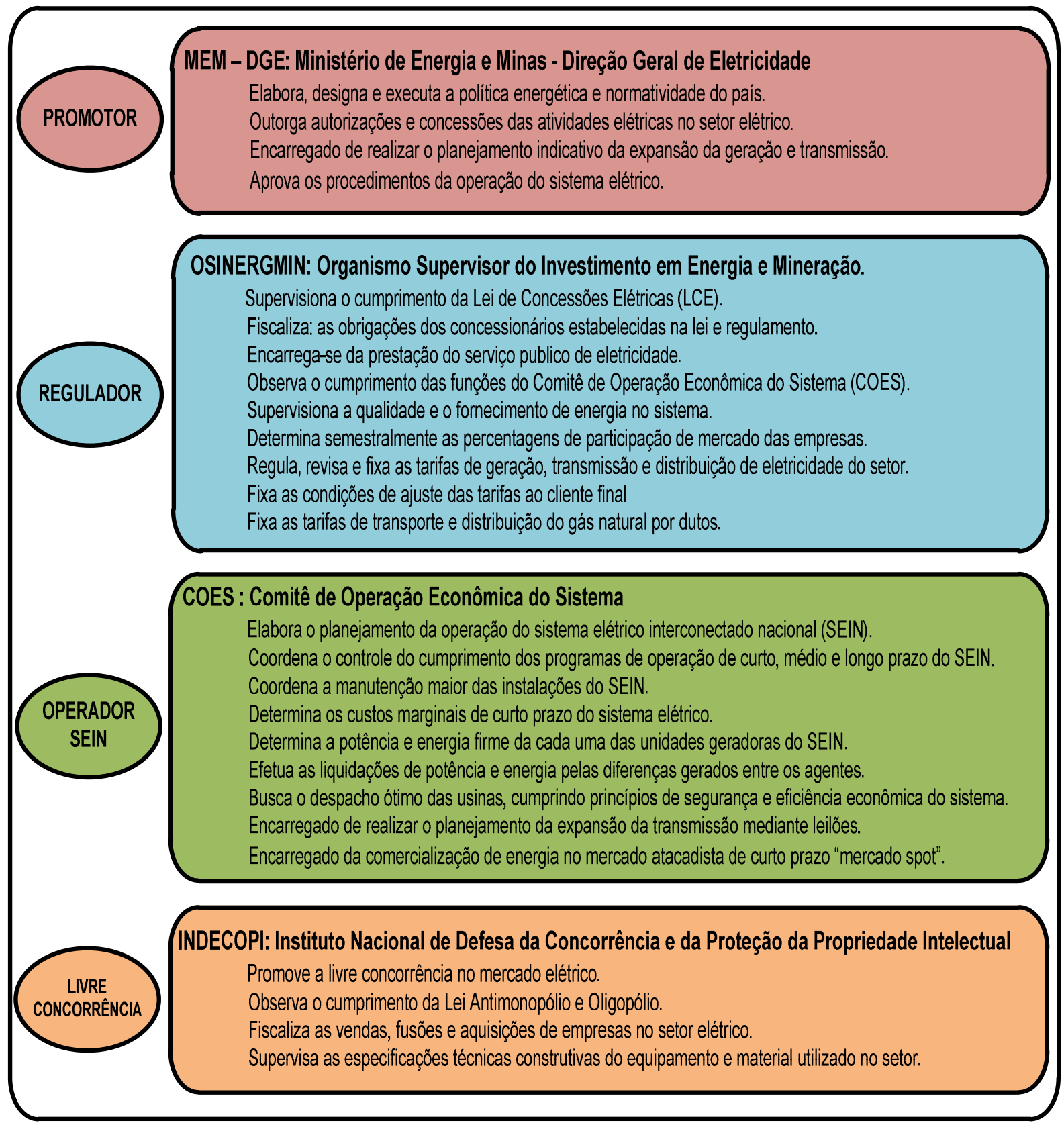

Figura 5 - Funções dos órgãos institucionais do setor elétrico peruano.

Fonte: Lei de Concessões Elétricas (LCE), regulamentos e modificações.

No setor elétrico peruano, são os agentes que participam, interagem segundo a normatividade vigente, e dentro de uma organização que promove o irrestrito respeito aos direitos das empresas para realizar atividades elétricas, estabelecem os meios de proteção ao consumidor e o cuidado do meio ambiente. $\mathrm{Na}$ figura 6, apresentam-se a organização das instituições do setor: Agentes promotores, reguladores, órgão operador, e agentes diretos (empresas e clientes), (PERU MINISTERIO DE ENERGIA Y MINAS, 2010a): 


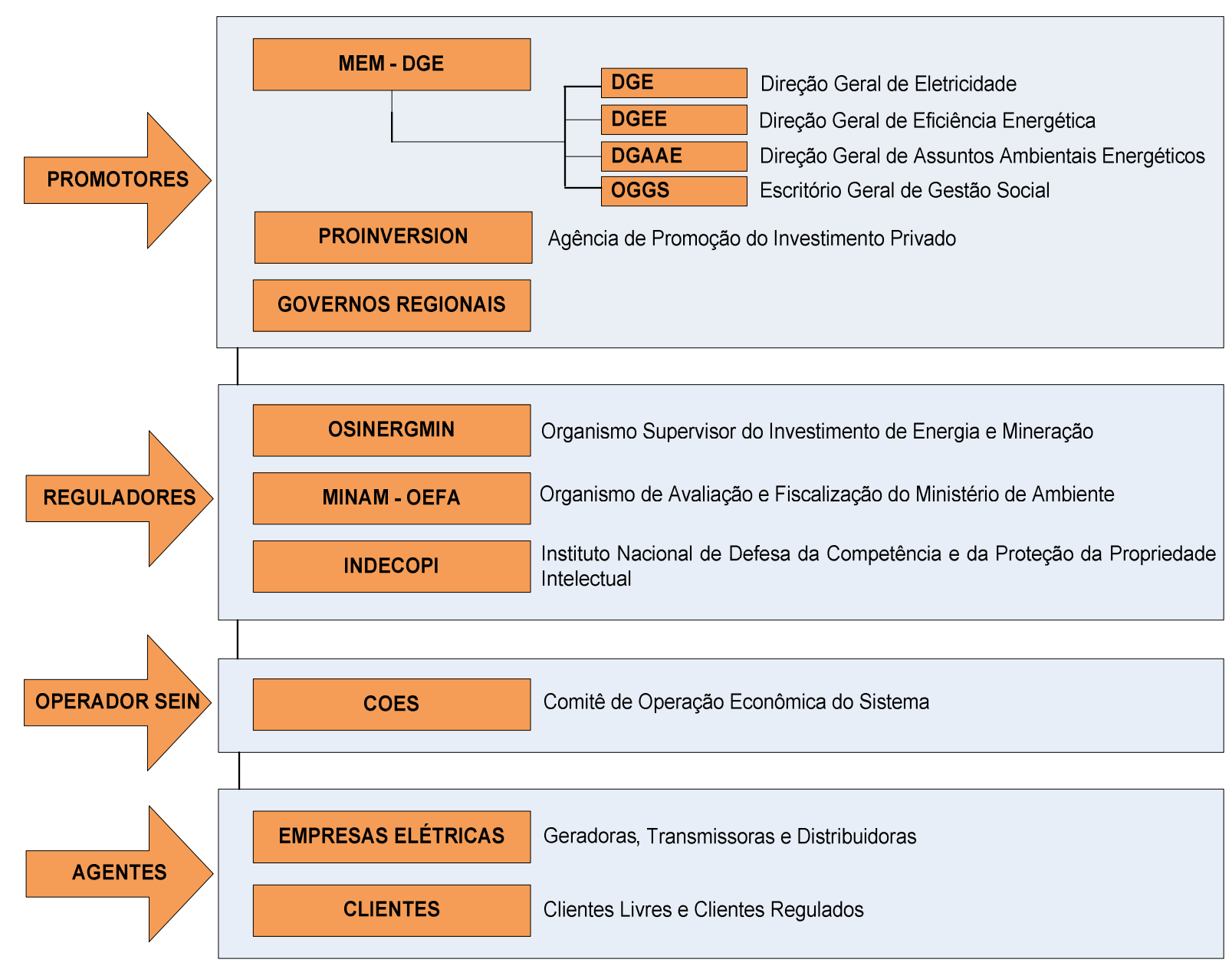

Figura 6 - Organização do setor elétrico peruano.

Onde:

DGE: Concede direitos para a realização de estudos e construção de infraestrutura elétrica considerando a aprovação prévia da licença ambiental da DGAAE. Também promove a formação de projetos e normatiza as políticas do governo central para o setor elétrico.

DGEE: Encarrega-se de propor a política de eficiência energética, que inclui as atividades promocionais e regulatórias que são necessárias em relação às atividades energéticas renováveis e não renováveis. Nesse sentido, encarrega-se de formular o Plano Energético Nacional, e atualizar o Balanço de Energia.

DGAAE: Avalia e aprova os estudos ambientais dos projetos elétricos de acordo com as políticas do Ministério de Ambiente e os padrões ambientais vigentes na normatividade nacional.

OGGS: Apoia o estabelecimento de uma relação harmoniosa entre as empresas e a população para um desenvolvimento sustentável em nível social e local. 
Governos Regionais: Impulsionam os pequenos projetos de eletricidade segundo seus planos e políticas locais.

OSINERGMIN: Determina os preços de referência com base na política de preços de eletricidade estabelecida pelo MEM, supervisiona e fiscaliza o cumprimento dos contratos de concessão elétrica. Nesse sentido normatiza os procedimentos necessários para suas atividades e exerce a aplicação das sanções respectivas.

MINAM - OEFA: Supervisiona e fiscaliza os efeitos ao meio ambiente de acordo com as políticas do Ministério de Ambiente (MINAM) e os padrões ambientais vigentes na normatividade nacional; além disso, exerce a aplicação de sanções respectivas.

INDECOPI: Defende a concorrência do mercado elétrico e os direitos dos consumidores.

COES: É um organismo técnico que coordena a operação do SEIN com um custo mínimo, preservando a segurança do sistema e o melhor aproveitamento dos recursos energéticos. Também planeja o desenvolvimento da transmissão do SEIN e administra o mercado de curto prazo. O COES é conformado por todos os agentes do SEIN (Geradores, transmissores, distribuidores e grandes usuários livres).

Empresas Elétricas: Dado que as atividades no mercado elétrico estão desintegradas verticalmente nas atividades de geração, transmissão e distribuição, logo, no setor participam empresas geradoras, transmissoras e distribuidoras de eletricidade, tanto privadas como estatais. Com respeito às empresas estatais, FONAFE é a entidade que normatiza e dirige a atividade empresarial do estado; esta inclui a ADINELSA, uma empresa estatal que administra a infraestrutura de eletrificação rural e isolada, que é executada pelo estado em forma de subsídio para as zonas de pobreza e extrema pobreza. Cabe mencionar que a Sociedade Nacional de Mineração, Petróleo e Energia (SNMPE) é uma instituição sem fins lucrativos que associa as empresas do setor mineiro e energético mais representativo do país.

CLIENTES: Consumidores diretos que demandam eletricidade para realizar suas atividades industriais e econômicas ou para seu uso residencial. Em caso dos grandes consumidores, têm a opção de serem clientes livres (liberdade de livre negociação do preço da energia). 


\subsection{CARACTERÍSTICAS DO SETOR ELÉTRICO PERUANO}

Com a integração dos subsistemas elétricos Centro-Norte com o sistema Sul, no inicio da presente década, a infraestrutura do setor elétrico peruano está conformada principalmente pelo Sistema Elétrico Interconectado Nacional (SEIN) que cobre quase a totalidade do território nacional. No entanto, por razões técnicas e econômicas, algumas zonas rurais ou muito isoladas são cobertas por pequenos sistemas isolados (SS AA).

A evolução da oferta elétrica nacional e particularmente do SEIN, no último quinquênio, em termos de capacidade, cresceu a incrementos anuais médio de $466 \mathrm{MW}$ e $372 \mathrm{MW}$ de potência, respectivamente; isto é uma média anual de 7\%. A demanda máxima do SEIN também cresceu uma média anual de $7 \%$, cabe ressaltar que, nesse mesmo período a inserção do gás natural como combustível das termelétricas mostrou um crescimento com média anual de 51\%, (PERU MINISTERIO DE ENERGIA Y MINAS, 2010a).

Por outro lado a evolução da produção de eletricidade nos últimos cinco anos mostrado no relatório oficial do Ministério de Energia e Minas (2010a), a nível Nacional e no SEIN, cresceu uma média anual de $7 \%$, significando um incremento médio por volta de $1800 \mathrm{GW}$.h/ano de energia gerada.

No mercado elétrico peruano, principalmente no SEIN, incluindo os sistemas isolados (SS AA), atualmente operam e participam 23 empresas elétricas de geração, 8 de transmissão e 24 de distribuição, entre empresas privadas e estatais como é mostrado na tabela 1. Por outro lado, existem empresas industriais denominadas produtores independentes, que operam usinas de geração elétrica para consumo próprio de forma total ou parcial.

Dos dados e indicadores expostos anteriormente, pode-se dizer que a cadeia de valor da eletricidade do mercado elétrico peruano está coberta pela participação de empresas e infraestrutura nos três segmentos mais importantes do mercado elétrico, como é na geração, transmissão e distribuição. 
Tabela 1 - Principais empresas elétricas do mercado elétrico peruano.

\begin{tabular}{|c|c|c|c|c|c|c|}
\hline TIPO & GERAÇÃO & MW & TRANSMISSÃO & Km & DISTRIBUIÇÃO & CLIENTES \\
\hline \multirow[t]{18}{*}{ PRIVADAS } & EDEGEL & 1571 & REPSA & 4342 & EDELNOR & 1060498 \\
\hline & ENERSUR & 1107 & TRANSMANTARO & 603 & LUZ DEL SUR & 829153 \\
\hline & DUKE EGENOR & 518 & REDESUR & 428 & ELECTROSURMEDIO & 166060 \\
\hline & KALLPA & 383 & ISA PERÚ & 392 & EDECAÑETE & 29086 \\
\hline & EGASA & 340 & ETESELVA & 392 & ELECTROTOCACHE & 11515 \\
\hline & TERMOSELVA & 203 & CONENHUA & 371 & EMSEMSA & 7362 \\
\hline & CHINANGO & 196 & ETENORTE & 342 & EMSEU & 6814 \\
\hline & ELECTROANDES & 184 & ATN & 89 & INADE CHAVIMOCHIC & 5130 \\
\hline & EEPSA & 159 & & & SERSA & 5068 \\
\hline & CAHUA & 92 & & & EILHICHA & 3536 \\
\hline & SHOUGANG & 67 & & & COELVISA & 1826 \\
\hline & ATOCONGO & 42 & & & ELECTROPANGOA & 1343 \\
\hline & SDF ENERGÍA & 40 & & & EGEPSA & 1095 \\
\hline & SINERSA & 39 & & & EDELSA & 887 \\
\hline & AIPSA & 23 & & & & \\
\hline & CORONA & 21 & & & & \\
\hline & GEPSA & 10 & & & & \\
\hline & SANTA CRUZ & 7 & & & & \\
\hline \multirow[t]{10}{*}{ ESTATAS } & ELECTROPERU & 1101 & & & HIDRANDINA & 538724 \\
\hline & EGASA & 340 & & & ELECTROCENTRO & 502327 \\
\hline & SAN GABÁN & 129 & & & ENOSA & 313091 \\
\hline & EGEMSA & 106 & & & ELECTROSURESTE & 306071 \\
\hline & EGESUR & 60 & & & SEAL & 291672 \\
\hline & & & & & ELECTRONORTE & 278789 \\
\hline & & & & & ELECTROPUNO & 174660 \\
\hline & & & & & ELECTRORIENTE & 172338 \\
\hline & & & & & ELECTROSUR & 119601 \\
\hline & & & & & ELECTROUCAYALI & 52308 \\
\hline
\end{tabular}

Fonte: Estatística Elétrica 2009, (PERU MINISTERIO DE ENERGIA Y MINAS, 2010a).

Um indicador importante da evolução positiva da expansão do mercado elétrico peruano é a evolução da produção de energia e sua alta correlação com o crescimento do PIB do país, como é mostrado na figura 7.

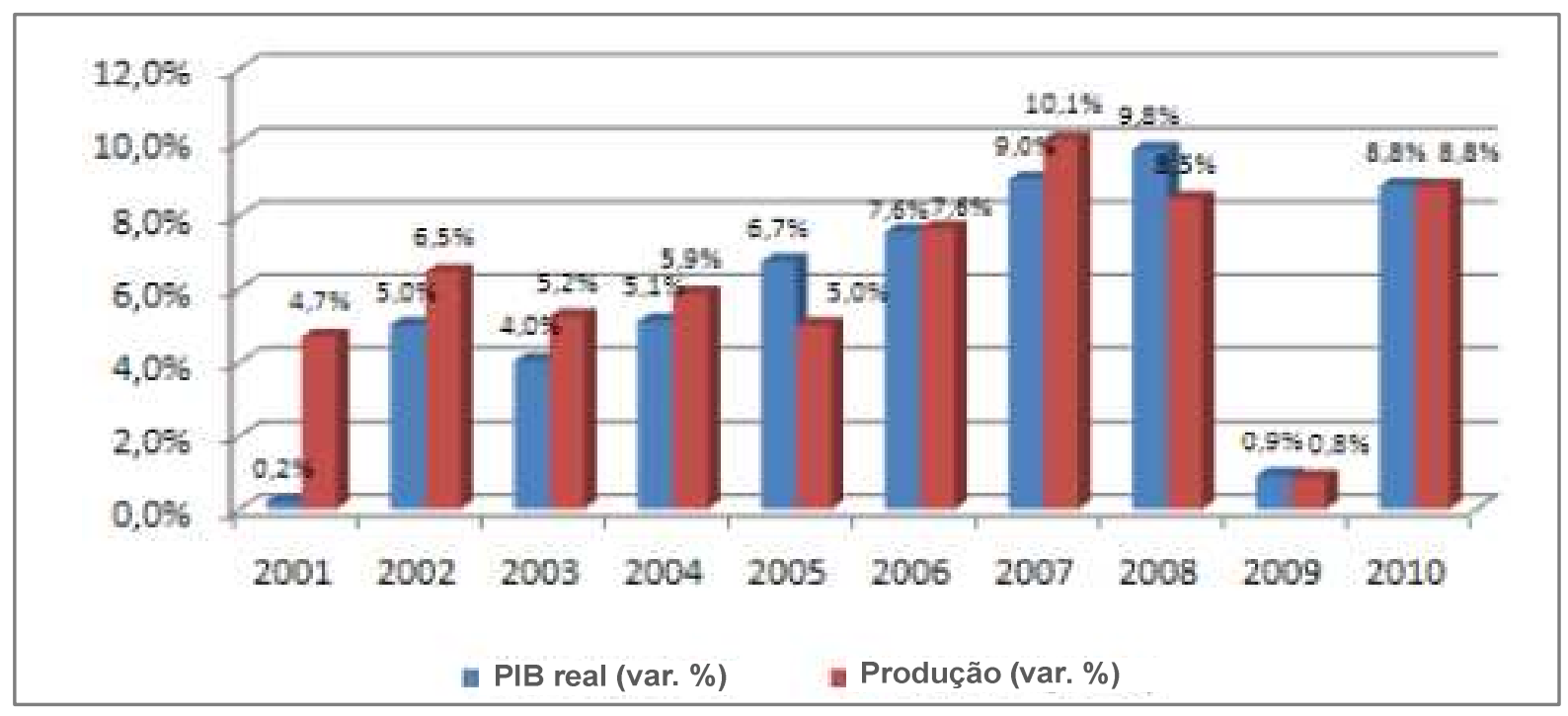

Figura 7 - Evolução do crescimento do PIB e da produção.

Fonte: (OSINERGMIN, 2011a) 


\subsubsection{Geração}

A oferta elétrica peruana está baseada em um sistema de forte participação de usinas hidrelétricas e termelétricas, sendo que $60 \%$ da energia elétrica é gerada por usinas hidrelétricas. Estas usinas aproveitam as quedas dos rios dos Andes no vertente do Pacífico, bem como da vertente do Atlântico do lado da Amazônia, e complementam a demanda com energia produzida por usinas termelétricas a gás natural, carvão, óleo combustível, diesel, em quantidades pequenas, e com o uso de biomassa (bagaço de cana e resíduos urbanos) ainda em quantidades ainda menores. Também considera-se no curto prazo a utilização de energia eólica e solar fotovoltaica.

Atualmente a oferta, a potência instalada ${ }^{6}$ do país é de $8600 \mathrm{MW}$, sendo $7293 \mathrm{MW}^{7}$ pertencente ao SEIN e $1307 \mathrm{MW}$ aos sistemas isolados, o que corresponde aproximadamente a uma participação de $85 \%$ e 15\%, respectivamente, como são mostrados no quadro 1 a seguir. Por outro lado, a expansão do SEIN é realizada por critério de energia através do balanço de energia, (PERU MINISTERIO DE ENERGIA Y MINAS, 2011a).

Quadro 1 - Potência instalada do setor elétrico peruano (2009 - 2010) em MW.

\begin{tabular}{|c|c|c|c|c|c|c|c|c|c|c|}
\hline \multirow{2}{*}{$\begin{array}{c}\text { TIPO SERVIÇO E } \\
\text { SISTEMA }\end{array}$} & \multirow{2}{*}{$\begin{array}{r}\text { GERAÇÃO: } \\
\text { Ano: }\end{array}$} & \multicolumn{3}{|c|}{ HÍDRICA } & \multicolumn{3}{|c|}{ TÉRMICA } & \multicolumn{3}{|c|}{ TOTAL NACIONAL* } \\
\hline & & 2009 & 2010 & $\Delta 10 / 09$ & 2009 & 2010 & $\Delta 10 / 09$ & 2009 & 2010 & $\Delta 10 / 09$ \\
\hline \multirow{2}{*}{ MERCADO ELÉTRICO } & SEIN & 3122 & 3351 & $7,3 \%$ & 3370 & 3755 & $11,4 \%$ & 6491 & 7105 & $9,5 \%$ \\
\hline & SS AA & 61 & 61 & $0,0 \%$ & 170 & 170 & $0,0 \%$ & 232 & 232 & $0,0 \%$ \\
\hline \multicolumn{2}{|c|}{ Total Mercado Elétrico } & 3183 & 3412 & $7,2 \%$ & 3540 & 3924 & $10,9 \%$ & 6723 & 7337 & $9,1 \%$ \\
\hline \multirow{2}{*}{ USO PRÓPRIO } & SEIN & 14 & 14 & $0,0 \%$ & 174 & 174 & $0,0 \%$ & 188 & 188 & $0,0 \%$ \\
\hline & SS AA & 81 & 81 & $0,0 \%$ & 995 & 995 & $0,0 \%$ & 1075 & 1075 & $0,0 \%$ \\
\hline \multicolumn{2}{|c|}{ Total Uso Proprio } & 94 & 94 & $0,0 \%$ & 1169 & 1169 & $0,0 \%$ & 1263 & 1263 & $0,0 \%$ \\
\hline \multirow{2}{*}{ TOTAL SISTEMAS } & SEIN & 3135 & 3364 & $7,3 \%$ & 3544 & 3929 & $10,9 \%$ & 6679 & 7293 & $9,2 \%$ \\
\hline & SS AA* & 142 & 142 & $0,0 \%$ & 1164 & 1164 & $0,0 \%$ & 1307 & 1307 & $0,0 \%$ \\
\hline \multicolumn{2}{|c|}{ TOTAL NACIONAL } & 3277 & 3506 & $7,0 \%$ & 4708 & 5093 & $8,2 \%$ & 7986 & 8600 & $7,7 \%$ \\
\hline
\end{tabular}

É a capacidade de energia que pode gerar e entregar uma central elétrica em condições ideais. Inclui a capacidade instalada correspondente a geradores livres ou independentes. 
A tabela 2 mostra a evolução e participação da potência efetiva ${ }^{8}$ por tipo de fonte energética, a demanda máxima e reserva do SEIN (no período 2001 2010). Atualmente o SEIN possui uma potência efetiva de $6463 \mathrm{MW}$, frente a uma demanda máxima de $4579 \mathrm{MW}$ em termos de capacidade, crescimentos registrados durante 2010 em torno de $10,5 \%$ e 5,9\%, respectivamente.

Tabela 2 - Potência efetiva, demanda máxima e reserva - SEIN (2001- 2010) (MW).

\begin{tabular}{lrrrrrrrrrr}
\hline \multicolumn{1}{c}{ Fonte } & $\mathbf{2 0 0 1}$ & $\mathbf{2 0 0 2}$ & $\mathbf{2 0 0 3}$ & $\mathbf{2 0 0 4}$ & $\mathbf{2 0 0 5}$ & $\mathbf{2 0 0 6}$ & $\mathbf{2 0 0 7}$ & $\mathbf{2 0 0 8}$ & $\mathbf{2 0 0 9}$ & $\mathbf{2 0 1 0}$ \\
\hline Hídrica & 2603 & 2626 & 2626 & 2626 & 2785 & 2789 & 2789 & 2781 & 2858 & 3098 \\
Gás Natural & 238 & 238 & 253 & 602 & 731 & 1073 & 1557 & 1557 & 2049 & 2641 \\
Carvão & 141 & 141 & 141 & 141 & 141 & 142 & 142 & 142 & 142 & 142 \\
Diesel+Oleo Comb.+Bagaço & 1400 & 1398 & 1361 & 966 & 814 & 797 & 685 & 668 & 799 & 582 \\
\hline Potencia Efetiva Total & $\mathbf{4 3 8 3}$ & $\mathbf{4 4 0 2}$ & $\mathbf{4 3 8 1}$ & $\mathbf{4 3 3 6}$ & $\mathbf{4 4 7 1}$ & $\mathbf{4 8 0 0}$ & $\mathbf{5 1 4 7}$ & $\mathbf{5 1 4 7}$ & $\mathbf{5 8 4 8}$ & $\mathbf{6 4 6 3}$ \\
\hline Demanda Maxima & $\mathbf{2 7 9 2}$ & $\mathbf{2 9 0 8}$ & $\mathbf{2 9 6 5}$ & $\mathbf{3 1 3 1}$ & $\mathbf{3 3 0 5}$ & $\mathbf{3 3 0 5}$ & $\mathbf{3 5 8 0}$ & $\mathbf{3 9 6 6}$ & $\mathbf{4 3 2 2}$ & $\mathbf{4 5 7 9}$ \\
\hline Reserva & $\mathbf{5 7 \%}$ & $\mathbf{5 1 \%}$ & $\mathbf{4 8 \%}$ & $\mathbf{3 9 \%}$ & $\mathbf{3 5 \%}$ & $\mathbf{4 5 \%}$ & $\mathbf{4 4 \%}$ & $\mathbf{3 0 \%}$ & $\mathbf{3 5 \%}$ & $\mathbf{4 1 \%}$ \\
\hline
\end{tabular}

Fonte: (OSINERGMIN, 2011a).

Uma das características mais importantes da atual situação do setor elétrico peruano, em particular do SEIN, é a evolução da margem de reserva do sistema, que vem diminuindo de 57\% em 2001 para 41\% para 2010, como é mostrado na figura 8 a seguir.

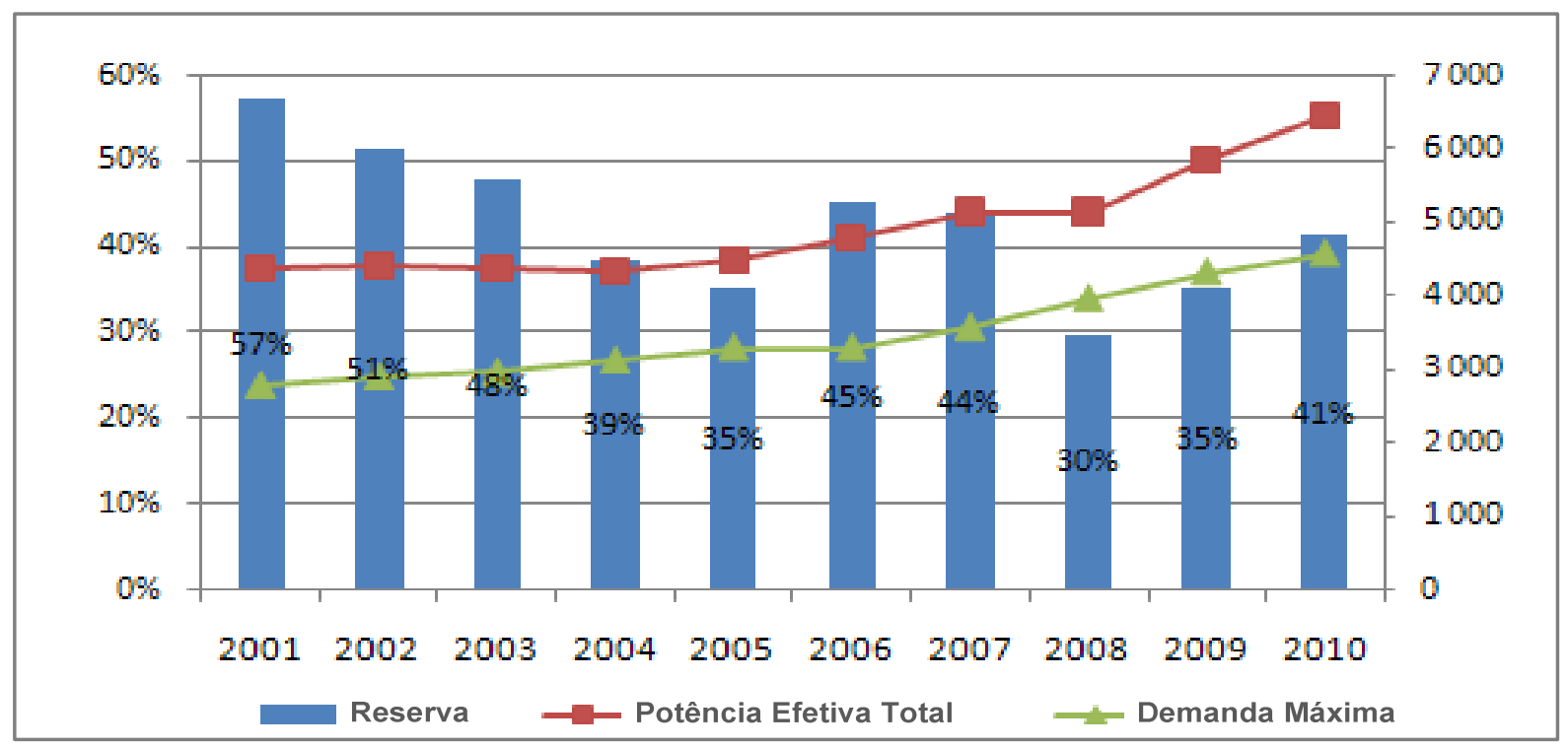

Figura 8 - Evolução da potência efetiva, demanda máxima e reserva (2001 - 2010) do SEIN.

Fonte: (OSINERGMIN, 2011a).

8 Indica a capacidade real de energia que as usinas podem entregar de forma contínua ao sistema. 
Em relação ao crescimento da potência efetiva e potência firme ${ }^{9}$ do SEIN registrados até 2010, pode-se observar uma participação maior das usinas termelétricas com $52,1 \%$ em relação ao $47,7 \%$ das hidrelétricas e uma participação bem pequena de $0,2 \%$ de outras fontes renováveis como o bagaço de cana, o que confirma a característica hidrotérmica do sistema elétrico peruano, como é mostrado na tabela 3.

Tabela 3 - Potência firme e potência efetiva do SEIN em 2010 (MW).

\begin{tabular}{lccc}
\hline \multicolumn{1}{c}{ FONTE } & $\begin{array}{c}\text { POT. FIRME } \\
\text { (MW) }\end{array}$ & $\begin{array}{c}\text { POT. EFETIVA } \\
\text { (MW) }\end{array}$ & (\%) \\
\hline Termelétrica & 3285 & 3345 & 52,1 \\
Hidrelétrica & 3017 & 3098 & 47,7 \\
Outras Renováveis & 11 & 20 & 0,2 \\
\hline TOTAL & $\mathbf{6 3 1 3}$ & $\mathbf{6 4 6 3}$ & $\mathbf{1 0 0}$ \\
\hline
\end{tabular}

Fonte: (OSINERGMIN, 2011a).

Analisando, através da fonte energética, a evolução da potência efetiva do SEIN apresentada na figura 9, é visível que a capacidade instalada das termelétricas a gás natural teve maior crescimento nos últimos anos, através da implantação de novas usinas incentivadas pela disponibilidade e menores custos do gás natural. Estas novas inserções das termelétricas a gás natural na potência efetiva do SEIN em 2010 atingiu em torno de 40,9\% de participação.

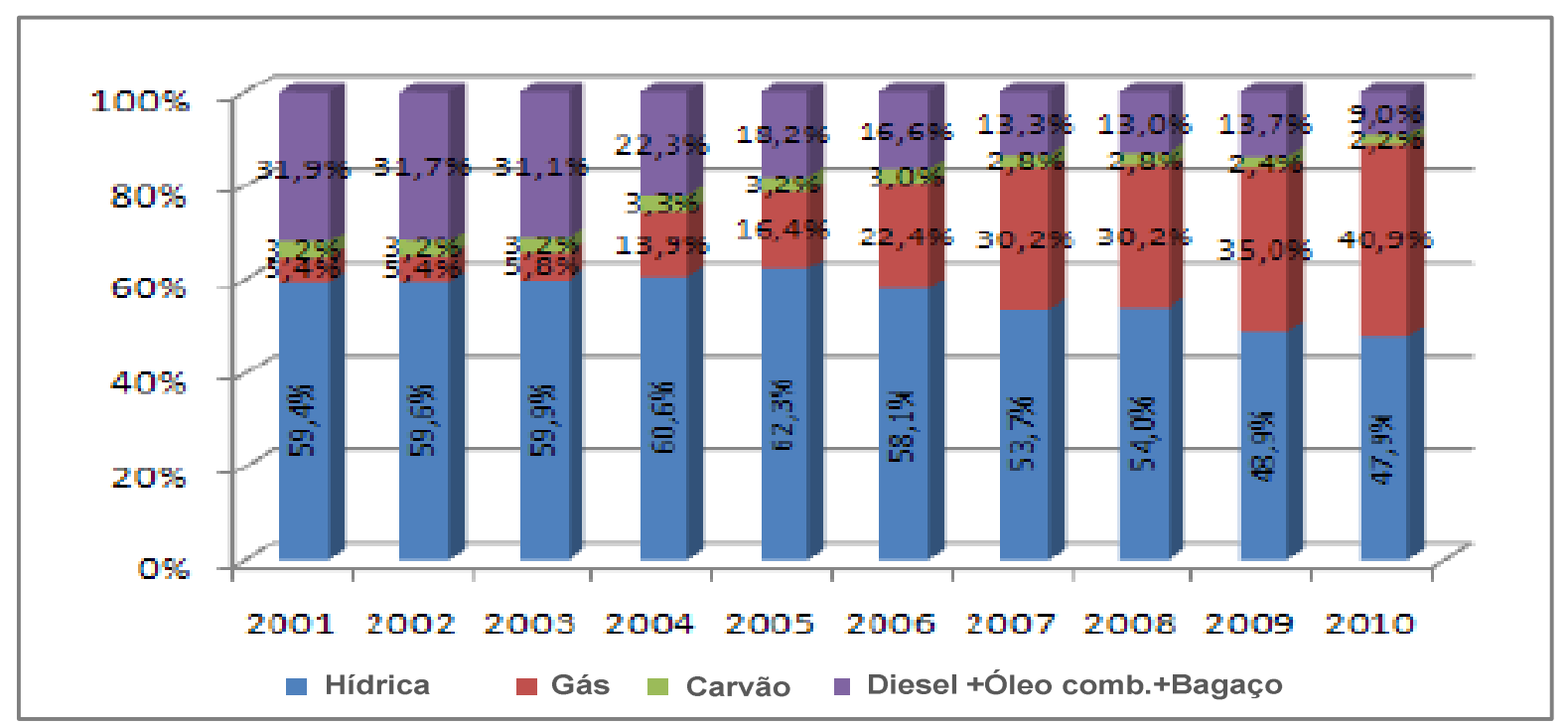

Figura 9 - Porcentagem de participação por fonte energética na potência efetiva do SEIN em 2010.

Fonte: (OSINERGMIN, 2011a).

9 É uma parte da potência efetiva e que corresponde à quantidade de energia que pode ser entregada de forma imediata (em tempo real) e com um alto nível de segurança ao sistema, pois têm garantidos os insumos (água, gás, etc.) necessários para sua geração de energia elétrica. 
A evolução da produção total de energia elétrica gerada no SEIN até 2010 mostrou um crescimento de 8,8\% em relação ao ano de 2009, atingindo 32426 GW.h, sendo que a geração hidrelétrica tem uma participação de 18965 GW.h $(58,5 \%)$ e o restante 13461 GW.h (41,5\%) através das termelétricas. A produção hidrelétrica nesse mesmo período incrementou-se em $1,1 \%$ e, por outro lado, a geração das termelétricas cresceu em 21,8\%, (OSINERGMIN, 2011).

Atualmente a geração hidrelétrica é a fonte energética com maior participação na produção total de energia, mesmo que a participação da geração termelétrica tenha se incrementado nos últimos anos com a instalação de novas usinas termelétricas que operam com gás natural. Por isso mesmo, o mercado elétrico peruano tem ainda uma dependência da hidreletricidade, como é apresentado na figura 10, (OSINERGMIN, 2011).

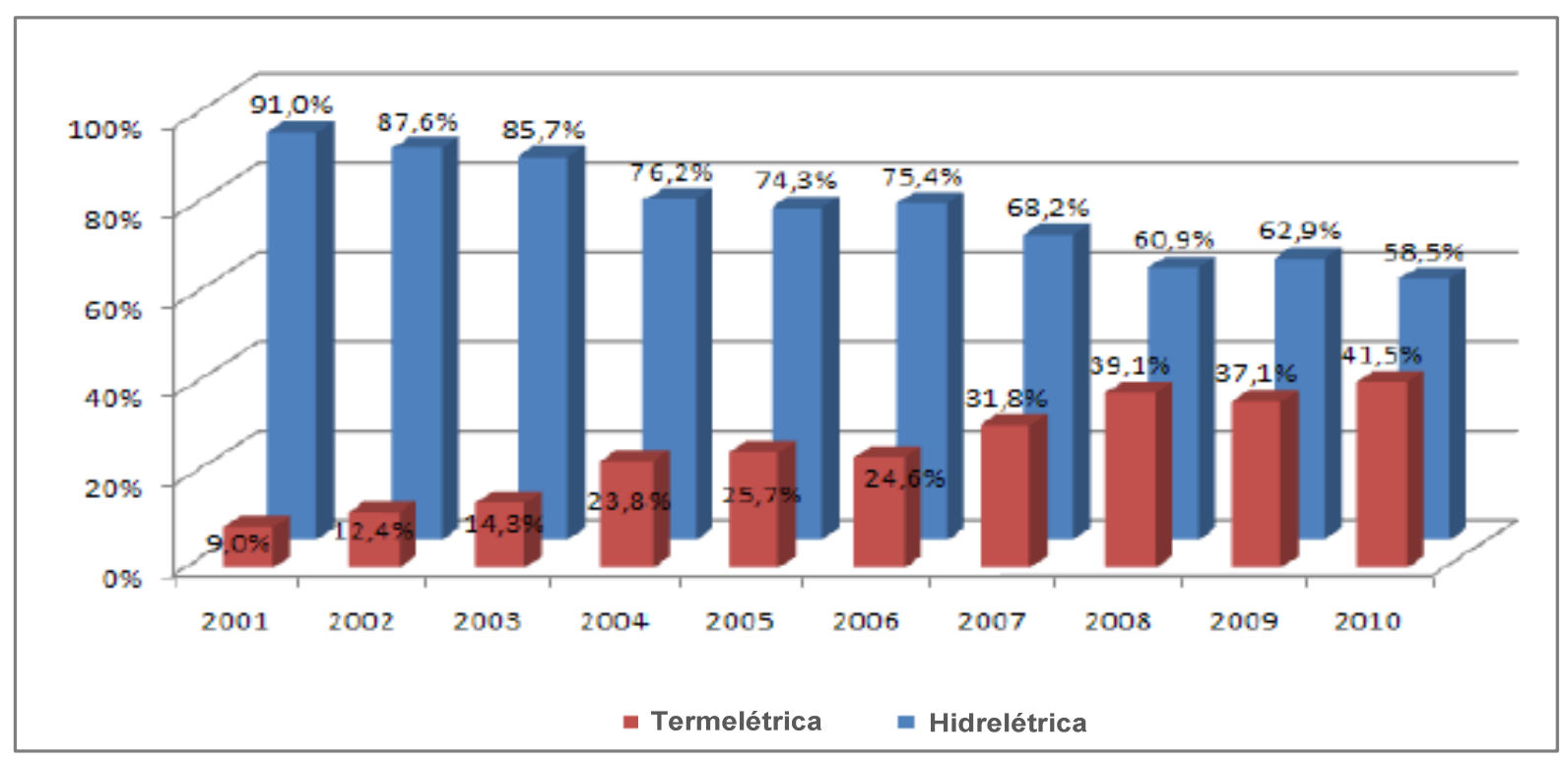

Figura 10 - Produção de energia por tipo de geração no SEIN 2010.

Fonte: (OSINERGMIN, 2011a).

A participação mensal, durante o ano de 2010, das principais fontes energéticas na produção é apresentada na figura 11. Observa-se principalmente a participação majoritária da hidrelétricidade como foi visto anteriormente, complementado pela produção das usinas termelétricas a gás natural, carvão, diesel, bagaço de cana e óleo combustivel durante os meses de menor hidrologia. 


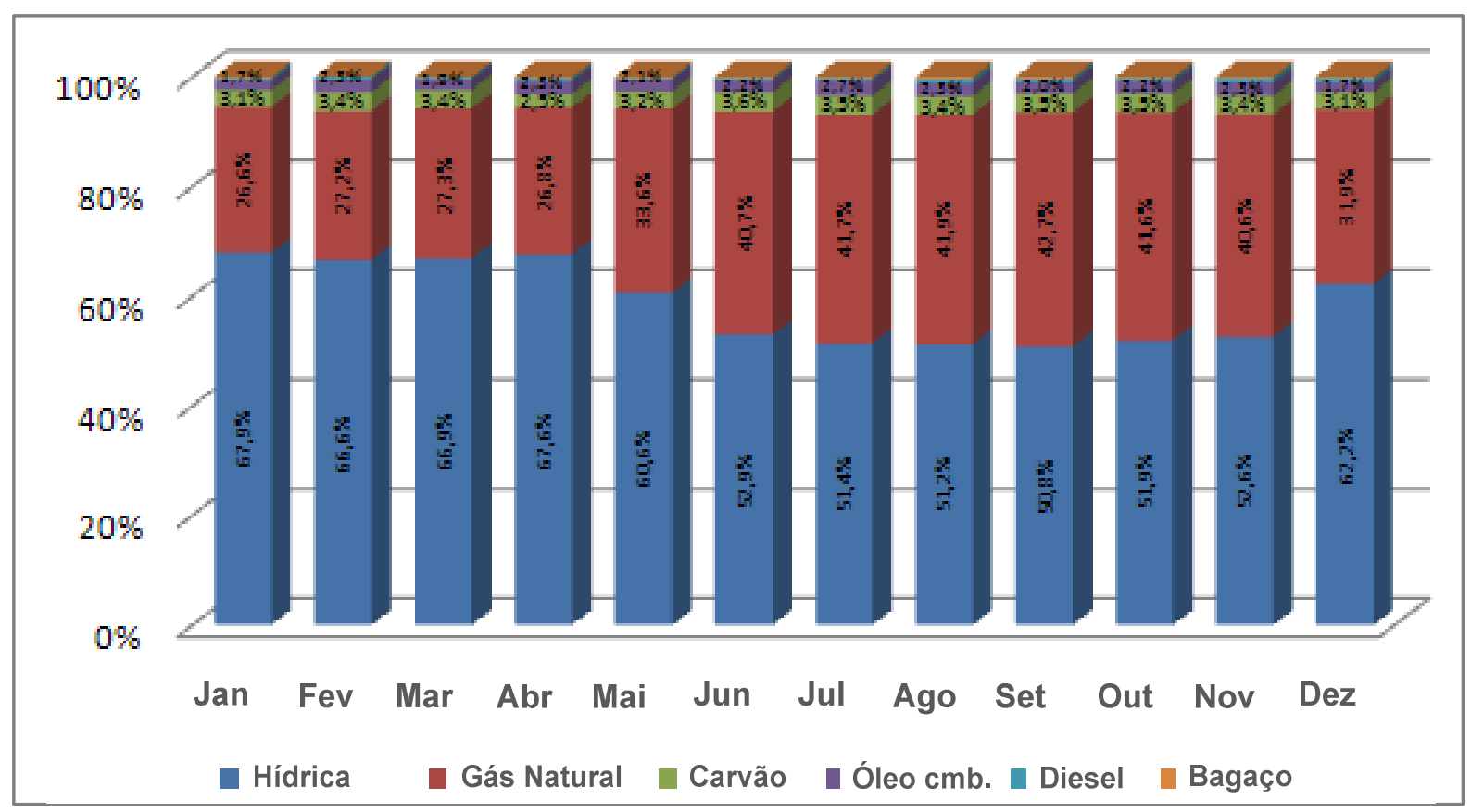

Figura 11 - Produção de energia por fonte de energia no SEIN 2010.

Fonte: (OSINERGMIN, 2011a).

Com relação às produtoras de energia destacam-se como as mais importantes e com a maior participação na capacidade instalada e energia produzida no SEIN peruano a: Edegel, Electroperú e Enersur com 23,4\%, 22,3\% e 14,5\%, respectivamente, de um total de 23 empresas geradoras em operação comercial, como é mostrado na figura 12.

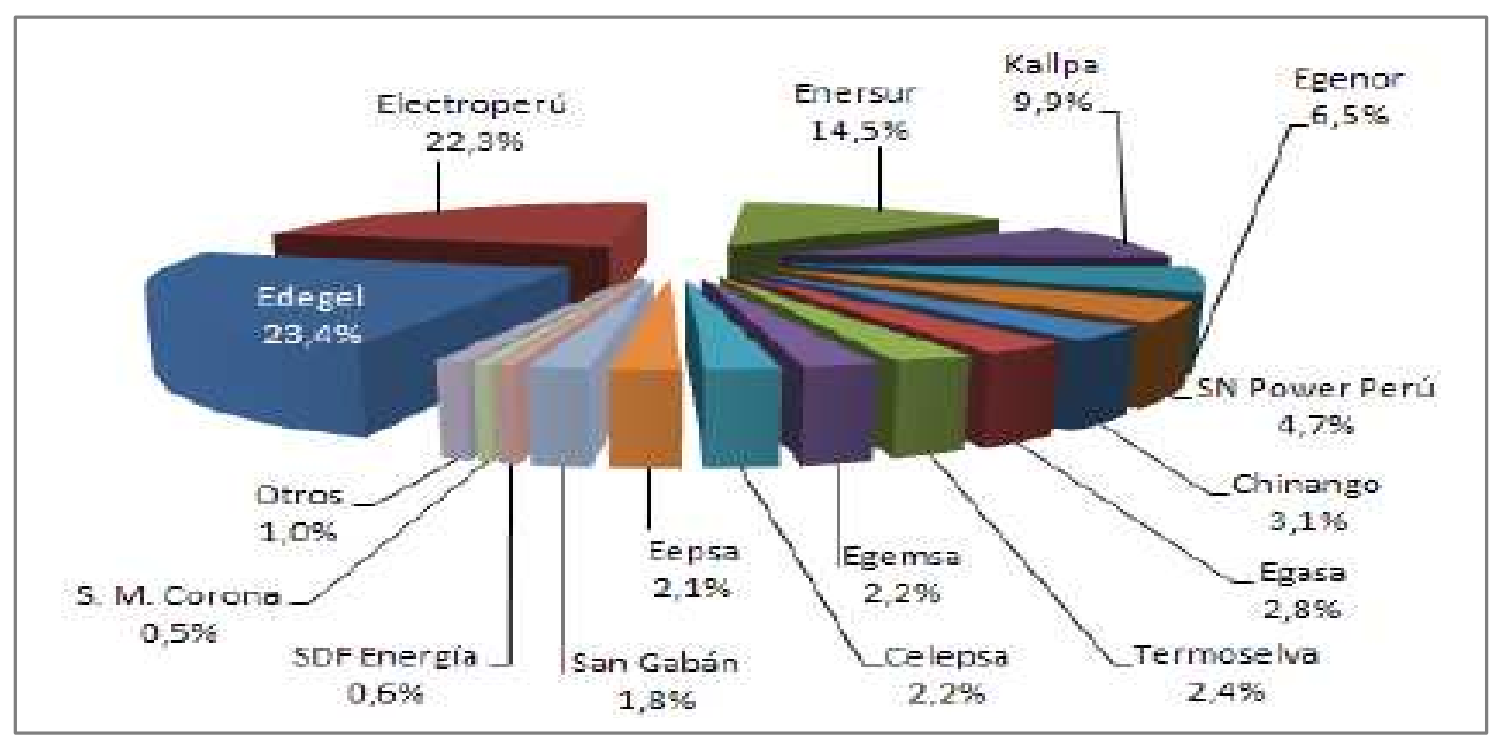

Figura 12 - Produção de energia por empresas no SEIN 2010.

Fonte: (OSINERGMIN, 2011a) 


\subsubsection{Transmissão}

A característica do transporte de energia elétrica no mercado elétrico peruano, desde as subestações elétricas das usinas de geração até os pontos de entrega nas subestações das empresas de distribuição e/ou mesmo dos consumidores livres é realizada em extra-alta tensão (EAT) e alta tensão ${ }^{10}$. Mediante o Sistema Elétrico Interligado Nacional (SEIN) que abarca quase a totalidade das regiões do país com linhas de transmissão de 220 kV, 138 kV e 60 kV de tensão nominal, a uma frequência de $60 \mathrm{~Hz}$, numa configuração principalmente radial. Como será apresentado no mapa do SEIN mais adiante, há previsão de curto e médio prazo para que o SEIN seja reforçado com redes de $500 \mathrm{kV}$, (PERU. MINISTERIO DE ENERGIA Y MINAS, 2010a).

\subsubsection{Sistema Elétrico Interligado Nacional (SEIN)}

Em outubro de 2000, o Sistema Elétrico Interligado Nacional (SEIN) é inaugurado. Neste período e após interligação de seus subsistemas regionais houve a privatização completa das empresas transmissoras. A partir dessa data a operação comercial do SEIN é centralizada e realizada pelo COES.

A implantação do sistema elétrico interligado nacional peruano SEIN, é muito complexa devido a difícil situação geográfica do território, pelo acesso complexo com elevadas altitudes superiores a cinco mil metros e presença de zonas montanhosas inacessíveis.

A interligação dos subsistemas elétricos a um único sistema elétrico nacional permitiu ao Peru garantir um melhor aproveitamento de seus recursos energéticos e a diversificação da oferta elétrica no setor, assim como tornar eficiente a operação do sistema elétrico; além disso, permitiu uma maior expansão da

10 As classificações no SEIN dos níveis de transmissão são: (EAT) Extra-Alta Tensão, superior a 100 kV; (AT) Alta Tensão igual ou superior a 30 kV até 100 kV; (MT) Média Tensão, maiores a 1 $\mathrm{kV}$ e inferiores a $30 \mathrm{kV}$; (BT) Baixa tensão, menores de $1 \mathrm{kV}$. 
transmissão e diminuição do custo global econômico do mercado, mesmo sendo a transmissão uma atividade de monopólio natural.

Atualmente, a transmissão elétrica no SEIN é realizada através de dois sistemas: o sistema principal de transmissão (SPT), que é comum ao conjunto de geradores do SEIN, que permite o intercâmbio de energia e a sua livre comercialização, onde estão inclusas as instalações de extra-alta e alta tensão (220 e $138 \mathrm{kV}$ ), e o sistema secundário de transmissão (SST), definido como a parte do sistema de transmissão destinada a transmitir energia para um distribuidor ou consumidor final a partir de um barramento do SPT. Fazem parte deste sistema as instalações que vinculam um sistema de geração e uma barra do SPT. No entanto a partir de 2006, com a promulgação da Lei $\mathrm{N}^{\circ} 28832^{11}$, além do Sistema Principal e Secundário, foi criado um Sistema Garantido e um Sistema Complementar de transmissão, para as novas linhas a construir no sistema.

O Sistema Garantido de Transmissão está formado pelas instalações implantadas dentro do Plano da Expansão da Transmissão cuja concessão e construção resultam de um processo de leilão, tendo um prazo máximo de concessão de trinta (30) anos (operação comercial), mais o tempo de construção (Art. 22/Lei28832). Por outro lado, o Sistema Complementar de Transmissão está formado pelas instalações que fazem parte do Plano de Expansão de Transmissão, em que a construção é o resultado da iniciativa de um ou vários agentes (geradores, transmissores, distribuidores e usuários livres) ou formado pelas instalações que não fizerem parte do Plano de Expansão da Transmissão (Art. 27/Lei28832). O objetivo da criação do Sistema Garantido e Complementar de Transmissão é centralizar o planejamento é garantir sua expansão eficiente, sendo o planejamento da expansão do SEIN do tipo centralizado, (HUAYLLAS, 2008).

As linhas de transmissão elétrica no SEIN atualmente têm uma extensão total de $16250 \mathrm{~km}$, onde no momento é realizado o transporte de energia principalmente em três níveis de tensão, em 220 kV, 138 kV e 69 kV. No entanto, vem sendo construídas três linhas de transmissão elétrica em 500 kV que interligarão no curto prazo a região central do país com as regiões norte e sul, o que permitirá ao setor ter maior confiabilidade e segurança na transmissão de energia elétrica, acompanhando a expansão do setor no país, como é mostrado na figura 13.

11 Denominado como "Lei para Assegurar o Desenvolvimento Eficiente da Geração Elétrica” (LADEGE). 


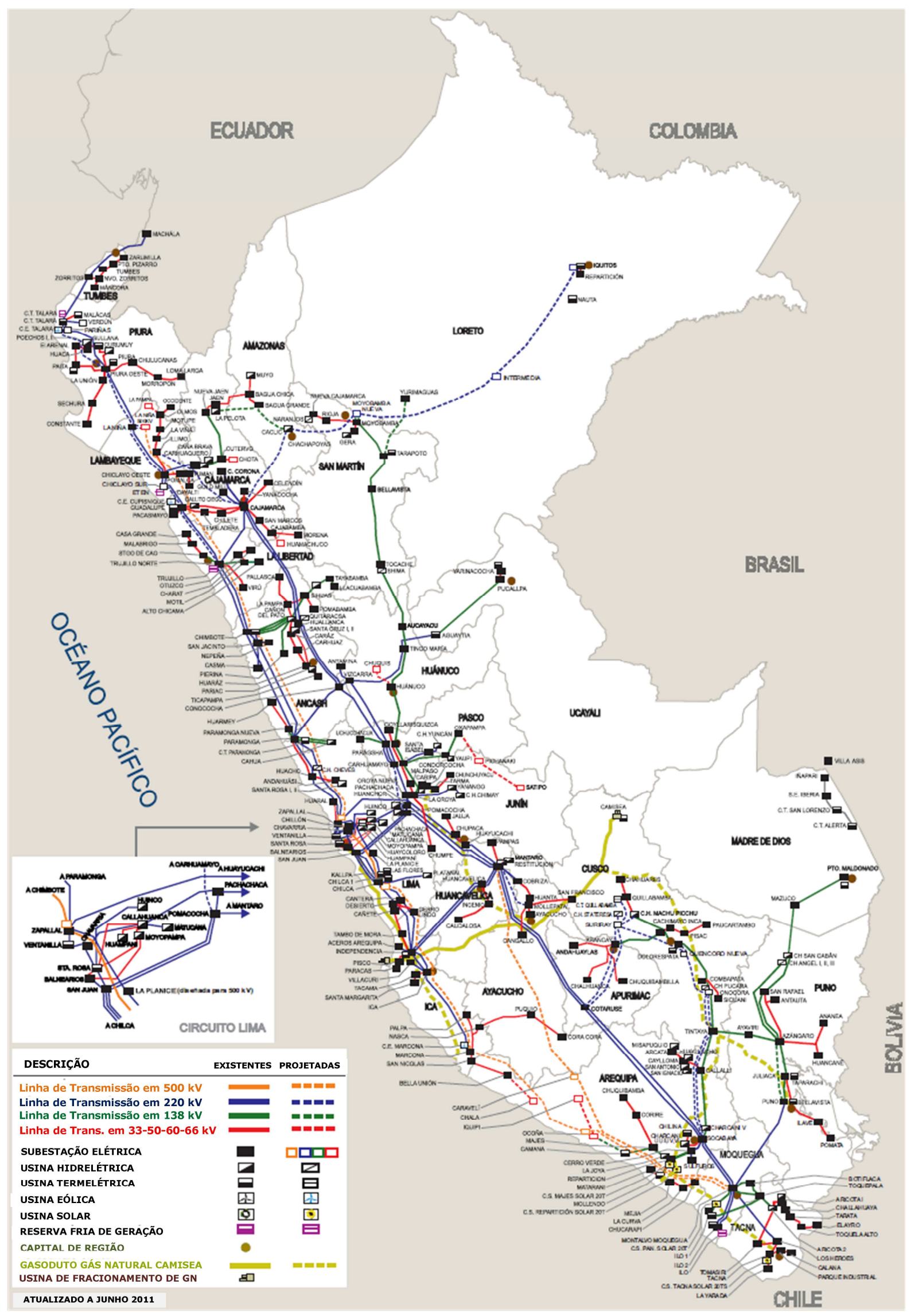

Figura 13 - Mapa do sistema elétrico interligado nacional peruano (SEIN), 2011.

Fonte: Ministério de Energia e Minas (Peru) 
A cobertura elétrica do país no SEIN está garantida, quase na maior parte do território peruano, cobrindo aproximadamente $85 \%$ do território e atendendo 90\% da demanda elétrica do país. Contudo, ainda há cidades com sistemas elétricos isolados, principalmente na Amazônia peruana devido ao difícil acesso. A demanda pequena destas cidades e a falta de atratividade em termos de mercado para a construção de linhas de longas distâncias e de áreas de difícil acesso dificultam sua interligação ao SEIN.

Nos últimos anos o governo peruano vem adotando uma política social conhecida como "Luz para todos", programa social que vem subsidiando os investimentos na ampliação da rede elétrica. Pretende-se alcançar a cobertura elétrica do país em $95 \%$ até 2020 .

No planejamento da expansão da transmissão elétrica do SEIN, apresentado no Primeiro Plano de Transmissão (PPT) que tenta assegurar a expansão eficiente da transmissão, consideram-se as interligações internacionais e a implantação de novas linhas de reforço de maior capacidade e de maiores níveis de tensão elétrica que as atuais.

Atualmente o Peru tem interligação elétrica com o Equador, mediante uma linha em 220 kV, de 160 MW de capacidade, o que permite os intercâmbios de exportação e importação de energia elétrica com o Equador, (COES, 2011).

Também está sendo considerada e estudada a interligação elétrica com a Colômbia, Bolívia e Brasil; com respeito à interligação com o Brasil o processo de integração tem avanços importantes que vem sendo encaminhados através de um tratado de integração elétrica bilateral de interesse dos governos dos dois países. É previsto que num cenário de médio prazo será possível a interligação elétrica de Peru e Brasil, que permitirá o fluxo de energia elétrica entre os dois países.

\subsubsection{Distribuição}

A distribuição elétrica é uma atividade caracterizada como monopólio natural, que se desenvolve dentro das zonas de concessão outorgadas às empresas 
distribuidoras, limitada por áreas geográficas das regiões e cidades. Comercializam a energia elétrica atendendo consumidores finais que são caracterizados em dois grupos em função do nível de sua demanda: consumidores livres e consumidores cativos ou regulados.

Com respeito à característica técnica das redes de distribuição, estas estão compostas por redes primárias e secundárias, que se encarregam do transporte e distribuição da energia para os consumidores cativos e clientes livres em média tensão $(1 \mathrm{kV}<\mathrm{MT}<30 \mathrm{kV}$ ) e baixa tensão menor a $1 \mathrm{kV}$ (geralmente em 220, 380 e 440 volts), a uma frequência nominal de 60 Hertz.

As instalações e o serviço da rede de distribuição devem cumprir com as normas técnicas estabelecidas pelo Código Nacional de Eletricidade e as Normas Técnicas de Qualidade de Serviços Elétricos (NTCSE).

\subsubsection{Comercialização}

A comercialização da energia elétrica no SEIN tem caráter competitivo, os consumidores livres com demanda superior a 0,2 MW participam num ambiente de livre mercado, e podem comprar energia no mercado atacadista de forma livre e direta das empresas geradoras, de empresas distribuidoras e/ou implantarem sua própria usina de geração como gerador independente, além disso, os consumidores com demanda entre 0,2 e 2,5 MW podem escolher entre comprar energia como consumidor livre ou comprar energia no mercado cativo.

A figura 14 mostra a evolução das vendas a clientes finais no mercado elétrico peruano nos últimos 5 anos, registrando um crescimento médio anual de $8 \%$ no mercado regulado, e $6 \%$ no mercado livre. Os clientes finais aumentaram à razão de 225 mil por ano, isto é uma média anual de 5\%, (PERU MINISTERIO DE ENERGIA Y MINAS, 2010a). 


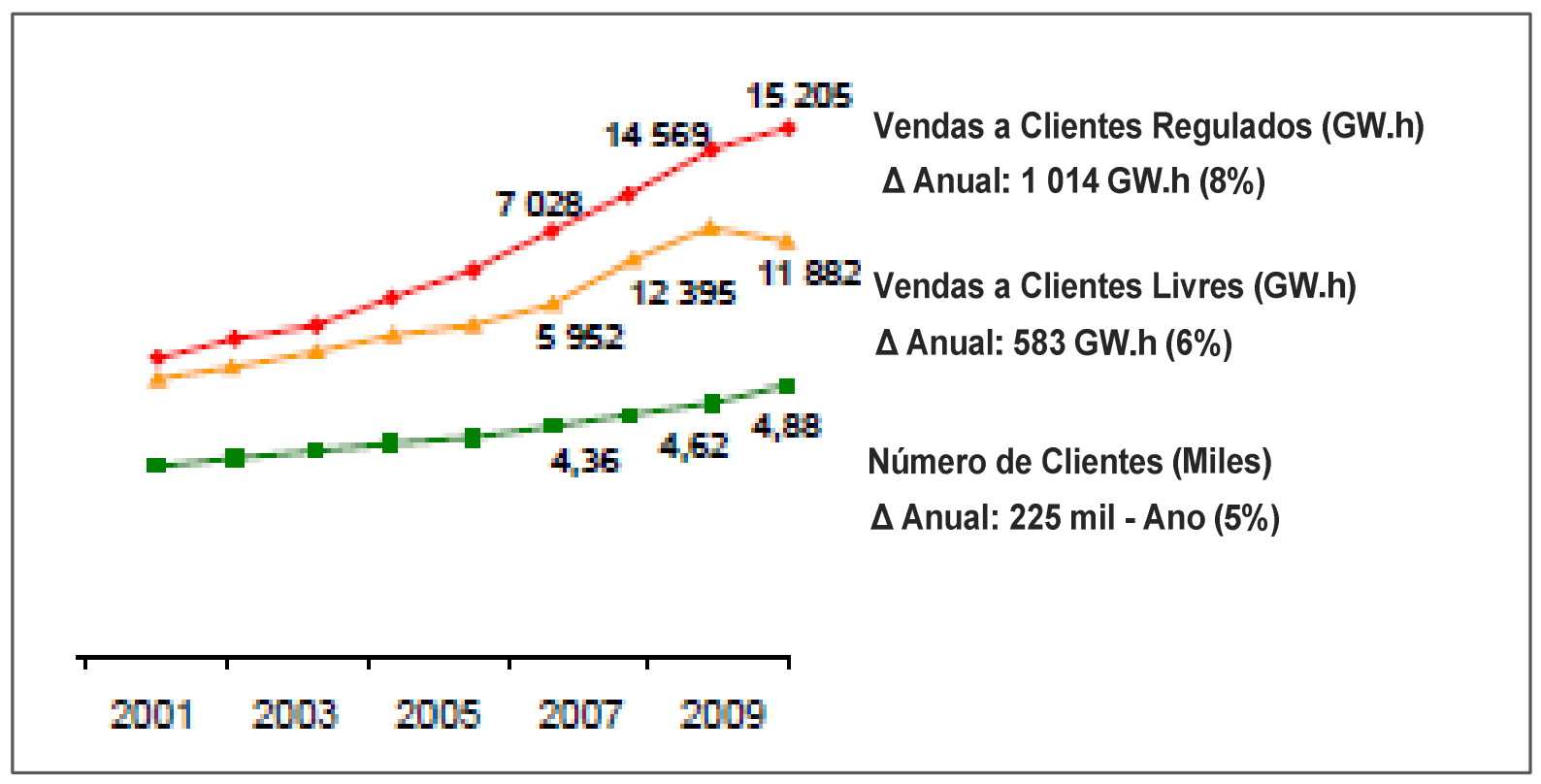

Figura 14 - Evolução das vendas de eletricidade no SEIN.

Fonte: (PERÚ. MINISTERIO DE ENERGIA Y MINAS, 2010a).

Segundo o Ministério de Energia e Minas do Peru (2011b), a venda de energia no mercado elétrico peruano é realizada no SEIN e nos sistemas isolados (SSAA), com uma participação de $98 \%$ e $2 \%$, respectivamente. Desse modo, quase a totalidade das vendas de energia no mercado elétrico peruano é efetuada no SEIN.

Atualmente no mercado elétrico peruano o número de clientes livres que registraram contrato com as empresas geradoras e as empresas distribuidoras são 119 e 140, respectivamente, totalizando 259 consumidores livres no setor até 2010. No caso do mercado cativo, a comercialização de energia está dividida em vários segmentos de consumo com demandas inferiores a 0,2 MW de capacidade, atingindo em 2010, 5.146.459 usuários, atendidos exclusivamente pelas empresas distribuidoras, sendo esta cifra superior em 5,5\% em comparação ao número de consumidores regulados de 2009, (PERU MINISTERIO DE ENERGIA Y MINAS, 2011b).

Segundo os dados apresentados na tabela 4, atualmente os maiores consumidores do mercado elétrico peruano são os clientes do setor industrial seguido pelo setor comercial, residencial e iluminação pública, características do setor registrados nas estatísticas de consumo dos últimos anos, totalizando 29540 GW.h de vendas de energia no SEIN em 2010, registrando um crescimento de 9,1\% em relação ao ano anterior 2009. 
Tabela 4 - Venda de energia em (GWh) por setores econômicos do SEIN

\begin{tabular}{lrrc}
\hline Setor Econômico & $\mathbf{2 0 0 9}$ & $\mathbf{2 0 1 0}$ & $\Delta \mathbf{1 0 / 0 9}$ \\
\hline Industrial & 14943 & 16526 & $10,6 \%$ \\
Comercial & 6645 & 7115 & $7,1 \%$ \\
Residencial & 4815 & 5191 & $7,8 \%$ \\
lluminação Pública & 684 & 708 & $3,4 \%$ \\
\hline Total & $\mathbf{2 7 0 8 7}$ & $\mathbf{2 9} \mathbf{5 4 0}$ & $\mathbf{9 , 1 \%}$ \\
\hline
\end{tabular}

Fonte: (PERU MINISTERIO DE ENERGIA Y MINAS, 2011b).

\subsubsection{Demanda}

A demanda elétrica no setor elétrico peruano é medida usualmente pela máxima demanda de potência ${ }^{12}$ e energia ${ }^{13}$, os quais se apresentaram nos últimos 5 anos com altas taxas de crescimento sustentado, em torno de 8,0\% de média anual. $O$ forte crescimento do mercado elétrico influenciado principalmente pelo crescimento econômico do país, que no período dos últimos 10 anos cresceu a uma taxa media anual de $\mathrm{PIB}^{14}$ de 6,0\%, atingindo em 2010 um crescimento extraordinário de $8,78 \%$. De forma referencial no Peru o crescimento do consumo elétrico encontra-se dois (2) pontos percentuais acima do crescimento do PIB.

Segundo o COES (2011), a demanda de energia no SEIN até dezembro de 2010 atingiu 32 426,83 GW.h, crescimento de 8,79\% em relação ao ano anterior. Por outro lado a máxima demanda de potência registrou o valor de 4 578,94 MW, 5,94\% superior a máxima de 2009 .

Na figura 15, apresenta-se a evolução da máxima demanda de potência mensal registrada no período (2001 - 2010). Cabe indicar que atualmente o crescimento da demanda de energia permanece numa tendência crescente.

\footnotetext{
12 Representa o máximo requisito de potência dos consumidores num instante de tempo, (MW).

13 É a soma de todos os requisitos de energia dos consumidores num período determinado, em (GW.h)

14 Produto Interno Bruto.
} 


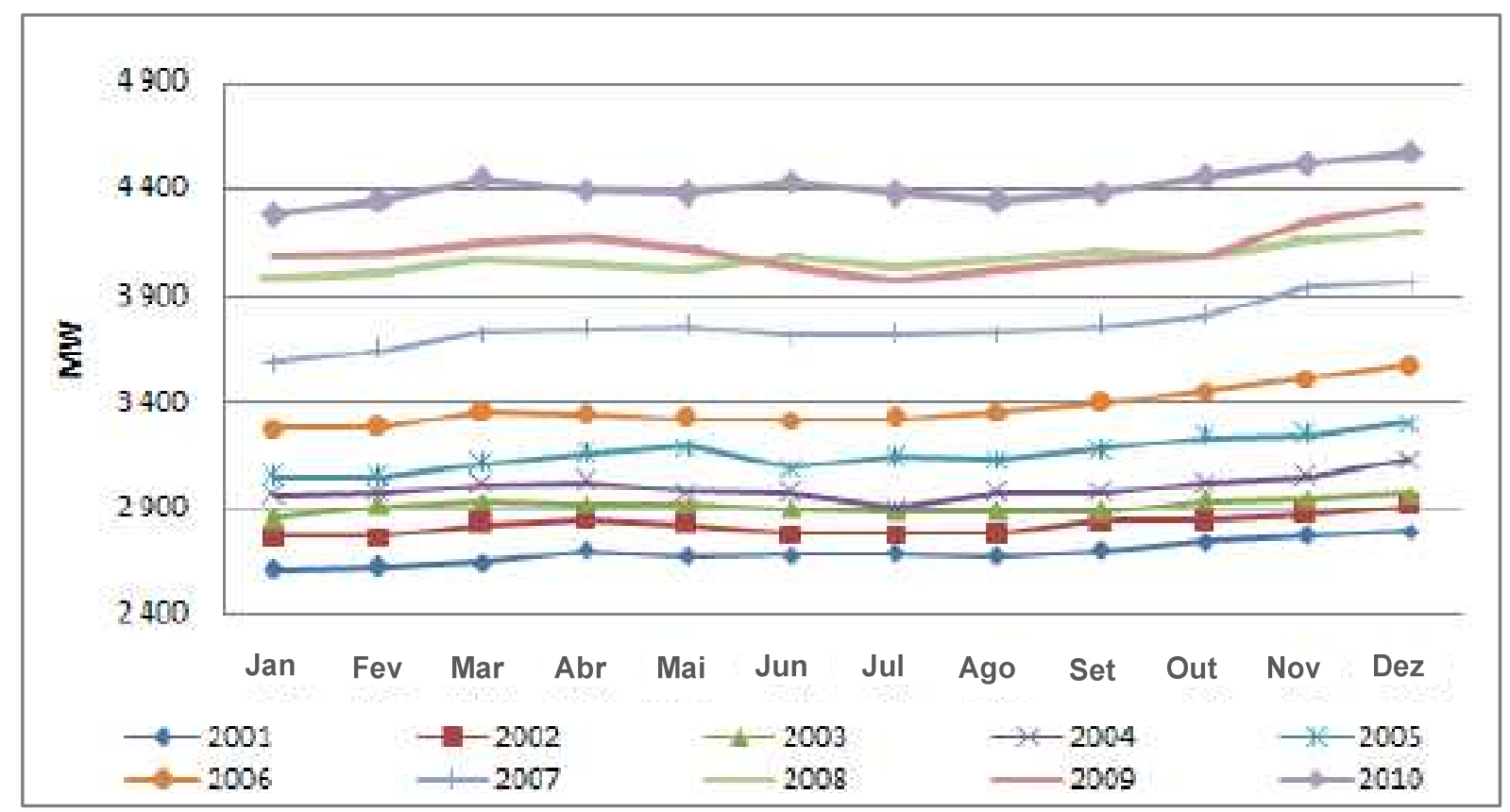

Figura 15 - Evolução da máxima demanda do SEIN.

Fonte: (Osinergmin, 2011a).

Segundo o MINISTÉRIO de ENERGIA e MINAS do Peru (2010a), as perspectivas e projeções do crescimento da demanda elétrica no SEIN para o período (2009 - 2019), considerando três cenários de crescimento: o otimista, médio e conservador, estima-se num acréscimo médio anual de 9,0\%, 8,1\% e 7,0\%, respectivamente, como é mostrado na figura 16.

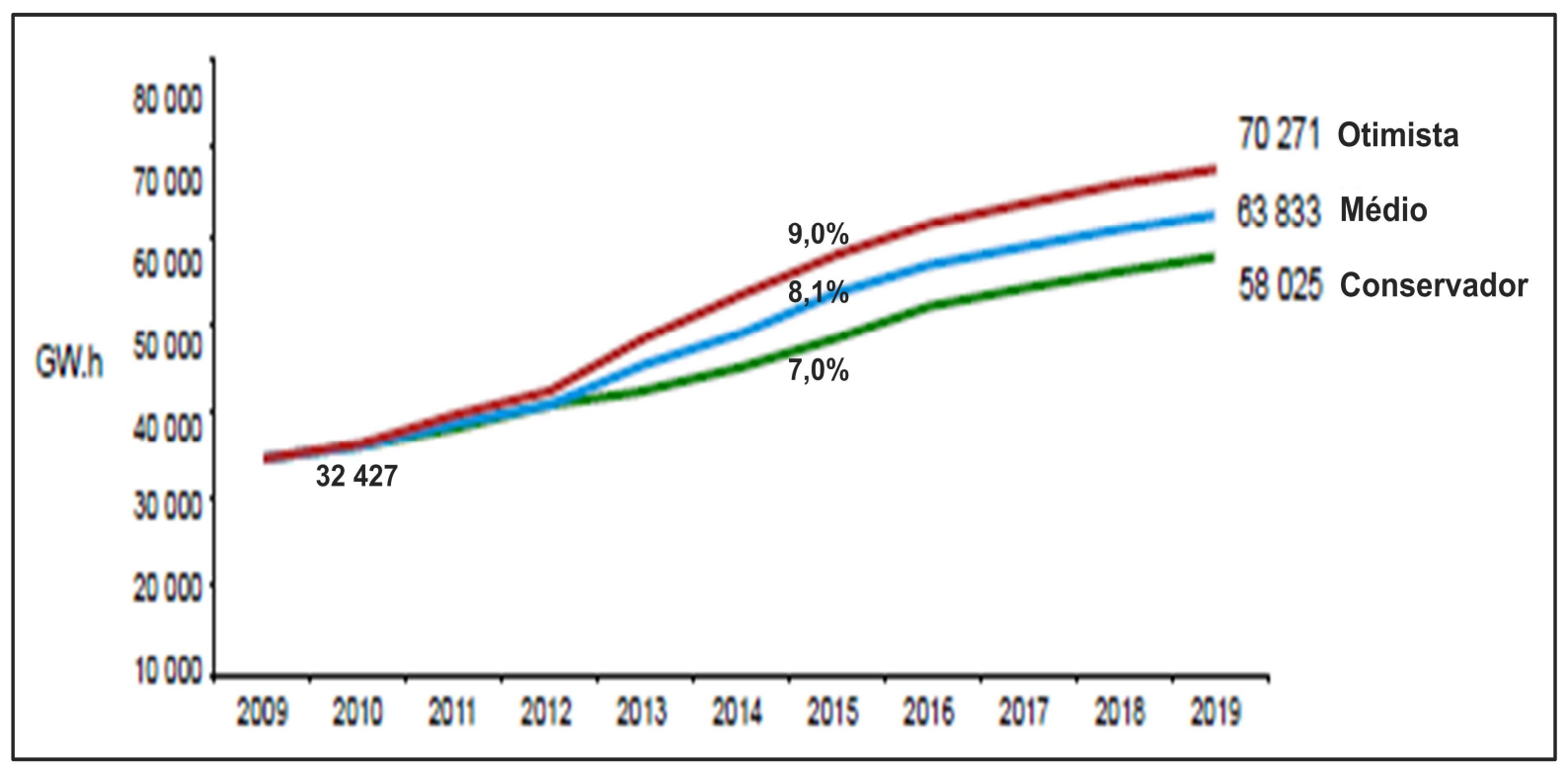

Figura 16 - Projeção da demanda de energia do SEIN (2009 - 2019).

Fonte: (PERU MINISTERIO DE ENERGIA Y MINAS, 2010a). 
O cenário otimista é aquele onde todos os grandes projetos de mineração do país são executados e o consumo em massa de eletricidade de pequenas demandas é crescente num contexto de boa situação econômica interna, no entanto, num cenário conservador a taxa de crescimento é menor.

Por outro lado para o crescimento da demanda em termos de potência, estima-se o crescimento médio anual da demanda no cenário médio de $7,8 \%$, que representa um incremento médio anual de $497 \mathrm{MW}$ de capacidade e uma potência total adicional de $4787 \mathrm{MW}$ desde fins de 2009 até 2019. Já para o cenário otimista e conservador, o crescimento médio anual previsto é de $8,9 \%$ e $6,8 \%$, respectivamente, e o incremento médio anual de potência é de $592 \mathrm{MW}$ e $412 \mathrm{MW}$, respectivamente, como mostra a figura 17, (PERU MINISTERIO DE ENERGIA Y MINAS, 2010a).

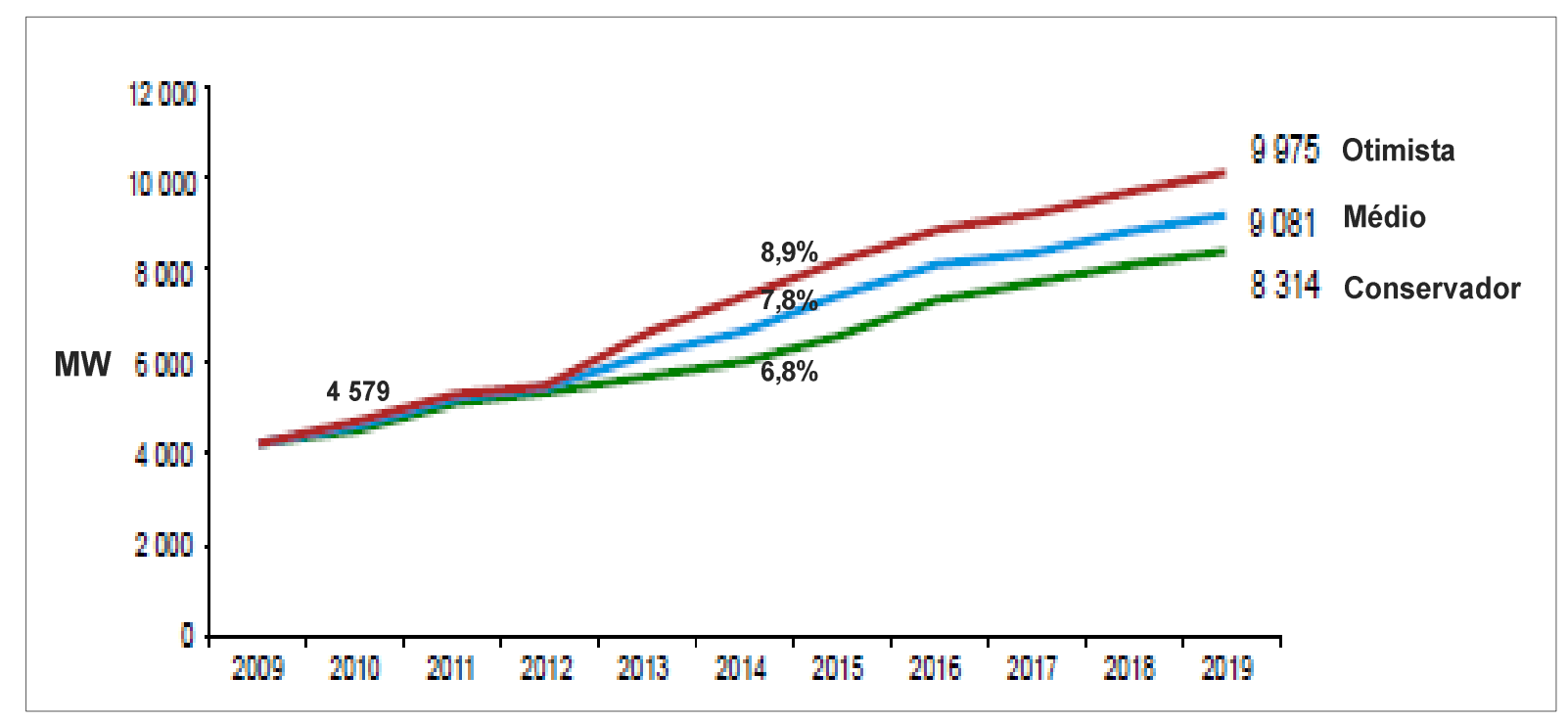

Figura 17 - Projeção da demanda por potência do SEIN (2009 - 2019).

Fonte: (PERU MINISTERIO DE ENERGIA Y MINAS, 2010a).

\subsection{MERCADO DO SETOR ELÉTRICO PERUANO}

Atualmente, no mercado elétrico peruano realizam-se transações entre diferentes agentes, segundo a potência e energia requerida para cada transação, os que participam do mercado regulado, mercado livre, mercado de curto prazo "mercado spot" e exportação. 


\subsubsection{Mercado Regulado}

São os consumidores ou clientes do mercado elétrico peruano atendidos pelas empresas de distribuição conhecidos também como clientes cativos ou de serviço público de eletricidade, são todos os consumidores dos segmentos residencial, comercial e da pequena indústria com cargas ou demandas inferiores a 0,2 MW de potência. Os preços máximos e tarifas de energia neste mercado são revisadas e fixadas pelo órgão regulador (OSINERGMIN) a cada ano no mês de maio, (NADIRA, et al., 2007).

\subsubsection{Mercado Livre}

No mercado livre participam os grandes consumidores, com demandas superiores a $0,2 \mathrm{MW}$, principalmente derivada de atividades da indústria pesada como: a mineração, industria do cimento, siderúrgicas, etc. No entanto atualmente os clientes ou consumidores com demanda de potência entre 0,2 e 2,5 MW podem optar por contratar entre o mercado regulado e livre. No atual marco regulatório, os clientes livres obtêm sua energia através de contratos bilaterais de abastecimento pleno (full requirement) assinados com os geradores ou através de contratos de comercialização com as empresas de distribuição, tendo liberdade de escolha dos preços. Os contratos são celebrados de forma livre, desde que sejam determinados o preço, volume e condições de mercado assumidas pelos agentes sem participação externa, (SOWITEC, 2010).

\subsubsection{Mercado Spot}

É o mercado de curto prazo conhecido também como mercado de intergeradores do setor elétrico peruano. Formado pelos intercâmbios e transferências de energia entre empresas geradoras de elétricidade operadas pelo 
operador do sistema, as empresas distribuidoras e grandes clientes livres.

As transferências servem para liquidar as diferenças entre o contratado e o efetivamente produzido pelos geradores. Esta comercialização e transferência de energia entre agentes no mercado elétrico peruano é feita ao mínimo custo da energia gerada, buscando gerar a eficiência econômica e segurança na operação do SEIN, ou seja as transações realizam-se ao custo marginal de curto prazo correspondente à operação real do sistema no período de transação, cada 15 minutos, (CAMPODÓNICO, 1999).

Com a Lei $\mathrm{N}^{\circ} 28832$, foi promovido o acesso de distr ibuidores e grandes clientes livres ao mercado de curto prazo (mercado spot) sendo estabelecido que: As distribuidoras podem acessar o mercado de curto prazo para atender os requisitos de seus clientes livres. Também foi estabelecida a participação de Grandes Usuários Livres, constituída por usuários (clientes) livres individuais ou agrupamentos de usuários livres com mais de $10 \mathrm{MW}$ de potência contratada, (HERRERA, et al., 2010).

As transações de energia entre os agentes que participam do mercado elétrico peruano é realizado a preço livre entre geradores, distribuidoras e clientes livres; no entanto, entre empresas distribuidoras e consumidores cativos é a preço regulado em subestação principal designado como preço em barramento ${ }^{15}$ incluindo os custos de transmissão mais o VAD (Valor Agregado de Distribuição), como é apresentado na figura 18.

15 São os preços que os geradores cobram aos distribuidores para o abastecimento do mercado regulado, incluídos os custos de transmissão. 


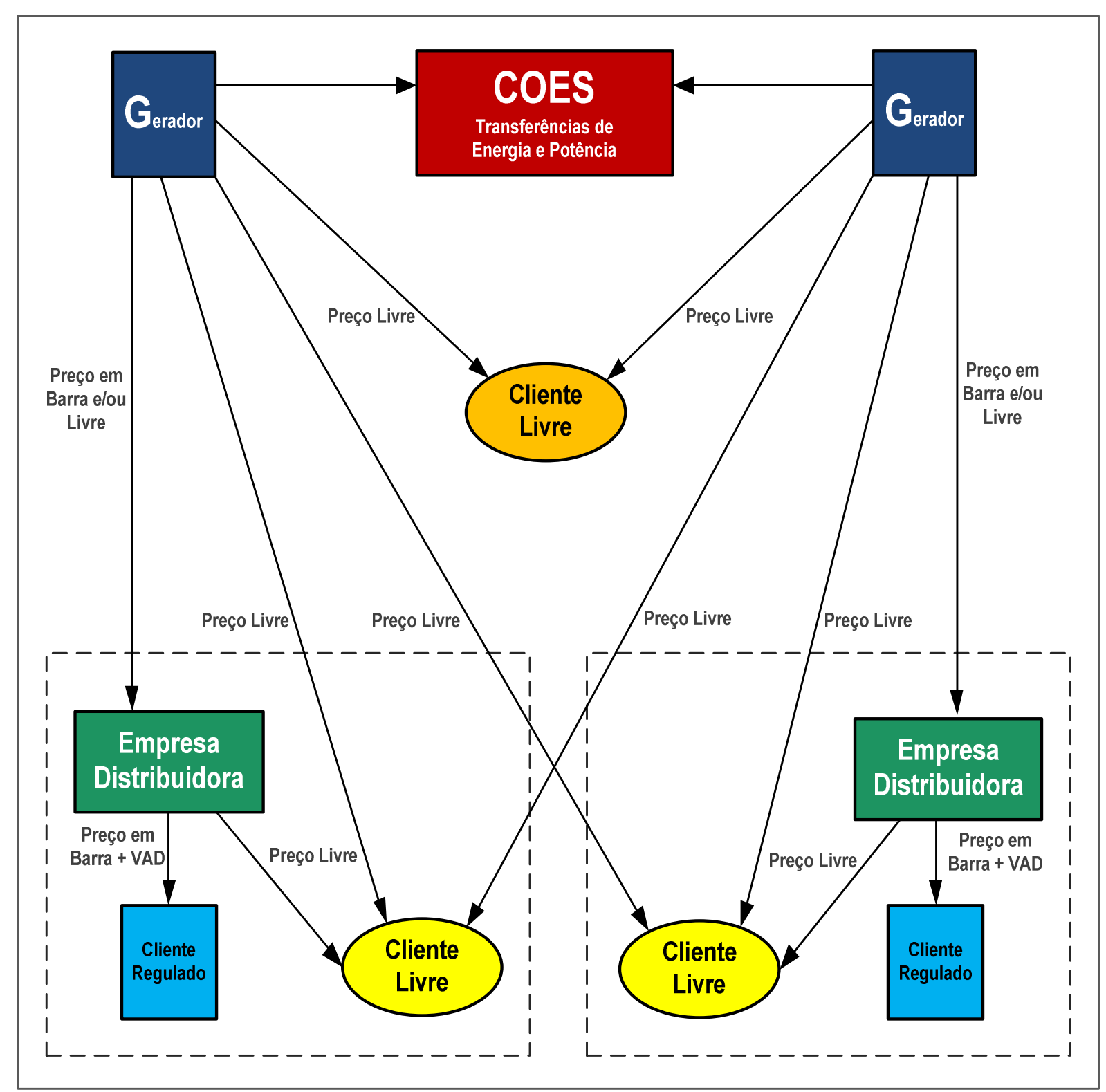

Figura 18 - Transações de energia no setor elétrico peruano.

Fonte: (OSINERG, 2005).

\subsubsection{Exportação}

A exportação de energia elétrica do SEIN a outros países está limitada aos excedentes de potência e energia que não sejam requeridos para atender a demanda do SEIN, isto porque, as quantidades de exportação de energia do setor elétrico peruano ainda são pequenas comparadas às experiências em outros países como no caso de Itaipu, entre Paraguay e Brasil. 
O único destino das exportações de eletricidade no momento é o Equador, mediante Decreto de Urgência № 109-2009, a empresa geradora com maior capacidade de geração do estado peruano (ELETROPERÚ) foi autorizada a subscrever contratos de exportação, sendo informado ao COES a assinatura do contrato bilateral entre ELECTROPERÚ ${ }^{16}$ e CNEL $^{17}$ para a viabilização da exportação.

Atualmente, de acordo com o balanço simples e geral da oferta demanda de energia elétrica, o Peru ainda tem limitações em sua capacidade instalada, energia produzida e reserva que lhe permitiria possuir blocos maiores para exportação de energia elétrica a seus pares vizinhos, pela falta de maior investimento em sua capacidade instalada e linhas de transmissão que possam permitir as interligações com o resto dos países vizinhos.

No entanto, o Peru vem implementando diferentes acordos bilaterais de convênio em cooperação técnica e grupos de trabalho para estudar e avaliar as futuras interligações internacionais com países como a Colômbia, Chile, Bolívia e Brasil. Um dos últimos acordos bilaterais mais importantes assinados pelo Peru foi com o Brasil, em junho de 2010, quando houve um avanço significativo na integração energética entre os dois países, mediante um acordo bilateral assinado pelos presidentes Alan Garcia Pérez do Peru, e Luiz Inácio Lula da Silva do Brasil, na cidade de Manaus; com o convênio concretizaram-se o acordo de integração energética entre Peru e Brasil.

No convênio considera-se a exportação de energia excedente gerada em território peruano, de até 7200 MW de potência máxima, mediante uma interligação elétrica entre os dois países. Energia que será gerada em futuras usinas hidrelétricas construídas na região amazônica do Peru.

Isto indica que nos próximos anos a capacidade instalada para exportação do Peru, terá um crescimento considerável, a partir da construção de novas usinas e sua interligação com os países vizinhos, que apresentarão novas perspectivas e viabilizará a interligação elétrica regional sul-americana.

\footnotetext{
16 A maior empresa estatal geradora do Peru.

17 Importante empresa distribuidora do Equador.
} 


\subsection{FIXAÇÃO DE TARIFAS NO SETOR ELÉTRICO PERUANO}

A regulação do setor elétrico peruano mediante a LCE estabelece um regime de liberdade de preços para os fornecimentos que possam efetuar-se em condições de concorrência, e um sistema de preços regulados naqueles fornecimentos que por sua natureza o requeiram, reconhecendo custos de eficiência segundo os critérios contidos na regulação do setor. Os preços regulados devem refletir os custos marginais de fornecimento e estruturam-se de modo que promovam a eficiência do setor, sendo reguladas pelo Osinergmin.

Então, as tarifas de geração para o abastecimento do serviço público são reguladas sobre a base de uma estimativa dos custos marginais esperados no sistema. No entanto, na distribuição e transmissão são reguladas as remunerações das atividades sobre a base de custos médios eficientes.

\subsubsection{Formação de Preço de Energia}

A formação do preço de energia elétrica no SEIN é caracterizada pela operação do sistema hidrotérmico a mínimo custo, onde o despacho é centralizado objetivando o uso otimizado dos recursos energéticos. O preço é indicado por um conjunto de modelos computacionais, que utiliza a metodologia de determinação do custo marginal de operação (CMO).

A tarifa final da eletricidade representa o custo de suprimento composto pelas etapas da cadeia de valor da eletricidade em custos de geração, transmissão e distribuição, baseados no custo marginal de curto prazo de fornecimento de energia e potência, calculadas para um programa otimizado de expansão do sistema elétrico. Este valor é diferenciado para cada tipo de cliente (livre e regulado) de acordo a quantidade de energia e potência contratada por cada consumidor. Os clientes livres possuem a capacidade de negociar direitamente com o agente gerador o preço da energia e potência contratada; por outro lado os clientes regulados estão sujeitos à revisão tarifária do órgão regulador, no caso peruano pelo Osinergmin. 


\subsubsection{Tarifa de Geração}

A fixação de tarifas de geração no sistema elétrico peruano baseia-se na minimização dos custos de suprimento de energia na operação e de investimento em base sob os menores custos marginais de energia e potência. O procedimento é administrativo, pois o regulador utiliza os custos auditados das empresas para fixar as tarifas máximas, diferente de outras experiências em outros países onde estas surgem da interação da oferta e demanda numa bolsa de energia.

No SEIN as tarifas são fixadas no mês de maio de cada ano pelo Osinergmin, que estabelece os preços regulados da energia depois de um processo de revisão das propostas realizadas pelo COES. O regulador estabelece dois preços regulados: o preço básico de energia e o de potência.

O Preço Básico de Energia corresponde à média ponderada dos custos variáveis auditados mínimos, que atende o suprimento da demanda projetada para os próximos 24 meses e 12 meses anteriores. A demanda projeta-se com base em um modelo econométrico que utiliza como variáveis independentes o PIB, a população e as tarifas médias elétricas, além de incorporar por fora algumas grandes cargas. Ademais, é necessário considerar a oferta esperada de geração e transmissão denominada "plano de obras", bem como os diferentes cenários hidrológicos possíveis, (OSINERG, 2005).

O procedimento para o cálculo do preço básico da energia é o seguinte: mediante o uso do modelo Perseo ${ }^{18}$ simula-se a operação do sistema hidrotérmico, incluindo todas as unidades geradoras ordenadas em função de seu menor custo variável auditado de geração, com múltiplos reservatórios em etapas mensais para 24 meses para frente e 12 meses passados anteriores. O objetivo é que se minimize a soma do custo atualizado da operação do sistema em seu conjunto e se inclua o custo de racionamento para o período de análise, considerando a taxa de atualização de $12 \%$ e três variáveis adicionais: séries hidrológicas históricas, a situação dos reservatórios, e os custos do combustível (líquidos carvão e gás natural). A partir da entrada desses dados são determinados os custos marginais

18 Modelo de simulação e otimização utilizado atualmente pelo órgão regulador na revisão de tarifas e planejamento da operação pelo operador (COES), e pelas empresas geradoras. 
esperados $^{19}$ e em função a estes custos marginais determina-se o preço básico da energia, (MACROINVEST, 2008).

O Preço Básico de Potência determina se a partir de uma unidade com turbina a gás como a alternativa mais econômica para abastecer o incremento da demanda durante as horas de máxima demanda anual (horário de pico). Corresponde à anualidade do investimento na unidade que atende o horário de pico da curva de carga do SEIN (incluídos os custos de interligação) além dos seus custos fixos de operação e manutenção anual. Consideram-se, também, o fator de indisponibilidade da unidade e a margem de reserva firme do sistema, (MACROINVEST, 2008).

Dessa forma, o preço da potência determina-se em geral como o custo anual unitário (por kW-ano) de uma unidade com turbina a gás nova de $120 \mathrm{MW}$ de potência média, usando uma taxa de desconto de $12 \%$, período de vida útil de 30 anos, expresso em US\$ por MW-mês, (OSINERG, 2005).

A partir da agregação destes preços básicos e os pedágios de transmissão (que também são estabelecidos pelo Osinergmin) ${ }^{20}$ constroem-se os preços em cada ponto importante ou subestação do sistema principal de transmissão, designado no sistema elétrico peruano como "Preço de barramento" e é este o valor máximo que as geradoras podem cobrar às distribuidoras para as compras de energia destinadas ao mercado regulado.

Estes critérios de remuneração baseiam-se em resultados do uso de critérios marginalistas no sistema elétrico peruano. Sob certas condições pode-se mostrar que se as empresas investem de forma eficiente em cada tipo de tecnologia de geração, os rendimentos obtidos cobrirão seus custos totais incluindo o custo de oportunidade do capital.

Em suma, o preço de potência é cobrado sobre o consumo de ponta, enquanto os preços de energia vêm a ser uma média dos custos marginais do sistema elétrico. Ao determinar os preços de geração seguindo a metodologia descrita, são gerados os sinais adequados aos consumidores sobre os custos que estão originando ao sistema elétrico e, desta forma, maximizando o bem-estar dos consumidores no mercado.

${ }^{19}$ Calculam-se para cada um dos blocos horários: ponta, média e base.

${ }^{20}$ Sobre a base de uma remuneração anual aos proprietários das redes de transmissão de acordo com o estabelecido no marco regulatório ou os contratos BOOT de concessão de redes de transmissão. 
No caso da energia, a LCE faz uma distinção clara entre os preços fixados pelo regulador (Osinergmin) e os preços baseados em custos marginais de curto prazo para saldar as transferências entre geradores (denominado mercado de curto prazo do COES). Os preços do regulador (preço básico da energia) ${ }^{21}$ constituem valores estáveis, equivalentes aos custos marginais de curto prazo, que aplicados à energia vendida permitem obter as mesmas receitas que seriam obtidas por aplicação dos custos marginais de curto prazo esperados. A equivalência efetuase para um período de três anos, 12 meses passados e 24 meses futuros, determinam-se como a média dos custos marginais dos próximos 2 anos, projetando a demanda e considerando o parque de geração comprometido ou factível de entrar em operação durante o período.

O preço básico da energia aceita-se como tarifa se é verificado que o preço em barramento que fixa Osinergmin, não poderá diferir em mais de dez por cento $(10 \%)^{22}$ da média ponderada dos preços dos leilões, vigentes ao 31 de março de cada ano, segundo a regulação estabelecida no setor, (MEM-OSINERG, 2005).

No caso do preço da potência a aplicação da metodologia denominada "bolsa de potência" considera a remuneração mediante a distribuição de $30 \%$ da bolsa para as unidades que despacham e o restante $70 \%$ às unidades que estão disponíveis. Antes desta metodologia toda a bolsa de potência repartia-se entre os $100 \%$ das unidades presentes no sistema, sem ter em conta sua real disponibilidade e seu custo de operação, (MEM-OSINERG, 2005).

No setor elétrico peruano é comum distinguir entre os preços de energia e preços de potência; no entanto, com a finalidade de obter um só indicador representativo do custo de geração constrói-se o "Preço monômio". O preço

${ }^{21}$ O Preço Básico da Energia seria determinado como:

$$
P B E=\frac{\sum_{i=12}^{24} \frac{C M g_{i} E_{i}}{(1+a)^{t}}}{\sum_{i=12}^{24} \frac{E_{i}}{(1+a)^{i}}}
$$

22 Na comparação do preço básico da energia existem algumas inconsistências observadas pelo regulador. Por um lado, comparam-se preços de contratos de diferente natureza (livre contra regulado) onde muitas vezes o preço oferecido ao cliente livre tem inerente uma diferente estrutura de consumo ou maiores exigências de qualidade ou fiabilidade que as exigidas ao mercado regulado. Por outro lado, o preço livre para fins de comparação determina-se olhando os últimos 6 meses, enquanto o preço regulado olha o futuro. Devido à falta de transparência nos contratos livres, em 1999 fez-se uma modificação à LCE para exigir que os contratos fossem de domínio público e postos a disposição do regulador, além disso, que os preços nas faturas deveriam ser desagregados em seus componentes básicos (geração, transmissão e distribuição). 
monômio é basicamente a soma do preço médio da energia e potência, que incorpora os encargos por energia (de ponta e fora de ponta) expressos em unidades de energia (US\$ por MW.h), considerando que esta não se consome em horário de pico durante todo o mês. Para determinar o preço monômio utiliza-se a seguinte fórmula, (OSINERG, 2005):

\section{Preço Monômio $=$ Preço de Energia $+\frac{\text { Preço de Potência }}{720^{\star} \text { Fator de Carga }}$}

Onde,

- Preço de energia: é o preço médio ponderado da energia durante os períodos em horas ponta (Fator de ponderação de Ponta, FPP) e fora de ponta. No Peru, considera-se período de ponta o compreendido entre as 18:00 e 23:00 horas.

- Preço de Potência: é o preço marginal de potência (PPM) expresso em US\$ por kW-mês.

- Fator de Carga: este se refere ao fator de carga do sistema (FC), o qual se obtém pela divisão entre a energia consumida durante 0 ano e a máxima demanda, multiplicada ao número de horas do ano.

Quanto às remunerações, os geradores recebem uma remuneração por potência e uma remuneração por suas contribuições de energia como foi mencionado anteriormente. A administração destes pagamentos faz-se dentro do COES com as regras estabelecidas na Lei. Em conjunto, o gerador pode ter as seguintes receitas ou encargos, (MEM-OSINERG, 2005):

- Receitas segundo seu contrato pactuado com clientes. Se o cliente é uma distribuidora e o fornecimento é para o mercado regulado, aplicam-se os preços nos barramentos.

- Transferências de energia (diferença entre as injeções menos as retiradas). As injeções (produção da usina) são valorizadas sob o custo marginal de curto prazo do barramento onde se injeta, e de igual forma as receitas (energia vendida ao cliente) são valorizadas sob o custo marginal do barramento onde se retira a energia para 
entrega ao cliente. As transferências totais de um gerador podem ser positivas ou negativas dependendo dos custos marginais nos barramentos, e da diferença entre a energia injetada e retirada.

- As receitas ou transferências de potência. Os geradores que vendem potência a um cliente, transferem este dinheiro ${ }^{23}$ à bolsa de potência para ser repartido entre todos os geradores que têm direito a cobrar ${ }^{24}$. A bolsa de potência define dois mecanismos de pagamento: por disponibilidade e por despacho. O mecanismo de pagamento por disponibilidade significa que paga-se às usinas presentes para que estejam abaixo do limite de reserva definido pelo MEM de acordo com a potência firme reconhecida. O mecanismo de pagamento por despacho redistribui o dinheiro arrecadado ao longo do ano de acordo com o preço ${ }^{25}$ por MW.h, de tal forma que o pagamento ao gerador faz-se multiplicando este preço pela energia produzida em cada hora.

- Os pagamentos pela operação da usina. A operação da usina é ordenada pelo COES de acordo com os custos variáveis de operação. Permite-se que as usinas a gás natural possam declarar por uma só vez ao ano seu custo variável de operação.

No caso do abastecimento do mercado regulado, a LCE exige que o distribuidor tenha contratos que cubram seus requerimentos de potência e energia com uma antecedência de 2 anos. A LCE não outorga flexibilidade às distribuidoras para poder comprar seu deficit ou vender seu superavit de energia ou capacidade num mercado de curto prazo ${ }^{26}$, (MEM-OSINERG, 2005).

23 O cliente paga o produto de sua máxima demanda mensal pelo preço de potência. O preço de potência inclui o custo da turbina de gás mais dois fatores que reconhecem a indisponibilidade da máquina de ponta e a margem de reserva do sistema.

24 O Ministério de Energia e Minas (MEM) define uma margem de reserva (diferente da margem contida no preço da potência) que determina até onde se localizarão as máquinas, ordenadas do menor ao maior custo variável, com direito a cobrar a potência.

25 Este preço determina-se em forma proporcional à probabilidade de falha do sistema.

26 Este último deu lugar durante o ano de 2004 a uma crise que colocou em risco a estabilidade do setor dado que existiram distribuidores que ficaram sem contratos (porque não existiam geradores dispostos a subscrever contratos com eles a preços em barra) e estiveram efetuando retiros de energia do sistema sem que estivessem legalmente autorizados para isso. A solução óbvia desde o ponto de vista econômico, cortar-Ihes o serviço ainda tendo suficiente capacidade de geração, era social e politicamente inviável. 
Através da Lei $28832^{27}$, a partir de 2006 foram introduzidas modificações nas condições de contrato de empresas de geração e distribuição através de leilões para suprimento de energia, onde o preço final vencedor do leilão tem a condição de preço firme e não pode ser modificado pelo órgão regulador. Espera-se que este mecanismo possa transferir progressivamente à demanda sinais de mercado e permita uma remuneração estável e eficiente aos agentes de geração, (MACROINVEST, 2008).

A evolução do custo marginal, média mensal do SEIN em função da produção total de energia desde janeiro de 2001 até dezembro de 2010, mostrando a variabilidade do custo marginal do mercado no decorrer do tempo, indicam que o custo marginal médio mensal tem um comportamento estacional anual, apresentando maiores valores durante o período junho - novembro (período de estiagem), como é mostrado na figura 19.

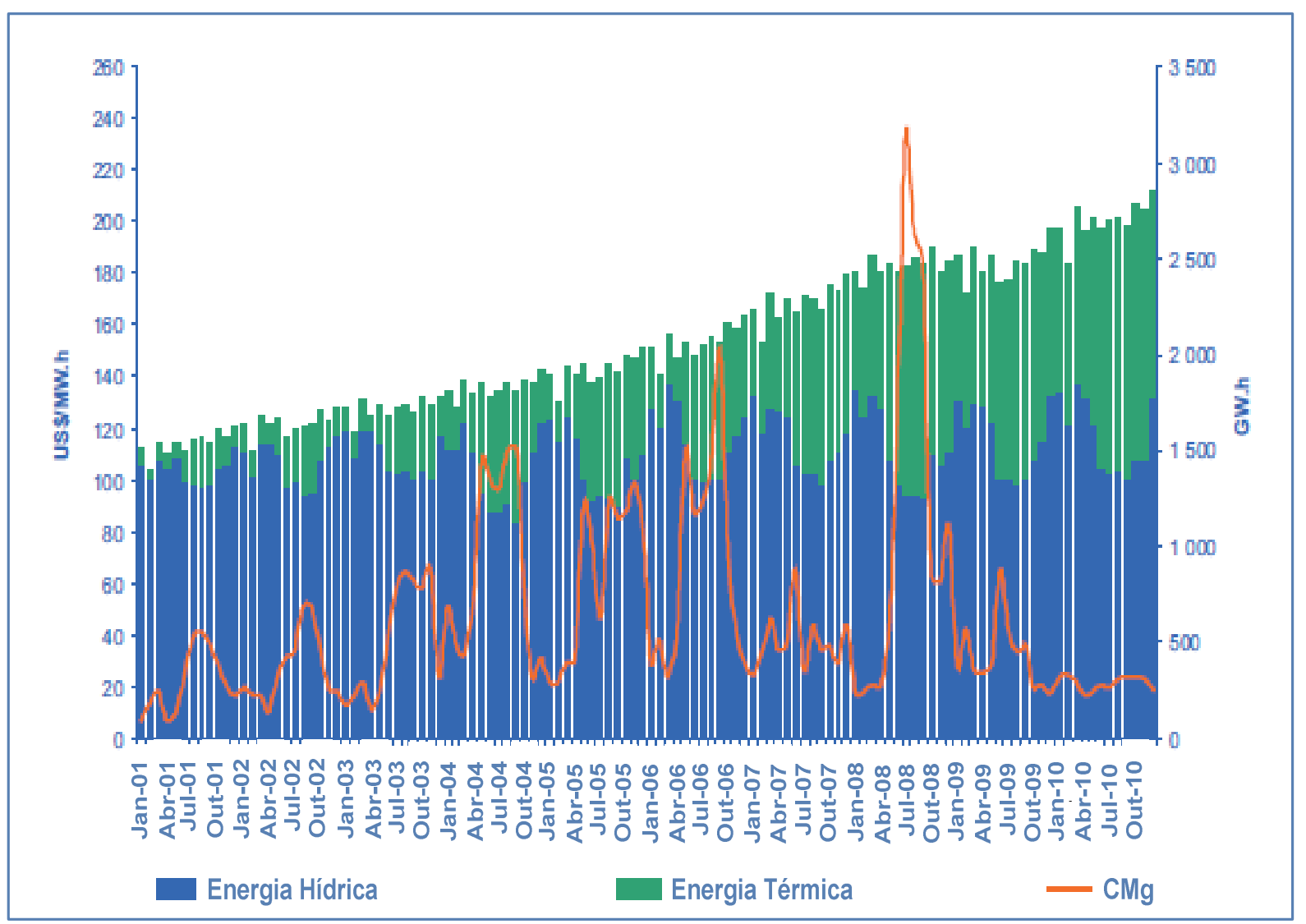

Figura 19 - Produção de energia e custos marginais médias mensais do SEIN.

Fonte: (COES, 2011)

27 Lei para Assegurar o Desenvolvimento Eficiente da Geração Elétrica (LADEGE). 
Segundo o relatório anual do COES (2011), os custos marginais mensais médios do SEIN durante o 2010 flutuaram entre um mínimo de 16,60 US\$/MW.h e um máximo de 24,55 US\$/MW.h registrado no mês de abril e fevereiro, respectivamente, em comparação ao valor máximo de junho 2009 que foi 65,70 US\$/MW.h, os valores do custo marginal de curto prazo (CMgCP) em 2010 mantiveram-se bastante estáveis pela boa hidrologia registrada no sistema.

As variações nos custos marginais estão diretamente relacionadas com o comportamento hidrológico das bacias aproveitadas pelo sistema de geração, a estratégia operativa de descarga dos reservatórios e a disponibilidade das unidades termelétricas mais eficientes. Assim, mesmo através de Resolução Ministerial № 607-2009-MEM/DM, o Ministério de Energia e Minas, em cumprimento da cláusula 1.2 do Decreto de Urgência $N^{\circ}$ 049-2008, estabeleceu um limite para o CMgCP fixado em 313,5 S/./MW.h (em moeda peruana o Nuevo Sol) equivalente a 115 US $\$ / M W . h$. aplicado durante 02010.

Os custos marginais de curto prazo, médias mensais, são obtidas dividindo a somatória do produto da energia a cada 15 minutos pelo custo marginal a cada 15 minutos, entre a energia do mês. O custo marginal médio por ano registrado em 2010 foi de 21,44 US\$/MW.h.

\subsubsection{Tarifa de Transmissão}

No caso da transmissão, no mercado elétrico peruano reconhecem-se os custos médios eficientes por ser um dos segmentos que atua como monopólio natural, os quais são pagos mediante às remunerações que geram o uso de custos marginais e um encargo complementar que garanta os custos restantes. Assim mesmo, outorgou-se ao regulador a responsabilidade de não considerar investimentos ineficientes.

$\mathrm{Na}$ regulação do setor elétrico peruano estabelece-se que os preços regulados deverão refletir os custos marginais de suprimento de energia e são estruturados de modo a promover a eficiência do setor, também estabelece-se que as tarifas de transmissão e distribuição são reguladas pelo Osinergmin, independentemente da energia ser vendida para o mercado regulado ou para o 
mercado livre. No caso destes últimos, os preços de geração serão obtidos segundo acordo entre as partes. As vendas de energia e potência destinadas ao mercado livre deverão considerar obrigatoriamente, e de forma separada, os preços conveniados no barramento de referência da geração, bem como os encargos de transmissão, distribuição e comercialização, (HUAYLLAS, 2008).

Para a determinação dos encargos de transmissão o sistema elétrico peruano está composto por um sistema principal de transmissão, que é aquele onde o fluxo de energia pode fluir em duas direções, razão que não permite identificar exatamente quais geradores e quais distribuidores usam a infraestrutura, e um sistema secundário, onde o fluxo da energia é unidirecional e, portanto, possibilita a identificação dos usuários, (DE LA CRUZ, et al., 2004).

Os geradores conectados ao sistema principal de transmissão (SPT) deverão pagar mensalmente ao menos uma parcela de compensação, a fim de cobrir o custo total de transmissão (CTT). Tanto os sistemas que compõem o SPT, quanto os do sistema secundário de transmissão (SST), deverão permitir aos geradores comercializar potência e energia em qualquer de seus barramentos, (HUAYLLAS, 2008).

O método base de tarifação é o sistema nodal baseado em custos marginais de curto prazo, além de encargos por conexão. O custo total anual eficiente de transmissão (CTT) é calculado em maio de cada ano, e corresponde à anuidade do investimento descontado em 12\% (aVNR) mais os custos de operação e manutenção (COeM), (OSINERG, 2005).

\section{$C T T=a V N R+C O e M$}

O valor novo de reposição (VNR) é o custo de renovação das instalações, ou seja, do investimento feito em (linhas, subestações, centro de controle, telecomunicações) e os custos da operação e manutenção (incluindo gestão, segurança, etc.). Considera-se que a vida útil das instalações de transmissão, é de 30 anos. A atualização do VNR das instalações de transmissão é feita pelo Osinergmin a cada quatro anos, com a informação apresentada pelos concessionários. Tanto o VNR como o COeM são calculados para as instalações principais e secundárias. Estas últimas devem ser desagregadas em linhas para serem atribuídas aos usuários, (DE LA CRUZ, et al., 2004). 
Uma vez definido o CTT, deve-se arrecadar a receita tarifária, assim os mecanismos de arrecadação dos custos são cobrados através de dois encargos: a receita Tarifária $(\mathrm{RT})$ e o Pedágio (Pdg), conforme o critério Marginal, (HUAYLLAS, 2008).

$$
C T T=a V N R+C O e M=R T+P d g
$$

Onde,

CTT : Custo Total de Transmissão (anual)

RT : Receita Tarifária baseado nos custos marginais

Pdg : Pedágio (cargo complementar para cobrir o CTT)

A receita tarifária é o valor das diferenças de preços entre os barramentos de entrega e o rendimento de energia ao sistema, os quais surgem pela existência de uma capacidade de transmissão limitada e pela forma como se valorizam as perdas de energia em cada barramento de entrega do sistema. Este valor deve ser transferido dos geradores às empresas transmissoras, a fim de quitar as despesas com instalações de transmissão. A diferença entre o custo total anual e o ingresso tarifário é coberta mediante um pedágio ou encargo complementar, o qual é calculado com diferentes critérios.

No caso das linhas principais, definidas como aquelas de uso comum e onde o fluxo de energia é bidirecional, o pedágio é cobrado através de um encargo mensal por potência, que transferem os geradores às distribuidoras e clientes livres nos contratos. Por outro lado, no caso das linhas secundárias, definidas como aquelas de uso exclusivo e onde o fluxo de energia é unidirecional, o encargo complementar é pago usando diferentes critérios que buscam identificar aos usuários. Então se a linha é usada por alguns geradores para chegar ao sistema, estes pagam o custo anual da mesma em proporção ao "uso" da linha. Este "uso" estima-se com base em uma série de algoritmos de validação física. Se a linha é usada por uma distribuidora para abastecer os clientes de sua área de concessão, seu custo é calculado de maneira equivalente à energia. Por último, no caso de linhas utilizadas por ambos, se utiliza o critério de partilha em relação aos benefícios (OSINERG, 2005), (REYES, 2005). 
Segundo Huayllas (2008) a receita tarifária ou ingresso tarifário é calculado em função da potência e energia, entrega e retirada nos barramentos principais das subestações, sem incluir o respectivo pedágio. A RT por energia no SPT é determinado através do modelo PERSEO. A RT por potência (anual) resulta da diferença entre os fatores de perdas marginais calculados para cada elemento do sistema de transmissão.

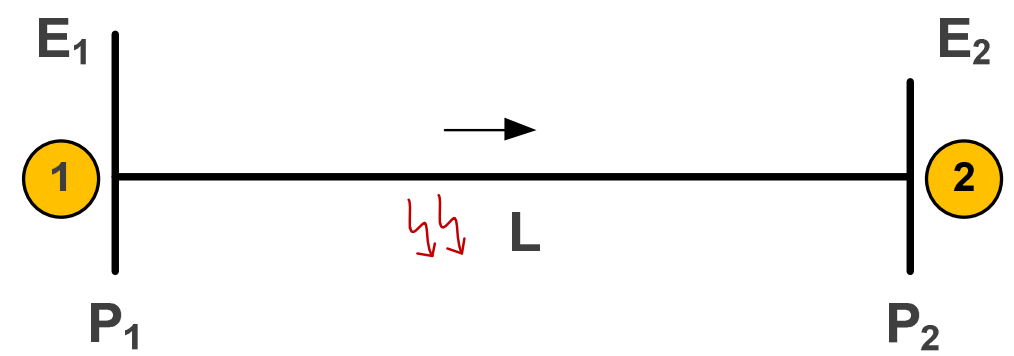

A receita tarifária é igual a:

$$
\begin{aligned}
& R T=R T_{\text {Potência }}+R T_{\text {Energia }} \\
& R T=\left(P_{2} P_{P 2}-P_{1} P_{P 1}\right)+\left(E_{2} P_{e 2}-E_{1} P_{e 1}\right)
\end{aligned}
$$

Onde,

RT : Receita Tarifária.

P1, P2 : Potência de entrega e retirada, respectivamente.

$E_{1}, E_{2}$ : Energia de entrega e retirada, respectivamente.

$P_{p 1}, P_{p 2}$ : Preços de potência em barramentos de entrega e retirada, respectivamente.

$P_{\mathrm{e} 1}, P_{\mathrm{e} 2}$ : Preços de energia em barramentos de entrega e retirada, respectivamente.

O pedágio por conexão resulta da diferença entre o custo total de transmissão (CTT) e a receita tarifaria RT.

$$
P d g=V N R+C O e M-R T=C T T-R T
$$

No caso das redes secundárias, onde é possível identificar os usuários que geram os fluxos de energia, foram estabelecidas duas formas de pagamento, isto segundo as linhas que são utilizadas pelos geradores, para se conectar ao SPT (linhas de Geração), ou se estas forem usadas pelos distribuidores para se conectar aos usuários finais (linhas de Demanda), (HUAYLLAS, 2008). 
Segundo Huayllas (2008) no sistema secundário de geração, as receitas são pagas pelos geradores que utilizam as instalações. O pagamento ao transmissor é feito ao final de cada mês e está baseado na mensalidade dos custos médios anuais, usando uma taxa de $12 \%$ a.a. Este valor é arrecadado pelo COES e é reajustado mensalmente segundo a variação da taxa de câmbio.

Quanto ao sistema secundário de demanda, estabelece-se um encargo de pedágio secundário, desta vez a ser pago pelos consumidores. Este pedágio unitário aos consumidores resulta da relação entre a energia e a potência transportada. O pedágio em cada instalação é calculado através da diferença entre o custo anual de transmissão e o ingresso tarifário, (HUAYLLAS, 2008).

No caso do tratamento dos contratos BOOT (Build, Own, Operate and Transfer $^{28}$, originados mediante contrato em leilões, o procedimento de remuneração das instalações utiliza também os conceitos de receita tarifária RT e pedágios, sendo o custo total de transmissão (CTT $=R T+P d g)$. No entanto existem algumas diferenças em relação aos investimentos realizados no marco da LCE, sendo a principal, o valor do VNR não se revisa periodicamente. No caso da concessão das empresas Etecen e Etesur a ISA, que constituiu a empresa Rede Elétrica do Peru (REP), se optou por uma modalidade diferente, onde 0 empreendedor se oferece a pagar o maior valor para ter o direito a uma quantidade fixa de rendimentos ao ano denominado: "Remuneração Anual Garantida" (RAG) ${ }^{29}$, (HUAYLLAS, 2008), (OSINERG, 2005).

\subsubsection{Tarifa de Distribuição}

Nas tarifas de distribuição de eletricidade do setor elétrico peruano, o modelo tarifário imposto baseia-se no reconhecimento de custos médios eficientes, empregando o conceito de concorrência por comparação (Modelo Empresa Eficiente-Yardstick Competition), é calculado a cada quatro anos um valor novo de

${ }^{28}$ BOOT indica que o concessionário constrói e opera um sistema de transmissão, mantendo sua propriedade por um período de 30 anos após o qual a propriedade da instalação passa ao estado.

29 Uma explicação sobre como operam este mecanismo e suas diferenças com as outras linhas se pode encontrar em De la Cruz e Garcia (2004). 
reposição do investimento (VNR) e os custos de exploração, os quais somados compõem o Valor Agregado de Distribuição (VAD), (REYES, 2005).

No cálculo do Valor Agregado de Distribuição (VAD) toma-se como base uma "Empresa Modelo Eficiente", aplicando-se critérios de concorrência por comparação. O procedimento consiste em construir uma "Empresa Modelo Eficiente" considerando diferentes "Sistemas de Distribuição Típicos", obtidos através da classificação dos sistemas, de acordo com os diferentes indicadores de densidade de carga, segundo os quais, calcula-se os custos eficientes dos diferentes concessionários. O VNR reconhecido corresponde aos custos de renovação das obras e bens físicos destinados a prestar o mesmo serviço, com a tecnologia e preços vigentes (art. N. ${ }^{\circ} 76$ da LCE), (OSINERG, 2005).

Finalmente, a LCE estabelece que depois de calcular um VAD unitário por setor típico (dividindo o VAD entre a máxima demanda), se verificará se as tarifas calculadas por setores típicos geram uma TIR (taxa interna de retorno) na faixa de $8 \%$ a $16 \%$. Se isso não for cumprido, estabeleceu-se que as tarifas serão somadas ao limite inferior ou superior, (REYES, 2005).

Em relação aos contratos assinados entre as distribuidoras $e$ as empresas geradoras, segundo a LCE e a Lei $N^{\circ} 28832$, os distribuidores estão obrigados a: ter contratos vigentes com empresas geradoras que lhes garantam seu requisito total de potência e energia, por no mínimo vinte e quatro (24) meses de sua demanda projetada. As vendas de eletricidade de um distribuidor, destinadas ao serviço público de eletricidade (mercado regulado), efetuam-se nos pontos onde se iniciam as instalações do consumidor.

A legislação peruana estabelece que nenhum gerador poderá contratar com clientes livres e distribuidores acima de sua garantia física (potência e energia firme) própria já contratada. As vendas de eletricidade de gerador a distribuidor, destinadas ao serviço público de eletricidade (mercado regulado), efetuam-se mediante: contratos sem leilão, cujos preços não poderão ser superiores aos preços nos barramentos (preços regulados) e contratos resultantes de leilões (preços firmes de longo prazo), (Art. $3^{\circ}$ da Lei $N^{\circ} 28832$ ). 


\subsubsection{Leilões de Energia}

A evolução do marco normativo do setor elétrico peruano através da Lei № 28832, "Lei para Assegurar o Desenvolvimento Efi ciente da Geração Elétrica", introduziu novos mecanismos para melhorar o desenvolvimento do setor, como o leilão de energia. Estas reformas têm a missão de alcançar investimentos que permitam uma expansão maior e ainda mais eficiente do setor, principalmente de origem privada, a preços justos (tarifas) que representem para o investidor remunerações razoáveis e para o consumidor custos eficientes.

A característica mais importante dos leilões é assegurar o abastecimento oportuno e eficiente de energia elétrica, em especial para o mercado regulado mediante leilões competitivos, que resultem em contratos de fornecimento de eletricidade de longo prazo com preços firmes que serão transladados aos usuários regulares. O processo de leilão será levado a cabo com a antecedência necessária para facilitar e promover o desenvolvimento de novos investimentos em geração, aproveitar as economias de escala, promover a concorrência pelo mercado e assegurar o abastecimento do mercado regulado.

Os leilões são convocados pelos distribuidores, que poderão incluir como parte da demanda a ser licitada aquela que corresponda a seus usuários livres e participação de outros distribuidores. Também é faculdade de cada distribuidor estabelecer seus requisitos e modalidades de compra de potência e energia, bem como os prazos contratuais a licitar. Os contratos com prazos inferiores a cinco (5) anos não poderão cobrir requisitos maiores ao $25 \%$ da demanda total dos usuários regulados do distribuidor (Art. 4.2, 4.4 da Lei $\mathrm{N}^{\circ}$ 28832). No caso do mercado livre ou consumidores livres estes têm faculdade e liberdade para convocar leilões para a compra e suprimento de suas demandas atuais e futuras.

Em relação ao prazo para iniciar os processos de leilão, o distribuidor é obrigado a iniciar um processo de leilão com uma antecedência mínima de três (3) anos, a fim de evitar que a demanda de seus usuários regulados fique sem cobertura de contratos. Isto permite: o desenvolvimento de novos projetos de geração, aproveitamento das economias de escala, promoção da competência pelo mercado e suprimento assegurado do mercado regulado, (HERRERA, et al., 2010).

No entanto o distribuidor poderá iniciar leilões com uma antecedência 
menor a três (3) anos por uma quantidade não maior a dez por cento (10\%) da demanda total de seus usuários regulados, a fim de cobrir os desvios produzidos em suas projeções de demanda. Nestes casos, o Osinergmin aprovará os prazos contratuais correspondentes à proposta do distribuidor (Art. 5.2 Lei N²8832).

Então estão previstos três tipos de leilões, a fim de que os distribuidores obtenham contratos com os geradores que brindam flexibilidade ao distribuidor para garantir a cobertura da demanda. No quadro 2 apresenta-se um resumo sobre os prazos de contrato de suprimento de energia previstos na Lei 28832, que foram mencionados anteriormente.

Quadro 2 - Prazos de contrato de energia no setor elétrico peruano.

\begin{tabular}{|c|c|c|c|c|}
\hline Tipo & $\begin{array}{c}\text { Prazo } \\
\text { Contrato }\end{array}$ & Convocação & $\begin{array}{c}\text { Quantidade a } \\
\text { Contratar }\end{array}$ & Objetivo \\
\hline $\begin{array}{c}\text { Longa } \\
\text { Duração }\end{array}$ & $\begin{array}{c}\text { Entre 5 e } 10 \\
\text { anos }\end{array}$ & $\begin{array}{c}\text { Com ao menos 3 anos } \\
\text { de antecedência }\end{array}$ & Até 100\% & $\begin{array}{c}\text { Contratar o total do crescimento } \\
\text { da carga estimada }\end{array}$ \\
\hline $\begin{array}{c}\text { Média } \\
\text { Duração }\end{array}$ & Até 5 anos & $\begin{array}{c}\text { Com ao menos 3 anos } \\
\text { de antecedência }\end{array}$ & Até 25\% & $\begin{array}{c}\text { Contratar desajustes detectados } \\
\text { respeito ao estimado } \\
\text { antecipadamente }\end{array}$ \\
\hline $\begin{array}{c}\text { Curta } \\
\text { Duração }\end{array}$ & $\begin{array}{c}\text { Definido pelo } \\
\text { OSINERGMIN }\end{array}$ & $\begin{array}{c}\text { Com uma antecedência } \\
\text { menor de } 3 \text { anos }\end{array}$ & Até 10\% & $\begin{array}{c}\text { Contratar pequenos desajustes } \\
\text { não previstos respeito do } \\
\text { estimado }\end{array}$ \\
\hline
\end{tabular}

Fonte:https://sites.google.com/site/regulacionsectorelectrico/peru.

Também é estabelecido pelo Osinergmin o preço máximo para cada leilão e a adjudicação dos contratos respectivos, o qual deverá incentivar investimentos eficientes em geração, levando em conta o prazo de fornecimento. Estes prazos de fornecimento contratados nos leilões são de até vinte (20) anos a preços firmes, e nenhum deles podem ser modificados por acordo das partes ao longo da vigência do contrato, salvo autorização prévia de Osinergmin, (Art. $8^{\circ}$ da Lei $N^{\circ} 28832$ modificado pelo D.L. 1041). Os preços firmes permitem atrair novos investimentos, encontrar preços de mercado eficientes ou promover contratos de longo prazo para o mercado regulado.

O preço regulado é igual à média ponderada das tarifas teóricas e os preços de leilão, além disso, existe o mecanismo de transferência entre distribuidoras, que assegura que os usuários regulares paguem preços iguais.

Atualmente existe um regime de incentivos para promover a convocação 
antecipada de leilões, regime destinado à cobertura da demanda de serviço público de eletricidade (mercado regulado). Refere-se a um esquema que autoriza a incorporação de um encargo adicional que o distribuidor poderá incluir em seus preços aos seus usuários regulares. Encargo que será diretamente proporcional ao número de anos de antecedência da convocação, o que não poderá ser superior ao três por cento (3\%) do preço de energia resultante do leilão. Incentivos como estes permitem gerar a segurança do sistema no suprimento da demanda elétrica do mercado elétrico peruano, além disso, permitem enviar sinais à oferta de geração.

Fazendo um resumo de cada atividade do mercado elétrico peruano (geração, transmissão e distribuição) apresentam-se no quadro 3, os principais conceitos e características da regulação e os sistemas de preços do setor.

Quadro 3 - Sistema de preços no setor elétrico peruano.

\begin{tabular}{|c|c|c|c|}
\hline SEGMENTO & & PRINCIPIOS - CRITERIOS - METODOLOGIA & PERIODO \\
\hline \multirow{3}{*}{ Geração } & \multicolumn{3}{|c|}{ Competência entre Geradores } \\
\hline & $\begin{array}{l}\text { LCE: } \\
\text { Competência } \\
\text { no Mercado }\end{array}$ & $\begin{array}{l}\text { Energía: Custos marginais produto da operação do sistema (Custo da última unidade despachada). } \\
\text { Potência: Custos marginais produto da usina de minimo custo de investimento para o suprimento da } \\
\text { ponta (Turbina a Gas). }\end{array}$ & 12 meses \\
\hline & $\begin{array}{l}\text { LADEGE: } \\
\text { Competência } \\
\text { por mercado }\end{array}$ & $\begin{array}{l}\text { - Leilões de energía. } \\
\text { - Oportunidade de novos agentes. }\end{array}$ & 20 anos \\
\hline
\end{tabular}

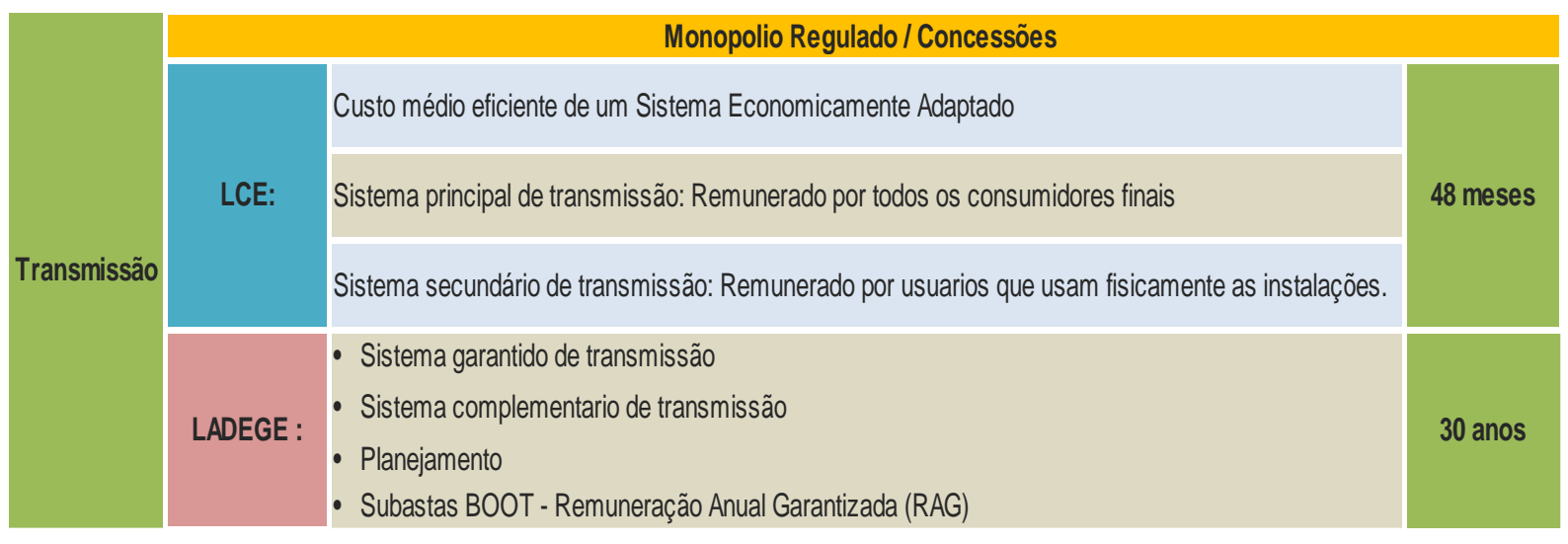

\begin{tabular}{l|l|l|l|}
\hline Distribuição & \multicolumn{2}{|c|}{ Monopolio Natural } \\
\hline
\end{tabular}

LCE: Lei de Concessões Elétricas

LADEGE: Lei para Assegurar o Desenvolvimento Ef iciente da Geração Elétrica

Fonte: (ACOSTA, 2008). 


\subsection{CRITERIOS DE PLANEJAMENTO DA EXPANSÃO DO SEIN}

O planejamento da expansão de longo prazo do sistema elétrico peruano é um processo complexo que envolve estudos energéticos, estudos elétricos e estudos financeiros, os quais geralmente realizam-se nessa ordem de maneira interativa, seguindo determinados critérios e premissas.

O maior objetivo de um país que busca a segurança do suprimento de suas necessidades de energia de forma sustentável, com qualidade, ambientalmente tolerável, socialmente solidário, a longo prazo e com preços justos e eficientes, é poder ampliar sua infraestrutura da geração, transmissão e distribuição ao ritmo que impõe a demanda. Para tal ponto, é necessária uma adequada estruturação do planejamento da expansão, bem como a operação do sistema elétrico.

O planejamento da expansão da geração do setor elétrico peruano, segundo a Lei de Concessões Elétricas (LCE) está a cargo do Ministério de Energia e Minas, quem elabora e propõe os planos de expansão referencial da geração, caracterizado de forma indicativa sobre a base de informação especializada, levando em conta critérios racionais, técnicos e econômicos.

O foco é pontuar períodos de planejamento e perspectivas da expansão da geração e transmissão em cenários de curto (5 anos), médio (5 - 10 anos) e de longo prazo (10 - 20 anos). A formulação da visão de expansão da geração do SEIN ao longo prazo compreende três aspectos importantes, (PERU MINISTERIO DE ENERGIA Y MINAS, 2009a):

- O diagnóstico; onde se avalia e revisa a situação conhecida "hoje" dos recursos energéticos para o curto, médio e longo prazo.

- A estratégia; onde se formula e propõe a fixação do objetivo estratégico, a definição da metodologia de orientação para o objetivo estratégico, o critério básico de planejamento, e o critério básico de assinatura de projetos no mercado.

- E o desenvolvimento estratégico; onde os passos do avanço estratégico da expansão da geração são apresentados com uma perspectiva de longo prazo, por períodos de evolução possíveis de expansão, considerando aspectos de dimensão e custos dos 
projetos, tempo de maturação, níveis de investimento, dificuldade de financiamento, complexidade em aprovação das licenças social e ambiental, participação de projetos de energia renovável não convencional, e projetos de implementação de curta duração.

Quanto à formulação da visão de planejamento da transmissão principal no SEIN, ela compreende também três aspectos importantes no longo prazo, (PERU MINISTERIO DE ENERGIA Y MINAS, 2009a):

- O diagnóstico; que é realizado sobre a evolução da rede de transmissão principal considerando três atributos: capacidade de transmissão, confiabilidade, e capacidade para interligações internacionais.

- A estratégia; contempla-se a definição da metodologia de orientação para o objetivo estratégico, o critério básico de planejamento, e o critério básico de assinatura de projetos no mercado.

- E o desenvolvimento estratégico; propõe em forma geral um processo da expansão da transmissão principal do SEIN para o longo prazo, a partir das configurações elaboradas no plano principal de transmissão do SEIN.

Os projetos de geração e transmissão elétrica geralmente são de longa maturação, pela magnitude do investimento que envolve e o período de vida útil das instalações, pelo que as previsões econômicas e de financiamento dos agentes econômicos que participam no mercado devem se projetar nesse horizonte, ou seja, dentro de um cenário de planejamento geralmente de longo prazo.

O planejamento no mercado elétrico peruano é baseado em critérios básicos como: a busca do "mínimo custo" total de energia, tomando em conta custos de investimento e custos operativos, os projetos técnicos e economicamente viáveis sob as considerações de operação econômica do mercado definidas pelo marco regulatório, e concordante com a estratégia de desenvolvimento elétrico estabelecido para o setor. O objetivo é de maximizar o aproveitamento do potencial hidrelétrico do país, complementado com a geração termelétrica a gás natural e outras fontes renováveis não tradicionais como a energia eólica, geotérmica, biomassa e solar.

Outro critério, tomado em conta no planejamento, são as projeções dos preços dos combustíveis, onde considera-se as médias da projeção do preço do 
petróleo cru, leve, de referência no mercado internacional, a projeção dos preços do gás natural de Camisea, para geração elétrica considerando os pedágios pelo uso dos gasodutos tipo "selo postal" (pagos por todos os usuários elétricos), a fim que as usinas a gás concorram no despacho em igualdade de custos de gasodutos, e de enlaces principais de transmissão. Além disso, considera-se os preços de gás natural de outras jazidas existentes, assim como a projeção do preço do carvão, (PERU MINISTERIO DE ENERGIA Y MINAS, 2009a).

São levadas também em conta as projeções de oferta de gás natural de Camisea disponível no mercado elétrico peruano a longo prazo, as previsões das reservas e ofertas garantidas deste recurso energético para os usos elétricos.

Os planos de expansão da geração e transmissão do SEIN são formulados sob uma metodologia de planejamento que, seguindo o enfoque da "visão de planejamento de longo prazo", busca satisfazer o critério geral de planejamento de expansão da geração e transmissão principal. Então com a metodologia seguida sustenta-se, para cada cenário (curto, médio e longo prazo) planos de expansão da geração e transmissão do SEIN de "mínimo custo", com projetos de geração e transmissão viáveis economicamente.

Um critério básico para o desenvolvimento da expansão do SEIN é a concessão de projetos novos que apresentem potencial de rentabilidade, mantendo a competitividade em relação aos custos, para finalmente serem viabilizados, para sua concessão definitiva, construção e operação comercial, mediante a realização de leilões.

A projeção da demanda elétrica é fundamental no planejamento da expansão do SEIN, pelo que são construídos projeções de demanda média, otimista e conservadora, o que é feito considerando dois tipos de projeção de cargas: a projeção da demanda vegetativa (cargas do mercado regulado) e projeção da demanda de grandes cargas (cargas especiais com importante impacto sobre a demanda global do SEIN). Estas projeções de demanda são determinadas para cada barra do SEIN.

$\mathrm{Na}$ determinação da demanda vegetativa são utilizadas duas metodologias. Uma para determinar a demanda a curto prazo mediante a utilização do modelo $\mathrm{ARIMA}^{30}$ e o modelo econométrico para a determinação da demanda em

${ }^{30}$ Auto Regressive Integrated Moving Average. Modelo de series temporais de previsão de curto prazo. 
longo prazo, que incluem a determinação do PIB, o crescimento da população, e a tarifa elétrica média do sistema. Em quanto à projeção de grandes cargas especiais, são determinadas mediante o resultado de pesquisas ou declarações dos investidores em grandes cargas especiais (agentes do mercado livre), novas incorporações e projetos com demanda considerável declaradas.

Após a definição das quantidades e projeções da demanda elétrica do SEIN considera-se importante os planos e programas de obras da geração e transmissão estabelecidas na visão do planejamento referencial da geração e transmissão, nos cenários de curto, médio e longo prazo. O que também traz estratégias que determinam os critérios básicos de planejamento da operação.

Atualmente está vigente o plano referencial de eletricidade (2008 2017) conhecido como (PRE-2008) aprovado e publicado pelo Ministério de Energias y Minas (MEM). Entretanto o planejamento da transmissão está a cargo do operador nacional do sistema, o COES, que elaborou o Primeiro Plano de Transmissão (PPT) e que foi aprovado pelo MEM em 2010. Este plano será atualizado e publicado a cada dois (2) anos, ressaltando-se que o plano de transmissão tem caráter vinculante para as decisões de investimento adotadas durante sua vigência.

Como dados relevantes do plano referencial de planejamento do SEIN apresenta-se uma perspectiva de crescimento da demanda média anual de energia de 8,1\% num cenário médio, no período (2009 - 2019), que será suprida principalmente por fontes como a hidroeletricidade e termeletricidade a gás natural, complementado com outros recursos renováveis não tradicionais como a energia eólica, geotérmica, biomassa, e solar, levando em conta a economia, segurança e confiabilidade do SEIN, consideram-se também as interligações internacionais, (PERU MINISTERIO DE ENERGIA Y MINAS, 2010a).

Em consequência a visão de evolução do mercado elétrico peruano é estabelecida sob critérios de eficiência econômica do conjunto. O planejamento da expansão do setor realizado pelo MEM, apresentado nos planos de expansão, é considerado com caráter indicativo econômico para a expansão da geração do SEIN, dado que a evolução de execução real dependerá do resultado da interação entre os diferentes agentes do setor dentro do marco regulatório vigente. De outro lado a expansão da transmissão tem caráter vinculante ao primeiro plano de transmissão apresentado pelo COES. 


\subsection{INTEGRAÇÃO ELÉTRICA PERU - BRASIL}

Das experiências de integração energética na América do Sul em relação às interligações elétricas, os acordos bilaterais são até o momento um dos mecanismos efetivos para avançar nesse objetivo comum, a busca da integração elétrica regional, entre países sul-americanos e mercados elétricos.

Estudos realizados pelo Comitê de Integração Energética Regional $(\mathrm{CIER})^{31}$ mostram que a integração energética da América do Sul, mediante a interligação elétrica conjunta é possível aproveitar de forma eficiente a energia de cada país complementariamente num único sistema interligado Sul-americano.

Os consumidores sul-americanos de energia elétrica poderiam ter uma economia de US\$ 1 bilhão em suas contas de luz se todos os projetos de interconexão entre os países da região estivessem prontos. $O$ trabalho também avaliou que a conclusão da interligação de todas as linhas de transmissão entre os países sul-americanos, evitaria a necessidade de investimentos de $R \$ 9,6$ bilhões em novas usinas, devido à possibilidade de transferência de energia, (ELETROSUL, 2009).

A interligação dos sistemas elétricos de vários países permitiria maior aproveitamento dos reservatórios das hidrelétricas do continente, com a possibilidade de transferir energia de uma região com grande volume de água nos reservatórios para outra com baixo volume armazenado. Permitindo a transferência de energia entre países e mercados elétricos, que atuariam de forma complementar, administrando melhor a hidreletricidade associada ao fator hidrológico, que entre regiões e países são variáveis entre estações.

Assim o Peru e o Brasil, depois de chegar a um acordo de integração elétrica bilateral, vêm impulsionando e implementando este processo, que permitirá a implantação de infraestrutura hidrelétrica no Peru, para atender a demanda elétrica peruana e exportar os excedentes ao Brasil, que viabilizaram a integração elétrica entre os dois países. Ao mesmo tempo permitirá a cooperação técnica e financeira, para o adequado aproveitamento dos recursos hídricos da Amazônia, tanto no lado

31 Instituição multinacional formada por 230 empresas do setor de energia com operações nos dez países sul-americanos. 
Peruano como no Brasileiro, de forma a complementar e atender as futuras demandas de energia com menor custo global.

Existe atualmente um acordo bilateral de integração energética assinado entre Peru e Brasil. O acordo e os convênios assinados prevêem a construção de cinco usinas hidrelétricas de aproximadamente $6700 \mathrm{MW}$ de capacidade instalada total, localizadas na Amazônia do Peru. O convênio contempla a cooperação técnica e financeira do governo do Brasil, mediante a Eletrobrás e outras empresas brasileiras, assim como o financiamento e desenvolvimento dos estudos e construção das usinas por parte do Banco Nacional de Desenvolvimento Econômico e Social do Brasil (BNDES) no Peru.

Atualmente o processo encontra-se na fase inicial de estudos de implementação de procedimentos técnicos e regulatórios, num marco legal com um convênio de integração elétrica, que deve no curto prazo dar seus primeiros frutos, com a finalização de estudos de factibilidade dos primeiros projetos hídricos e a possibilidade do início das obras.

\subsubsection{Cronologia do Processo de Integração}

Entre os anos de 1976-1979, a Direção de Eletricidade do Ministério de Energia e Minas do Peru (DGE), com apoio da Cooperação Técnica Alemã (GTZ), realizou a avaliação do potencial hidrelétrico peruano tanto na vertente do Pacífico quanto na do Atlântico, para o desenvolvimento de centrais hidrelétricas, encontrando-se um vasto potencial na Amazônia peruana.

Em novembro de 2006, foi assinado um memorando de entendimento entre os Ministérios de Peru e Brasil para o estabelecimento de uma comissão mista permanente em matéria de energia, mineração e geologia.

Em novembro de 2007, a Direção Geral de Eletricidade (DGE) do Ministério de Energia e Minas do Peru, apresentou o relatório final "Elaboração de resumos executivos e fichas de estudos das Centrais hidrelétricas com potencial para a exportação a Brasil".

Em maio de 2008, em Lima, assina-se o convênio de integração 
energética entre o Ministério de Minas e Energia do Brasil e o Ministério de Energia e Minas do Peru, com o objetivo de desenvolver estudos sobre a integração energética entre os dois países e a avaliação do potencial de projetos hidrelétricos do Peru.

Em junho de 2008, o Ministério de Energia e Minas do Peru outorga concessão temporária ao primeiro projeto do acordo de integração, à Empresa de Geração Elétrica Amazonas Sur (EGASUR) para realização de estudos da Hidrelétrica Inambari.

Em abril de 2009, foi assinado o memorando de entendimento para a cooperação e apoio aos estudos de interligação elétrica entre o Peru e Brasil, contempla-se os estudos, financiamento, construção e operação de projetos hidrelétricos, localizados na Amazônia peruana de até 6700 MW de capacidade total.

Em junho de 2010, em Manaus, os presidentes Alan García Pérez, do Peru, e Luiz Inacio Lula da Silva, do Brasil, assinaram o acordo para o fornecimento de eletricidade à República do Peru e exportação de excedentes à República Federativa do Brasil, estabelecendo um acordo de integração energética entre os dois países, mediante a interligação elétrica.

\subsubsection{Análise do Processo de Integração}

Do acordo efetuado em 2009 entre ambos os países, se contempla a cooperação técnica e financeira por parte do Brasil para a realização dos estudos de viabilidade da interligação elétrica entre os sistemas elétricos dos dois países, para a exportação de energia de Peru para o Brasil e o abastecimento de energia elétrica ao mercado elétrico peruano.

Para a realização de estudos, financiamento, construção e operação dos projetos hídricos localizados na Amazônia peruana foi estimado um custo total de US\$ 16 bilhões de dólares. O convênio prevê que a maior parte do financiamento será com investimento de capitais privados brasileiros com associação da Eletrobrás, via o Banco Nacional de Desenvolvimento Econômico e Social (BNDES) do Brasil, que será a encarregada do financiamento. 
Dentro do acordo propõe-se prioritariamente a construção de cinco grandes usinas hidrelétricas, que se detalham na tabela 5.

Tabela 5 - Potencial hidrelétrico amazônico peruano comprometido ao Brasil

\begin{tabular}{llc}
\hline NOME DO PROJETO & TIPO & P (MW) \\
\hline U.H. Inambari & Hidro & 2200,0 \\
U.H. Paquitzapango & Hidro & 2000,0 \\
U.H. Mainique I & Hidro & 607,0 \\
U.H. Tambo 40 & Hidro & 1286,0 \\
U.H. Tambo 60 & Hidro & 580,0 \\
\hline
\end{tabular}

Fonte: Ministério de Energia e Minas (Peru).

As localizações geográficas destes potenciais estão situadas na Amazônia Sul do Peru e na vertente do Atlântico, em regiões próximas à fronteira com Brasil (estado do Acre) como se mostra na figura 20.

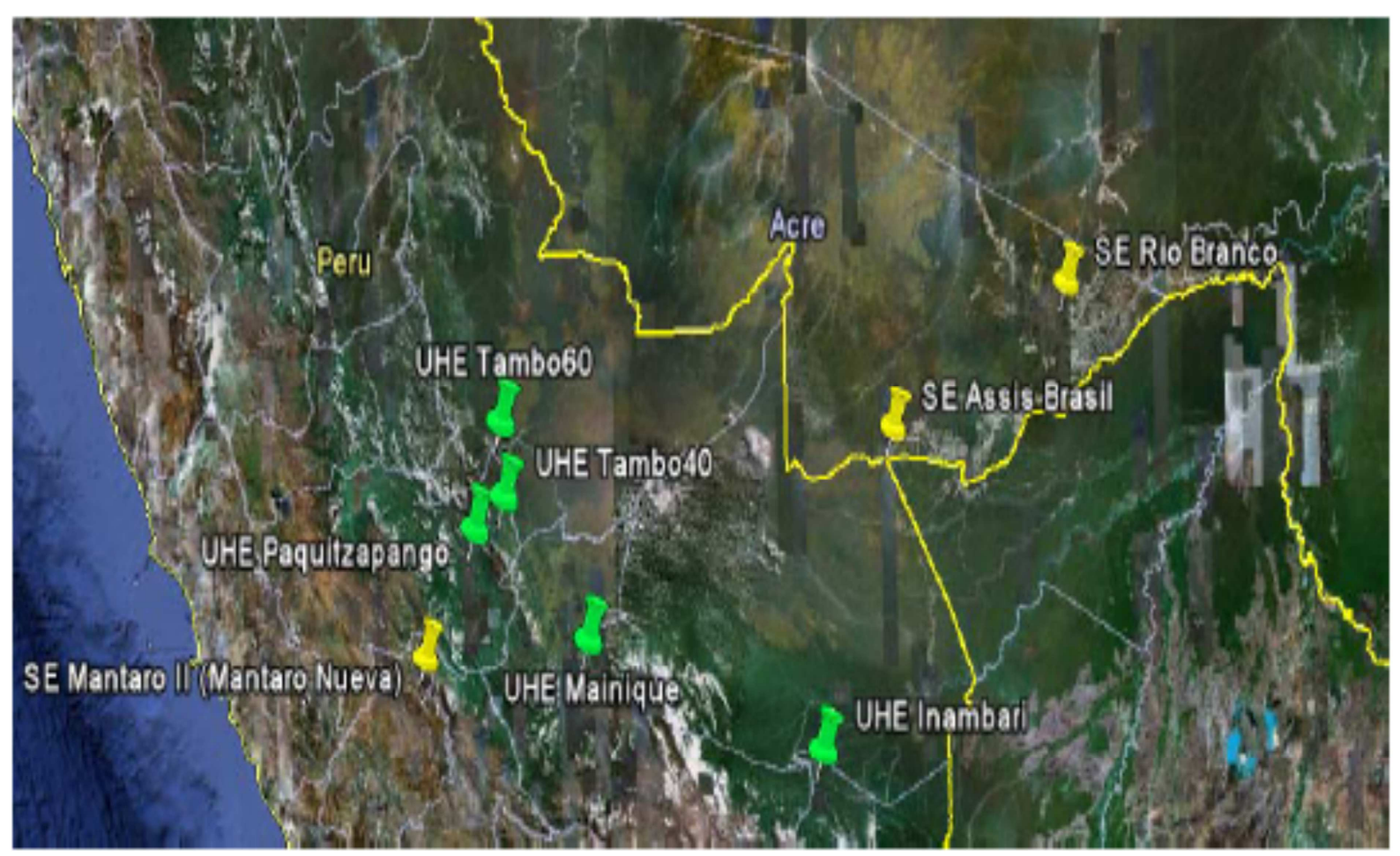

Figura 20 - Localização geográfica das hidrelétricas da Amazônia Peruana.

$\overline{\text { Fonte: COES - PERU. }}$

As implicações do acordo de Integração energética entre Peru e Brasil para o fornecimento de eletricidade ao Peru e sua exportação de excedentes ao Brasil geram algumas considerações que merecem ser abordadas dentro do 
processo de integração elétrica entre ambos países, como parte do contexto da situação atual e futura do setor elétrico peruano.

Menciona-se principalmente alguns aspectos relevantes do acordo que prevê definitivamente, dentro de seu marco legal, a promoção de infraestrutura em território peruano para a produção de eletricidade que atenda ao mercado peruano e a exportação de excedentes de potência e energia elétrica ao Brasil, com a finalidade de viabilizar a interligação elétrica entre os dois países.

Sob a capacidade acumulada de todas as usinas de geração hidrelétrica contempladas preferencialmente dentro do convênio, adota-se o compromisso para a exportação de 6000 MW de potência, mais uma tolerância de 20\%, o que implica uma capacidade máxima comprometida à exportação de 7200 MW, por um período de 30 anos com contrato fixo a partir da entrada em operação de cada usina hidrelétrica, desde que sejam determinadas as quantidades de potência e energia excedentes de exportação.

Em relação à potência e energia elétrica associada a cada uma das usinas de Geração, destinadas a cobrir as necessidades do mercado elétrico peruano e a exportar os excedentes ao mercado elétrico brasileiro, comprometeramse no acordo a respeitar a seguinte ordem: (1) o mercado regulado peruano, (2) o mercado livre peruano e (3) o mercado brasileiro, isso indica que na ordem de prioridades o suprimento em primeira ordem é do mercado elétrico peruano.

Também foi definido que antes da autorização da concessão definitiva das usinas hidrelétricas e estudos realizados, o estado Peruano determinará a quantidade de potência e energia elétrica associada, destinadas ao mercado regulado peruano, com os correspondentes preços por um período de 30 anos.

Com respeito ao suprimento do mercado livre peruano serão considerados os processos públicos de venda de potência e energia elétrica para determinar as quantidades que serão comprometidas ao mercado livre peruano, estes serão levados pelos titulares dos projetos, mediante procedimentos que estabeleça o estado peruano.

As quantidades de potência e energia elétrica serão destinadas ao mercado regulado e livre peruano conjuntamente com seus respectivos preços e a expectativa de preços de exportação, os projetos somente serão levados a cabo caso tenham comprovada sua viabilidade técnica, econômica, social e ambiental; isso quer dizer que necessariamente terão que cumprir com os requisitos prévios 
exigidos para sua viabilidade completa, levando em conta a regulação do setor elétrico peruano, bem como estabelece-se que o estado peruano que definirá os excedentes de potência e energia elétrica associada para a exportação.

As quantidades definidas e comprometidas para a exportação de energia e potência do SEIN para o Brasil, que constaram nos contratos de concessão de cada projeto manterão-se fixos por um período de 30 anos.

A respeito da energia exportada ao Brasil, os titulares dos projetos hidrelétricos mediante agentes de exportação e/ou importação de energia elétrica do mercado brasileiro, poderão vender nos leilões de compra de eletricidade no mercado regulado do Brasil, da mesma forma que no Peru, por um período de 30 anos, seguindo procedimentos do sistema de leilões brasileiros, até o limite de quantidade de potência e energia elétrica, definida pelo Peru.

A construção das linhas de transmissão que interligaram as usinas hidrelétricas do convênio, bem como os gastos da utilização do sistema interligado brasileiro será financiada pelo agente vendedor do leilão de compra de eletricidade para o mercado brasileiro conforme procedimento estabelecido no sistema interligado nacional do Brasil. Por outro lado, o custo da construção das linhas de transmissão que interligue as usinas hidrelétricas com o sistema elétrico peruano, será assumido pelo mercado elétrico peruano.

Também foi estabelecido, que para o desenvolvimento, construção e operação das usinas de geração e linhas de transmissão localizada em território peruano, será necessário obter do estado peruano concessões de geração hidrelétrica e de transmissão, as que se outorgarão por um prazo de 30 anos, adicional aos anos gastos para a construção da usina.

De acordo com os respectivos contratos de concessão, ao vencimento dos prazos de concessão, deverão transferir-se ao estado peruano, sem custo algum, os direitos elétricos e a propriedade da infraestrutura. Isto significa que ao termino dos 30 anos, o estado peruano poderá dispor livremente e decidir manter as quantidades de potência e energia elétrica, comprometida à exportação.

Também existe o compromisso do estado peruano de manter sua margem de reserva em não menos de $30 \%$ durante o mesmo período, com o objetivo de atender de forma segura sua demanda interna bem como os contratos de exportação.

Dentre os aspectos importantes que considera este acordo está a 
operação e despacho das futuras usinas do convênio a cargo do operador do sistema interligado peruano (COES) quem realizará as transferências de potência e energia comprometidas para a exportação ao Brasil, e a cooperação técnica entre o COES e o operador nacional do sistema elétrico Brasileiro (ONS) e a câmara de comercialização de energia elétrica do Brasil (CCEE), além de outros aspectos regulatórios e procedimentos que terão que ser implementados pelos ministérios do setor e, portanto pelos governos de cada estado.

O acordo estabelecido colocou um marco geral que ainda precisa ser estruturado de forma específica sobre os procedimentos técnicos e aspectos regulatórios que ainda precisam ser levados a um acordo comum entre os dois países, pelo que atualmente a integração energética bilateral encontra-se numa etapa inicial, estima-se que no médio a longo prazo seja concretizado.

No entanto o avanço da construção das usinas hidrelétricas priorizadas dentro do convênio atualmente encontra-se em etapa de estudos, pelo que vem sendo estudada sua viabilidade técnica, econômica, ambiental e social dos projetos. Como é o caso do projeto da usina hidrelétrico de Inambari, um dos projetos com maior avanço em seus estudos e processo de licenciamento ambiental e social.

\subsubsection{Interligação Elétrica Peru - Brasil}

Em relação à interligação elétrica entre os sistemas elétricos de Peru e Brasil, será desenvolvida de forma conjunta, no Peru, com a construção dos projetos hidrelétricos das bacias amazônicas do centro e sul do Peru e as linhas de transmissão que interligarão ao SEIN e a fronteira entre os dois países; no Brasil, com a construção de linhas de transmissão que interligarão ao SEIN peruano. A interligação está baseada na exportação dos excedentes produzidas nas usinas implantadas dentro do convênio de integração elétrica Peru - Brasil.

O estudo do primeiro plano de transmissão do COES define um sistema de transmissão de interligação das usinas ao SEIN e interligação ao Brasil, em extra-alta tensão. Deve-se mencionar que as frequências de transmissão elétrica em ambos países é de $60 \mathrm{~Hz}$.

Considera-se a construção de linhas de transmissão elétrica de 357 km 
aproximadamente, desde a futura usina em estudo, hidrelétrica Inambari, até a fronteira peruano-brasileira, em $500 \mathrm{kV}$ de corrente alterna e $60 \mathrm{~Hz}$ de frequência. Ali conectar-se-ia à rede elétrica brasileira, onde uma linha de $600 \mathrm{kV}$ em corrente contínua e 810 km de extensão a uniria a Rio Branco ${ }^{32}$, Porto Velho e as usinas do rio Madeira, pelo que está sendo considerado uma estação elétrica retificadora na fronteira e uma inversora em Porto Velho, (SERRA, 2010).

Por outro lado, no sistema elétrico brasileiro, está previsto no planejamento da transmissão a construção de linhas de transmissão de alta tensão e sua interligação elétrica a seu sistema interligado nacional (SIN) com a cidade de Porto Velho em 600 kV, daí a Rio Branco cidade importante mais próxima à fronteira com Peru com duas linhas de $230 \mathrm{kV}$.

Além disso, Brasil vem construindo em Rondônia (estado fronteiriço ao Peru e Bolívia) a aproximadamente $700 \mathrm{~km}$ da fronteira peruana, duas usinas hidrelétricas (as usinas de Santo Antonio e Jirau) na bacia do rio Madeira em Porto Velho, com uma capacidade de potência instalada total de $6500 \mathrm{MW}$ aproximadamente. Estas novas usinas brasileiras terão uma direta interação com a usina hidrelétrica de Inambari, pelo fato da interação das bacias dos rios Madeira, Inambari e Beni na Bolívia.

Pelo que está previsto, o projeto hídrico Inambari que será uma usina de regulação integrada ao sistema hídrico brasileiro, por sua capacidade de regularizar o volume do rio Inambari, que tem direta interação com os aproveitamentos hídricos do rio Madeira, melhorando consideravelmente a energia assegurada e a capacidade de geração destas duas usinas hidrelétricas no Brasil, que por sua concepção não tem capacidade de represamento ou regularização de suas águas.

Também se deve mencionar que na mesma bacia hidrográfica se prevê na Bolívia, no rio Beni, a construção da usina hidrelétrica Cachuela Esperanza, que atualmente encontra-se em etapa de estudo, pelo que a usina hidrelétrica Inambari poderia melhorar a rentabilidade de ambas centrais, assumindo um papel de regulador mediante o aumento de sua energia firme. Isto requer uma estratégia operativa conjunta entre Peru e Brasil.

A seguir, na figura 21, se apresenta a localização da interligação elétrica dos dois países e a configuração das usinas na bacia dos rios Inambari, Beni e

32 Cidade Brasileira mais importante próxima à fronteira com Peru 
Madeira.

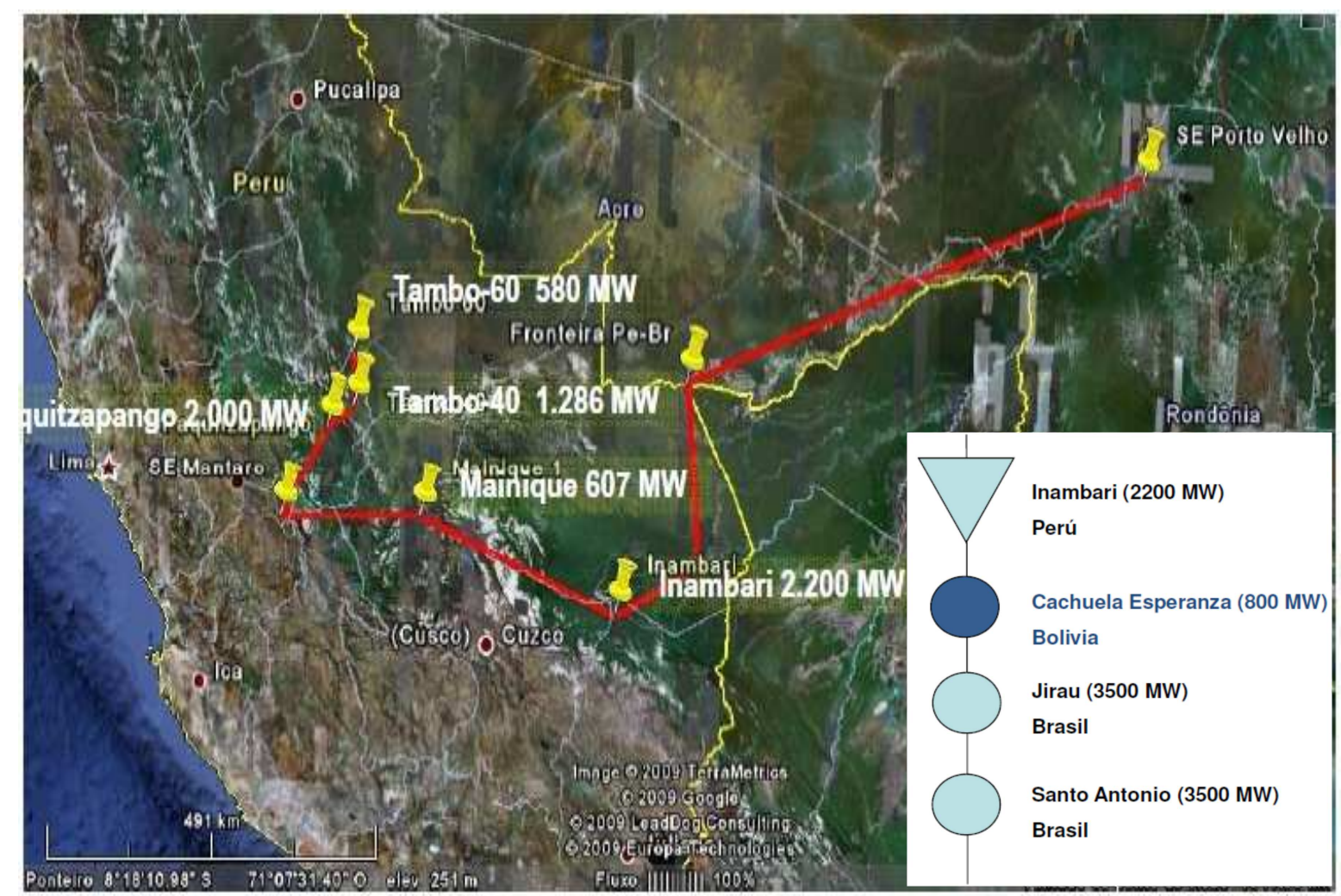

Figura 21 - Localização geográfica da futura interligação elétrica Peru - Brasil

Fonte: ELETROBRÁS, Apresentação: Integração Energética na América Latina.

Por outro lado com a possibilidade da construção da hidrelétrica Inambari, poderia-se viabilizar a intenção de aproveitar a navegabilidade dos rios Madre de Dios, Beni e Madeira, permitindo conexão ao Atlântico pelo rio Amazonas, mediante hidrovias e sua interligação com o pacifico, pelas estradas interoceânicas do Peru, Brasil e também Bolívia.

Nesse sentido, entende-se a importância da integração elétrica de Peru e Brasil, que permitiria a exportação de energia ao Brasil e uma maior confiabilidade de suprimento no SEIN, pelos benefícios comuns que possam trazer a ambos países na consolidação da segurança energética, eficiência econômica nos custos globais de energia, entre outros aspectos. Todavia é possível gerenciar melhor os aspectos técnicos e regulatórios que possam permitir o melhor o aproveitamento dos recursos energéticos comprometidos no acordo de integração bilateral.

Também é possível permitir a consolidação do objetivo futuro da integração elétrica Sul Americana, incluindo integralmente o caráter estratégico da 
zona e a localização das cidades fronteiriças entre Peru e Brasil como novos eixos comerciais e de trânsito, em torno da cidade brasileira de Porto Velho como cidade de enlace de saída ao Atlântico para o Peru e Bolívia, bem como a saída do Brasil para o Pacifico. Isto permite observar que a integração elétrica de Peru e Brasil é estratégica por sua importância na integração energética e econômica da America do Sul.

Desta forma, são construídas as alternativas para integração econômica da região, estabelecendo as condições iniciais, sendo que a integração efetiva se fara mediante infraestrutura já em processo de definição pelos países envolvidos. Logo, linhas de transmissão elétrica não será um impedimento à convergência econômica e desenvolvimento dos países sul-americanos. 


\section{GERAÇÃo EÓLICA E TERMELÉTRICA A GN NO PERU}

Este capítulo visa apresentar as características dos recursos energéticos em estudo no presente trabalho. Na primeira parte são apresentadas as particularidades da implantação da geração eólica, já na segunda parte é tratada a geração termelétrica a gás natural.

Esta abordagem trata da evolução e atual situação do recurso eólico e térmico a gás natural na geração elétrica do SEIN; além disso, são descritas as principais perspectivas de seu desenvolvimento futuro, como os incentivos outorgados à geração eólica e a competitividade dos custos baixos do gás natural na geração termelétrica.

\subsection{GERAÇÃO EÓLICA NO PERU}

No Peru a energia eólica, é um recurso que sempre esteve presente na natureza e por sua vez vem sendo aproveitado por sua população em aplicações voltadas ao bombeamento de água, moagem de grãos, dentre outros usos de menor escala. Recentemente esta energia vem sendo usada para gerar eletricidade em zonas isoladas no setor rural e, no futuro, planeja-se o uso de usinas de maior potência interligadas às redes de concessionárias.

O país possui grandes extensões de terrenos viáveis para implementar projetos de parques eólicos para a produção de energia elétrica que podem ser distribuídos através do sistema interligado nacional (SEIN) ou usados em aplicações isoladas, (FONAM, 2006).

No setor elétrico peruano a utilização desta fonte energética na geração de energia elétrica é relativamente nova. Os registros mostram que as melhores condições para o desenvolvimento de parques de geração eólica estão no litoral do país, principalmente no litoral norte e centro-sul e em certas zonas do interior do país que contam com micro-climas favoráveis a tal fonte de energia. 


\subsubsection{Potencial Eólico}

O desenvolvimento da energia eólica para geração elétrica interligada a rede convencional no Peru ainda está atravessando um processo de evolução. $\mathrm{O}$ interesse pelo recurso eólico começou em 1983 quando a Organização Latino Americana de Energia (OLADE) apresentou o primeiro mapa eólico preliminar do Peru com 48 pontos de medição.

Posteriormente, em 1989, a ELECTROPERU inicia os estudos de investigação da energia eólica na costa peruana e define a potencialidade de dois locais pilotos localizados na costa norte e sul do Peru, nomeados como projeto piloto Malabrigo e San Juan de Marcona.

Em 1993, uma década depois da publicação do primeiro mapa eólico, a Empresa de Administração de Infraestrutura Elétrica (ADINELSA) publica o segundo mapa eólico preliminar do Peru com 153 pontos de medição, efetuada no período de 1985 a 1993, estimando-se um potencial de 57000 MW de energia eólica ao longo de toda a costa peruana, (PETROMONT, 2008).

Em 2001 o MEM publicou no documento "Atlas de Minério e Energia no Peru 2001", o potencial de energia eólica disponível no âmbito nacional, apresentando valores de velocidade média do vento em cada região do país.

Em seguida, em 2004, a ADINELSA apresentou o documento "Avaliação Técnica e Econômica das Usinas Eólicas Piloto Malabrigo e San Juan de Marcona", baseada nos resultados das medições efetuadas durante os anos prévios. Os dois projetos piloto apresentam respectivamente velocidades médias superiores a $8 \mathrm{~m} / \mathrm{s}$ (30 $\mathrm{m}$ de altura) e $9 \mathrm{~m} / \mathrm{s}$ (40 m de altura), fator de capacidade de $35 \%$ e $39 \%$ e densidade de potência de $310 \mathrm{~W} / \mathrm{m}^{2}$ e $441 \mathrm{~W} / \mathrm{m}^{2}$, respectivamente, (PETROMONT, 2008).

Em 2007, ante as perspectivas positivas do desenvolvimento mundial da geração eólica e do crescimento da demanda elétrica peruana, o interesse de muitas empresas em investir e desenvolver futuros parques eólicos aumentou. Nesse ano o MEM outorgou as primeiras concessões temporais para desenvolver estudos relacionados à atividade de geração elétrica com base eólica em vários locais da costa peruana.

Em 2008, o MEM contratou os serviços do consórcio (Meteosim 
Truewind - Latin Bridge Business), que elaborou o atlas eólico peruano e apresentou dados preliminares da capacidade e potencial eólico do país. Isto foi realizado mediante a implementação do sistema digital (VIENTOGIS) onde foi calculado e estimado o potencial eólico peruano a $50 \mathrm{~m}, 80 \mathrm{~m}$ e $100 \mathrm{~m}$ de altura, gerando mapas para cada região, como é apresentado na figura 22.

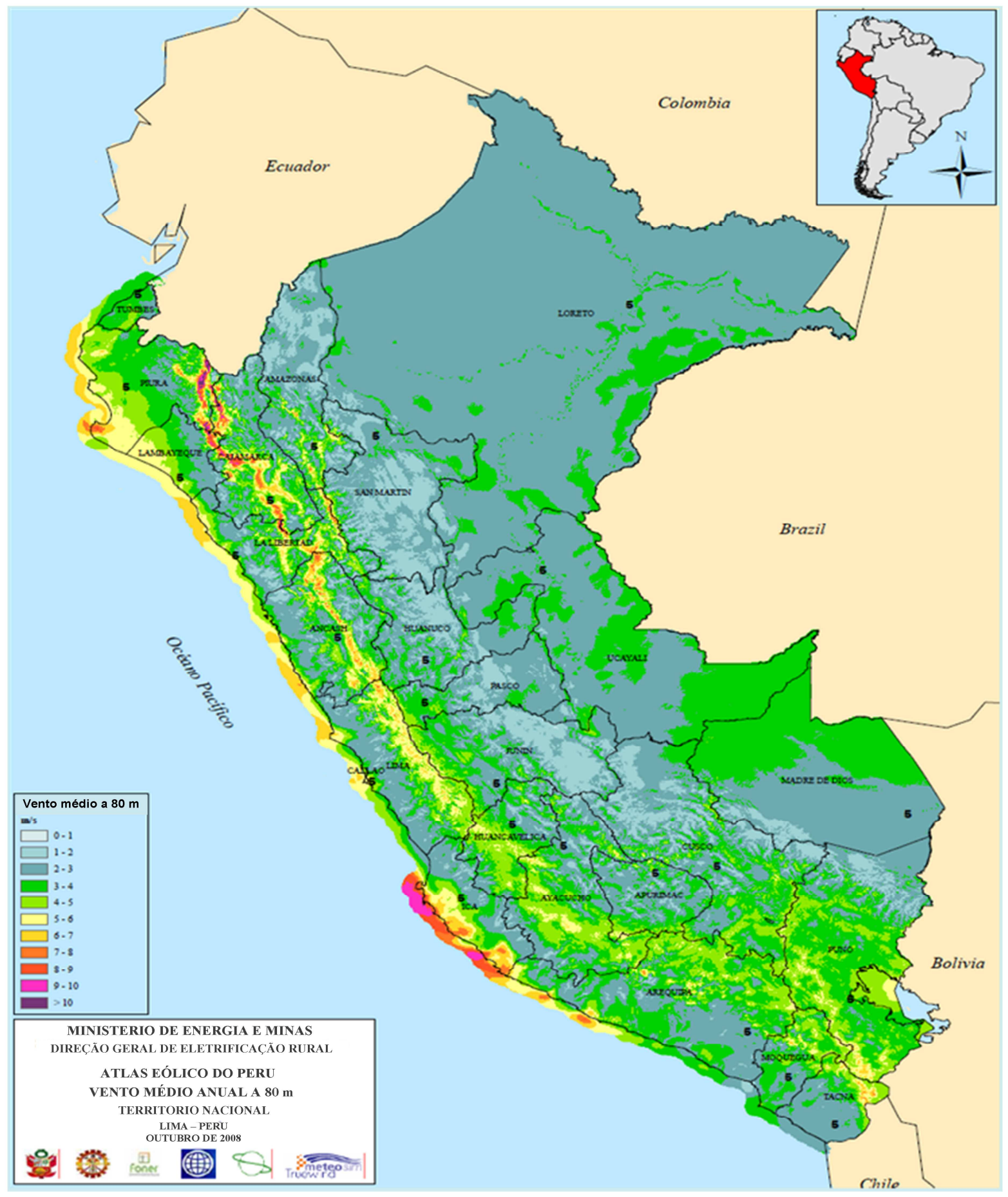

Figura 22 - Mapa da velocidade média anual do vento a $80 \mathrm{~m}$.

Fonte: http://dger.minem.gob.pe/AtlasEolico/AtlasEolicoLibro.asp 
Para a elaboração deste mapa foi usado o sistema "WindSurvey" juntamente com o modelo numérico de predição atmosférica MASS (Mesoscale Atmospheric Simulation System), que trabalha com uma resolução de $5 \mathrm{~km} \times 5 \mathrm{~km}$, e quando acoplado ao modelo WindMap, apresenta velocidades de vento em escala menor de resolução, de $1 \mathrm{~km} \times 1 \mathrm{~km}$.

Utilizando técnicas de modelamento meso-escalares, micro-escalares, e combinando a utilização de um sofisticado modelo de simulação atmosférica foi possível reproduzir os padrões de vento do território peruano. Com um modelo de vento micro-escalar que responde às características do terreno e à topografia foi finalmente determinada a estimativa das velocidades do vento e do potencial eólico em todas as regiões do país.

O potencial bruto de energia eólica estimada foi de $77 \mathrm{GW}$. Deste total, a potência instalável é de $22 \mathrm{GW}$, com registros de vento médio de $9-10 \mathrm{~m} / \mathrm{s}$, a $80 \mathrm{~m}$ de altura, sem considerar zonas off-shore (no mar). Os locais com melhor potencial encontram-se nas regiões de Ica e Piura na costa sul e norte do país, com potências instaláveis de $9144 \mathrm{MW}$ (42\%) e 7554 MW (34\%), respectivamente, como é mostrado no quadro 4, (PERU MINISTERIO DE ENERGIA Y MINAS, 2008).

Quadro 4 - Potencial eólico do Peru.

\begin{tabular}{|c|c|c|}
\hline Região & $\begin{array}{c}\text { Potêncial } \\
\text { Bruto } \\
\text { (MW) }\end{array}$ & $\begin{array}{c}\text { Potência } \\
\text { Instalável } \\
\text { (MW) }\end{array}$ \\
\hline Amazonas & 1380 & 6 \\
\hline Ancash & 8526 & 138 \\
\hline Apurimac & O & $\mathrm{O}$ \\
\hline Arequipa & 1992 & 1158 \\
\hline Ayacucho & 114 & O \\
\hline Cajamarca & 18360 & 3450 \\
\hline Callao & $\mathrm{O}$ & O \\
\hline Cuzco & $\mathrm{O}$ & $\mathrm{O}$ \\
\hline Huancavelica & O & $\mathrm{O}$ \\
\hline Huánuco & 54 & $\mathrm{O}$ \\
\hline lca & 18360 & 9144 \\
\hline Junin & 48 & O \\
\hline La Libertad & 4596 & 282 \\
\hline Lambayeque & 2880 & 564 \\
\hline Lima & 1434 & 156 \\
\hline Loreto & $\mathrm{O}$ & $\mathrm{O}$ \\
\hline Madre de Dios & O & $\mathrm{O}$ \\
\hline Moquegua & 144 & $\mathrm{O}$ \\
\hline Pasco & O & O \\
\hline Piura & 17628 & 7554 \\
\hline Puno & 162 & $\mathrm{O}$ \\
\hline San Martin & 504 & $\mathrm{O}$ \\
\hline Tacna & 942 & O \\
\hline Tumbes & O & $\mathrm{O}$ \\
\hline Ucayali & $\mathrm{O}$ & $\mathrm{O}$ \\
\hline TOTAL PERU & 77394 & 22452 \\
\hline
\end{tabular}

Fonte: (PERÚ MINISTERIO DE ENERGIA Y MINAS, 2008). 
O estudo do atlas eólico peruano apresenta os indicativos médios dos recursos eólicos anuais do país. O potencial exato ainda será confirmado por medições de campo, pois os registros do vento e as estimativas do recurso eólico apresentados no estudo em escala nacional ainda são referenciais, indicando os locais com maior expectativa de vento, (PERÚ MINISTERIO DE ENERGIA Y MINAS, 2008).

Outra característica importante do recurso eólico no Peru é a complementaridade com a geração hidrelétrica. Existem estudos que indicam que o regime de chuvas e o regime de vento complementam-se ao longo do ano. A figura 23, com escala aumentada da geração eólica para a comparação gráfica, mostra que existe uma alta produção hidrelétrica de dezembro a maio e um regime favorável de recurso eólico de maio a novembro, (Tech4CDM, 2009).

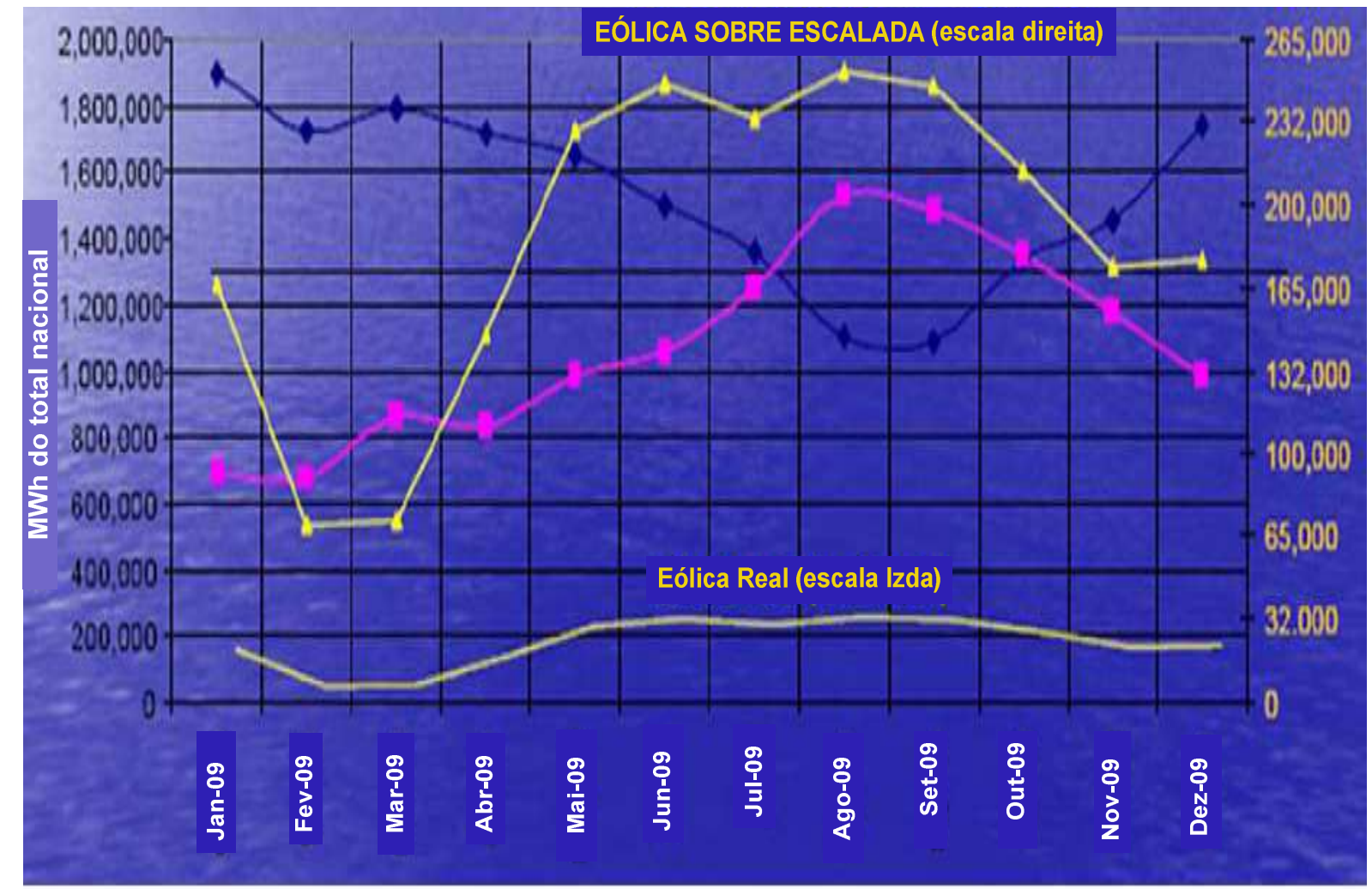

\section{—Hídrica - - Térmica Eólica}

Figura 23 - Complementaridade da geração eólica - hidrelétrica.

Fonte: (Tech4CDM, 2009). 


\subsubsection{Incentivos às Energias Renováveis}

Em 2008, o Decreto Legislativo 1002 - Lei de promoção de investimento em geração de eletricidade com o uso de energias renováveis - designado como (Lei RER), estabeleceu as bases regulatórias para o desenvolvimento das energias renováveis não-tradicionais, como a energia eólica, solar fotovoltaica, biomassa e pequenas usinas hidrelétricas (PCHs) com até $20 \mathrm{MW}$ de capacidade, impulsionando assim a implantação da geração eólica no SEIN.

A Lei permitiu a declaração de interesse nacional e necessidade pública, o desenvolvimento de nova geração elétrica mediante o uso de recursos energéticos renováveis (RER) e a promoção do uso eficiente da energia no setor elétrico peruano, outorgando os seguintes incentivos:

- É garantida a participação de $5 \%$ dos geradores no suprimento do consumo energético do SEIN durante os primeiros 5 anos. Posteriormente esta porcentagem será modificada pelo Ministério de Energia e Minas em 2013.

- Através de leilões de energia garante-se ao empreendedor vencedor do leilão um preço firme (ofertado no leilão) pela energia que injeta no sistema durante o período de contrato de fornecimento de até 20 anos, período tal que o gerador compromete-se a fornecer energia baseada em RER ao SEIN.

- A venda de energia é garantida no mercado de curto prazo a custo marginal somado a uma "prima,33 caso o custo marginal seja menor que a tarifa estabelecida por OSINERGMIN.

- A geração elétrica baseada em RER terá prioridade no despacho diário estabelecido pelo COES, custo variável zero (0), e acesso livre às redes de transmissão e distribuição do SEIN.

Estes incentivos dados pela lei viabilizaram a construção dos primeiros parques eólicos, permitindo incentivar o mercado e impulsionar uma maior

${ }^{33}$ É o valor pago pela diferença do custo da energia elétrica contratada em relação ao custo marginal de curto prazo dos empreendimentos RER, rateados entre todas as classes de consumidores finais atendidas pelo SEIN. 
participação desta fonte na matriz elétrica, como uma fonte complementar ao sistema hidrotérmico. Além disso, a lei permitirá a geração de fundos para o desenvolvimento de pesquisa em aproveitamentos (RER), como está estabelecida na regulação do setor.

A quantidade proposta e requerida pelo MEM para o primeiro leilão de energia RER foi de $500 \mathrm{MW}$, capacidade tomada com base em $5 \%$ do consumo real de energia total do SEIN. As adjudicações dos empreendimentos no leilão foram para os projetos cujas ofertas de preço e quantidades de energia propostas cumpriram com os limites estabelecidos pelo Osinergmin.

O desenvolvimento dos projetos eólicos no marco da lei RER exige dos empreendedores alguns requisitos, como contar com ao menos um (01) ano de medições válidas de vento. Também considera que os geradores que não são vencedores do leilão podem vender energia a clientes livres no mercado de curto prazo. Os leilões são convocados com periodicidade não menor que 2 anos.

O regime de remuneração aplicável à geração $R E R$ resume-se no seguinte, (OSINERGMIN, 2010b):

- O gerador RER tem o compromisso de entregar ao menos sua energia anual contratada e estipulada no contrato, com obrigação de suprimento ao SEIN à tarifa do respectivo contrato.

- Ao gerador RER é garantido uma receita igual ao produto de sua tarifa de adjudicação por sua energia contratada. Quando as injeções líquidas de energia num período tarifário são menores que a energia contratada, a tarifa de adjudicação será reduzida aplicando um fator de correção, estabelecido no contrato inicial.

- As injeções líquidas de energia, até o limite da energia adjudicada, são remuneradas conforme a tarifa de adjudicação; no entanto as injeções líquidas de energia em excesso à energia adjudicada são remuneradas ao correspondente custo marginal. Com respeito ao último caso, o Artigo $19^{\circ}$ do Regula mento RER define que as injeções líquidas de energia correspondem à diferença entre a geração menos os retiros de energia por compromissos contratuais que tenha o Gerador RER com terceiros.

- É estabelecida uma "prima" na tarifa apenas quando o que foi 
arrecadado nas vendas de energia (até pela energia adjudicada) e por potência no mercado de curto prazo for menor que o rendimento garantido.

- Para efeitos da primeira determinação da "prima", a energia adjudicada será igual à alíquota do período compreendido desde o início do prazo de vigência até o fim do respectivo período tarifário (o qual se compreende desde o dia primeiro de maio até 30 de abril).

- A tarifa de adjudicação é atualizada com frequência anual que coincide com o final do período tarifário, de acordo com a fórmula contida no anexo dos contratos RER.

O regime de remunerações descrito é mostrado graficamente nas figuras 24, 25 e 26 para melhor entendimento.

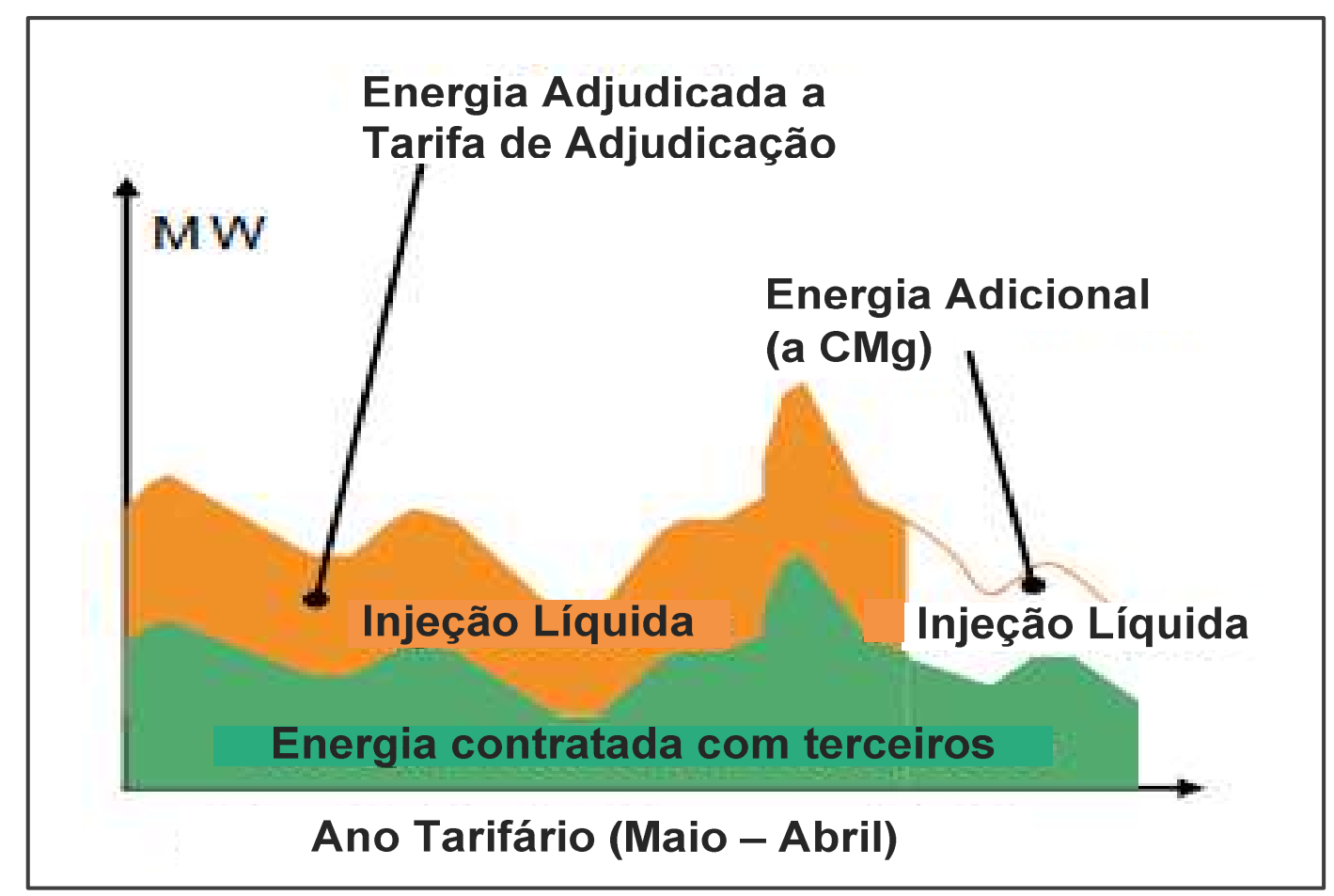

Figura 24 - Estrutura geral da remuneração da geração RER

Fonte: (OSINERGMIN, 2010b).

Nota-se que o cumprimento da entrega da energia adjudicada (área alaranjada da figura 24) se efetua com o acúmulo da energia desde primeiro de maio até no máximo 30 de abril do correspondente ano tarifário; se fosse verificado o cumprimento da injeção de energia contratada antes de finalizar o ano tarifário, a 
valorização das injeções líquidas de energia que se produz daí em adiante não seriam consideradas para a determinação da "prima".

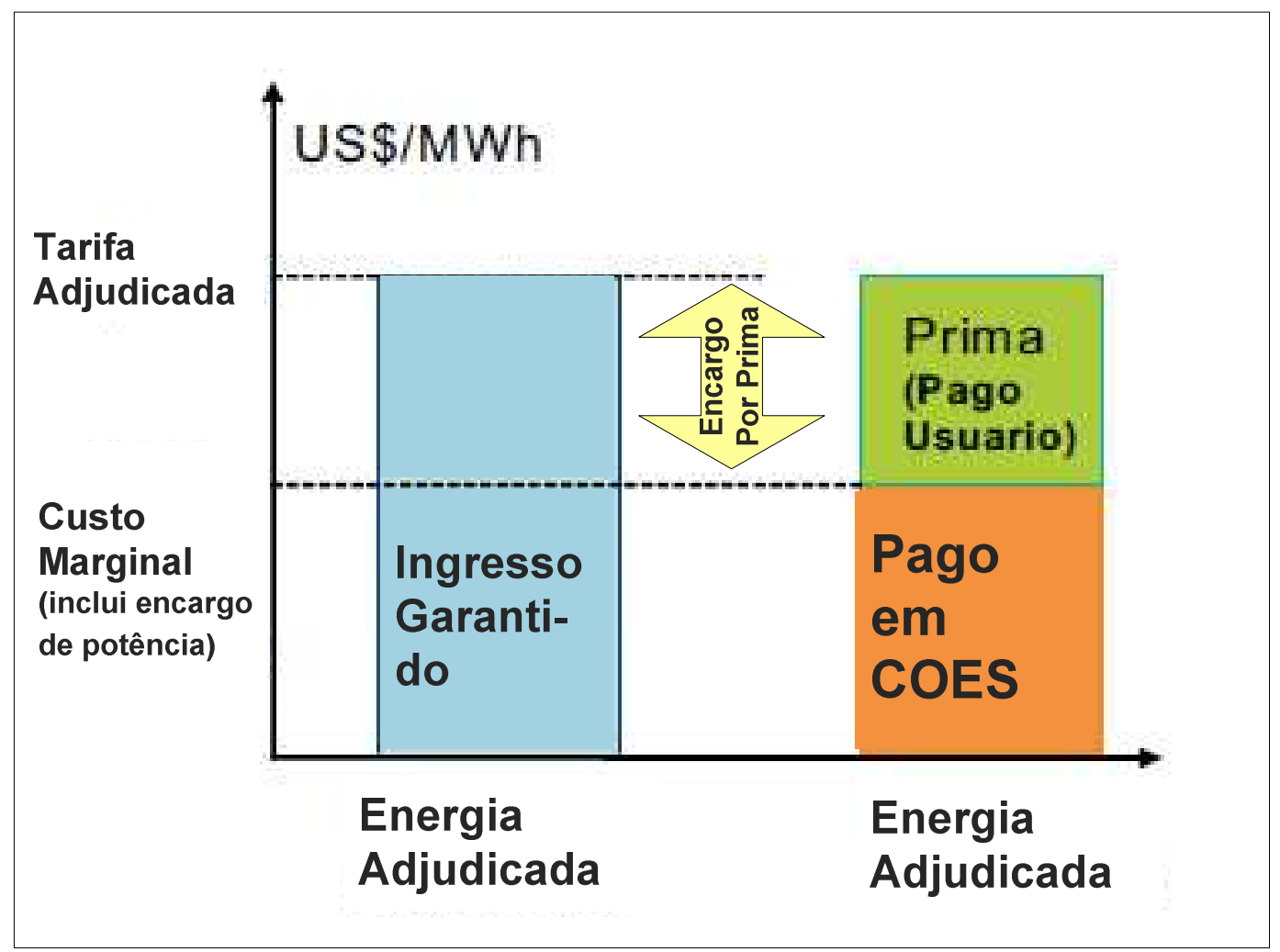

Figura 25 - Composição da renda dos geradores RER

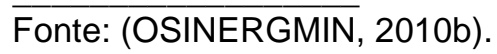

Observa-se na figura anterior que a receita total de um gerador RER que opere no SEIN resulta da soma da receita garantida (caso seja vencedor de um leilão), das vendas de eletricidade a terceiros (outros geradores, usuários livres ou usuários regulados via contratos bilaterais) e ainda das vendas de energia excedente não contratada em leilões ou por terceiros no mercado de curto prazo.

A receita total obtida por um gerador RER de acordo com o DL 1002 é consistente, pois pode operar no SEIN sem a necessidade de ter participado ou ter obtido contrato em um leilão RER. Se assim fosse a figura 24 sofreria modificações, pois não teria a obrigação com a energia adjudicada, portanto também não teria direito à tarifa "prima" como é mostrado na figura 26 a seguir. 


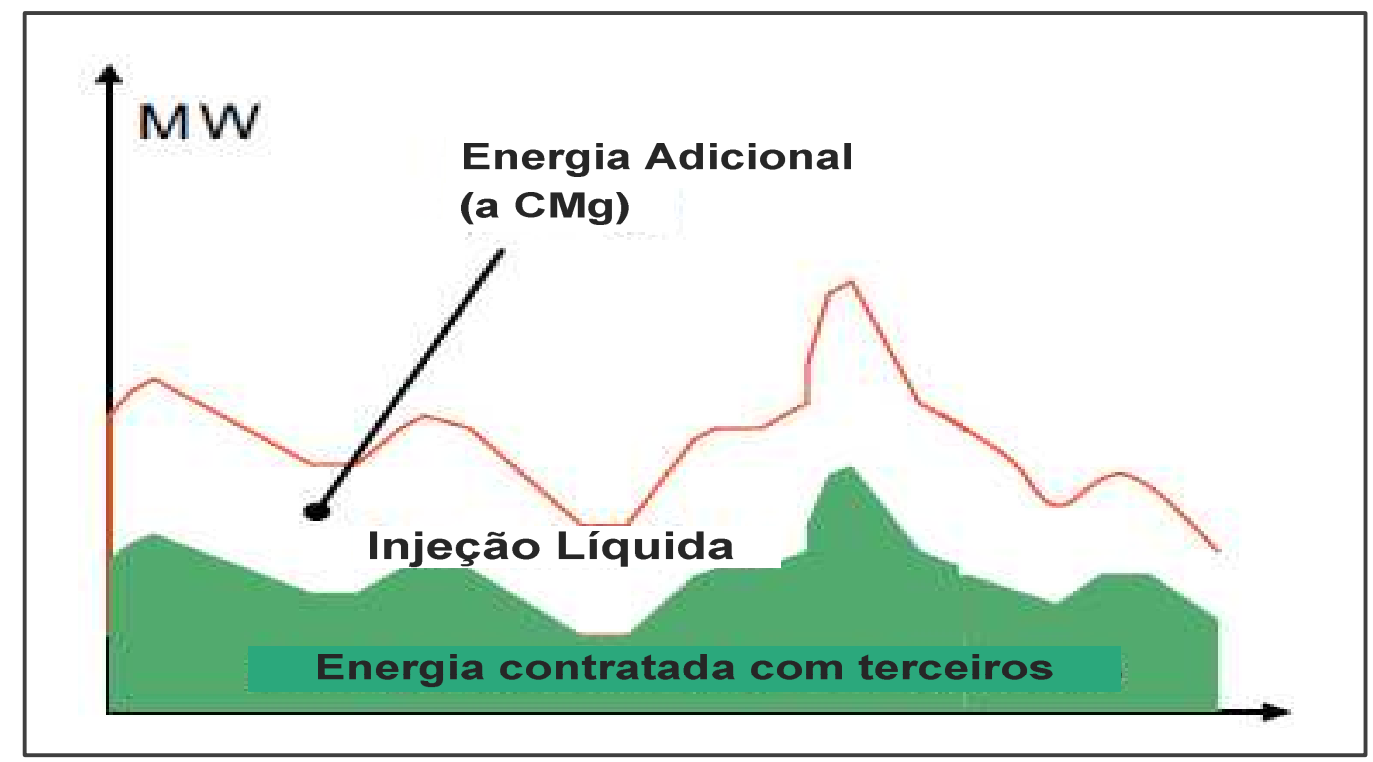

Figura 26 - Estrutura da remuneração dos geradores RER sem ingresso garantido

Fonte: (OSINERGMIN, 2010b).

A tarifa de geração RER é complementada com o valor da tarifa "prima" se os preços do mercado de curto prazo $(\mathrm{CMg})$ são menores que o custo da energia contratada. A tarifa "prima" para cada gerador RER é a diferença entre a renda garantida e a renda obtida através das transferências no mercado spot. A "Prima" deverá cobrir as diferenças quando o preço Spot for menor que as tarifas RER, de modo que seja cumprido o pagamento das remunerações mínimas garantidas dos empreendimentos RER, como é mostrada na figura 27, (OSINERGMIN, 2011b).

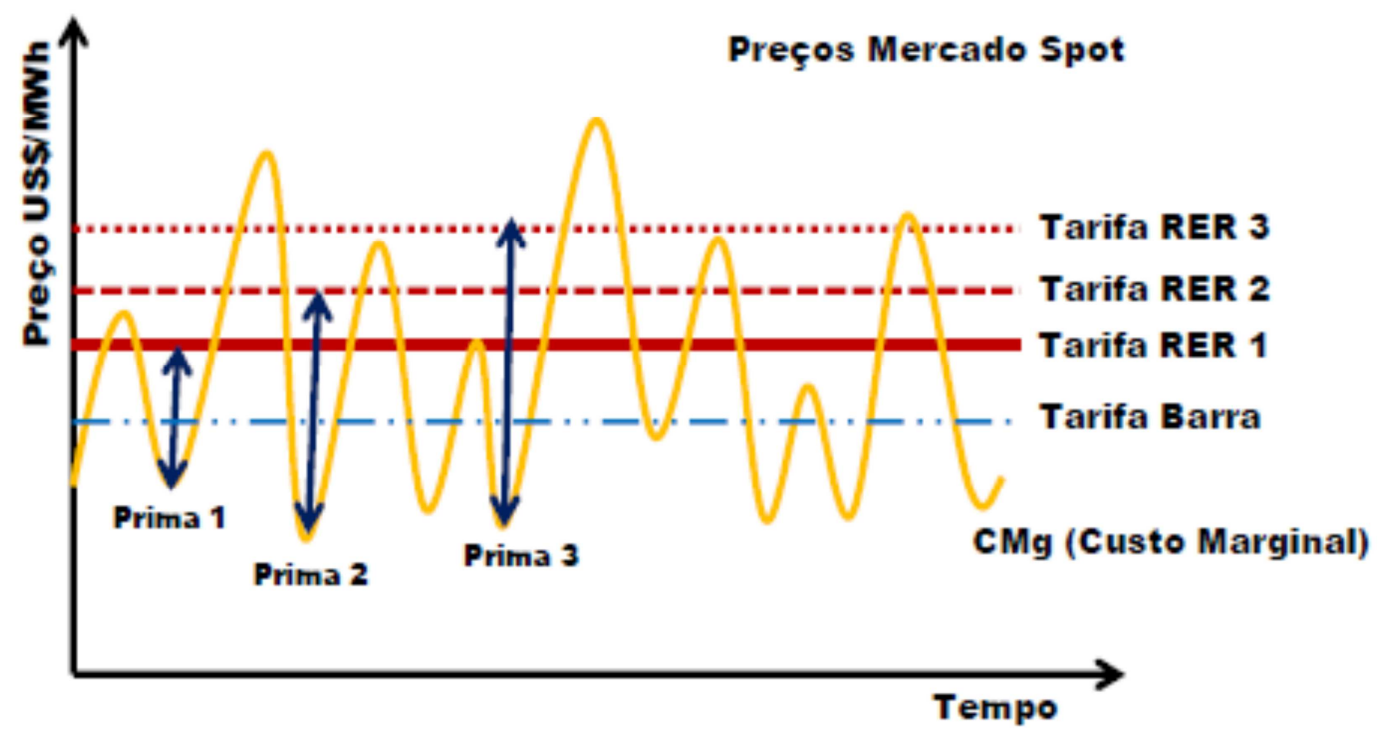

Figura 27 - Remuneração dos geradores RER.

Fonte: Ministério de Energia e Minas (Peru). 
Esta tarifa "prima" é paga aos geradores RER anualmente e é calculada (ex-post ao final do ano) pelo Osinergmin, assegurando uma remuneração mínima de $12 \%$ aos empreendimentos. As "primas" são cobertas pelos usuários e é adicionada como um encargo anual nas tarifas, repassadas aos custos de transmissão ou pedágios, e liquidadas depois de um ano, garantindo uma receita constante ao longo do tempo, como é mostrado na equação abaixo.

\section{Remuneração por energía RER : $R_{R E R}=R_{C M g}+$ Prima}

Onde:

$\mathrm{R}_{\mathrm{RER}}=$ Remuneração por energia $\mathrm{RER}=\mathrm{T}_{\mathrm{RER}} \times$ Energia Líquida Injetada

$\mathrm{R}_{\mathrm{CMg}}=$ Remuneração a custo marginal $=\mathrm{Cmg} \times$ Energia Líquida Injetada

Prima $=R_{R E R}-R_{C M g}=$ Energia Líquida Injetada $\times\left(T_{R E R}-C m g\right)$

$\mathrm{R}_{\mathrm{CMg}}$ : Remunerado pelo mercado.

Prima: Remunerado pelos consumidores.

\subsubsection{Projetos Eólicos}

Os incentivos outorgados aos empreendimentos de geração eólica interligados ao SEIN trouxeram iniciativas para o desenvolvimento de estudos e projetos de parques eólicos. A partir da vigência do D.L. № 1002 incrementou-se o número de projetos através das concessões efetuadas pelo MEM, superando os 11 GW de capacidade em estudo, distribuídos principalmente na costa Norte, Centro Sul e Sul do Peru. Os quadros 5, 6 e 7 apresentam os projetos em estudo distribuídos por regiões. 


\section{Quadro 5 - Usinas eólicas em estudo na zona norte do SEIN.}

\begin{tabular}{|c|c|c|c|c|c|}
\hline Usina Eólica & $\begin{array}{l}\text { Proprietario da } \\
\text { Concessão }\end{array}$ & $\begin{array}{c}\text { Potência } \\
\text { (MW) }\end{array}$ & $\begin{array}{l}\text { ZONA } \\
\text { SEIN }\end{array}$ & Localização & $\begin{array}{c}\text { Barra candidata } \\
\text { interligação ao SEIN }\end{array}$ \\
\hline PARQUE. TUMBES - ZORRITOS & IBEROPERUANA INVERSIONES S.A.C. & 150,0 & Norte & Tumbes & Zorritos $220 \mathrm{kV}$ \\
\hline PARQUE MANCORA & IBEROPERUANA INVERSIONES S.A.C. & 100,0 & Norte & Piura & Talara $220 \mathrm{kV}$ o Zorritos $220 \mathrm{kV}$ \\
\hline PARQUE NEGRITOS-LA BREA & GAZ \& L'ENERGIE S.A.C. & 180,0 & Norte & Piura & Talara 220 kV o Zorritos 220 kV \\
\hline EL TUNAL & NORWIND S.A.C. & 105,0 & Norte & Piura & Talara $220 \mathrm{kV}$ \\
\hline PUNTA BALCONES & HUAYRA KALLPA S.A.C. & 200,0 & Norte & Piura & Talara $220 \mathrm{kV}$ \\
\hline PARQUE TALARA & ENERGÍA EÓLICA S.A. & 240,0 & Norte & Piura & Talara $220 \mathrm{kV}$ \\
\hline BALNEARIO PUNTA BALCONES & GENERALIMA S.A.C. & 300,0 & Norte & Piura & Talara $220 \mathrm{kV}$ \\
\hline PARQUELOBITOS & IBEROPERUANA INVERSIONES S.A.C. & 150,0 & Norte & Piura & Talara $220 \mathrm{kV}$ \\
\hline EL ALTO & PETROLERA MONTERRICO S.A. & 200,0 & Norte & Piura & Talara $220 \mathrm{kV}$ \\
\hline LA BREA & PETROLERA MONTERRICO S.A. & 170,0 & Norte & Piura & Talara $220 \mathrm{kV}$ \\
\hline TALARA & PERÚ ENERGÍA RENOVABLES.A. & 300,0 & Norte & Piura & Talara $220 \mathrm{kV}$ \\
\hline PARQUE LAGUNITOS & SOWITEC ENERGÍAS RENOVABLES & 150,0 & Norte & Piura & Talara $220 \mathrm{kV}$ \\
\hline PARQUE VICHAYAL & IBEROPERUANA INVERSIONES S.A.C. & 80,0 & Norte & Piura & Talara 220 kV o Piura 220 kV \\
\hline PARQUE YACILA-ISLILLA & GAZ \& L'ENERGIE S.A.C. & 80,0 & Norte & Piura & Piura $220 \mathrm{kV}$ \\
\hline PIURA-PATTA-LOTE 1 & GENERALIMA S.A.C. & 300,0 & Norte & Piura & Piura $220 \mathrm{kV}$ \\
\hline YACILA & GENERALIMA S.A.C. & 100,0 & Norte & Piura & Piura $220 \mathrm{kV}$ \\
\hline PIURA-PATA-LOTE 2 & GENERALIMA S.A.C. & 300,0 & Norte & Piura & Piura $220 \mathrm{kV}$ \\
\hline SAN PEDRO & GENERALIMA S.A.C. & 200,0 & Norte & Piura & Piura $220 \mathrm{kV}$ \\
\hline PARQUE BAYOVAR 1 & IBEROPERUANA INVERSIONES S.A.C. & 200,0 & Norte & Piura & Piura $220 \mathrm{kV}$ \\
\hline PARQUE BAYOVAR 2 & IBEROPERUANA INVERSIONES S.A.C. & 200,0 & Norte & Piura & Piura $220 \mathrm{kV}$ \\
\hline PARQUE VICE & IBEROPERUANA INVERSIONES S.A.C. & 80,0 & Norte & Piura & Piura $220 \mathrm{kV}$ \\
\hline PARQUE LAMBA YEQUE & IBEROPERUANA INVERSIONES S.A.C. & 100,0 & Norte & Lambayeque & Chiclayo $220 \mathrm{kV}$ \\
\hline PARQUE CUPISNIQUE & ENERGÍA EÓLICA S.A. & 240,0 & Norte & La Libertad & Guadalupe $220 \mathrm{kV}$ \\
\hline PARQUE SAN PEDRO DE LLOC & IBEROPERUANA INVERSIONES S.A.C. & 100,0 & Norte & La Libertad & Guadalupe $220 \mathrm{kV}$ \\
\hline PACASMAYO & SOLEOL S.A.C. & 50,0 & Norte & La Libertad & Guadalupe 220 kV \\
\hline SAN PEDRO DE LLOC & SOLEOL S.A.C. & 50,0 & Norte & La Libertad & Guadalupe $220 \mathrm{kV}$ \\
\hline PARQUE MAGDALENA DE CAO & IBEROPERUANA INVERSIONES S.A.C. & 240,0 & Norte & La Libertad & Trujillo $220 \mathrm{kV}$ \\
\hline ASCOPE & PERÚ ENERGÍA RENOVABLE S.A. & 100,0 & Norte & La Libertad & Trujillo $220 \mathrm{kV}$ \\
\hline LA PAMPA & PERÚ ENERGÍA RENOVABLE S.A. & 100,0 & Norte & La Libertad & Trujillo $220 \mathrm{kV}$ \\
\hline MALABRIGO & PETROLERA MONTERRICO S.A. & 60,0 & Norte & La Libertad & Trujillo 220 kV o S. del Cao 138 kV \\
\hline MALABRIGO ॥ & PETROLERA MONTERRICO S.A. & 40,0 & Norte & La Libertad & Trujillo 220 kV o S. del Cao 138 kV \\
\hline PARQUE CASMA & ENERGÍA EÓLICA S.A. & 240,0 & Norte & Ancash & Chimbote $220 \mathrm{kV}$ \\
\hline PARQUE CHIMBOTE & ENERGÍA EÓLICA S.A. & 240,0 & Norte & Ancash & Chimbote $220 \mathrm{kV}$ \\
\hline PARQUE NUEVO CHIMBOTE & IBEROPERUANA INVERSIONES S.A.C. & 180,0 & Norte & Ancash & Chimbote $220 \mathrm{kV}$ \\
\hline CASMA I & PERÚ ENERGÍA RENOVABLE S.A. & 100,0 & Norte & Ancash & Chimbote $220 \mathrm{kV}$ \\
\hline CHIMBOTE I & PERÚ ENERGÍA RENOVABLES.A. & 100,0 & Norte & Ancash & Chimbote $220 \mathrm{kV}$ \\
\hline CASMA & SOLEOL S.A.C. & 50,0 & Norte & Ancash & Chimbote $220 \mathrm{kV}$ \\
\hline PARQUE PAMPA MATACABALLI & SOWITEC ENERGÍAS RENOV ABLES & 150,0 & Norte & Ancash & Chimbote $220 \mathrm{kV}$ o Paramonga $220 \mathrm{kV}$ \\
\hline PARQUE HUACHO & IBEROPERUANA INVERSIONES S.A.C. & 240,0 & Norte & Lima & Huacho $220 \mathrm{kV}$ \\
\hline HUACHO I & PERÚ ENERGÍA RENOVABLES.A. & 100,0 & Norte & Lima & Huacho $220 \mathrm{kV}$ \\
\hline HUACHO & SOLEOL S.A.C. & 50,0 & Norte & Lima & Huacho $220 \mathrm{kV}$ \\
\hline PARQUE LAS LOMAS & ENERGÍA EÓLICA S.A. & 240,0 & Norte & Lima & Cantera $220 \mathrm{kV}$ \\
\hline
\end{tabular}

Fonte: (ESC, 2009).

Quadro 6 - Usinas eólicas em estudo na zona centro sul do SEIN.

\begin{tabular}{|c|c|c|c|c|c|}
\hline Usina Eólica & $\begin{array}{c}\text { Proprietario da } \\
\text { Concessão }\end{array}$ & $\begin{array}{l}\text { Potência } \\
\text { (MW) }\end{array}$ & $\begin{array}{l}\text { ZONA } \\
\text { SEIN }\end{array}$ & Localização & $\begin{array}{c}\text { Barra candidata } \\
\text { interligação ao SEIN }\end{array}$ \\
\hline PARQUE LOMTAS 1 & IBEROPERUANA INVERSIONES S.A.C. & 200,0 & Centro-Sul & Ica & Ica 220 kV \\
\hline PARQUE OCUCAJE 1 & IBEROPERUANA INVERSIONES S.A.C. & 150,0 & Centro-Sul & Ica & Ica $220 \mathrm{kV}$ \\
\hline PARQUE OCUCAJE 2 & IBEROPERUANA INVERSIONES S.A.C. & 150,0 & Centro-Sul & Ica & Ica $220 \mathrm{kV}$ \\
\hline PAMPA POROMA & HUAYRA KALLPA S.A.C. & 200,0 & Centro-Sul & Ica & Marcona $220 \mathrm{kV}$ \\
\hline MARCONA & PERÚ ENERGÍA RENOVABLE S.A. & 100,0 & Centro-Sul & Ica & Marcona $220 \mathrm{kV}$ \\
\hline POROMA & SOLEOL S.A.C. & 50,0 & Centro-Sul & Ica & Marcona 220 kV \\
\hline TRES HERMANAS & HUAYRA KALLPA S.A.C. & 200,0 & Centro-Sul & Ica/Arequipa & Marcona $220 \mathrm{kV}$ \\
\hline
\end{tabular}

Fonte: (ESC, 2009). 
Quadro 7 - Usinas eólicas em estudo na zona sul do SEIN.

\begin{tabular}{|c|c|c|c|c|c|}
\hline Usina Eólica & $\begin{array}{c}\text { Proprietario da } \\
\text { Concessão }\end{array}$ & $\begin{array}{l}\text { Potência } \\
\text { (MW) }\end{array}$ & $\begin{array}{l}\text { ZONA } \\
\text { SEIN }\end{array}$ & Localização & $\begin{array}{c}\text { Barra candidata } \\
\text { interligação ao SEIN }\end{array}$ \\
\hline BELLA UNION & HUAYRA KALLPA S.A.C. & 200,0 & Sul & Arequipa & Marcona $220 \mathrm{kV}$ \\
\hline YAUCA & INVERSIONES TROY S.A.C. & 300,0 & Sul & Arequipa & Marcona $220 \mathrm{kV}$ \\
\hline PARQUE PUNTA LOMAS & IBEROPERUANA INVERSIONES S.A.C. & 240,0 & Sul & Arequipa & Caraveli 500 kV \\
\hline P. MIRAMAR DE SANTA MARIA & IBEROPERUANA INVERSIONES S.A.C. & 80,0 & Sul & Arequipa & Mollendo o Camaná 138 kV \\
\hline PARQUE ILO & ENERGÍA EÓLICA S.A. & 240,0 & Sul & Moquegua & Ilo $220 \mathrm{kV}$ \\
\hline ILO 1 & PERÚ ENERGÍA RENOVABLE S.A. & 200,0 & Sul & Moquegua & Ilo $220 \mathrm{kV}$ \\
\hline PARQUE PAMPA ALTA & SOWITEC ENERGÍAS RENOVABLES & 240,0 & Sul & Moquegua & Moquegua $220 \mathrm{kV}$ \\
\hline PARQUE ICLA & IBEROPERUANA INVERSIONES S.A.C. & 80,0 & Sul & Moquegua/Tacna & Moquegua $220 \mathrm{kV}$ \\
\hline PARQUETACNA & IBEROPERUANA INVERSIONES S.A.C. & 150,0 & Sul & Tacna & Los Héroes 220 kV \\
\hline
\end{tabular}

Fonte: (ESC, 2009).

Um dos últimos projetos aprovados pelo MEM para a realização de estudos técnicos e econômicos é o futuro parque eólico Estherfilia, localizado na costa norte do país, com potência instalável estimada de $750 \mathrm{MW}$.

Outro aspecto importante da energia eólica é sua integração na rede e a busca da operação no SEIN, sem maiores dificuldades de estabilidade e confiabilidade. Nesse sentido, em 2008 foi realizado o estudo para a determinação das quantidades de potência e energia admissíveis no SEIN a partir da inserção da energia eólica. Este estudo indicou uma potência máxima admissível na rede de 375 MW. Em 2009 este potencial foi ampliado para 640 MW após uma revisão feita pelo COES que finalmente estabeleceu este limite para as características atuais do sistema de transmissão até 2012.

Neste estudo não foi levada em consideração a expansão futura do sistema de transmissão do SEIN, porém, em cenários de médio e longo prazo uma maior expansão das redes permitiria uma inserção adicional de geração eólica. A localização dos projetos e recursos eólicos é distribuída ao longo da costa peruana de forma paralela ao sistema principal de transmissão, o que facilita a interligação dos futuros parques eólicos com o SEIN, como é mostrado na figura 28 , (Tech4CDM, 2009). 


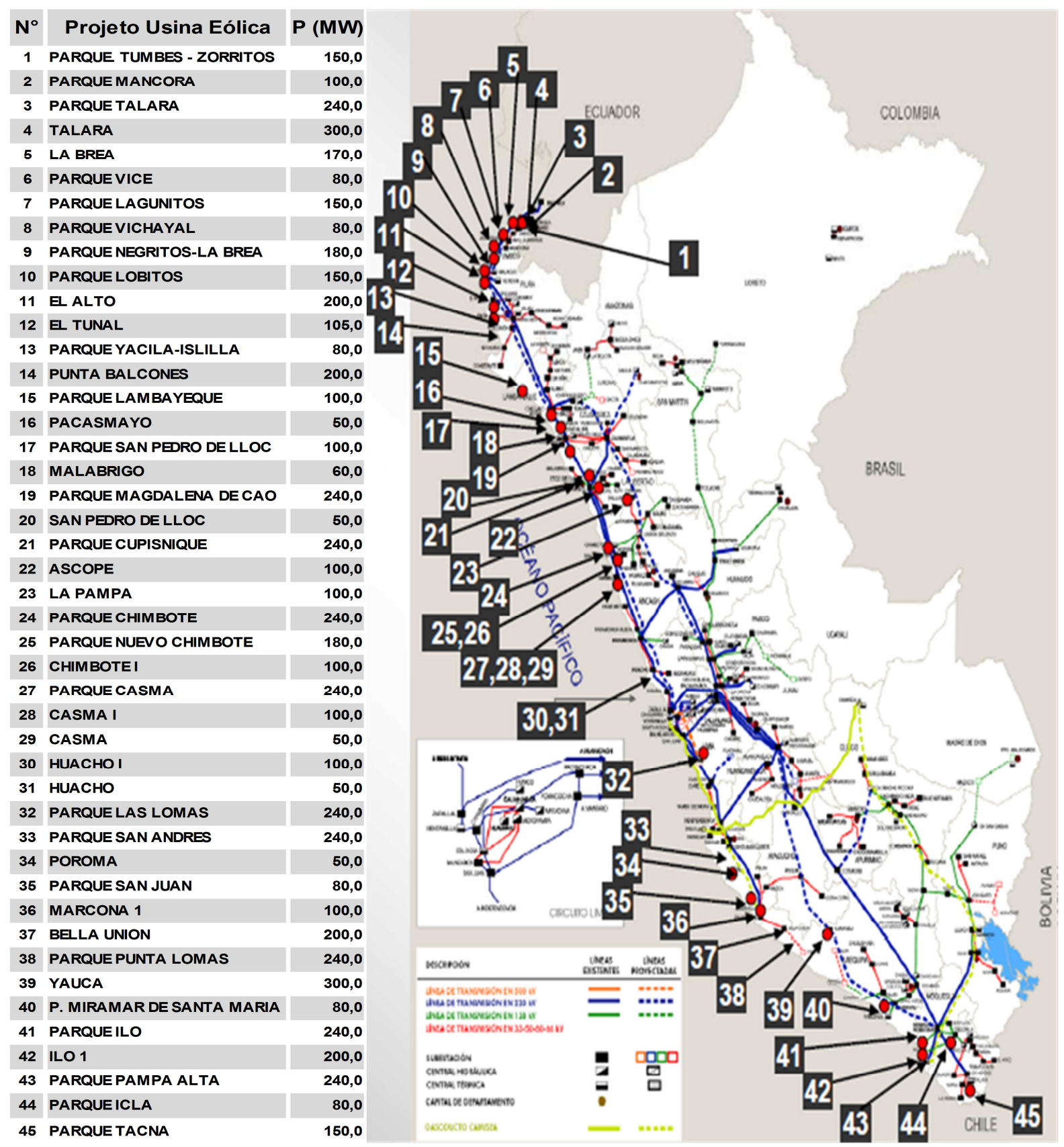

Figura 28 - Localização de projetos eólicos em estudos.

Fonte: Ministério de Energia e Minas (Peru).

\subsubsection{Leilões e Capacidade Contratada de Energia Eólica}

A geração eólica no Peru teve início em 1996 quando a Direção Executiva de Projetos (DEP) do Ministério de Energia e Minas (MEM) implementou o primeiro projeto piloto conhecido como Malabrigo com um gerador assíncrono 
trifásico de 250 kW de capacidade, instalado na costa norte do país. Posteriormente em 1999 a DEP instala o segundo projeto piloto San Juan de Marcona, com um gerador de indução de 450 kW de capacidade, instalado na costa sul.

No momento a capacidade instalada de geração eólica interligada ao SEIN segundo Tech4CDM (2009) está em torno de 1 MW, embora o país disponha de um potencial eólico instalável de $22 \mathrm{GW}$. O aproveitamento deste potencial ainda é baixo, o que vai mudar a médio e longo prazo com a construção de novos parques eólicos de grande porte. O setor elétrico peruano atualmente não tem geração eólica a nível comercial.

Em 2010 foi realizado pelo OSINERGMIN o primeiro leilão para contratar $500 \mathrm{MW}$ de capacidade de fontes renováveis de energia (RER), e o resultado foi a contratação de $142 \mathrm{MW}$ de energia eólica para o suprimento do SEIN com entrada em operação comercial em 2012, contrato fixo por um período de 20 anos, distribuídos em três parques eólicos que serão implantados pela primeira vez no Peru. Os preços ofertados da geração eólica nesse primeiro leilão variaram entre 65,52 e 87,00 US $\$$ MWh, como é apresentado no quadro 8.

Quadro 8 - Usinas eólicas vencedoras do primeiro leilão RER do SEIN.

\begin{tabular}{|c|c|c|c|c|c|c|}
\hline Usina Eólica & $\begin{array}{l}\text { Potência } \\
\text { (MW) }\end{array}$ & Barra SEIN & F.C. $(\%)$ & $\begin{array}{c}\text { Ener. Ofertada } \\
\text { (GWh/Ano) }\end{array}$ & $\begin{array}{c}\text { Preço Ofertado } \\
\text { US\$/MWh }\end{array}$ & $\begin{array}{c}\text { Data - Operação } \\
\text { Comercial }\end{array}$ \\
\hline U.E. MARCONA & 32,0 & Marcona $220 \mathrm{kV}$ & 52,93 & 148,378 & 65,52 & $1 / 12 / 2012$ \\
\hline U.E. TALARA & 30,0 & Talara 220 kV & 46,00 & 119,673 & 87,00 & 29/6/2012 \\
\hline U.E. CUPISNIQUE & 80,0 & Guadalupe $220 \mathrm{kV}$ & 43,00 & 302,952 & 85,00 & 29/6/2012 \\
\hline Total a Instalar & 142 MW & \multicolumn{3}{|c|}{ Preco Medio US\$/MWh } & 79,17 & \\
\hline
\end{tabular}

Fonte: OSINERGMIN, 2010.

E recentemente em 2011, foi realizado o segundo leilão de energias renováveis (RER) para o suprimento do SEIN, com participação de (06) projetos eólicos, sendo que o vencedor foi o projeto de parque eólico Três hermanas de 90 MW de capacidade, com preço de 69 US $\$ / M W h$. Vale frisar ainda que o projeto dispõe de contrato fixo por um período de 20 anos, e tem sua entrada em operação comercial prevista para dezembro de 2014; localizado na costa sul do Peru. Uma característica interessante do projeto eólico vencedor é o fator de capacidade 
ofertada de $52,73 \%$, que é um valor bem mais alto que a média geral dos parques eólicos que têm fatores de capacidade entre 30 e $40 \%$, como é apresentado no quadro 9 a seguir.

Quadro 9 - Usina eólica vencedora do segundo leilão RER do SEIN.

\begin{tabular}{|c|c|c|c|c|c|c|}
\hline Usina Eólica & $\begin{array}{c}\text { Potência } \\
\text { (MW) }\end{array}$ & Barra SEIN & F.C. (\%) & $\begin{array}{c}\text { Ener. Ofertada } \\
\text { (GWh/Ano) }\end{array}$ & $\begin{array}{c}\text { Proço Ofertado } \\
\text { US\$/MWh }\end{array}$ & $\begin{array}{c}\text { Data - Operação } \\
\text { Comercial }\end{array}$ \\
\hline TRES HERMANAS & 90,0 & Marcona 220 kV & 52,73 & 415,76 & 69,0 & $31 / 12 / 2014$ \\
\hline
\end{tabular}

Fonte: OSINERGMIN, 2010.

Os leilões de energias renováveis (RER) permitiram a contratação dos primeiros parques eólicos a serem implantados no Peru, diversificando a matriz elétrica peruana mediante o uso de fontes energéticas renováveis que contribuirão com o uso eficiente de outros recursos, como o gás natural.

\subsection{GERAÇÃO TERMELÉTRICA A GÁS NATURAL NO PERU}

Em 1975 entrou em operação a primeira usina termelétrica a gás natural do setor elétrico peruano, a UTE Malacas, localizada a $1120 \mathrm{~km}$ ao norte da cidade de Lima, que vem utilizando o gás proveniente das jazidas da costa norte do Peru. Esta usina conta com três unidades de turbinas a gás em ciclo simples de 19,35 MW de capacidade cada, que totalizava $58 \mathrm{MW}$ de potência instalada. No entanto, a evolução em larga escala da geração termelétrica com gás natural é recente, possibilitado pelo inicio da operação em 2004 do gasoduto que transporta o gás natural da jazida de Camisea à cidade de Lima.

O gasoduto (Camisea - Lima) possibilitou a construção de novas usinas termelétricas, assim como a adaptação das usinas que utilizavam outros combustíveis dentre eles o diesel e óleo combustível para o uso do gás natural. Desde então, a implantação das termelétricas a gás natural tem crescido dinamicamente e esta constitui atualmente a segunda fonte mais importante de geração elétrica do Peru. 


\subsubsection{O Gás Natural no Peru}

O gás natural no Peru teve pouco desenvolvimento até o início da exploração das jazidas de Camisea. Até esse momento a indústria do gás natural era dependente de duas jazidas: a jazida Aguaytia, localizada na floresta amazônica central e as jazidas da costa noroeste. A exploração e produção limitavam-se aos aproveitamentos locais em processamento de produtos líquidos derivados do combustível e, em menor proporção, à geração de energia elétrica em usinas termelétricas instaladas perto das jazidas.

A quantidade de reservas menores e a demanda reduzida do combustível inviabilizavam o transporte em dutos até os principais lugares de demanda ou cidades importantes que poderiam aproveitar melhor o recurso energético.

Atualmente, o gás natural no Peru é produzido em três áreas geográficas: na zona da costa do noroeste peruano (jazidas de Talara), na floresta amazônica central (jazida Aguaytia) e nas jazidas da floresta amazônica sul (jazidas de Camisea) como é mostrado na figura 29.

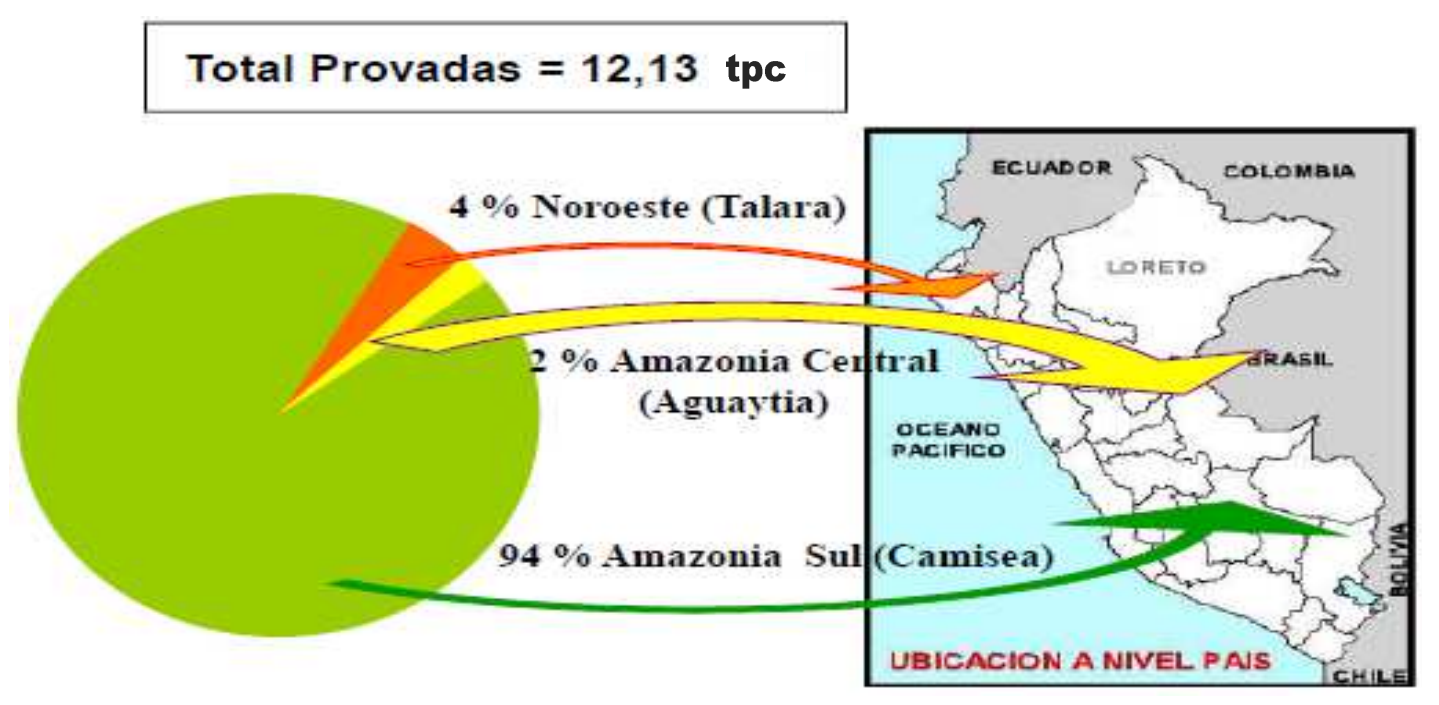

Figura 29 - Localização e participação das jazidas de gás natural no Peru. * tpc: Trilhões de pés cúbicos.

Fonte: Ministério de Energia y Minas Perú, 2010. 
Camisea é atualmente a jazida mais importante de gás natural no Peru. Sua descoberta data entre os anos 1984 e 1987, na floresta amazônica da região de Cusco, a $431 \mathrm{~km}$ a leste da cidade de Lima. A operação comercial da jazida teve início em agosto de 2004 com a chegada do combustível à cidade de Lima, após a inauguração do duto de transporte e sua disponibilidade para seu uso comercial, (OSINERGMIN, 2010a).

A produção inicial de gás natural em Camisea foi de $450 \mathrm{MMPCD}^{34}$, inicialmente utilizada para a geração de eletricidade em usinas termelétricas instaladas perto do ponto principal de chegada e distribuição do gás na cidade de Lima, (CAMISEA, 2010).

O transporte do gás natural desde as jazidas de Camisea até a cidade de Lima é realizado por meio de dois gasodutos, um com $714 \mathrm{~km}$ de extensão para transporte de gás natural e outro de $540 \mathrm{~km}$ de extensão para transporte dos líquidos de gás natural. Os dois gasodutos foram construídos em paralelo desde os campos de Camisea até a costa peruana. O gasoduto de GN líquido termina numa planta de fracionamento a $200 \mathrm{~km}$ ao sul de Lima, dali o gasoduto de gás segue para o norte e segue paralelamente à costa até um City Gate em Lima, como é mostrado na figura 30, (CAMISEA, 2002).

$34 \quad$ Milhões de pés cúbicos diários 


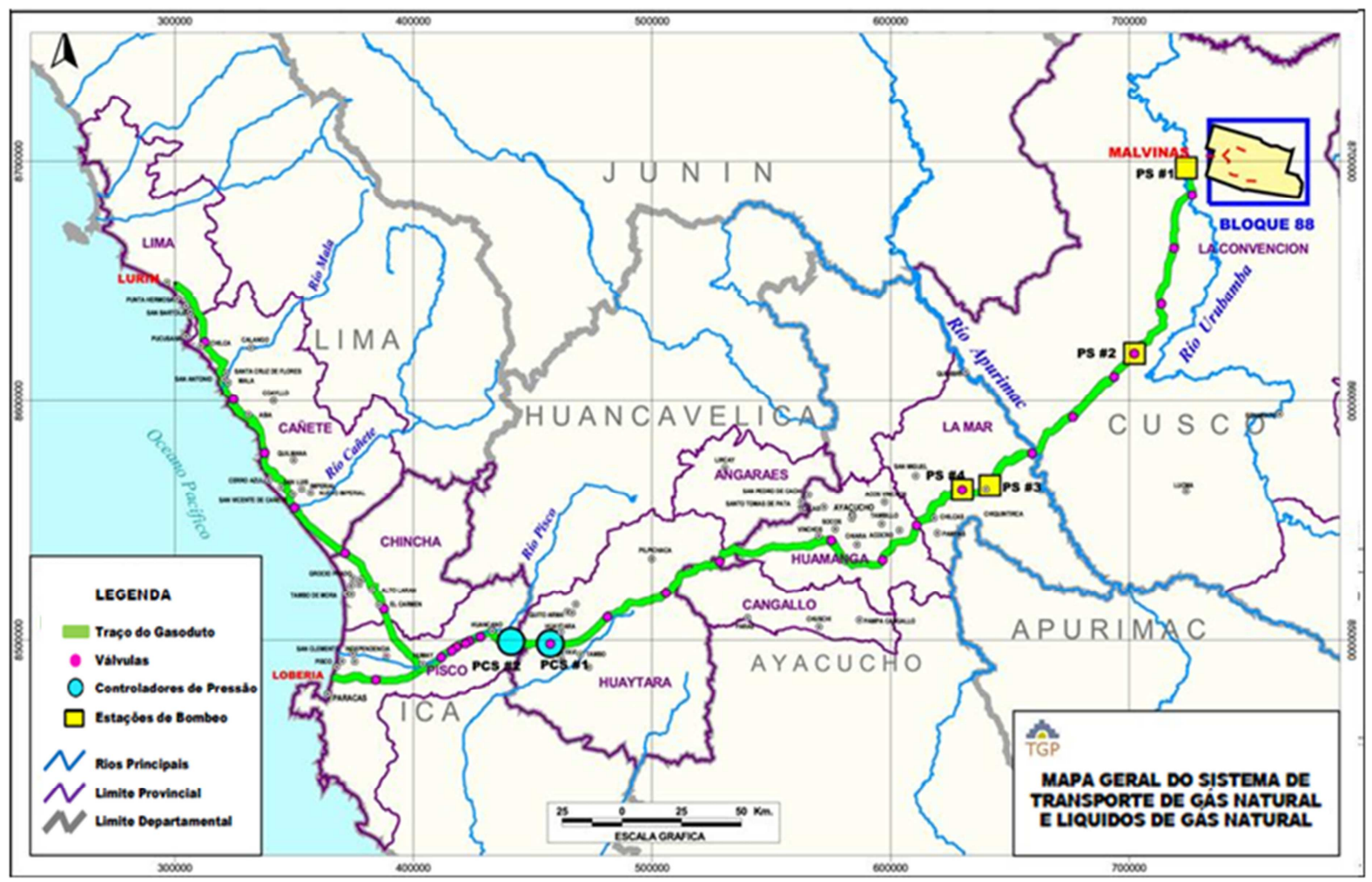

Figura 30 - Mapa do gasoduto de transporte de gás natural (Camisea - Lima).

Fonte: Projeto Camisea, disponível em: http://www.camisea.pluspetrol.com.pe/

O total das reservas provadas de gás natural até 2010 no Peru foi de 12,13 trilhões de pés cúbicos (tpc), sendo a jazida de Camisea a mais importante pela quantidade de reservas de gás natural em comparação às outras jazidas como é mostrado na tabela 6 .

Tabela 6 - Reservas de gás natural no Peru em $\left(\operatorname{tpc}^{35}\right)$.

\begin{tabular}{lccc}
\hline \multicolumn{1}{c}{ ZONA } & $\begin{array}{c}\text { PROVADAS } \\
\text { (tpc ) }\end{array}$ & $\begin{array}{c}\text { PROVÁVEIS E } \\
\text { POSSÍvEIS } \\
\text { (tpc) }\end{array}$ & $\begin{array}{c}\text { TOTAL } \\
\text { RESERVAS } \\
\text { (tpc) }\end{array}$ \\
\hline Norooeste & 0,51 & 5,95 & 6,46 \\
Amazonia Central & 0,44 & 0,14 & 0,36 \\
Amazonia Sul & & & \\
$\quad$ Camisea (Lote 88) & 8,73 & 5,88 & 14,61 \\
$\quad$ Camisea (Lote 56) & 2,45 & 1,54 & 3,99 \\
Outras áreas & & 7,46 & 7,46 \\
Total País & $\mathbf{1 2 , 1 3}$ & $\mathbf{2 0 , 9 7}$ & $\mathbf{3 2 , 4 3}$ \\
\hline
\end{tabular}

Fonte: Elaboração própria com dados do MEM e Osinergmin, 2010.

35 Trilhões de pés cúbicos 
As reservas de gás natural dos lotes 88 e 56 de Camisea ${ }^{36}$ são sem dúvida as maiores jazidas de gás natural exploradas até o momento no Peru, permitindo a evolução do setor energético peruano em sua organização segmentalmente vertical de quatro fases: exploração, produção, transporte, e distribuição até o usuário final, por intermédio de dutos de transporte desde a jazida de Camisea até os pontos de consumo.

As características do gás natural entre as jazidas apresentam diferenças. As reservas do noroeste caracterizam-se pelo gás natural associado com o petróleo cru, e as reservas de Aguaytía e Camisea têm as características de serem gás não associado, pelo que a composição do gás natural de Camisea tem maior presença de metano, acima de $80 \%$ o que é mostrado na tabela 7 .

Tabela 7 - Composição das reservas de gás natural de Camisea.

\begin{tabular}{|c|c|c|c|}
\hline Composição & $\begin{array}{c}\text { Bloco } 88 \\
\text { San Martin (\%) }\end{array}$ & $\begin{array}{c}\text { Bloco } 88 \\
\text { Cashiriari (\%) }\end{array}$ & $\begin{array}{c}\text { Total } \\
(\%)\end{array}$ \\
\hline Nitrogênio & 0,55 & 0,73 & 0,64 \\
\hline Dióxido de Carbono & 0,18 & 0,27 & 0,23 \\
\hline Metano & 80,59 & 83,34 & 81,97 \\
\hline Etano & 9,80 & 8,39 & 9,10 \\
\hline Propano & 3,80 & 3,00 & 3,40 \\
\hline Butano & 1,70 & 1,28 & 1,49 \\
\hline Gasolina natural & 3,38 & 2,99 & 3,19 \\
\hline Total & 100 & 100 & 100 \\
\hline
\end{tabular}

Fonte: (BELTRÁN, 2004).

A exploração das jazidas de Camisea do Peru possibilitou, além do aproveitamento de seus recursos, a diversificação da matriz energética peruana e ajudou a diminuir sua dependência da importação do petróleo. A geração de eletricidade com gás natural de Camisea também trouxe mudanças importantes na

36 Jazida adjudicada no ano 2000 para a exploração ou produção até 40 anos, ao consorcio Camisea, formado por PLUSPETROL 36\% (Argentina), Hunt Oil Co. 36\% (EE.UU.), SK CorP. 18\% (Corea) e Hidrocarburos Andinos 10\% (Argentina). O transporte e distribuição por 33 anos, no caso do transporte ao consórcio liderado por Techint 30\% (Argentina), PLUSPETROL 19,2\% (Argentina), Hunt Oil Co. 19,2\% (EE.UU.), SK CorP. 9,6\% (Corea), Sonatrach 10\% (Argélia) e Graña y Montero 12\% (Perú). Após a conformação do consórcio, foi constituída a empresa Transportadora de Gás do Perú (TGP). A distribuição de gás natural na cidade de Lima foi concedida à Tractebel (Grupo Suez, Bélgica) em 2002, posteriormente foi constituída a empresa Gás Natural de Lima e Callao S.A. (Cálidda). 
matriz elétrica nacional, permitindo ter uma fonte complementar à hidroeletricidade com menores custos finais de energia e impactos ambientais.

Como em outros países da América Latina, a indústria energética do Peru sofreu profundas transformações na década de 1990. Novos mecanismos de regulação viabilizaram a transição de um controle central (predomínio estatal com alguma participação privada) em direção a um mercado mais aberto, livre e competitivo.

Nesse sentido, adotou-se uma estrutura de produção, transporte e comercialização do gás seguindo a cadeia de valor do gás natural, configurada nos segmentos característicos do mercado de gás em upstream (exploração e produção), midstream (transporte e logística) e downstream (refino, distribuição e comercialização), (ZAMALLOA, 2004).

O mercado do gás natural no Peru compreende dois grandes segmentos, o mercado elétrico que compreende o uso do GN para a geração de eletricidade, e o mercado não elétrico, que compreende o uso do GN nos setores doméstico, comercial, industrial, e uso automotivo. Atualmente o gás natural liquefeito (LNG) tem sido também exportado ao mercado internacional, como é mostrado na tabela 8.

Tabela 8 - Consumidores do gás natural de Camisea.

\begin{tabular}{lcc}
\hline Principais Consumidores & MMPCD & $\%$ \\
\hline Industrial, Residencial, Transporte & 221,6 & 23,5 \\
Setor Elétrico & 141,5 & 15,0 \\
Exportação & 580,0 & 61,5 \\
\hline Total & $\mathbf{9 4 3 , 1}$ & $\mathbf{1 0 0 , 0}$ \\
\hline
\end{tabular}

Fonte: (OSINERGMIN, 2011b).

* Consumos médios diários de dezembro 2010.

Verifica-se que a participação do gás natural de Camisea no setor elétrico é de 15\%, no setor industrial, comercial e transporte de 23,5\%, e na exportação de $61,5 \%$, participação baseada no consumo médio diário registrado em dezembro de 2010. 
O consumo do gás natural no Peru nos últimos anos teve um crescimento acentuado, principalmente na geração de energia elétrica do SEIN, conforme mostra a figura 31 a seguir. Nesta verifica-se a evolução e o consumo total de gás natural no setor elétrico desde 1998 até 2010 tendo uma participação maior do gás natural de Camisea.

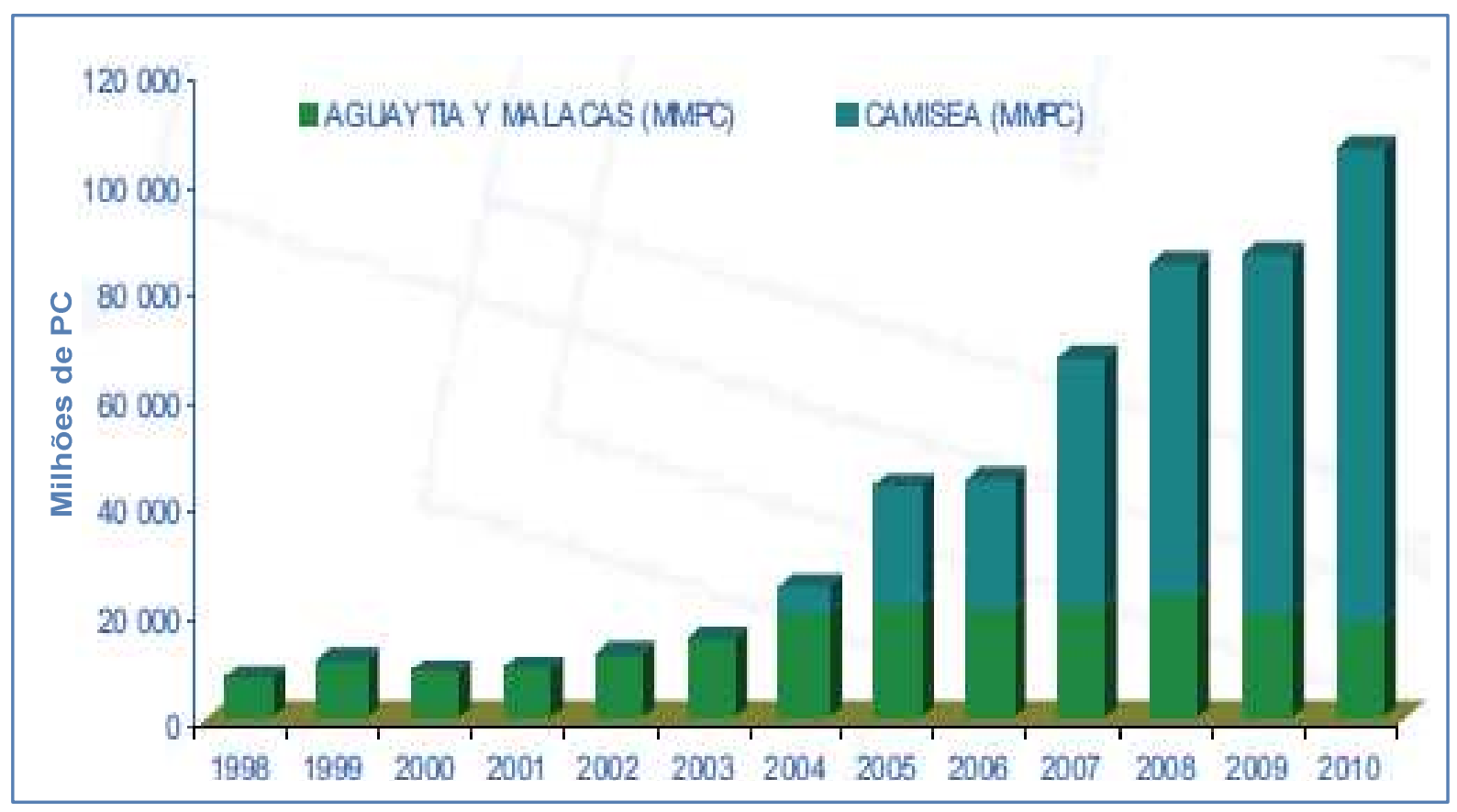

Figura 31 - Evolução de consumo de gás natural no setor elétrico.

$\overline{\text { Fonte: (COES, 2011). }}$

A expansão da geração termelétrica a gás natural atualmente depende, de forma direta, da disponibilidade futura das reservas provadas e disponíveis do gás natural de Camisea. O planejamento da expansão da geração do setor leva em conta os custos do gás competitivos, bem como a ampliação da capacidade de transporte do gasoduto, e a construção de novos gasodutos regionais que proporcionam um maior aproveitamento do recurso a curto prazo.

Segundo o Ministério de Energia e Minas do Peru, considera-se no planejamento de curto e médio prazo do SEIN a expansão de gasodutos regionais com a construção de gasodutos provenientes da jazida de Camisea até as três principais zonas do país, como é mostrado na figura 32. 


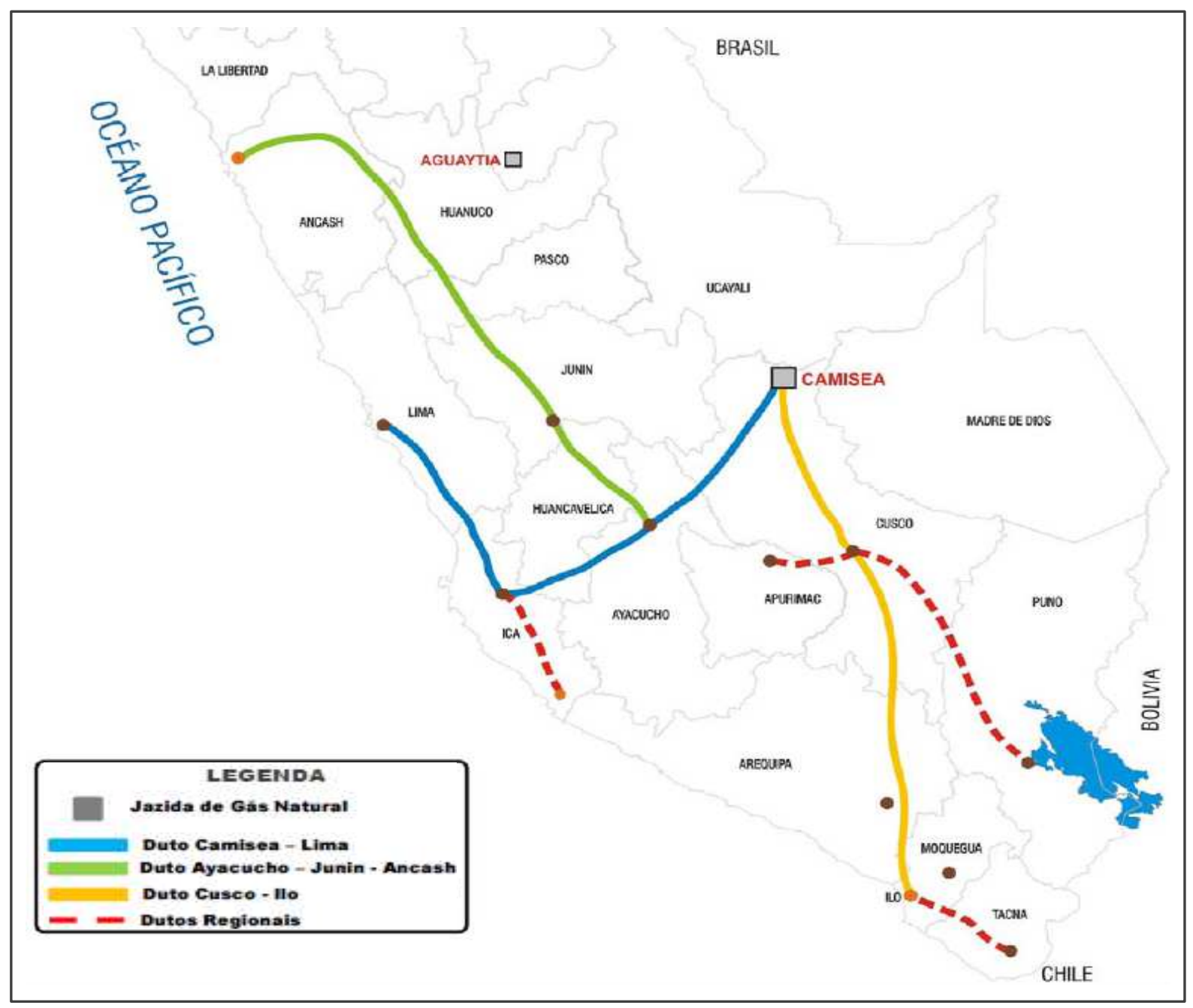

Figura 32 - Plano de expansão de gasodutos no Peru.

Fonte: Ministério de Energia e Minas (Peru)

A atual capacidade de transporte do gasoduto limita uma maior expansão do consumo de gás natural de Camisea a curto prazo. Por outro lado a médio prazo, segundo as projeções feitas pelo MEM, a capacidade disponível do gás para a geração elétrica tem limites que restringem a uma quantidade quase fixa a utilização do gás, apresentando uma oferta garantida ${ }^{37}$ em torno de 500 MMPCD. No entanto a longo prazo a partir de 2017 até 2028 esta quantidade poderia aumentar com a oferta remanescente possível e disponível, já que a máxima produção estimada da jazida em 2028 será 2348 MMPCD, como é mostrado na figura

37 Oferta que só considera a projeção da produção dos lotes 56 e 88, da jazida de Camisea, sem incluir a produção futura de outros lotes vizinhos em exploração que ainda não contam com certificação. 


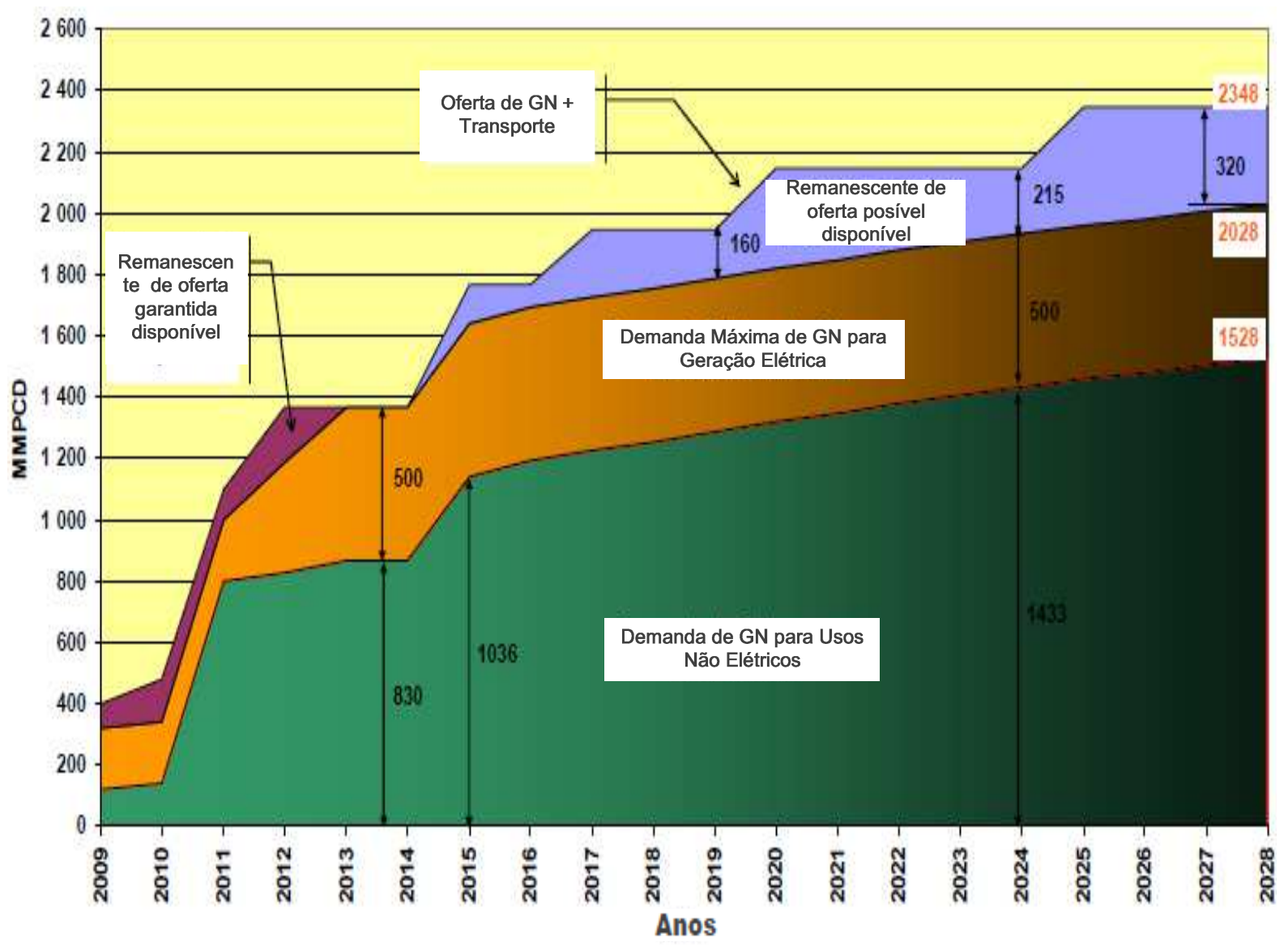

Figura 33 - Oferta máxima garantida de gás natural de Camisea.

Fonte: Ministério de Energia e Minas (Peru)

O preço do gás natural no mercado peruano na jazida ou boca de poço não é regulado pelo OSINERGMIN, já que é determinado de forma livre, segundo o contrato de licença de exploração e produção do consórcio. O contrário acontece com os preços e tarifas do gás, no transporte e distribuição que são regulados e determinados pelo marco normativo do setor formado pelas leis, regulamentos e resoluções de cumprimento obrigatório por todos os agentes que participam da indústria do gás natural, nas diferentes zonas de concessão, (OSINERGMIN, 2010a).

A atual normativa estabelece que a rede principal de transmissão elétrica do SEIN tem uma remuneração parecida ao de tipo Selo Postal. Por outro lado, existe concorrência entre os custos da transmissão elétrica e os de transporte de gás natural, já que ambos competem por reduzir os custos finais de fornecimento elétrico, pelo que, para igualdade de condições, o transporte de gás também utiliza a remuneração tipo Selo Postal, essa é a razão pela qual são socializados os custos 
do transporte do gás entre todos os consumidores, (PERU MINISTERIO DE ENERGIA Y MINAS, 2009).

Atualmente o preço do gás natural de Camisea para geração elétrica é único em todos os pontos de consumo do SEIN, adotando o método de Preço "Selo Postal"38, tarifa que inclui os preços na boca do poço em Camisea, todos os custos de transporte pela rede de gasodutos principais existentes, e o custo do reforço destes e os novos gasodutos regionais.

Também é importante indicar que o preço do gás natural de Camisea dos lotes 88 e 56 são regulamentados, no entanto diferenciado para o uso em geração elétrica e para os outros consumidores, e foram fixados conforme o contrato de exploração subscrito entre o governo e o consórcio explorador da jazida. Atualmente as usinas termelétricas pagam US\$1.60 por MMBTU na boca de poço pelo preço do gás, enquanto os industriais pagam US\$2.40 por MMBTU.

No entanto, a implantação de gasodutos regionais, aplicando o critério de tarifas de tipo "Selo Postal", incrementará os custos dos pedágios de transporte do gás do SEIN, e em consequência também da tarifa final do gás natural aos geradores, o que vai acontecer a partir de 2013.

Por outro lado, considera-se que os preços estimados pelo MEM para o gás natural das outras jazidas, noroeste (Talara-Tumbes) e Amazônia central (Aguaytía) mantenham-se a preços constantes, dado que estes estão associados à produção de líquidos combustíveis.

Com a finalidade de comparar os preços do gás natural de Camisea com preços equivalentes relacionados com o mercado internacional foram determinados e estimados pelo MEM os preços refletidos do preço de referência internacional Henry Hub (net-back) na costa peruana, sob a premissa de que o Peru exporta gás natural. Na figura 34, é apresentado o esquema dos preços projetados de gás natural e sua comparação com a referência do mercado internacional "Henry Hub"39.

Ao entender que o valor da valorização global (net-back) é adotado para a precificação do gás no Peru, e que ele tem o princípio fundamental para composição dos preços do gás natural em estruturas monopólicas, onde a formação

O método Selo Postal vem sendo usado para a tarifação do gás no Peru.

É o preço do gás natural no mercado Spot de Henry Hub, sendo ele o maior mercado spot e de futuros de gás natural dos Estados Unidos. Muitos intermediários de gás natural também empregam o Henry Hub como seu ponto de entrega física do contrato ou seu preço de comparação para suas transações spot de gás natural. 
de preços de gás é realizada pela dedução dos custos de transporte e distribuição e comparada com o preço médio das energias concorrentes no mercado final, calculase este preço em cada etapa da cadeia, onde são retirados todos os custos de distribuição, transporte, armazenagem do gás e impostos, mais um lucro razoável para as companhias transmissoras e distribuidoras. Desta forma, o valor "net-back" é um modelo de precificação característico de situações de monopólio, já que a base para formação dos preços é um energético semelhante e regulado, (ROCHA, et al., 2003).

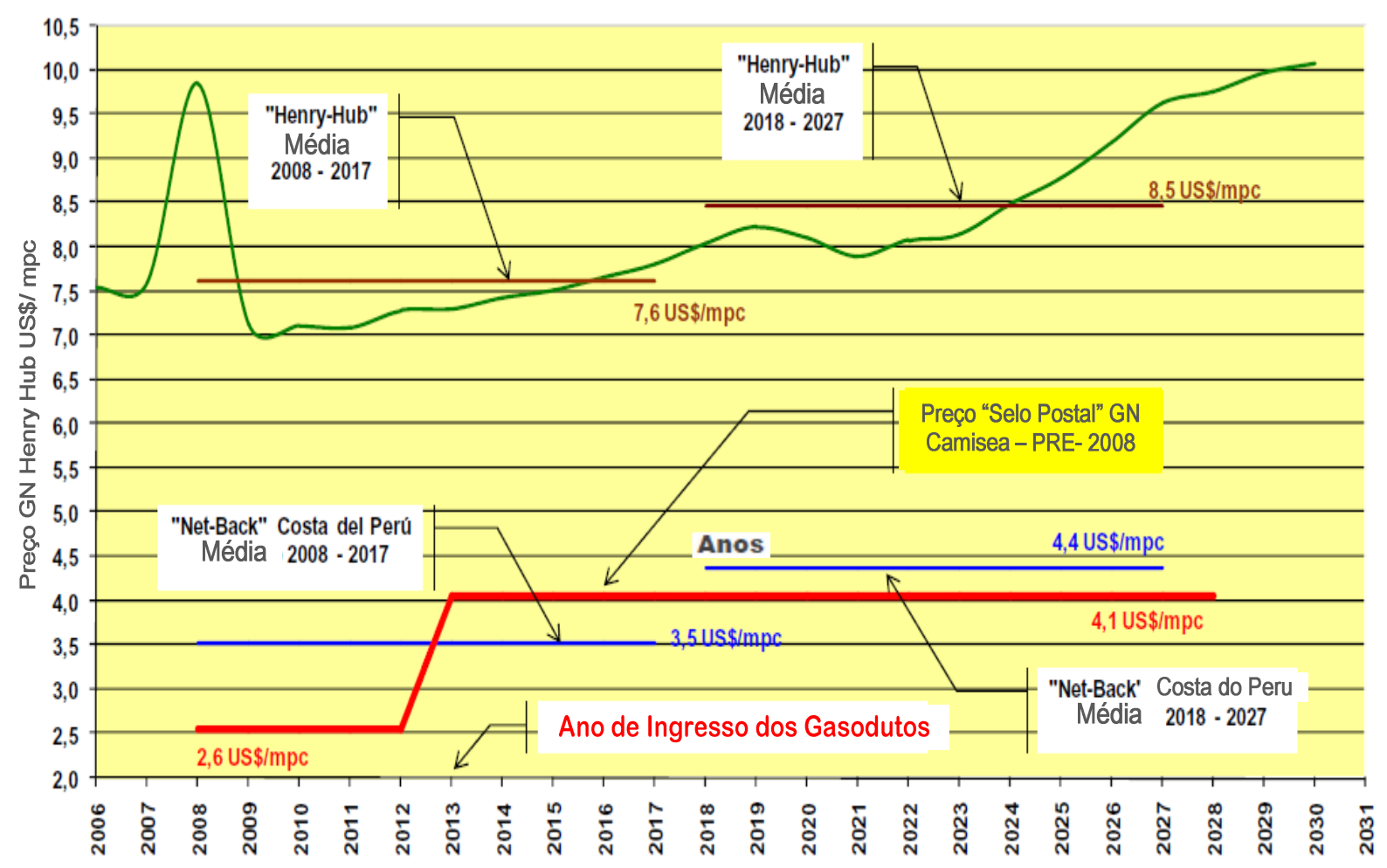

Figura 34 - Projeção do preço do GN de Camisea em referencia internacional "Henry Hub".

Fonte: (PERU MINISTERIO DE ENERGIA Y MINAS, 2009).

Para a projeção do preço de referência Henry Hub foi adotada a projeção de custos do EIA, obtendo como custos médios nos períodos (2008 - 2017) e (2018-2027), 7,6 US $\$ / \mathrm{mpc}$ e 8,5 US $\$ / \mathrm{mpc}$, respectivamente. Estes preços refletidos na costa peruana a preços "net-back" resultam em 3,5 US $\$ /$ mpc e 4,4 US $\$ / \mathrm{mpc}$, para os mesmos períodos, respectivamente. A diferença do valor "netback" entre o preço de referência internacional e o preço refletido no Peru estimou-se em 4,1 US\$/mpc, (PERU MINISTERIO DE ENERGIA Y MINAS, 2009). 
Então, pelos cálculos feitos pelo MEM, os valores dos preços do gás natural na costa peruana, projetados para o cenário de médio e longo prazo encontram-se dentro da faixa dos preços de referência do mercado internacional, refletidos no Peru.

A disponibilidade de gás natural para o curto prazo, oriunda das jazidas exploradas de Camisea com reserva certificada garantida, tem o preço do gás relativamente baixo e com tempo de exploração conhecido. Embora no médio prazo o incremento da oferta de gás natural de Camisea dependerá dos resultados das explorações em curso, os quais se apresentam auspiciosos em reservas e produção, mesmo que o custo do GN seja baixo, se comparado aos outros energéticos.

No longo prazo, pelo fato de serem desconhecidos os resultados futuros das explorações de novas jazidas de gás, bem como a evolução da demanda, a incerteza da disponibilidade para expansão da geração a longo prazo é relativamente alta, além disso, depende também dos custos de oportunidade do gás natural inclusos nos preços internacionais, tornando difícil estimar os custos futuros do gás natural.

Atualmente a regulação tarifária no transporte, distribuição e supervisão do mercado de gás natural é realizada pelo OSINERGMIN. Algumas das primeiras leis mais importantes da regulação no setor são: a lei orgânica de hidrocarbonetos, promulgada em agosto de 1993, e a lei $n^{\circ} 27133$, conhecida por lei de promoção do desenvolvimento da indústria do gás natural, promulgada em junho de 1999.

A participação do Estado é feita através do Ministério de Energia e Minas (MEM), pela Direção Geral de Hidrocarbonetos (DGH), órgão concedente, promotor e normativo do setor, encarregado das concessões, licenças para exploração e todas as atividades relacionadas aos hidrocarbonetos.

A inserção do gás natural na matriz elétrica peruana permitiu a redução da volatilidade dos preços da energia que enfrentavam os usuários elétricos, já que a utilização do gás natural em usinas de ciclo simples e combinado permitiu atenuar a volatilidade do preço no mercado "spot" de eletricidade e atenuar as flutuações abruptas do preço da eletricidade nos períodos de estiagem.

A característica evolutiva da participação do gás natural na produção de eletricidade do SEIN nos últimos dez anos é apresentada na figura 35. 


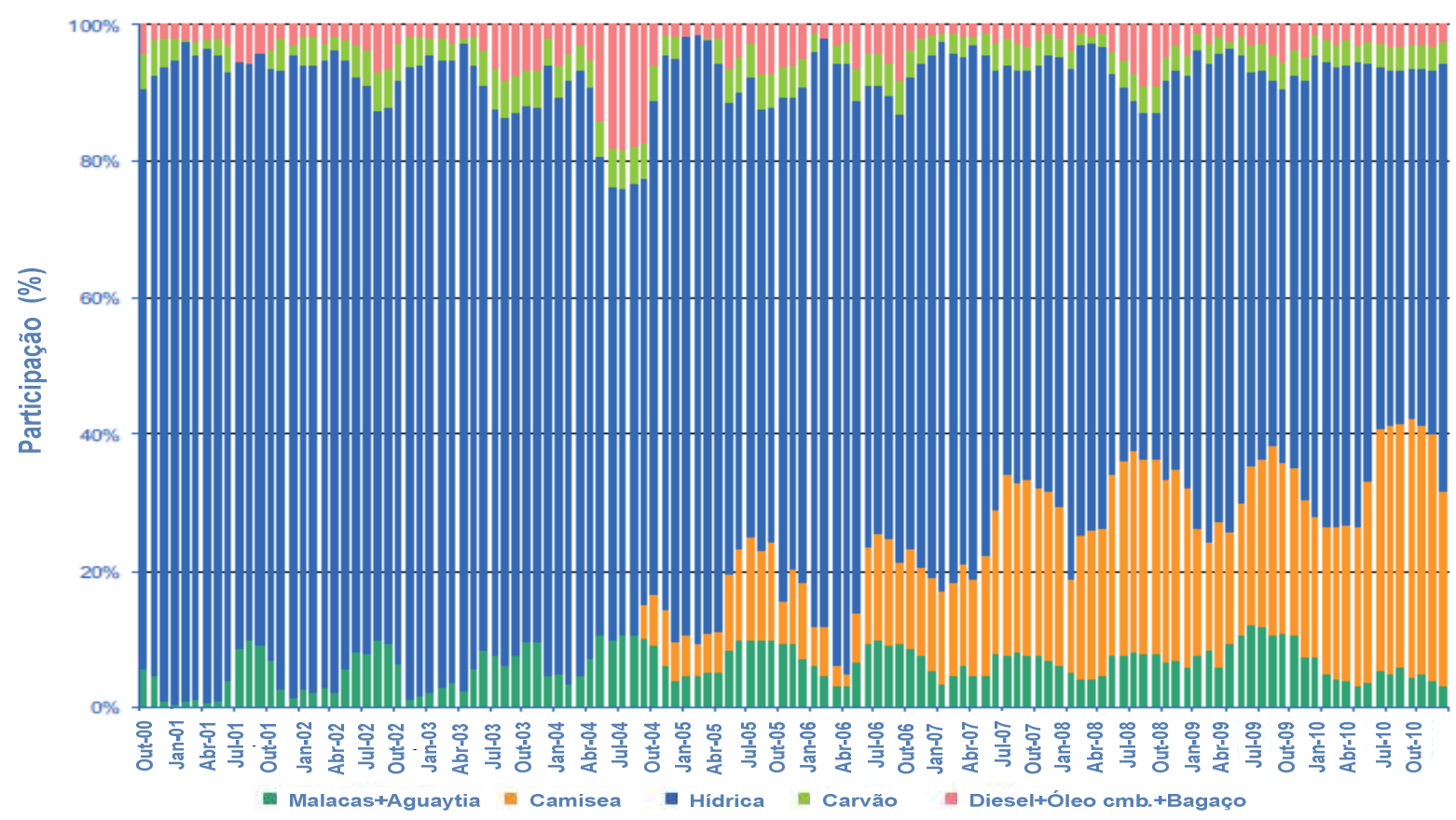

Figura 35 - Evolução da participação porcentual do GN na produção de energia do SEIN (GW.h) Fonte: (COES, 2011)

\subsubsection{Expansão da Geração Termelétrica}

A expansão da geração termelétrica a gás natural no Peru é determinada principalmente pela disponibilidade do combustível com reservas provadas consideráveis, o acesso a elas com a viabilização da construção do gasoduto e a atratividade dos custos baixos advindos do gás das jazidas de Camisea comparados a outros combustíveis, transformando assim o sistema elétrico peruano em um sistema hidrotérmico, (PERU MINISTERIO DE ENERGIA Y MINAS, 2010).

Cabe assinalar que até ao final da década de 90 a capacidade instalada das termelétricas a gás natural no Peru tinha uma participação bem menor em relação ao total nacional. As usinas termelétricas implantadas até essa época eram à base de combustíveis líquidos, principalmente diesel e óleo combustível, e ainda a pequena participação do carvão e do gás natural, até então sem participação das jazidas de gás de Camisea. 
A partir da exploração do gás de Camisea o panorama energético mudou no Peru, tanto que a capacidade instalada do SEIN evoluiu consideravelmente, passou de um sistema com predominância hídrica no início da década a um sistema hidrotérmico com forte participação do gás natural de Camisea. Atualmente, a geração elétrica com gás conta com uma participação na potência efetiva total do SEIN de $42 \%$, como é apresentado na figura 36 .

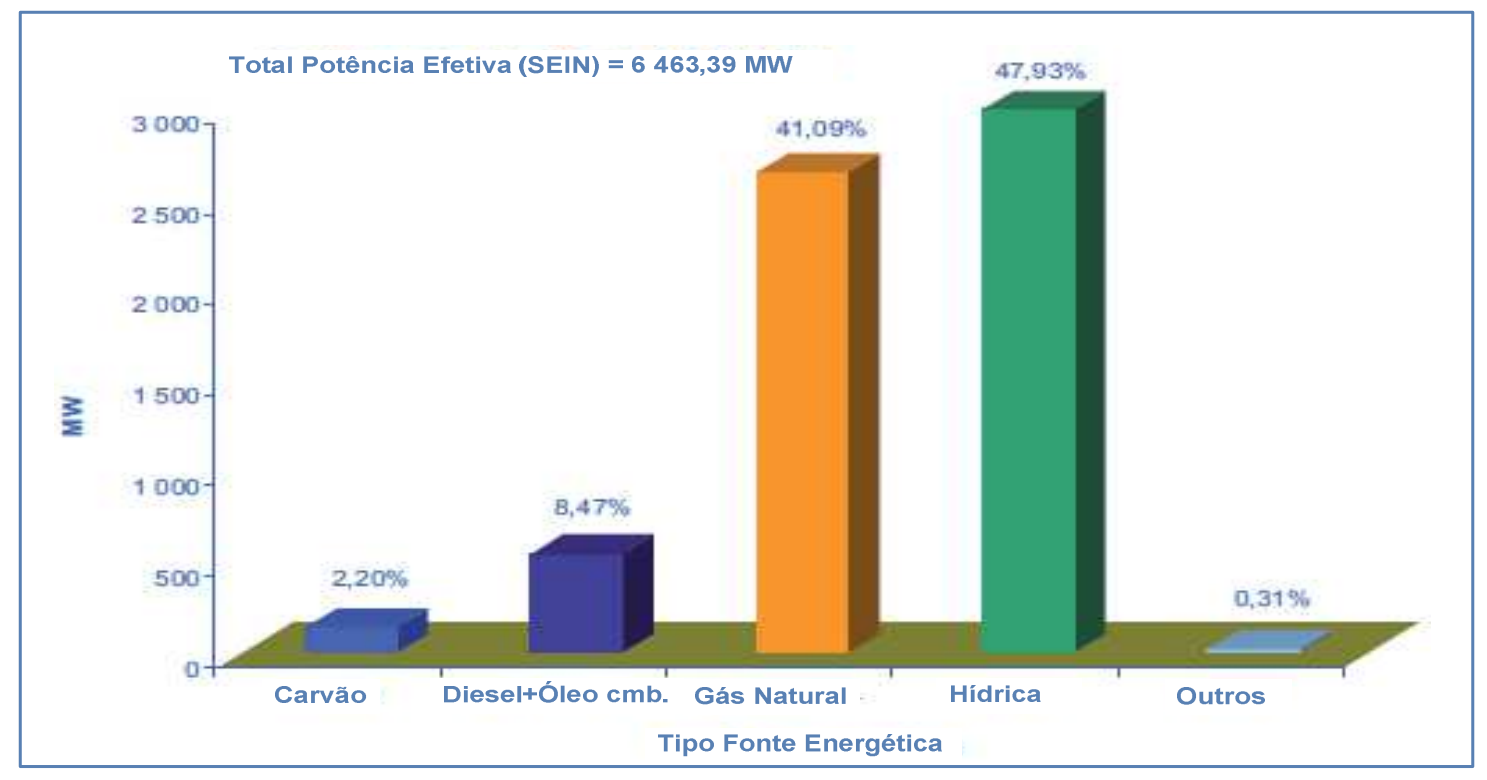

Figura 36 - Distribuição da potência efetiva por tipo de fonte energética do SEIN.

Fonte: (COES, 2011)

As perspectivas da expansão da geração no Peru realizadas pelo MEM num balanço energético de potência e demanda do SEIN são apresentados na figura 37. Verifica-se para o período entre 2010 e 2019 as previsões de expansão da geração termelétrica no SEIN.

No cenário mais curto, no período entre 2010 e 2013, é prevista a construção e entrada em operação de quantidades consideráveis de capacidade termelétrica que utilizarão o gás natural de Camisea, com participação de usinas novas em ciclo simples e de ciclo combinado.

No período de 2014 e 2019 no cenário de médio prazo a expansão da geração termelétrica a gás natural terá origem na construção de gasodutos para o Sul e Norte do País, o que permitirá uma maior expansão e descentralização desta fonte energética, já que atualmente sua utilização está focada e centralizada nas zonas central e centro-sul do país. 
Quanto ao cenário de longo prazo espera-se que as explorações de novas jazidas permitam a certificação de mais reservas provadas de gás natural e contribuam com a expansão da termeletricidade no SEIN.

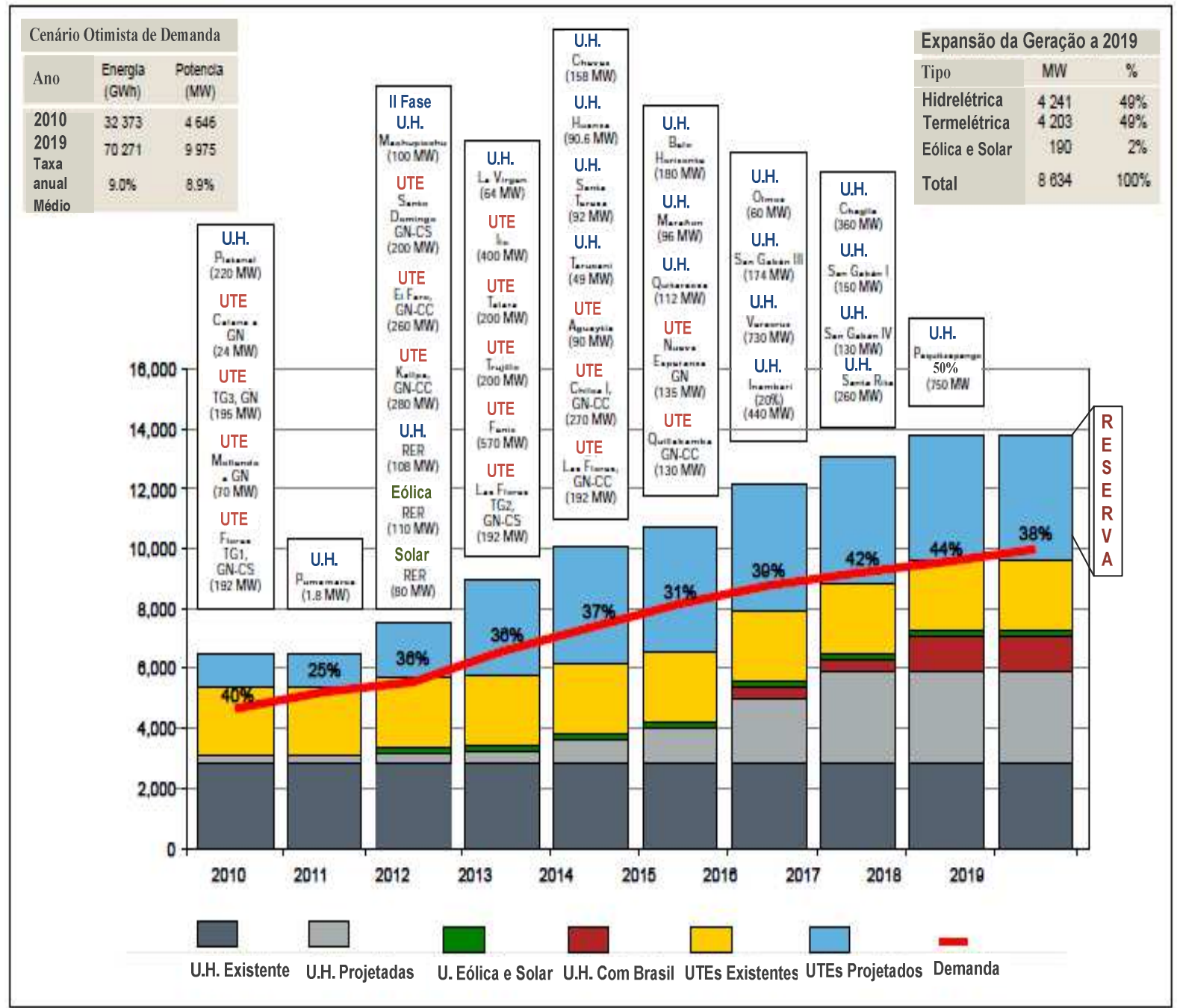

Figura 37 - Balanço energético de potência - demanda do SEIN para o período 2010 - 2019.

Fonte: (PERU MINISTERIO DE ENERGIA Y MINAS, 2010a).

De acordo com a figura 37, as projeções e estimativas feitas pelo MEM no caso da expansão da geração do SEIN prevêm o incremento de capacidade de geração de 8634 MW no período entre 2009 e 2019 sendo 49\% em usinas hidrelétricas, $49 \%$ em termelétricas a gás natural (incluindo a reserva fria) e $2 \%$ em usinas RER (eólica solar e biomassa). Percebe-se que a participação da termeletricidade a gás natural na expansão da geração estaria em torno de $50 \%$. Como resultado, a reserva de potência do SEIN no ano 2019 ficaria em torno de $38 \%$. 


\subsubsection{Características das Usinas a Gás Natural}

As principais características da configuração dos projetos térmicos a gás natural no Peru consideram turbinas a gás em ciclo aberto e em ciclo combinado, baseados em unidades turbo gás de $180 \mathrm{MW}$ de capacidade, sendo que a central de ciclo combinado é formada por duas unidades de ciclo aberto de $180 \mathrm{MW}$ e uma unidade a vapor, também de $180 \mathrm{MW}$, constituindo uma usina de $540 \mathrm{MW}$. A unidade básica de $180 \mathrm{MW}$ é o tamanho da unidade marginal de potência, e é a faixa de potência de maior participação nas novas unidades a gás instaladas no SEIN, (PERU MINISTERIO DE ENERGIA Y MINAS, 2009).

Em dezembro de 2010 a potência térmica instalada do SEIN era de 3500 MW, representando $53 \%$ da capacidade total. Deste total instalado a potência efetiva $^{40}$ de geração termelétrica distribuída entre os diferentes tipos de tecnologia foi 3365,21 MW de capacidade.

Atualmente há $2265,31 \mathrm{MW}(67,32 \%)$ de capacidade instalada com turbinas a gás, 509,44 MW (15,14\%) em ciclo combinado, 394,47 MW (11,72\%) com turbinas a vapor e 195,98 MW (5,82\%) com motores a diesel. Estas centrais utilizam principalmente o gás natural como combustível, complementado em menor proporção com óleo combustível, carvão, bagaço de cana e diesel na geração de energia elétrica. A figura 38 mostra esta distribuição de capacidade em função do tipo de usina, (COES, 2011).

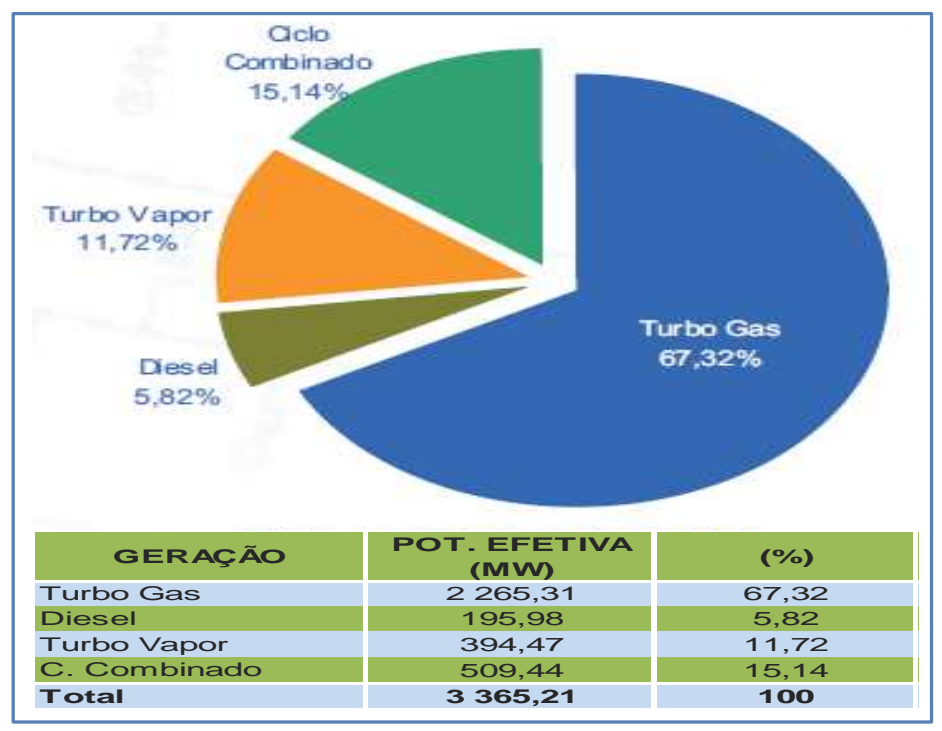

Figura 38 - Potência efetiva termelétrica por tipo de tecnologia no SEIN.

\footnotetext{
40 Indica a capacidade real de energia que as usinas podem entregar de forma contínua ao sistema.
} 
Atualmente de forma específica, a potência efetiva implantada no SEIN com base no gás natural de Camisea alcançou 2318,41 MW de capacidade que equivale a uma participação em torno de $36 \%$ do total, como é mostrado na figura 39, a seguir, (COES, 2011).

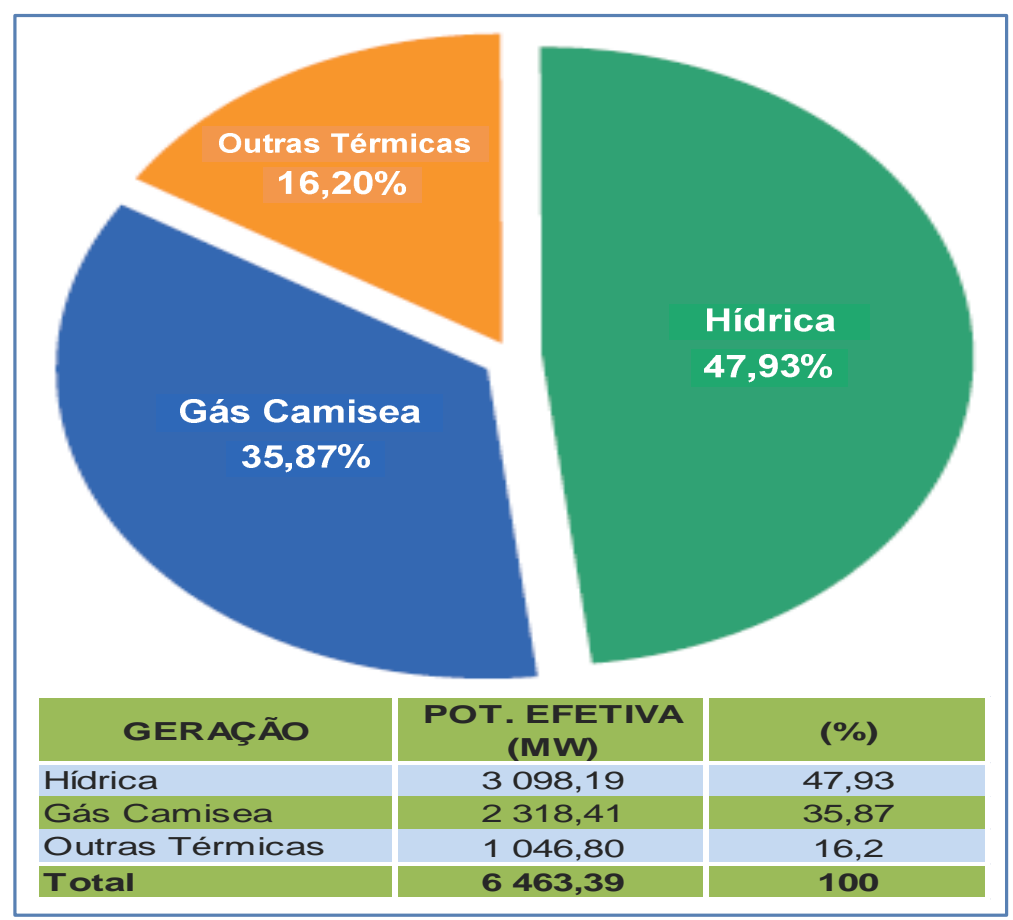

Figura 39 - Potência efetiva com geração termelétrica no SEIN.

Fonte: (COES, 2011)

As principais características das termelétricas a gás natural no setor elétrico peruano podem ser observadas através do crescimento da participação das usinas a gás natural na capacidade instalada do país, consequentemente refletindo em maior produção de energia elétrica no SEIN.

A tabela 9 mostra a participação da geração termelétrica por tipo de tecnologia na produção de energia do SEIN em 2010, registrando 13462,27 GW.h, o que representou $41,52 \%$ do total produzido pelo sistema. Deste 8282,46 GW.h $(61,52 \%)$ foram gerados por unidades com turbina a gás; 3216,88 GW.h $(23,90 \%)$ por unidades com turbinas a ciclo combinado; 1650,33 GW.h (12,26\%) por unidades com turbinas a vapor e 312,59 GW.h (2,32\%) produzidos por unidades com motores a diesel (COES, 2011). 
Tabela 9 - Produção termelétrica por tipo de tecnologia no SEIN 2010.

\begin{tabular}{lcc}
\hline $\begin{array}{c}\text { PROD. TÉRMICA TIPO DE } \\
\text { TECNOLOGÍA }\end{array}$ & GW.h & (\%) \\
\hline Turbo Gás & 8282,46 & 61,52 \\
Turbo Vapor & 1650,33 & 12,26 \\
Diesel & 312,59 & 2,32 \\
C. Combinado & 3216,88 & 23,90 \\
Total & $\mathbf{1 3 4 6 2 , 2 7}$ & $\mathbf{1 0 0 , 0 0}$ \\
\hline
\end{tabular}

Fonte: (COES, 2011).

A participação do gás natural de Camisea na produção total de energia do SEIN nos últimos anos teve um crescimento considerável, atingindo em 2010 35,3\%. Esta evolução positiva dos incrementos de participação da geração termelétrica a gás natural no SEIN é mostrado na figura 40.

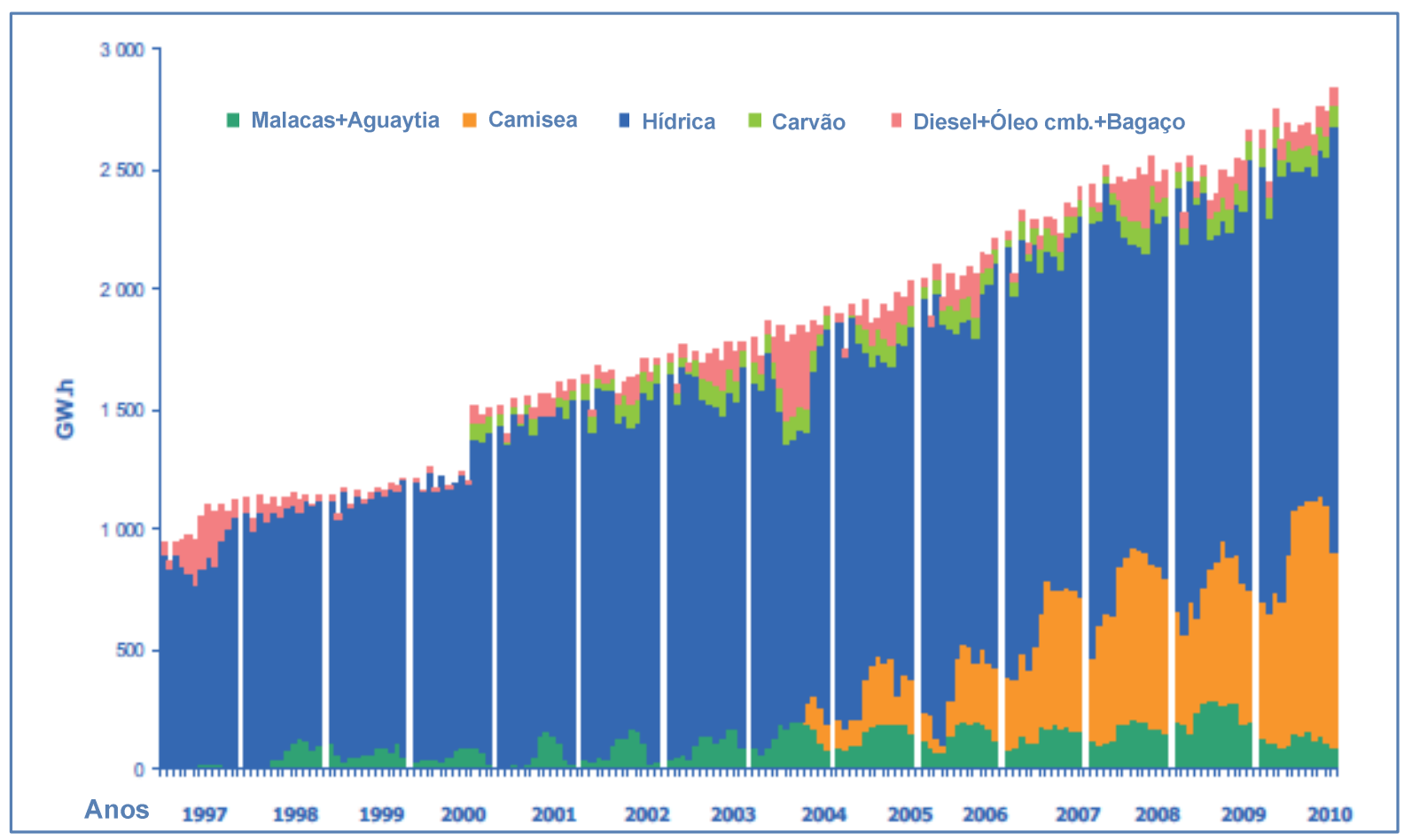

Figura 40 - Evolução da produção termelétrica de gás natural na matriz elétrica.

Fonte: (COES, 2011).

Diante dos dados e estatísticas apresentadas pode-se perceber que 0 desenvolvimento da termeletricidade no SEIN, em função da disponibilidade do gás natural, transformou o sistema elétrico peruano em um sistema hidrotérmico, embora 
a potência instalada das usinas termelétricas seja ligeiramente maior que das hidrelétricas, por uma margem pequena de $53 \%$ a $47 \%$, conforme apresentado anteriormente. $\mathrm{Na}$ energia produzida no SEIN o comportamento é um tanto diferente, tendo a energia de fonte hídrica, produção superior à energia produzida pela térmica, em função do despacho otimizado.

A geração termelétrica utilizando gás natural foi a fonte energética com maior crescimento no suprimento da demanda elétrica do SEIN peruano nos últimos anos, atuando de forma complementar à geração hidrelétrica do sistema, o que mostra a importância deste recurso como oferta de geração na matriz elétrica peruana.

\subsubsection{Competitividade das Termelétricas a Gás Natural}

No mercado elétrico peruano o custo de geração de energia é variável, pois depende do tipo de combustível utilizado. Um fator que incide diretamente no custo é o nível de investimento aplicado na implantação da usina. De forma geral no caso das usinas hidrelétricas, é conhecido que os custos de investimentos são maiores que nas termelétricas. Por outro lado, o custo da energia gerada por uma fonte renovável, como a hidroeletricidade, é vantajoso por seu menor custo variável.

Para poder avaliar a competitividade das termelétricas a gás natural em relação a outras tecnologias de geração elétrica é preciso realizar uma avaliação da viabilidade econômica dos projetos. E uma maneira de comparar as tecnologias de geração de energia com relação ao custo é calcular o custo nivelado de energia em relação ao tempo de vida econômica dos projetos.

O custo nivelado de eletricidade (Levelized Cost of Electricity - LCOE), ou índice de mérito, é um indicador de avaliação econômica de fontes energéticas de geração, custo que precisa ser recuperado durante o tempo de vida da usina para cobrir o requisito total de capital (RTC), incluindo todos os custos durante a vida útil dos empreendimentos: investimento inicial, operação e manutenção (O\&M) fixa e variável, custo de combustível, custo de capital, e o pagamento do retorno aceito pelos investidores, (HOFFMANN, 2010), (NREL, 2011). 
Este custo nivelado permite a comparação das diferentes tecnologias de geração de energia que têm vida econômica, custo de capital, risco e retorno, fator de capacidade, eficiência ou a taxa de calor da usina, custos de combustível e prazos de construção desiguais. Através desse custo verifica-se a competitividade de uma tecnologia no contexto de uma determinada matriz elétrica. Determina-se então o custo anual por unidade de energia elétrica gerada, por exemplo, indicado em US\$/MWh, (NREL, 2011).

O LCOE é calculado pela modelagem do valor presente líquido (VPL) de todos os fluxos de caixa que incorrem durante a vida útil do projeto de geração e é indicado pela seguinte equação, (HOFFMANN, 2010).

$$
L C O E=\frac{(R T C * F R C)+C F O \& M}{8760 * F C}+C V O \& M+H R * C C O M B
$$

Onde:

LCOE: custo nivelado de eletricidade (US\$/kWh)

$R T C$ : requisito total de capital (US\$/kW)

CFO\&M: custos anuais de operação e manutenção fixos (US\$/kW - ano)

CVO\&M: custos anuais de operação e manutenção variáveis (US\$/kWh)

$H R$ : taxa de calor líquido da usina (BTU/kWh)

CCOMB: custo de combustível (US\$/MMBTU)

$F R C^{41}$ : fator de recuperação de capital (fração 1/ano)

No denominador 8760 é o número de horas em um ano e fator de capacidade $F C$.

$41 \quad$ O fator de recuperação de capital é a razão entre o valor da anuidade e o valor presente da serie anual uniforme de recuperação de capital calculado pela seguinte equação:

$$
F R C=\frac{i(1+i)^{n}}{(1+i)^{n}-1}
$$

Onde: $n$ é o número de anuidades recebidas.

$i$ taxa de juros. 
Segundo estudos realizados pelo Banco Central de Reserva do Peru (BCRP) para avaliar a viabilidade e eficiência da estrutura de custos de implantação de usinas elétricas de diferentes fontes energéticas da matriz elétrica peruana foram simuladas a rentabilidade (VPL e TIR) e o custo nivelado de eletricidade (LCOE), considerando informações e dados do National Renewable Energy Laboratory (NREL) de EUA e fontes locais.

As simulações foram realizadas para pressupostos de implantação de 1 MW de potência instalada, onde nota-se que os custos de investimento em usinas a gás natural em ciclo simples e ciclo combinado são mais baixos em relação a outras fontes e tecnologias. No nível intermediário encontram-se a hidrelétrica e eólica, a energia solar fotovoltaica é a de mais alto custo.

No entanto o contrário acontece com os custos anuais de operação que inclui os custos fixos e variáveis para cada tecnologia onde a mais cara é a usina a gás natural em ciclo simples, por ter custos variáveis mais altos, influenciados principalmente pelo custo do combustível. Além disso, considera-se a vida útil dos empreendimentos que são diferentes entre cada tecnologia e que tem impactos nos custos de geração de energia. Nas tabelas 10 e 11, são apresentados os dados que serviram para os cálculos da simulação.

Tabela 10 - Pressupostos de cálculo para $1 \mathrm{MW}$ de potência instalada no SEIN.

\begin{tabular}{|c|c|c|c|c|c|c|}
\hline & $\begin{array}{l}\text { G.N. Ciclo } \\
\text { Simples }\end{array}$ & $\begin{array}{l}\text { G.N. Ciclo } \\
\text { Combinado }\end{array}$ & Hidrelétrica & Eólica & Geotérmica & $\begin{array}{c}\text { Solar } \\
\text { Fotovoltaica }\end{array}$ \\
\hline Fator de Capacidade & $60 \%$ & $70 \%$ & $60 \%$ & $39 \%$ & $85 \%$ & $22 \%$ \\
\hline Produção de Energia Total (MWh-ano) & 5256 & 6132 & 5256 & 3435 & 7421 & 1927 \\
\hline Investimento (US\$/MW) & 605.002 & 769.094 & 1.555 .151 & 1.382 .857 & 2.757 .813 & 4.636.202 \\
\hline Custos Fixos Anuais (O\&M) (US\$/MW) & 6.508 & 6.287 & 14.626 & 15.528 & 44.040 & 8.136 \\
\hline Custo do Combustivel (US\$/MWh) & 17 & 11 & & & & \\
\hline Custos Anuais (US\$/MW-ano) & 93.483 & 84.422 & 26.539 & 17.253 & 70.869 & 8.136 \\
\hline Vida Util & 30 anos & 30 anos & 70 anos & 20 anos & 25 anos & 25 anos \\
\hline Periodo de Depreciação & 10 anos & 10 anos & 5 anos & 5 anos & 5 anos & 5 anos \\
\hline
\end{tabular}

Fonte: (BARCO, 2010).

$\mathrm{Na}$ tabela 11 são apresentados pressupostos adicionais de cálculo utilizados nas simulações como o preço anual da potência, o preço da energia de 33 
US\$/MWh que é o equivalente ao preço médio ponderado de horário de pico e fora de pico do SEIN em 2010. Estes preços levaram em conta preços atualizados de gás natural e o custo da eletricidade, assim como os impostos aplicados no setor.

Tabela 11 - Dados de cálculo adicionais de (LCOE).

\begin{tabular}{lrl}
\hline \multicolumn{1}{c}{ Conceito } & Quantidade & Unidad \\
\hline Preços & & \\
Potência & 65.743 & US $\$ / M W-a n o$ \\
Energia & 33 & US $\$ / M W h$ \\
Tipo de Cambio & 2,8 & \\
Impostos & & \\
Imposto de renda & $30 \%$ & \\
IGV (Imposto Geral às Vendas) & $19 \%$ & \\
Taxa de desconto & $10 \%$ & \\
\hline
\end{tabular}

Fonte: (BARCO, 2010).

Os resultados apresentados na tabela 12 pelo BCRP mostram o custo nivelado de eletricidade das diferentes fontes energéticas que participam no SEIN. Observa-se que a tecnologia de ciclo combinado e ciclo simples a gás natural, são as mais atrativas economicamente. Seguido pela hidrelétrica, eólica, geotérmica, carvão e outros recursos.

Tabela 12 - Custo total nivelado de eletricidade por tipo de fonte no SEIN.

\begin{tabular}{lc}
\hline \multicolumn{1}{c}{ Fonte Energética } & $\begin{array}{c}\text { Custo Nivelado de Eletricidade } \\
\text { LCOE (US\$/kWh) }\end{array}$ \\
\hline Gás Natural Ciclo Combinado & 0,02 \\
Gás Natural Ciclo Simples & 0,03 \\
Hidrelétrica & 0,03 \\
Eólica Onshore & 0,05 \\
Geotérmica & 0,05 \\
Carvão & 0,05 \\
Carvão Ciclo Combinado Gasificado & 0,06 \\
Eólica Offshore & 0,07 \\
Biomassa & 0,08 \\
Solar Termal & 0,16 \\
Solar Fotovoltaica & 0,24 \\
\hline
\end{tabular}

Fonte: (BARCO, 2010). 
O resultado da avaliação econômica baseado no valor presente líquido (VPL) das tecnologias de geração do SEIN mostra o gás natural em ciclo simples como a forma de geração com o maior retorno, seguido pelo gás natural em ciclo combinado e outras fontes. Simulação realizada para um pressuposto de um milhão de dólares (1 milhão US\$) investido em cada fonte energética, como é apresentado na tabela 13 e figura 41 , a seguir.

Tabela 13 - VPL por milhão investido (US\$) por fonte energética no SEIN.

\begin{tabular}{lr}
\hline \multicolumn{1}{c}{ Fonte Energética } & $\begin{array}{r}\text { VPL por milhão } \\
\text { Investido (US\$) }\end{array}$ \\
\hline Gás Natural Ciclo Simples & 862.837 \\
Gás Natural Ciclo Combinado & 849.556 \\
Hidrelétrica & 253.405 \\
Eólica & -4.469 \\
Geotérmica & -166.791 \\
Eólica Offshore & -333.818 \\
Carvão Ciclo Combinado Gasificado & -551.746 \\
Carvão & -576.310 \\
Solar Fotovoltaica & -585.120 \\
\hline
\end{tabular}

Fonte: (BARCO, 2010).

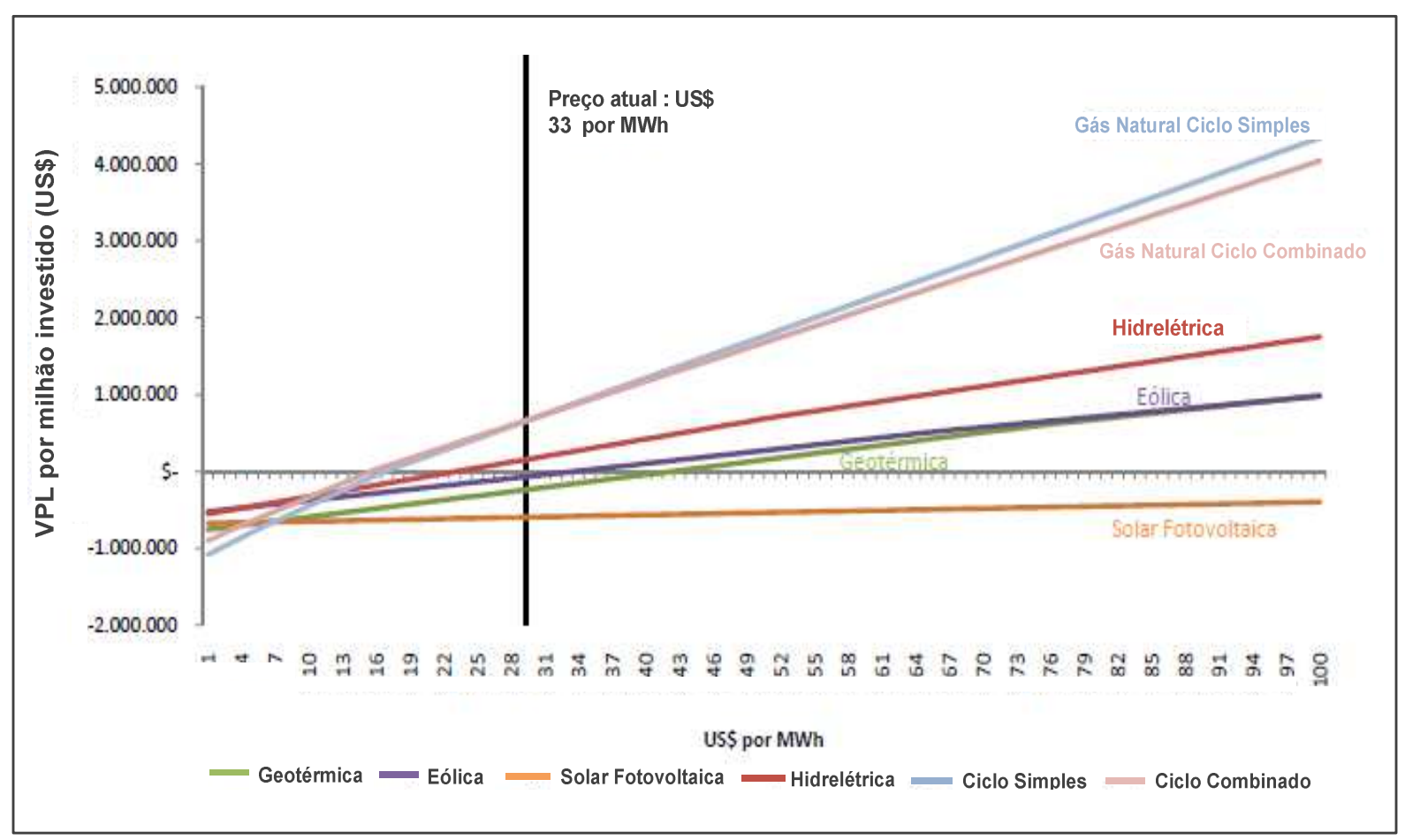

Figura 41 - VPL por milhão investido (US\$) e preços de energia no SEIN.

Fonte: (BARCO, 2010). 
A rentabilidade das fontes energéticas do mercado elétrico peruano, comparadas entre elas (custos eficientes), explica o crescimento considerável nos últimos anos da expansão das usinas termelétricas a gás natural em ciclo simples e combinado, tendo uma vantagem considerável deste tipo de geração em relação aos outros pelos melhores retornos apresentados, o que também é apresentado na tabela 14 e figura 42, no cálculo da taxa interna de retorno (TIR) para cada fonte energética no SEIN.

Tabela 14 - TIR por milhão investido (US\$) por fonte energética no SEIN

\begin{tabular}{lc}
\hline \multicolumn{1}{c}{ Fonte Energética } & TIR \\
\hline Gás Natural Ciclo Simples & $23 \%$ \\
Gás Natural Ciclo Combinado & $23 \%$ \\
Hidrelétrica & $14 \%$ \\
Eólica & $10 \%$ \\
Geotérmica & $7 \%$ \\
Eólica Offshore & $2 \%$ \\
Carvão Ciclo Combinado Gasificado & $-2 \%$ \\
Carvão & $-2 \%$ \\
Solar Fotovoltaica & $-4 \%$ \\
\hline
\end{tabular}

Fonte: (BARCO, 2010).

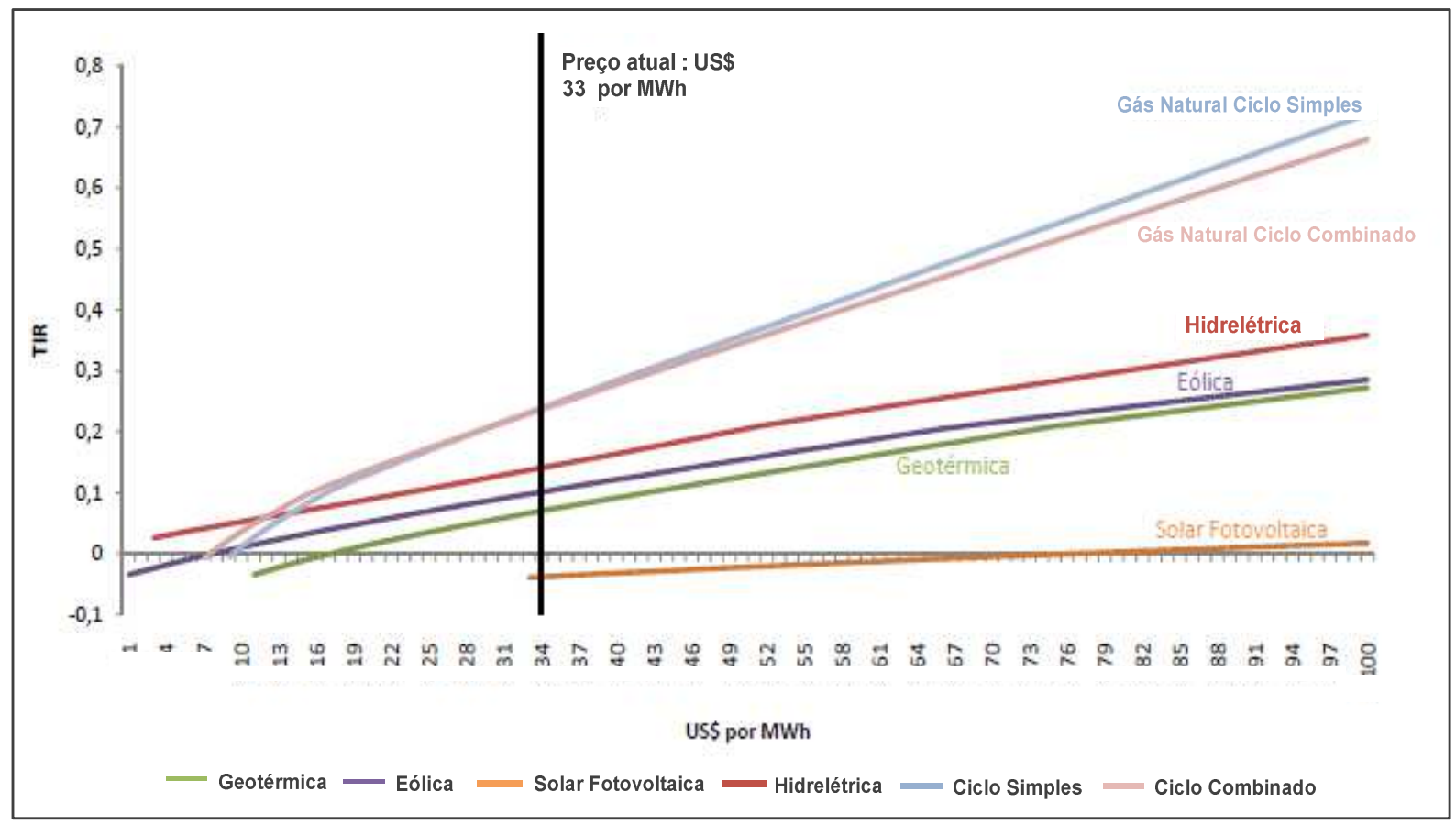

Figura 42 - TIR por milhão investido (US\$) e preços de energia no SEIN.

$\overline{\text { Fonte: (BARCO, 2010). }}$ 
Diante dos resultados, as rentabilidades das usinas a gás natural, seja em ciclo simples ou combinado, são as mais altas do setor principalmente pelos preços mais baratos do gás natural de Camisea. Nesse sentido foi proposto e realizado um exercício com os mesmos dados e pressupostos anteriores, mas desta vez, levando em conta o valor do preço internacional do gás natural, o preço "Henry Hub" para o mercado elétrico peruano, ou seja, sem que se fixasse o preço do gás de Camisea, igual ao preço de referência internacional. Nesse exercício alterou-se o preço do gás natural de US\$1.6 por MMBTU (preço atual pago pelos geradores do SEIN) para US\$3.56 por MMBTU (preço internacional Henry Hub).

Dado que o gás natural representa o custo marginal da geração elétrica do SEIN, o preço para o consumidor teria que se incrementar de US\$33 para US\$ 46 por MWh para os pressupostos de cálculo utilizados no exercício.

Os resultados apresentados consideram que a geração hidrelétrica é a forma mais barata de gerar energia no setor elétrico peruano deslocando a geração termelétrica a gás natural em ciclo simples e combinado; aliás, o custo de geração da energia eólica e geotérmica ficaria muito próximo das usinas a gás em ciclo simples e combinado, o que significa que o custo baixo do gás natural no setor elétrico peruano não incentiva a utilização de outras fontes renováveis, como é apresentado na tabela 15.

Tabela 15 - Custo nivelado de eletricidade com preço Henry Hub de GN no SEIN.

\begin{tabular}{lc}
\hline \multicolumn{1}{c}{ Fonte Energética } & $\begin{array}{c}\text { Custo Nivelado de Eletricidade } \\
\text { LCOE (US\$/kWh }\end{array}$ \\
\hline Hidrelétrica & 0,03 \\
Gás Natural Ciclo Combinado & 0,04 \\
Gás Natural Ciclo Simples & 0,05 \\
Eólica Onshore & 0,05 \\
Geotérmica & 0,05 \\
Carvão & 0,05 \\
Carvão Ciclo Combinado Gasificado & 0,06 \\
Eólica Offshore & 0,07 \\
Biomassa & 0,08 \\
Solar Termal & 0,16 \\
Solar Fotovoltaica & 0,24 \\
\hline
\end{tabular}

Fonte: (BARCO, 2010). 
Quanto aos valores de retorno VPL e TIR por milhão investido (US\$), considerando o preço do gás natural igual ao preço de referência internacional "Henry Hub" no SEIN, verifica-se que a geração a gás natural em ciclo combinado é a que apresenta os maiores retornos, seguido pela hidrelétrica, o que significa que a geração a gás em ciclo simples seria menos rentável que a hidroeletricidade. Desta forma, os preços mais altos do gás natural no SEIN incentivariam o uso mais eficiente do combustível em usinas a ciclo combinado, como é apresentado na tabela 16, a seguir.

Tabela 16 - VPL e TIR por fonte energética com preço Henry Hub de GN no SEIN.

\begin{tabular}{lrr}
\hline \multicolumn{1}{c}{ Fonte Energética } & $\begin{array}{r}\text { VPL por milhão } \\
\text { Investido (US\$ ) }\end{array}$ & TIR \\
\hline Gás Natural Ciclo Combinado & 818.197 & $23 \%$ \\
Hidrelétrica & 571.159 & $19 \%$ \\
Gás Natural Ciclo Simples & 469.476 & $18 \%$ \\
Eólica & 199.416 & $14 \%$ \\
Geotérmica & 66.367 & $11 \%$ \\
Carvão & -44.231 & $9 \%$ \\
Eólica Offshore & -199.976 & $6 \%$ \\
Carvão Ciclo Combinado Gasificado & -227.491 & $6 \%$ \\
Solar Fotovoltaica & -549.102 & $-3 \%$ \\
\hline
\end{tabular}

Fonte: (BARCO, 2010).

Dos resultados mostrados no exercício anterior, conclui-se que com o preço do gás natural de Camisea igual ao nível de referência internacional, preço "Henry Hub", as usinas a gás natural de ciclo combinado tornaram-se as mais rentáveis do SEIN. Por outro lado, as hidrelétricas seriam a opção mais barata para gerar energia. Além disso, estas apresentam, no longo prazo, menores custos e maior duração pela longa vida útil da tecnologia.

Outra opção rentável, sobre condições favoráveis, é a geração eólica, mesmo que os resultados prévios não levem em conta que alguns projetos podem se beneficiar da venda de Certificados de Redução de Emissões (CERs) ou créditos de carbono. Desta forma, se fosse atribuído um valor à venda dos certificados de carbono, seria possível que os resultados mudassem e a energia eólica conseguiria um retorno mais adequado e competitivo, (BARCO, 2010). 
As diferenças mostradas nos níveis de investimento para cada tipo de fonte somadas ao prazo de implantação das usinas, de 5 anos em média para uma hidrelétrica e de 2 a 3 anos para uma termelétrica, permitem avaliar e conhecer as vantagens de se ter os custos de implantação diferenciados para cada tipo de fonte e tecnologia. Entretanto a diferença mostrada no caso peruano permitiu que a maioria dos investimentos nos últimos anos estivesse focada na implantação de usinas termelétricas a gás natural, devido aos baixos custos do combustível e suas vantagens adicionais derivadas dela.

Tal fato finalmente refletiu na diminuição dos custos de geração no mercado elétrico peruano com um considerável ganho quanto ao aproveitamento adequado do gás natural, limitando o uso de combustíveis mais caros no sistema. Por outro lado este custo menor não incentiva eficientemente a participação de outras fontes alternativas no mercado elétrico.

Com o menor preço do gás natural, o gerador termelétrico tem um menor custo médio de produção, portanto pode ofertar sua energia a um preço mais competitivo fazendo com que a tarifa elétrica seja reduzida. Na figura 43, mostra-se o efeito do preço do gás natural no custo da eletricidade do SEIN. Assumindo que todo o resto de variáveis permanece constante, o gás natural é um forte elemento de decisão no desenvolvimento do setor elétrico peruano.

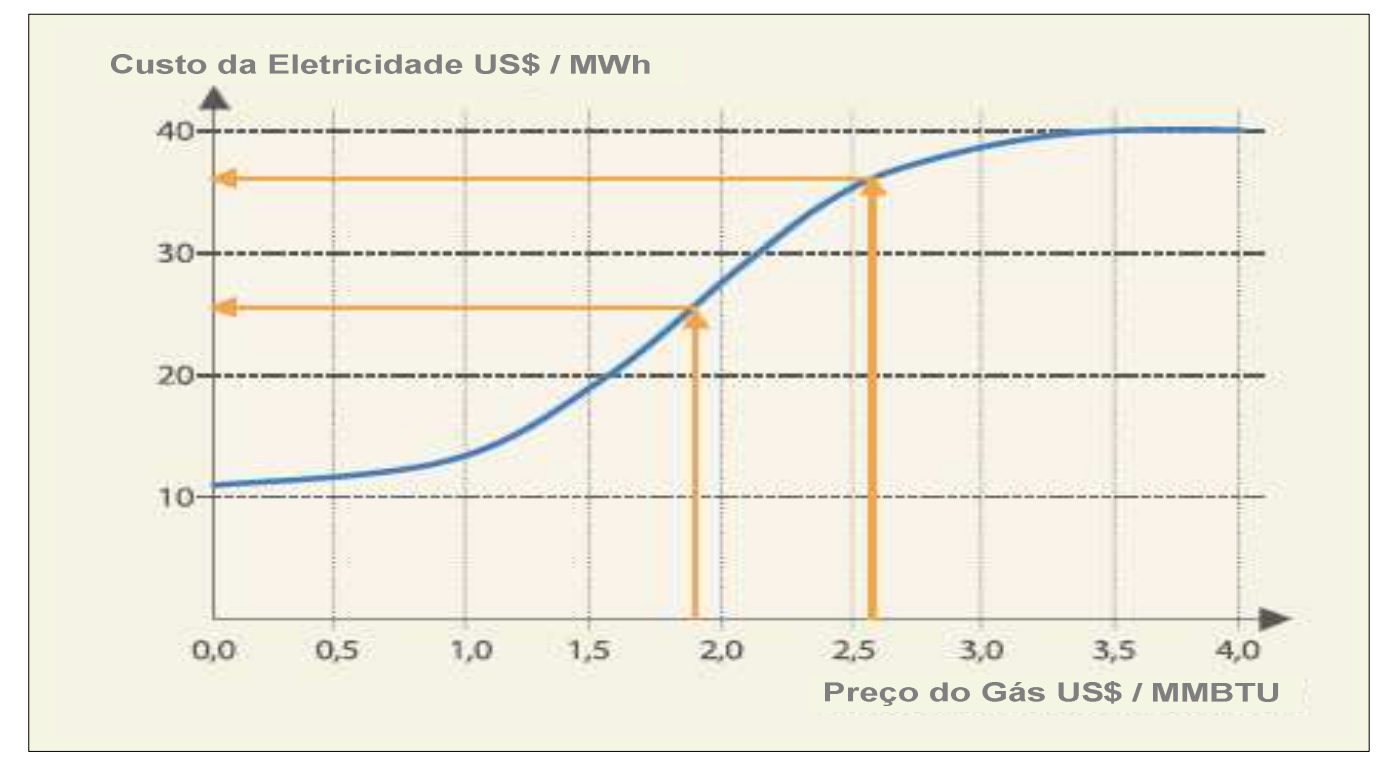

Figura 43 - Impacto do gás natural no custo de longo prazo da eletricidade do SEIN.

Fonte: (OSINERGMIN, 2009). 
Observa-se que o impacto da geração termelétrica a base de gás natural na estrutura de custos do mercado elétrico peruano é considerável, pelo que se pode confirmar através da competitividade do gás natural em relação a outros recursos. Entre as usinas termelétricas, as de ciclo combinado têm um destaque importante por serem mais eficientes, o que permite ter maior eficiência econômica e energética, diferentemente das usinas de ciclo simples que têm uma menor eficiência.

Uma simulação de custos de investimento máximos em usinas hidrelétricas, feito pelo Osinergmin com relação às usinas de ciclo combinado a gás natural, operando com diversos preços do gás no SEIN, mostrou que, para serem competitivas, as usinas hidrelétricas não deveriam ter um custo de investimento superior a US\$ 1200 por kW, para um preço do gás natural de 2,5 US $\$$ por milhão de BTU, como é indicado na figura 44, a seguir.

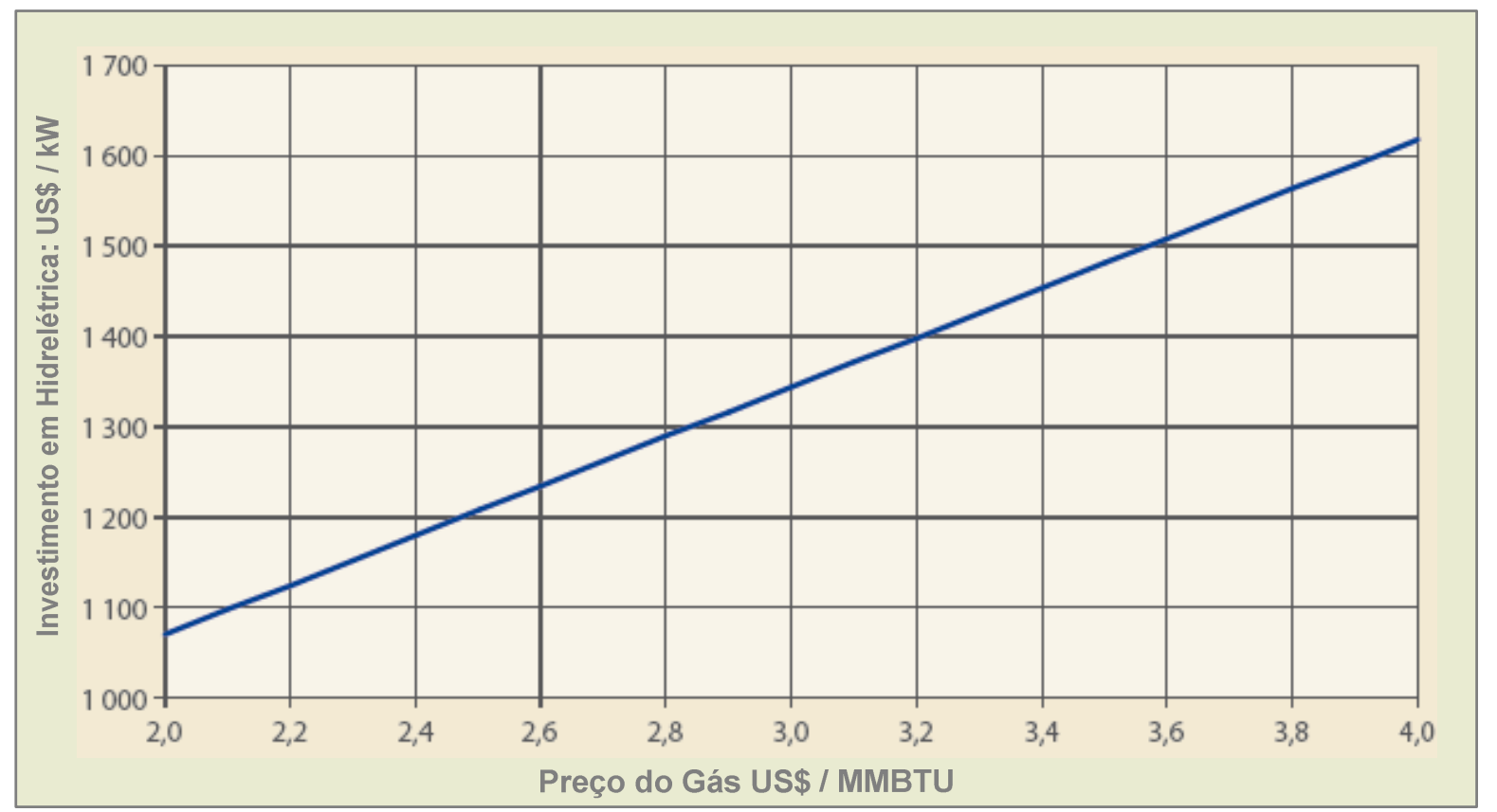

Figura 44 - Preço do gás natural x investimento em hidrelétrica.

Fonte: (OSINERGMIN, 2008).

O quadro 10 apresenta os critérios e dados pressupostos utilizados pelo Osinergmin na determinação da relação da competitividade do investimento das usinas hidrelétricas versus o preço do gás natural no setor elétrico peruano. 
Quadro 10 - Critérios de investimento e custos de projetos de geração no SEIN.

\begin{tabular}{|c|c|c|c|c|c|c|}
\hline \multirow[b]{2}{*}{ Usina Elétrica } & Símbolos & Unidade & \multicolumn{2}{|c|}{ Hidrelétrica } & \multicolumn{2}{|c|}{ Ciclo Combinado a GN } \\
\hline & & & & & & \\
\hline Capacidade & $P$ & MW & 300 & MW & 300 & MW \\
\hline Fator de Capacidade & FC & & $80 \%$ & & $80 \%$ & \\
\hline Produção de Eletricidade & $\mathrm{E}=\mathrm{P} \times \mathrm{FC} \times 8760$ & MWh & 2.102 .400 & MWh & 2.102 .400 & MWh \\
\hline Vida Util & $\mathrm{N}$ & Anos & 50 & anos & 25 & anos \\
\hline Taxa de Desconto Anual & $i$ & & $12 \%$ & & $12 \%$ & \\
\hline
\end{tabular}

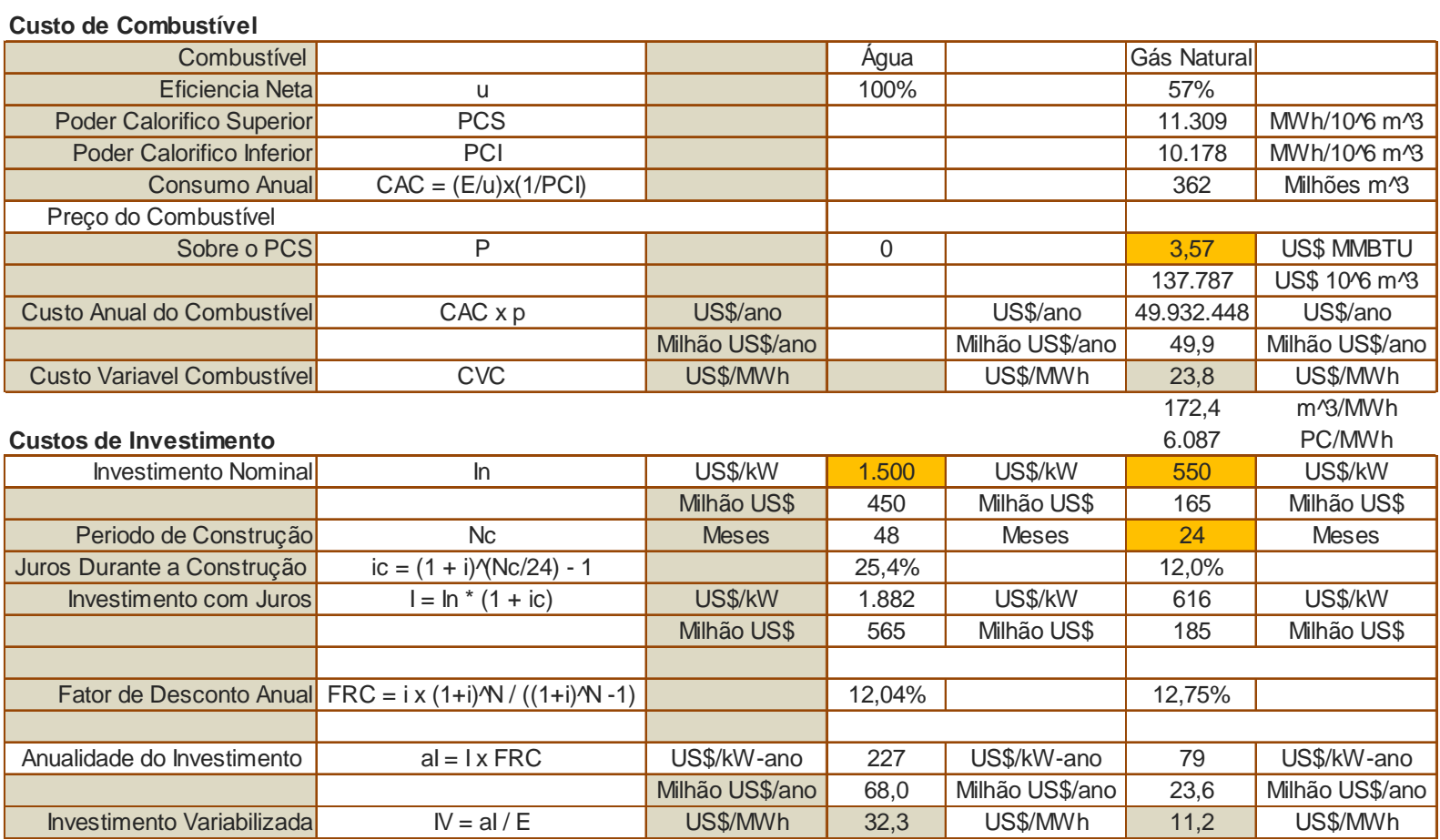

\section{Custos de Operação e Manutenção}

\begin{tabular}{|c|c|c|c|c|c|c|}
\hline Custos Fixos de O\&M & $\% \operatorname{cof}=\% \ln$ & & $4,0 \%$ & & $3,0 \%$ & \\
\hline & $\mathrm{COF}=\% \operatorname{cof} x \ln$ & US\$/kW & 60 & US\$/kW & 17 & US\$/kW \\
\hline & & Milhão US\$/ano & 18,0 & Milhão US\$/ano & 5,0 & Milhão US\$/ano \\
\hline \multirow[t]{2}{*}{ Outros Custos Variaveis } & cvnc & US\$/MWh & 0,3 & US\$/MWh & 1,0 & US $\$ / M W h$ \\
\hline & & Milhão US\$/ano & 0,6 & Milhão US\$/ano & 2,1 & Milhão US\$/ano \\
\hline \multirow[t]{2}{*}{ Custo Total de Operação } & CTO & Milhão US\$/ano & 18,6 & Milhão US\$/ano & 7,1 & Milhão US\$/ano \\
\hline & & US\$/MWh & 8,9 & US\$/MWh & 3,4 & US\$/MWh \\
\hline
\end{tabular}

Custo Total

\begin{tabular}{|c|c|c|c|c|c|c|}
\hline Investimento & al & Milhão US\$/ano & 68,0 & Milhão US\$/ano & 23,6 & Milhão US\$/ano \\
\hline Combustível & CVC & Milhão US\$/ano & 0,0 & Milhão US\$/ano & 49,9 & Milhão US\$/ano \\
\hline $\mathrm{O} \& \mathrm{M}$ & CTO & Milhão US\$/ano & 8,9 & Milhão US\$/ano & 3,4 & Milhão US\$/ano \\
\hline Total & & Milhão US\$/ano & 76,8 & Milhão US\$/ano & 76,8 & Milhão US\$/ano \\
\hline & & US\$/MWh & 36,6 & US\$/MWh & 36,6 & US\$/MWh \\
\hline
\end{tabular}

Fonte: (OSINERGMIN, 2008).

Nos últimos anos os investimentos do setor em geração concentraramse em usinas termelétricas a gás natural, devido ao menor custo variável e à facilidade de acesso ao gás de Camisea, como foi visto anteriormente. O contrário acontece com o investimento em usinas hidrelétricas que foi mínimo, dadas às tarifas atuais, devido ao alto nível de investimento requerido e a um longo período de retorno. 
Nesse sentido, para incentivar e manter o investimento em tecnologias de energia limpa e de baixo custo variável (como as hidrelétricas), o governo implementou os Decretos Legislativos 1041 e 1058, que estabelecem incentivos para os projetos hidrelétricos ou que utilizem outro tipo de energias renováveis, entre os que destacam, (BBVA, 2008):

- Um prêmio ou fator de desconto nos leilões e concessões, diferente das usinas termelétricas que não possuem essa vantagem,

- O repasse dos custos de transmissão aos consumidores (o que coloca as hidrelétricas perto das principais "cargas", normalmente localizadas longe das cidades e que se viam obrigadas a assumir o custo, diminuindo sua viabilidade), e

- Um benefício tributário de um regime de depreciação acelerada sob o imposto da renda, de rápida recuperação do investimento realizado.

Com os incentivos dados à geração hidrelétrica o setor busca aproveitar os recursos energéticos de forma eficiente com menor custo social para seus usuários, manter em equilíbrio o sistema hidrotérmico atual para aumentar a participação da fonte renovável no futuro, conservando o aproveitamento eficiente das termelétricas a gás natural por sua competitividade, como apresentado acima. 


\section{DESCRIÇÃO DA METODOLOGIA E MODELO UTILIZADO}

Este capítulo tem por objetivo apresentar a metodologia empregada na avaliação dos impactos causados nos preços de curto e longo prazo da geração de energia elétrica, com a inserção da energia eólica e térmica a gás natural no sistema hidrotérmico peruano.

\subsection{ASPECTOS DA OPERAÇÃO DO SISTEMA HIDROTÉRMICO PERUANO}

O segmento da geração, desde a reforma do setor elétrico peruano em 1992 mediante a LCE, foi concebido com o objetivo de gerar competição em termos de mercado, por meio da busca da otimização dos custos de despacho e geração de energia elétrica.

A operação do SEIN tem como principais objetivos minimizar os custos de operação, manutenção e racionamento, mantendo os fluxos de potência elétrica pelas linhas e transformadores, bem como as tensões no sistema dentro de seus limites operativos através do operador do sistema (COES).

A característica mais importante na operação dos sistemas hidrotérmicos é a gestão da energia hídrica armazenada nos reservatórios do sistema, buscando evitar assim gastos de combustível com a geração térmica.

Embora a água armazenada não tenha um preço direto, a disponibilidade desta energia gratuita está restrita pela capacidade de armazenagem dos reservatórios e pela incerteza dos volumes afluentes ao sistema, gerando então uma dependência entre a decisão operativa presente e os custos operativos futuros. Em outras palavras se forem utilizadas as reservas de água para evitar custos com geração térmica no presente, e no futuro houver uma seca, os custos por racionamento serão muito elevados. Se por outro lado, a água for armazenada, o uso de geração térmica no presente seria maior e caso ocorra uma afluência futura elevada, haverá vertimento de água nos reservatórios com consequente desperdício de energia, assim um aumento dos custos operativos seria inevitável, (OSINERG, 
2006a). Este “dilema” vivido pelo operador está ilustrado na figura 45 a seguir.

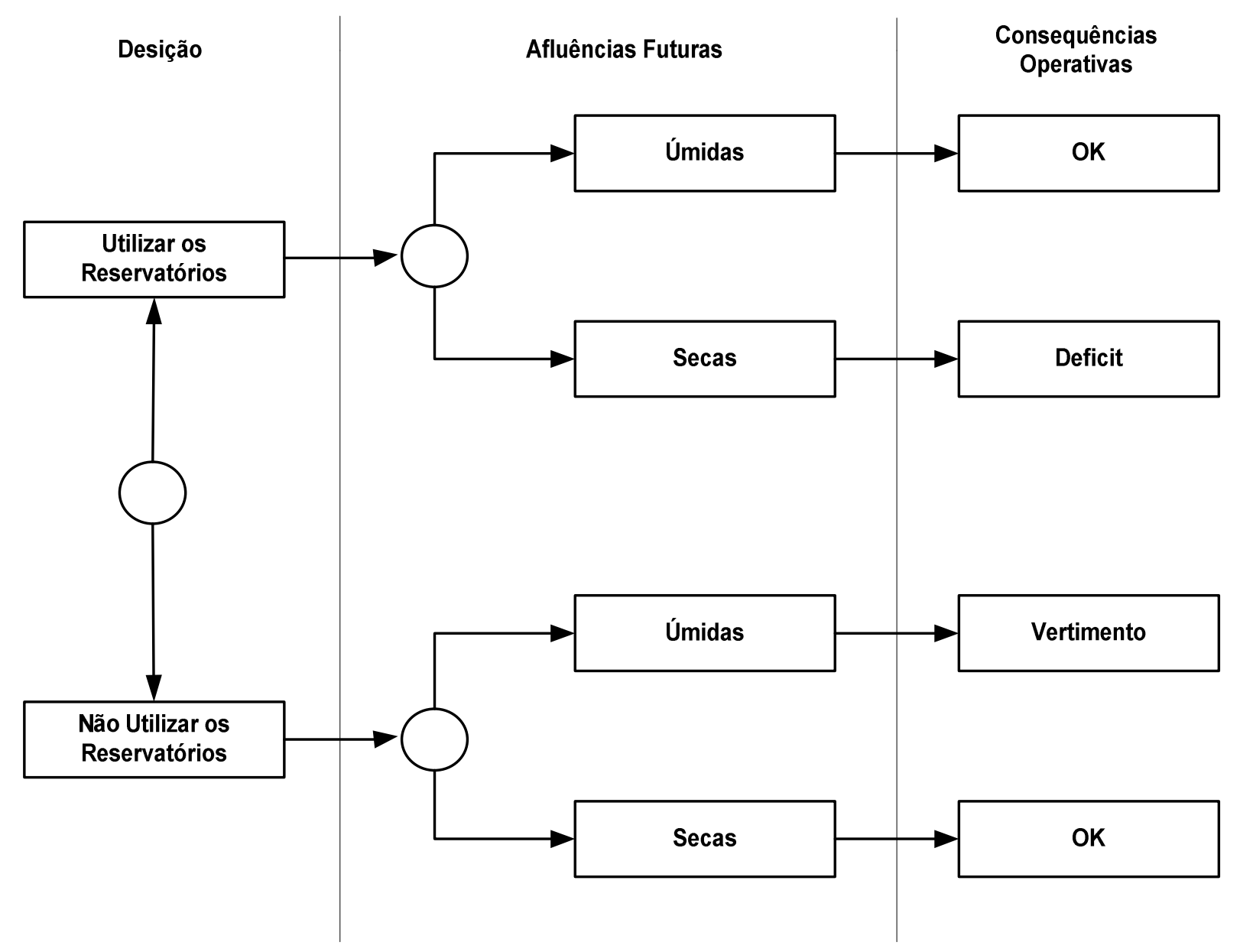

Figura 45 - Processo de decisão em sistemas hidrotérmicos.

Fonte: (OSINERG, 2006a).

Devido às incertezas associadas à disponibilidade futura de vazões afluentes e a demanda a ser atendida, o problema de planejamento é classificado como estocástico. Como as funções de custo de operação das usinas termelétricas e as funções de produção das usinas hidrelétricas são não-lineares, o problema é também caracterizado como não-linear. Como as decisões envolvem um grande número de variáveis associadas aos vários reservatórios e os diversos intervalos do horizonte de planejamento, o problema é de grande porte.

Por outro lado, como o valor de geração hidrelétrica é expresso de forma indireta em função da economia de combustível proporcionada pela diminuição no despacho das fontes termelétricas, o problema é considerado não separável. 
Resumindo, encontrar a melhor política de operação de um sistema hidrotérmico consiste na solução de um problema dinâmico, estocástico, não-linear, de grande porte e não separável. A melhor solução corresponde ao estabelecimento do equilíbrio entre o benefício presente do uso da água e o benefício futuro de seu armazenamento.

Devido às características citadas anteriormente, em um sistema hidrotérmico, deve se equilibrar o beneficio imediato do uso da água, dado pela função de custo imediato, com o beneficio futuro de seu armazenamento, dado pela função de custo futuro, como é mostrado na figura 46.

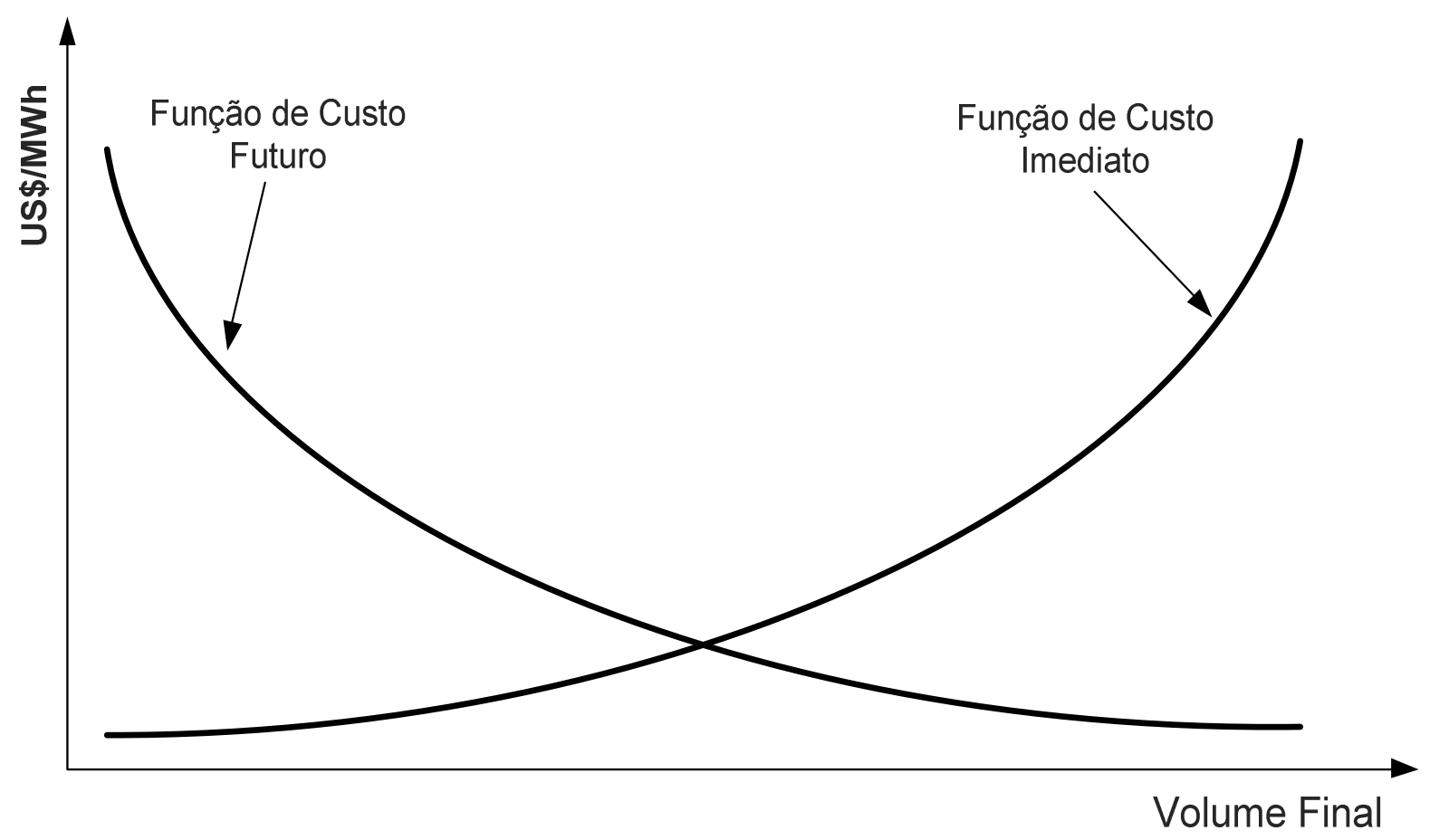

Figura 46 - Custos associados à operação dos reservatórios.

Ao afirmar que a principal característica do planejamento da operação de um sistema hidrotérmico é garantir, de forma econômica e confiável, o suprimento da demanda prevista no horizonte de planejamento, confirma-se que o objetivo macroeconômico é minimizar os custos de combustível nas usinas termelétricas (gás natural, óleo, carvão, etc.) e evitar o custo de racionamento do sistema.

A estratégia de operação de mínimo custo do SEIN peruano é usualmente calculada por um processo de otimização chamado de Programação Dinâmica Estocástica (PDE). Embora os detalhes computacionais da PDE sejam bastante complexos, seu produto final é basicamente uma tabela com os valores do 
Custo Marginal de Operação (CMO), que indica a variação futura dos custos de operação do sistema, em função do armazenamento dos reservatórios e da tendência hidrológica.

Em geral a análise do planejamento da operação do SEIN em curto, médio e longo prazo tem como objetivo determinar os despachos de geração a mínimo custo, os custos marginais, as restrições no sistema de transmissão e no fornecimento de gás natural, bem como, os possíveis racionamentos que são levados em conta na programação da operação do sistema.

A programação da operação busca aperfeiçoar a utilização dos recursos energéticos disponíveis para atender a demanda de eletricidade ao mínimo custo, cumprindo com requisitos de segurança e qualidade, como foi mencionado anteriormente.

A programação da operação do SEIN é realizada mediante o uso do modelo e ferramenta de otimização PERSEO ${ }^{42}$ (Planejamento Estocástico com Restrições em Sistemas Elétricos), que é um modelo de simulação de despacho hidrotérmico, estocástico, multi-nodal, de multi-cénario e de multi-reservatório.

O modelo PERSEO foi concebido com o objetivo de resolver o problema do planejamento da operação do SEIN, simulando o planejamento da operação com suficiente precisão, levando em conta as características operativas das usinas hidrelétricas e termelétricas; isto é, a busca de um plano otimizado que minimize o custo total de operação do SEIN em estágios mensais. Através do despacho otimizado obtêm-se os custos marginais adequados em cada barra do sistema elétrico, que finalmente se utilizam na formação da estrutura de preços e tarifas do sistema, (CTE, 2000).

A utilização prática do modelo de otimização requer definições prévias em relação a quatro fatores fundamentais: previsão da demanda, expansão do sistema (parque gerador e linhas de transmissão), custos variáveis da geração térmica e custos correspondentes a eventual racionamento futuro.

São considerados também, além da análise energética, os parâmetros elétricos das instalações de geração e transmissão, bem como, informações relacionadas com as simulações de fluxos de carga, estudos de curto circuito e estudos de comportamento dinâmico. Além disso, geralmente, na análise elétrica de

${ }_{42}$ Modelo de otimização utilizado pelo COES na programação da operação do SEIN em curto, médio e longo prazo. 
curto prazo, determinam-se as restrições nas linhas de transmissão e principais transformadores do SEIN; identificam-se os problemas de queda de tensão e requisitos de compensação reativa, assim como os níveis de curto circuito e problemas de segurança do SEIN, através de estudos realizados pelo COES mediante o uso de modelos ou programas de simulação como o Power Factory de Digisilent.

A programação da operação do SEIN supõe a coordenação e aprovação de programas de despacho das unidades do sistema considerando custos variáveis e restrições operativas de geradores termelétricos, as características e restrições próprias de sistemas hidrelétricos e da rede elétrica, bem como, a programação da manutenção das unidades, linhas de transmissão e equipamentos necessários na operação ótima do sistema.

A programação da operação do SEIN considera diferentes horizontes temporais: longo prazo, para períodos maiores que um ano; médio prazo, para períodos anuais e mensais; e curto prazo para períodos semanais e diários, bem como a reprogramação em tempo real. A sequência da programação da operação do SEIN é descrita no quadro 11, a seguir.

Quadro 11 - Programação da operação do SEIN.

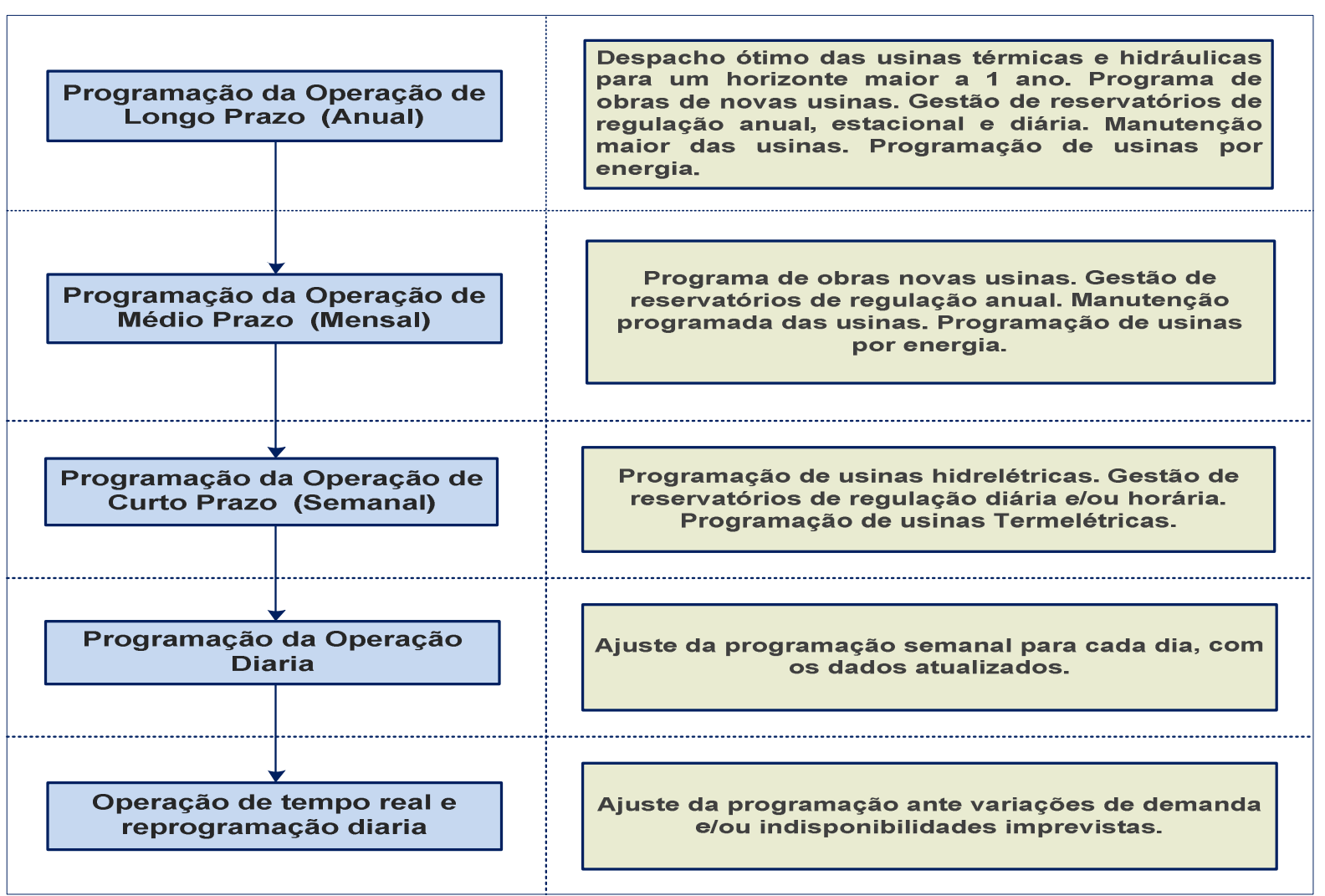


A regulamentação do setor, mediante a LCE, estabelece que 0 despacho econômico das usinas seja ordenado pelo mérito em função do menor custo variável de geração. As usinas hidrelétricas geram energia na base da carga por serem as mais baratas do SEIN. Nesta ordenação participam outras tecnologias como as usinas termelétricas a gás natural em ciclo combinado e simples, carvão e óleo combustível, tendo cada tecnologia uma eficiência relativa variável. No entanto, as menos eficientes e mais caras como as usinas termelétricas a diesel são dispostas ao final da curva de carga, ou mantidas como reserva.

\subsection{METODOLOGIA E MODELO UTILIZADO}

A metodologia proposta tem como objetivo avaliar o diagnóstico das condições operativas do SEIN do ponto de vista energético, no período de curto prazo (2011 - 2013) e do longo prazo de (2014 - 2020), de acordo com os objetivos propostos no presente trabalho e tendo como referência os critérios e metodologia utilizada pelo órgão oficial operador do sistema COES no diagnóstico da operação do SEIN.

Os cenários e casos de estudo propostos consideram os seguintes procedimentos de análise:

- Caso 1: Definição de um cenário de expansão de referência período (2011 - 2020), onde não haja participação de energia eólica.

- Caso 2: Definição de um cenário de expansão de curto prazo (2011- 2013), contendo 65 MW médios (142 MW de capacidade instalada) de geração eólica contratada no leilão RER 2010 com entrada em operação prevista para 2012. A partir de 2014 até 2020 (cenário de longo prazo), supõem-se um cenário de inclusão sustentada de $65 \mathrm{MW}$ médios de geração eólica por ano, totalizando $520 \mathrm{MW}$ médios. As usinas eólicas seriam implantadas através da substituição de parte da geração termelétrica (diesel, e gás natural) prevista para o cenário de referência. Em outras palavras, a energia firme (garantia física) 
total de ambos os cenários em cada ano do período de análise não muda; só o que muda é o "mix" de geração.

- Caso 3: Caso 2 com desenvolvimento das grandes usinas na Amazônia e exportação de $50 \%$ ao Brasil.

Para a simulação da operação a mínimo custo (despachos de geração do sistema hidrotérmico) dos casos propostos utiliza-se o programa PERSEO, modelo com representação da rede de transmissão do SEIN.

A metodologia assumida compreende a projeção da demanda, a definição dos programas de geração e transmissão e o diagnóstico propriamente proposto. Os critérios gerais utilizados na metodologia proposta são os seguintes:

- A programação da operação econômica do sistema tem como objetivo minimizar os custos de operação, manutenção e racionamento, mantendo os fluxos de potência no sistema elétrico dentro de seus limites operativos.

- A demanda está dividida em dois componentes: demanda vegetativa e demanda dos grandes clientes. O primeiro componente foi projetado utilizando um modelo econométrico, enquanto o segundo baseia-se em informação proporcionada pelos agentes.

- Para a simulação da operação das usinas hidrelétricas considerase a hidrologia histórica dos últimos 46 anos (1965 - 2010), distribuídas em 30 bacias e inclui-se as restrições de manejo de água para irrigação e outros usos.

- Para a simulação da operação das usinas termelétricas consideram-se os custos variáveis constantes, a restrição no fornecimento de gás pelos limites de capacidade de transporte no gasoduto até 2013, após esse período sem restrições. Também considera-se que as atuais unidades termelétricas continuarão em serviço durante todo o período de estudo.

- Custo de racionamento de US\$250/MWh.

- O valor da água considerado foi 0,3019 US\$/MWh.

- A taxa de indisponibilidade forçada e programada da unidade de ponta e a margem de reserva firme objetivo do SEIN, foram 
fixados em 3,0\% e 32,0\%, respectivamente, de acordo a resolução do Osinergmin.

- Para a elaboração do plano de obras de transmissão considerouse os projetos do plano transitório de transmissão com contrato em leilão ou em processo de leilão. Também se incluiu os projetos de transmissão dos concessionários, aprovados pelo MEM.

- Para a elaboração do plano de obras de geração de curto prazo considerou-se em primeiro lugar os projetos que contam com os estudos de operatividade estabelecidos pelo COES. De maneira complementar incluiu-se os projetos mais prováveis para entrada em operação neste período.

- Para o longo prazo, a oferta de geração está baseada na previsão realizado pelo COES. Tendo incerteza na cobertura da oferta adotou-se um programa de geração que considera os projetos hidrelétricos com concessão definitiva e data estimada de ingresso, os projetos com concessão temporária das empresas geradoras integrantes do COES, além dos projetos hidrelétricos localizados na Amazônia previstos para a exportação ao Brasil.

Para a simulação energética dos casos avaliados e outros parâmetros econômicos associados à operação do sistema, considerou-se a informação disponível até 31 dezembro de 2010.

Também foram utilizados os custos variáveis atualizados das unidades de geração até 2010, inclusive para as geradoras a gás natural. Os preços de gás consideram os custos de suprimento, transporte, e distribuição.

Além disso, é preciso mencionar que a rede de transmissão utiliza cálculos de fluxo de potência em cada barra do sistema, considerando limites nos fluxos de potência, o cálculo de perdas, assim como restrições de segurança. Uma visão geral da metodologia mostra-se na figura 47. 


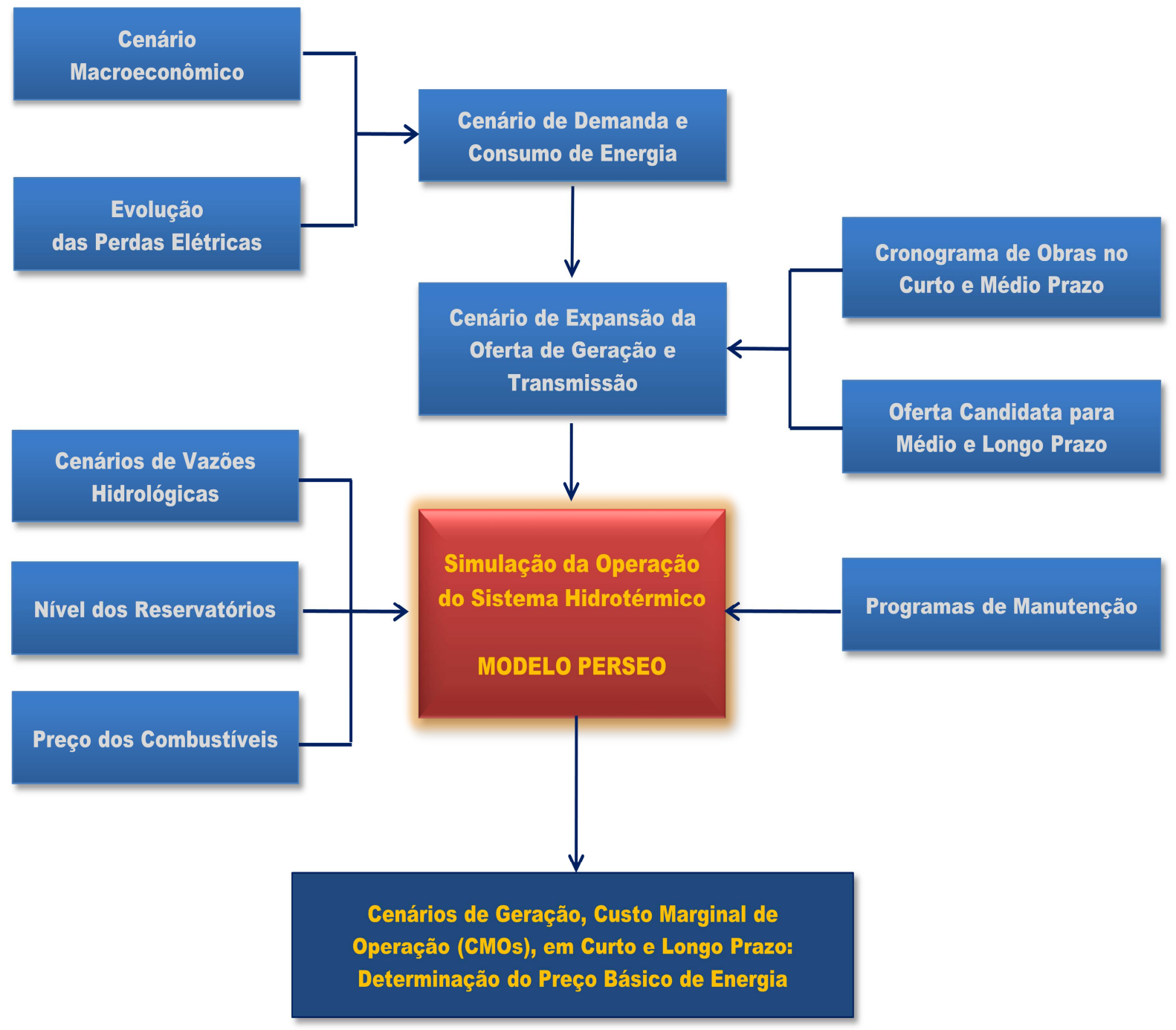

Figura 47 - Visão geral da metodologia.

As usinas eólicas e os projetos RER foram modelados como usinas térmicas com custos operacionais (custo variável de combustível, manutenção, etc.) nulos com o fim de se ter prioridade no despacho. Estas unidades são despachadas com uma potência média mensal, considerando os fatores de capacidade mensais de cada projeto com o intuito de avaliar a complementaridade existente com a geração hidrelétrica. A localização dos projetos RER no PERSEO foi considerada nas barras onde fisicamente se localizam cada um dos projetos.

O modelo apresenta como resultados os custos marginais, custos de congestão da transmissão, níveis de despachos, a energia gerada por cada fonte, além de outros resultados.

Os custos marginais do sistema são os indicadores de déficit ou excesso de energia e/ou restrições de transmissão em cada zona do país, e podem indicar as principais características da programação futura da geração do SEIN. 


\subsection{MODELO PERSEO}

Modelo matemático de simulação que permite determinar o despacho hidrotérmico de geração do SEIN, apresentando resultados dos custos marginais e custo futuro de energia em cada subestação elétrica principal do sistema, em diferentes horizontes de estudo. O despacho hidrotérmico é realizado mediante uma modelagem matemática, utilizando técnicas de otimização linear, que permite a entrada de dados de todo o sistema (demanda, hidrologia, planos de expansão da oferta, custos de combustível, etc.), considerando inclusive as restrições na transmissão.

Os estudos do custo marginal e diagnóstico da operação futura do setor são realizados com o objetivo de determinar o despacho a mínimo custo de suprimento da demanda do SEIN. Geralmente em horizontes de curto prazo (programação da operação) e de longo prazo (planejamento da operação).

O modelo é de uso oficial pelo órgão regulador (Osinergmin) e operador (COES) e empregado para os estudos tarifários e da operação econômica do SEIN, assim como para o planejamento da operação. No presente trabalho o modelo é utilizado como ferramenta de avaliação futura da operação econômica dos casos propostos.

\subsubsection{Características do Modelo Perseo}

O modelo permite, (CTE, 2000):

- Representar as características do sistema elétrico peruano:

- Multi-reservatório; representação individual da cada reservatório, tomadas de água, canais de condução e usinas hidrelétricas de cada bacia; respeitando sua disposição física e bacia hidrográfica.

- Multi-nodal; representação da cada nó (barra) do sistema elétrico de transmissão (SEIN) e do efeito de suas perdas;

- Multi-cenário; permite avaliar o desempenho do sistema 
frente a diversos cenários hidrológicos estabelecidos a partir de sequências hidrológicas geradas com os registros históricos de vazões afluentes ou com séries de vazões sintéticas.

Adicionalmente considera-se as seguintes características:

- A possibilidade de definir o número de blocos de demanda de energia representada através de uma curva de duração de carga, representando a demanda em múltiplos blocos horários.

- A possibilidade de realizar mudanças ou melhorias nos parâmetros que descrevem os elementos do sistema (linhas, canais de irrigação, usinas, etc.) durante o horizonte de análise.

- A possibilidade de agrupar as usinas sob uma denominação comum (empresas).

O modelo considera restrições operativas relevantes, (CTE, 2000):

- Custo de operação, que inclui o valor da água, os custos variáveis combustíveis e não combustíveis (gastos da manutenção), o custo de racionamento e as penalidades pelo desabastecimento das demandas agrícolas ou de água potável.

- Cronogramas de manutenção dos grupos termelétricos e unidades hidrelétricas.

- Potência efetiva das unidades de geração

- Para as usinas hidrelétricas:

- Registros hidrológicos.

- A simulação das bacias hidráulicas, com detalhe de capacidade de regulação anual, mensal, diária e horária dos reservatórios; limites de armazenagem e limites nos volumes turbinados dos reservatórios, vazões vertidas e absorvidas pelo solo, e as restrições de irrigação mínima para cada mês do horizonte de estudo, etc.

- Sequências hidrológicas geradas a partir dos registros históricos de vazamentos naturais afluentes a todos os pontos de interesse das bacias hidrográficas. 
- Para as usinas termelétricas:

- Catálogo de combustíveis, com a possibilidade de incorporar variações no preço ao longo do período de análise.

- Potências mínimas permissíveis.

- Rendimentos térmicos das unidades.

- Taxas de saída forçada das unidades.

- Para as linhas de transmissão:

- Representada através do fluxo de potência linear.

- Capacidades de transmissão.

- Parâmetros de tensão, extensão, resistência unitária e impedância unitária de cada linha.

O modelo apresenta como resultado da simulação da operação econômica do sistema, o despacho de cada unidade geradora. Especificado por sequência hidrológica e bloco horário, a seguinte informação:

- Plano otimizado de operação ao longo do horizonte de planejamento: energia e potência gerada, fluxos de energia e potência, perdas de energia e potência nas linhas de transmissão, vazões reguladas e turbinadas, volumes armazenados e vertidos, etc.

- Custos do sistema: operação, congestão nas linhas de transmissão, falha e outras penalidades por desabastecimento.

- Custos marginais em cada barragem do SEIN, bem como o valor da água em cada reservatório do sistema.

- Resumos das receitas por venda de energia e custos esperados por empresa, consumos esperados de combustível, receitas tarifárias nas linhas de transmissão, balanço econômico do sistema, etc.

- Consumo de combustíveis.

- Obtém resultados com uma resolução mensal.

A formulação matemática da função objetivo no modelo estocástico de operação de sistemas hidrotérmicos (PERSEO) para uma sequência hidrológica é 
representada através do modelo recursivo em programação dinâmica estocástica, como é indicado nas seguintes equações, (OSINERG, 2006a):

$$
\begin{aligned}
& \alpha_{t}\left(v_{t}, A_{t-1}\right)=E_{A t \mid A t+1}\left\{\operatorname{Min}\left[\sum_{j=1}^{N_{J}} c o_{j} g t_{j, t}+\alpha_{t+1}\left(v_{t+1}, A_{t}\right)\right]\right\} \\
& s / a \\
& \sum_{j \in k} g t_{j, t}+\sum_{i \in k} \rho_{i} q_{i, t}+\sum_{m \in \Omega(k)}\left(\left(1-0.5 \gamma_{m k, t}\right) f_{m k, t}-\left(1+0.5 \gamma_{k m, t}\right) f_{k m, t}\right)=d_{k, t} \quad \pi_{d_{k, t, s}}^{c p} \\
& g t_{j, t} \leq \overline{g t}_{j, t} \\
& f_{m k, t} \leq \bar{f}_{m k} \\
& \begin{array}{l}
v_{i, t+1}-v_{i, t}-\sum_{l \in M i}\left(q_{l}+s_{l}\right)+q_{i}+s_{i}=a_{i, t}- \\
v_{i, t, k-1}-v_{i, t, k}-\sum_{l \in M i}\left(q_{l}+s_{l}\right)+q_{i}+s_{i}=a_{i, t}
\end{array} \\
& v_{i, t} \leq \bar{v}_{i, t} \\
& v_{i, t} \geq \underline{v}_{i, t} \\
& v_{i, t, k} \leq \bar{v}_{i} \\
& q_{i, t} \leq \bar{q}_{i, t} \\
& q_{i, t} \geq \underline{q_{i, t}} \\
& r_{i, t} \leq \bar{r}_{i, t} \\
& r_{i, t} \geq \underline{r}_{i, t} \\
& f_{m k, t}=f_{m k}\left(\theta_{m}, \theta_{k}\right) \geq 0 \\
& \forall \quad k=1, \ldots, N_{K} ; \quad i=1, \ldots, N_{I} ; \quad j=1, \ldots, N_{J} ; \quad t=1, \ldots, N_{T} \\
& \pi_{g t_{j, t, s}}^{c p} \\
& \pi_{f_{m k, t, s}}^{c p} \\
& \pi_{a_{i, t, s}}^{c p} \\
& \pi_{v_{i, t, s}}^{c p} \\
& \pi_{q_{i, t, s}}^{c p} \\
& \pi_{r_{i, t, s}}^{c p}
\end{aligned}
$$

Onde:

$\mathrm{K} \quad$ Índice das barras elétricas equivalentes.

$N_{K} \quad$ Número total de barras equivalentes no sistema. 
$\Omega_{\mathrm{k}} \quad$ Conjunto de linhas de transmissão conectadas à barra equivalente $\mathrm{k}$.

$f_{m k, t}$ Fluxo de energia da barra equivalente $m$ para a barra equivalente $k$ na etapa $t$.

$\gamma_{m k, t}$ Coeficiente de perdas de fluxo de transmissão de $\mathrm{m}$ para $\mathrm{k}$ durante a etapa $\mathrm{t}$, expressado em \% do fluxo atual.

$d_{k, t}$ Demanda de energia na barra equivalente $\mathrm{k}$ durante a etapa $\mathrm{t}$.

$\bar{v}_{i, t} \quad$ Volume mínimo do reservatório.

$\underline{v}_{i, t} \quad$ Volume máximo do reservatório.

$\bar{v}_{i} \quad$ Volume máximo nos reservatórios diários.

$q_{i, t}$ Volume turbinado na i-ésima usina hidrelétrica durante a etapa t.

$\bar{q}_{i, t} \quad$ Volume máximo turbinado.

$\underline{q_{i, t}}$ Volume mínimo turbinado.

$r_{i, t} \quad$ Vazões reguladas.

$\underline{r}_{i, t} \quad$ Vazões mínimas reguladas de irrigação, navegação ou recreação.

$\bar{r}_{i, t} \quad$ Vazões máximas reguladas caso das grandes estações chuvosas.

Para efetuar a formulação matemática programou-se no modelo em linguagem FORTRAN e $\mathrm{C}++$ um conjunto de rotinas que traduzem os dados ingressados nas equações matemáticas correspondentes ${ }^{43}$.

$\mathrm{Na}$ figura 48 mostra-se o esquema funcional do Modelo. O primeiro nível corresponde à leitura dos arquivos de dados, os quais contêm toda a informação relevante que se requer para representar o sistema energético e elétrico no modelo matemático.

Uma vez efetuada a modelagem matemática, realiza-se a chamada à ferramenta de otimização, que neste caso, corresponde ao otimizador CPLEX®. Este otimizador encarrega-se de obter a solução de mínimo custo para cada uma das sequências hidrológicas avaliadas, com base nas várias técnicas de otimização linear.

Finalmente, de acordo com as opções de configuração de saída dos resultados definidas no arquivo correspondente geram-se os registros de resultados em um formato compatível com o EXCEL, (OSINERG, 2006b).

\footnotetext{
${ }^{43}$ Uma descrição com maior detalhe das equações matemáticas do modelo Perseo encontra-se no Anexo A.
} 


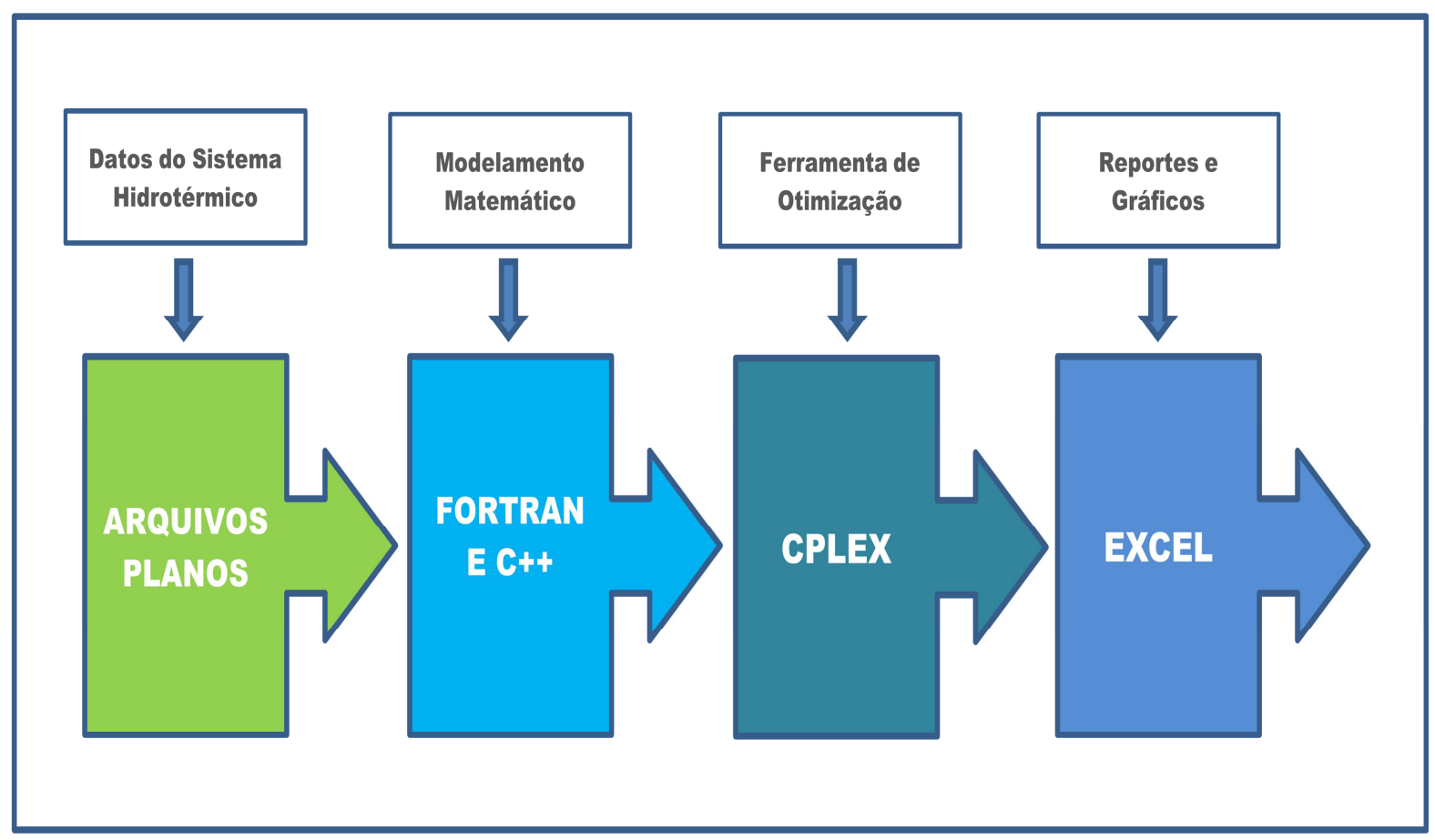

Figura 48 - Esquema funcional do modelo PERSEO.

Fonte: (OSINERG, 2006b).

\subsubsection{Módulos do Modelo Perseo}

O programa está estruturado em seis módulos. Cada um deles agrupa subprogramas e funções específicas para cumprir determinadas funções nos níveis definidos previamente no esquema funcional do modelo. A seguir são descritos os seis módulos, (OSINERG, 2006b).

Leitura: tem a função de ler os dados da oferta e demanda do sistema hidrotérmico. Além disso, prepara os dados para facilitar a utilização na construção do modelo matemático.

Cálculo: tem a função de realizar todos os cálculos necessários antes e depois do processo de otimização. Parte dos subprogramas deste módulo correspondem à formulação do modelo matemático.

Otimização: contém os subprogramas de otimização cuja função é encontrar a melhor solução ao modelo matemático proposto.

Operação: tem a função principal de administrar todos os subprogramas para efetuar o despacho hidrotérmico para cada sequência hidrológica avaliada. 
Planejamento: é o modelo mestre desde o qual é feita a coordenação e ligação a todos os subprogramas contidos nos módulos.

Impressão: tem a função de gerar todos os relatórios em formato CSV (Comma Separated Values), compatíveis com os arquivos Excel.

Os dados e variáveis de entrada utilizados no modelo PERSEO são organizados em arquivos, como é apresentado no quadro 12:

Quadro 12 - Arquivos de entrada no modelo PERSEO.

\begin{tabular}{|l|l|}
\hline SINAC.AFL: & Dados das afluências existentes nas bacias hidrográficas. \\
\hline SINAC.BAR: & Dados das barras do sistema elétrico. \\
\hline SINAC.CGT: & Dados das usinas termelétricas. \\
\hline SINAC.CHH: & Dados das usinas hidrelétricas. \\
\hline SINAC.CMB: & Dados dos combustiveis. \\
\hline SINAC.CUE: & Dados das bacias hidrográficas. \\
\hline SINAC.DAG: & Dados da configuração dos requisitos de água nas bacias hidrográficas. \\
\hline SINAC.DAT: & Dados gerais do estudo. \\
\hline SINAC.DEM: & Dados da demanda de energia nos barramentos. \\
\hline SINAC.EMB: & Dados dos reservatórios existentes nas bacias hidrográficas. \\
\hline SINAC.EMP: & Dados das empresas que agrupam UTEs e UHEs. \\
\hline SINAC.GTT: & Dados dos grupos termelétricos. \\
\hline SINAC.HID: & Series de vazões hidrológicas dos afluentes. \\
\hline SINAC.HOR: & Duração dos blocos horários. \\
\hline SINAC.LIN: & Dados das linhas do sistema elétrico modelado. \\
\hline SINAC.MAN: & Dados de manutenção das usinas UTEs e UHEs. \\
\hline SINAC.PAR: & Parâmetros de execução e de impressão de resultados. \\
\hline SINAC.PIN: & Dados dos puntos de interés nas bacias hidrográficas. \\
\hline SINAC.RGO: & Dados de requisitos de água. \\
\hline SINAC.TRY: & Dados da configuração hidráulica das bacias hidrográficas. \\
\hline
\end{tabular}

Fonte: (OSINERG, 2006b).

\subsection{CONSIDERAÇÕES DOS DADOS DE ENTRADA}

$\mathrm{Na}$ construção dos dados de entrada na simulação, considera-se a projeção da demanda no período (2011 - 2020) para os horizontes de estudo de curto e longo prazo. Os dois componentes importantes da demanda: a demanda vegetativa e a demanda de grandes cargas (cargas especiais, cargas incorporadas e projetos) foram projetadas mediante o uso de um modelo econômetrico e a recompilação de informação direta dos agentes e promotores de novos projetos, 
respectivamente.

$\mathrm{Na}$ projeção da demanda econométrica considera as seguintes variáveis:

- Vendas históricas de energia do sistema elétrico interconectado nacional (SEIN) desde 1981 até 2009.

- Prognóstico do Produto Interno Bruto (PIB) de 2010 até 2022.

- Série histórica do crescimento populacional e sua projeção no período (2010 - 2022).

- Valores históricos da tarifa ao cliente final para o período 1981 2009.

- Para o período (2010 - 2022) supôs-se que a tarifa se mantém no valor da tarifa estimada do ano 2009.

A projeção da demanda de grandes cargas incorpora a contribuição de três grupos importantes de carga: cargas especiais, incorporações e projetos, e estão baseados nos resultados de declarações efetuados pelos empreendedores, proprietários e grandes consumidores do sistema.

O operador do sistema (COES) também realiza a distribuição de demanda por zonas e barras do SEIN em função de fatores de distribuição típicos resultantes dos registros históricos. O quadro 13 apresenta a demanda considerada no período $2011-2020$.

Quadro 13 - Projeção da demanda no período (2011 - 2020).

\begin{tabular}{|c|c|c|c|c|}
\hline \multirow{2}{*}{ Ano } & \multicolumn{2}{|c|}{ Potência } & \multicolumn{2}{c|}{ Energia } \\
\cline { 2 - 5 } & MW & \% & GWh & $\%$ \\
\hline 2011 & 4967 & $9,0 \%$ & 35311 & $9,0 \%$ \\
2012 & 5370 & $8,7 \%$ & 38662 & $9,5 \%$ \\
2013 & 6100 & $13,6 \%$ & 43374 & $14,5 \%$ \\
2014 & 6856 & $12,4 \%$ & 48883 & $12,7 \%$ \\
2015 & 7440 & $8,5 \%$ & 54085 & $10,6 \%$ \\
2016 & 7867 & $5,8 \%$ & 57106 & $5,6 \%$ \\
2017 & 8385 & $6,7 \%$ & 60648 & $6,2 \%$ \\
2018 & 8763 & $4,5 \%$ & 63204 & $4,2 \%$ \\
2019 & 9216 & $5,2 \%$ & 66201 & $4,7 \%$ \\
2020 & 9702 & $5,3 \%$ & 69575 & $5,1 \%$ \\
\hline
\end{tabular}

Fonte: (COES, 2011a). 
O plano de obras de geração de curto prazo considera em primeiro lugar os projetos hidrelétricos e termelétricos baseados em estudos de operatividade já determinado pelo COES. De maneira complementar incluiu-se os projetos mais prováveis de entrar em operação nesse período, além dos projetos RER com contrato e entrada em operação comercial nesse mesmo cenário.

Já para o plano de obras de geração de longo prazo, tendo em vista incerteza na cobertura da oferta de geração, elaborou-se um programa de geração que considera os projetos hidrelétricos, termelétricos e projetos RER com concessão definitiva (com data estimada de operação comercial), os projetos de concessão temporária das empresas geradoras integrantes do COES (projetos em estudo) e os projetos hidrelétricos da Amazônia previstos para a exportação ao Brasil. Projetos que são apresentados nos quadros 14, 15, 16 e 17.

Quadro 14 - Programa de obras de projetos hidrelétricos (2011 - 2020).

\begin{tabular}{|l|c|c|}
\hline \multicolumn{2}{|c|}{ PROJETOS HIDRELÉTRICOS } \\
\hline \multicolumn{1}{|c|}{ Nome } & Pot. Efetiva (MW) & Data \\
\hline UHE Pias I & 12,6 & $\mathrm{dez} / 12$ \\
UHE Machupicchu 2da. Etapa & 101,8 & $\mathrm{jan} / 13$ \\
UHE Huanza & 90,6 & $\mathrm{fev} / 13$ \\
UHE Santa Teresa & 90,7 & $\mathrm{ago} / 14$ \\
UHE Quitaracsa & 112,0 & $\mathrm{out} / 14$ \\
UHE Cheves & 168,0 & $\mathrm{dez} / 14$ \\
UHE La Virgen & 64,0 & $\mathrm{jan} / 15$ \\
UHE Chaclla & 400,0 & $\mathrm{dez} / 15$ \\
UHE Cerro del Aguila & 402,0 & $\mathrm{jan} / 16$ \\
UHE Santa Rita & 255,0 & $\mathrm{jan} / 18$ \\
UHE San Gaban 1 & 150,0 & $\mathrm{jan} / 18$ \\
UHE Pucara 720 & 130,0 & $\mathrm{jan} / 18$ \\
UHE Tarucani & 50,0 & $\mathrm{jan} / 19$ \\
UHE San Gaban 4 & 82,0 & $\mathrm{jan} / 19$ \\
UHE Marañon & 96,0 & $\mathrm{jan} / 19$ \\
UHE Belo Horizonte & 180,0 & $\mathrm{jan} / 20$ \\
UHE Santa Maria & 750,0 & $\mathrm{jan} / 20$ \\
UHE San Gaban 3 & 187,9 & $\mathrm{jan} / 20$ \\
UHECuribamba & 195,0 & $\mathrm{jan} / 20$ \\
UHE Churo & 35,5 & $\mathrm{jan} / 20$ \\
UHE Pelagatos & 25,0 & $\mathrm{jan} / 20$ \\
UHE Tambo1 & 54,0 & $\mathrm{jan} / 20$ \\
UHE Carhuac & 20,0 & $\mathrm{jan} / 20$ \\
\hline
\end{tabular}

Fonte: (COES, 2011a). 
Quadro 15 - Programa de obras de projetos termelétricos (2011 - 2020).

\begin{tabular}{|c|c|c|}
\hline \multicolumn{3}{|c|}{ PROJETOS TERMELÉTRICOS } \\
\hline Nome & Pot. Efetiva (MW) & Data \\
\hline UTE Reserva Fría - Mollendo & 60,0 & ago/11 \\
\hline UTE Reserva Fría - Trujillo & 60,0 & ago/11 \\
\hline UTE Kallpa - TV - Ciclo Combinado - KALLPA & 292,8 & set/12 \\
\hline UTE Nueva Esperanza - TG123 & 135,0 & $\mathrm{jan} / 13$ \\
\hline UTE Quillabamba - (4 TGs - 50 MW) & 200,0 & $\mathrm{fev} / 13$ \\
\hline UTE Santo Domingo de los Olleros - TG1 & 197,6 & $a b r / 13$ \\
\hline UTE C.C. Fenix - TG1 + TG2 + TV - FENIX & 534,3 & $\mathrm{abr} / 13$ \\
\hline UTE C.C. Chilca 1 - TV - ENERSUR & 262,0 & ago/13 \\
\hline UTE Turbo Gas Dual D2 - ILO & 400,0 & out/13 \\
\hline UTE Turbo Gas Dual D2 - Talara & 200,0 & set/13 \\
\hline UTE Turbo Gas Dual D2 - Chiclayo & 200,0 & fev/14 \\
\hline UTE C.C. Santo Domingo de los Olleros & 99,3 & $\mathrm{abr} / 14$ \\
\hline UTE EI Faro - TG - GN - SHOUGESA & 169,0 & $\mathrm{jul} / 14$ \\
\hline UTE EI Faro - TV - C.C. - SHOUGESA & 88,0 & $\mathrm{jul} / 15$ \\
\hline UTE Piura & 30,0 & $\mathrm{jan} / 18$ \\
\hline UTE Trujillo -2TG+TV1 & 520,0 & $\mathrm{jan} / 20$ \\
\hline UTE IIo -2TG+TV1 & 520,0 & $\mathrm{jan} / 20$ \\
\hline UTE Trujillo $-2 T G+T V 2$ & 520,0 & $\mathrm{jan} / 20$ \\
\hline
\end{tabular}

Fonte: (COES, 2011a).

Quadro 16 - Programa de obras de projetos RER (2011 - 2020).

\begin{tabular}{|c|c|c|}
\hline \multicolumn{3}{|c|}{ PROJETOS RER } \\
\hline Nome & Pot. Efetiva (MW) & Data \\
\hline $\begin{array}{l}\text { PCH Purmacana } \\
\text { UTE Biomasa Huaycoloro } \\
\text { PCH Nueva Imperial } \\
\text { PCH Huasahuasi II } \\
\text { PCH Huasahuasi I } \\
\text { PCH Shima } \\
\text { PCH Yanapampa } \\
\text { Usina Solar Panamericana } \\
\text { Usina Solar Majes } \\
\text { Usina Solar Repartición } \\
\text { Usina Solar Tacna } \\
\text { PCH Chancay } \\
\text { PCH Angel I } \\
\text { PCH Angel II } \\
\text { PCH Angel III } \\
\text { PCH Las Pizarras } \\
\text { PCH Manta } \\
\text { UTE Biomasa La gringa V } \\
\text { Usina Solar Moquegua FV } \\
\text { PCH Canchayllo } \\
\text { PCH Huatziroki I } \\
\text { PCH RenovAndes H1 } \\
\text { PCH } 8 \text { De Agosto } \\
\text { PCH El Carmen } \\
\text { PCH Runatullo III }\end{array}$ & $\begin{array}{c}1,8 \\
4,4 \\
4,0 \\
8,0 \\
7,8 \\
5,0 \\
4,1 \\
20,0 \\
20,0 \\
20,0 \\
20,0 \\
19,2 \\
20,0 \\
20,0 \\
20,0 \\
18,0 \\
19,8 \\
2,0 \\
16,0 \\
3,7 \\
11,1 \\
20,0 \\
19,0 \\
8,4 \\
20,0\end{array}$ & $\begin{array}{l}\text { jul/11 } \\
\text { jul/11 } \\
\text { set/11 } \\
\text { abr/12 } \\
\text { out/12 } \\
\text { out/12 } \\
\text { dez/12 } \\
\text { jan/13 } \\
\text { jan/13 } \\
\text { jan/13 } \\
\text { jan/13 } \\
\text { jan/13 } \\
\text { jan/13 } \\
\text { jan/13 } \\
\text { jan/13 } \\
\text { jan/13 } \\
\text { mai/13 } \\
\text { jul/14 } \\
\text { dez/14 } \\
\text { dez/14 } \\
\text { dez/14 } \\
\text { dez/14 } \\
\text { dez/14 } \\
\text { dez/14 } \\
\text { jul/14 }\end{array}$ \\
\hline
\end{tabular}

Fonte: (COES, 2011a). 
Quadro 17 - Projetos hidrelétricos da Amazônia para exportação ao Brasil.

\begin{tabular}{|l|c|c|}
\hline \multicolumn{3}{|c|}{ PROJETOS HIDRELÉTRICOS EXPORTAÇÃO BRASIL } \\
\hline \multicolumn{1}{|c|}{ Nome } & Pot. Efetiva (MW) & Data \\
\hline UHE Inambari & 2200,0 & jan/20 \\
UHE Tambo 40 & 1286,0 & jan/20 \\
UHE Paquitzapango & 2000,0 & jan/20 \\
UHE Mainique 1 & 607,0 & jan/20 \\
UHE TAMBO 60 & 580,0 & jan/20 \\
\hline
\end{tabular}

Fonte: (COES, 2011a).

O plano de obras de transmissão considera os projetos do plano transitório de transmissão com contrato ou concessão, os projetos comprometidos no primeiro plano de transmissão (PPT) do SEIN, além dos projetos em processo de leilão. Também se incluiu os projetos dos concessionários de transmissão aprovados pelo MEM para o período de análise (2011-2020), apresentados no quadro 18.

Quadro 18 - Plano de obras de transmissão SEIN (2011 - 2020).

\begin{tabular}{|c|c|}
\hline Data & Projetos Transmissão \\
\hline $\begin{array}{c}\text { fev/11 } \\
\text { fev/11 } \\
\text { mar/11 } \\
\text { jul/11 } \\
\text { jan/12 } \\
\text { jun/12 } \\
\text { jun/12 } \\
\text { jan/13 } \\
\text { mar/13 } \\
\text { abr/13 } \\
\text { jul/13 } \\
\text { dez/13 } \\
\text { jul/13 } \\
\text { jan/14 } \\
\text { jan/14 } \\
\text { jan/14 } \\
\text { jan/14 }\end{array}$ & $\begin{array}{l}\text { L.T. } 500 \text { kV Mantaro - Caravelí - Montalvo. } \\
\text { L.T. } 220 \text { kV Machupicchu - Cotaruse. } \\
\text { L.T. } 500 \text { kV Chilca - Zapallal (circuito simples). } \\
\text { S.E. } 220 / 60 \text { kV - } 180 \text { MVA - Los Industriales. } \\
\text { L.T. } 138 \text { kV Interligação Tarapoto - Moyobamba - Bellavista (Sistema Isolado). } \\
\text { L.T. } 500 \text { kV Zapallal - Trujillo. } \\
\text { L.T. } 500 \text { kV Chilca - Marcona - Caravelí. } \\
\text { L.T. } 220 \text { kV Machupicchu - Abancay - Cotaruse (dupla terna) e SS.EE. associados. } \\
\text { S.E. } 220 / 60 \text { kV - } 85 \text { MVA Los Industriales - Adição Transformador. } \\
\text { L.T. } 220 \text { kV Tintaya - Socabaya (dupla terna) e SS.EE. associados. } \\
\text { L.T. } 500 \text { kV Chilca - Marcona - Montalvo e SS.EE. associados. } \\
\text { L.T. } 500 \text { kV Trujillo - Chiclayo e SS.EE. associados. } \\
\text { L.T. } 220 \mathrm{kV} \text { Cajamarca Norte - Cadic e SS.EE. associados. } \\
\text { L.T. } 138 \mathrm{kV} \text { Cadic - Moyobamba e SS.EE. associados. } \\
\text { L.T. } 220 \mathrm{kV} \text { Machupicchu - Quencoro - Onocora e SS.EE. associados. } \\
\text { S.E. } 220 / 138 \text { kV - } 50 \text { MVA Quencoro. } \\
\text { L.T. } 220 \mathrm{kV} \mathrm{Onocora} \mathrm{-} \mathrm{Tintaya.}\end{array}$ \\
\hline $2016-2020$ & 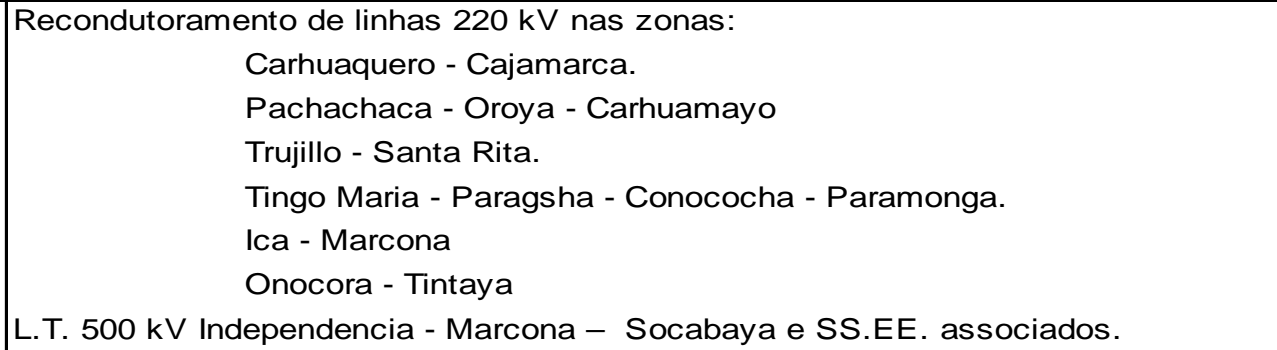 \\
\hline
\end{tabular}

Fonte: (COES, 2011a). 
O sistema hidrológico do SEIN é composto por reservatórios que obedecem a diferentes necessidades, tais como: geração de energia elétrica, irrigação e água potável. Como no presente estudo a prioridade do uso da água é para geração elétrica, só se otimizou os reservatórios que obedecem estritamente a necessidades de energia elétrica. As descargas dos reservatórios que obedecem a necessidades de irrigação e água potável, informadas pelos integrantes, foram consideradas como restrições de operação.

No presente estudo, os valores utilizados dos preços de combustíveis líquidos, carvão e gás natural foram atualizados e estimados pelo COES e pelo MEM no plano referencial de eletricidade (2008 - 2017). Para o caso dos preços de gás natural de Camisea, estes preços resultam da aplicação dos contratos de seu fornecimento, transporte e distribuição. 


\section{IMPACTOS NO SISTEMA HIDROTERMICO PERUANO}

Este capítulo apresenta os resultados obtidos da simulação e análise da operação econômica do sistema hidrotérmico peruano com inserção da energia eólica e expansão das termelétricas a gás natural realizada mediante a utilização do modelo matemático de simulação PERSEO, levando em conta os cenários de oferta e demanda do SEIN para o período (2011-2020), assim como as premissas dos casos de estudo indicados na metodologia.

\subsection{RESULTADOS NO CURTO PRAZO (2011 - 2013)}

Neste período foram avaliados os impactos da inserção de $142 \mathrm{MW}$ de energia eólica na operação econômica do SEIN. Das simulações realizadas foram obtidos resultados que mostram indicadores que nos permitiram determinar o grau de impacto desta fonte, assim como a participação fundamental das termelétricas a gás natural no atendimento da demanda futura do mercado elétrico peruano.

\subsubsection{Expansão de Referência sem Energia Eólica}

Como referência foi simulado o caso de expansão do SEIN sem geração eólica, mantendo todas as características atuais do sistema, assim como tendo em conta a programação da oferta e demanda com data de entrada estimada nesse período. Os resultados da simulação do despacho de energia são mostrados na figura 49. 


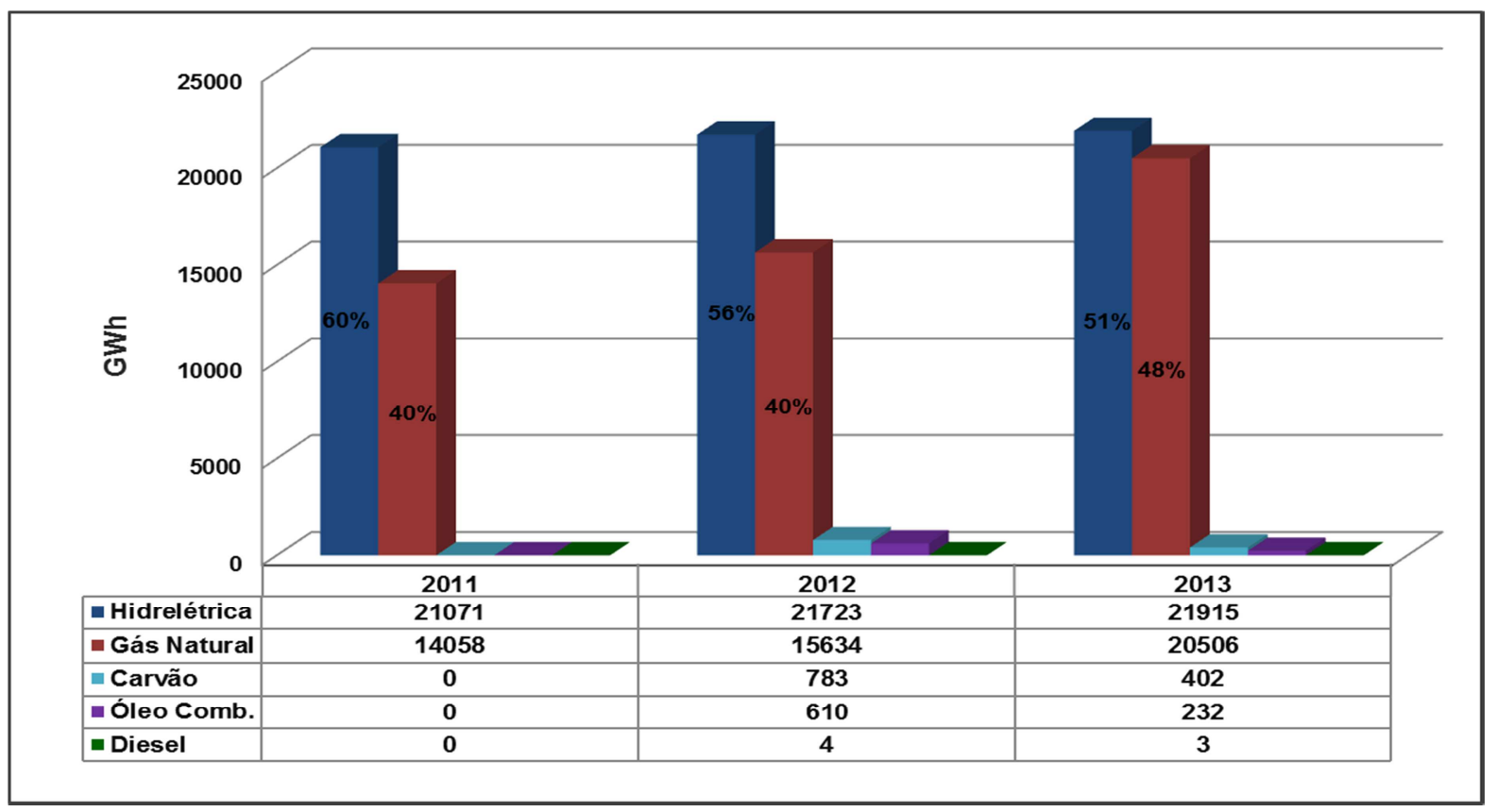

Figura 49 - Energia sem geração eólica no curto prazo.

Verifica-se que a geração hidrelétrica tem a maior participação, seguida pelas termelétricas a gás natural, sendo que estas atingem, em 2013, 48\% de participação do total de energia despachada do SEIN. O restante de oferta de geração é completado com térmicas a carvão, óleo combustível e diesel, como é mostrado na figura 50 , a seguir.

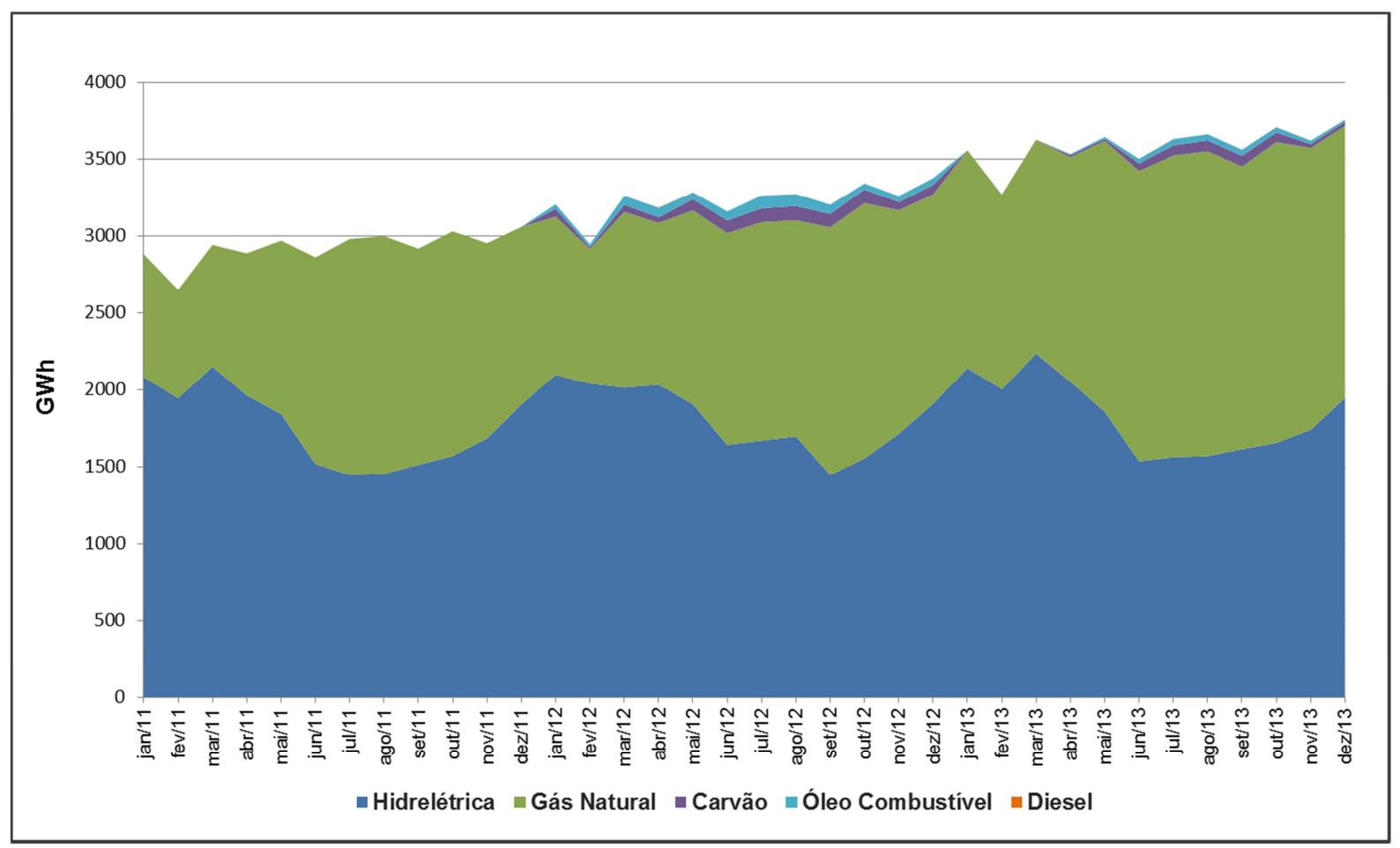

Figura 50 - Produção de energia por tipo de fonte no curto prazo. 


\subsubsection{Expansão com Inserção de Energia Eólica}

Os resultados da operação econômica do SEIN, apresentam o despacho de 261 GWh de energia eólica em 2012, ano de entrada em operação comercial dos primeiros parques eólicos, atingindo, em 2013, $609 \mathrm{GWh}$, como é mostrado na figura 51.

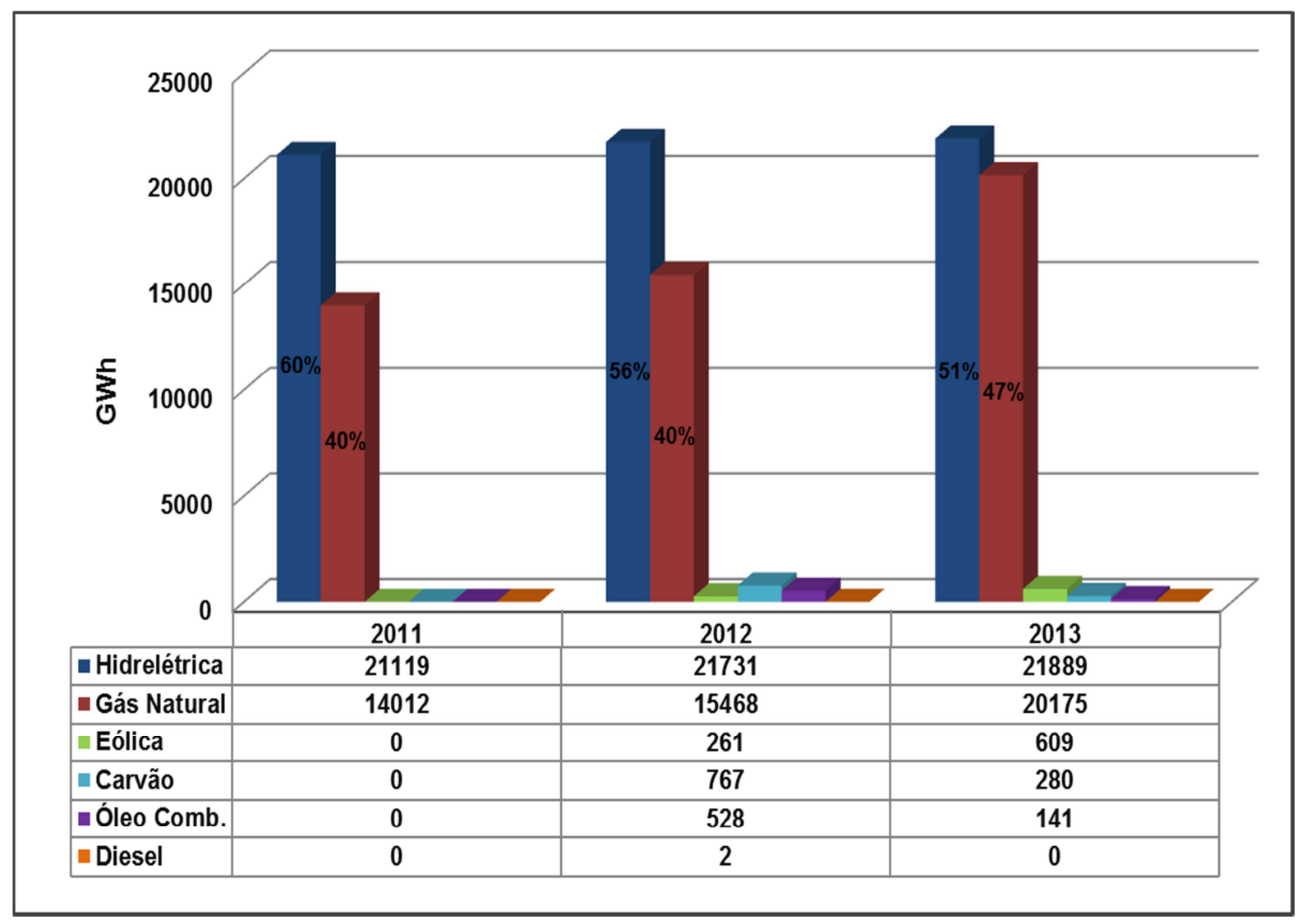

Figura 51 - Energia com geração eólica no curto prazo.

A partir da entrada da primeira usina eólica em julho de 2012 até atingir em dezembro desse mesmo ano $142 \mathrm{MW}$ de capacidade, a evolução da participação desta fonte no despacho apresenta uma participação crescente, alcançando em 2013 uma participação de 1,4\% do total de energia gerada no SEIN, como é apresentado no quadro 19. 
Quadro 19 - Participação de energia por tipo de fonte no curto prazo (GWh).

\begin{tabular}{|l|l|r|r|r|}
\hline \multicolumn{2}{|c|}{ Fonte } & \multicolumn{1}{c|}{2011} & \multicolumn{1}{c|}{$\mathbf{2 0 1 2}$} & \multicolumn{1}{c|}{2013} \\
\hline Hidrelétrica & Hidro & $60,1 \%$ & $56,1 \%$ & $50,8 \%$ \\
\hline \multirow{3}{*}{ Termelétrica } & Gás Natural & $39,9 \%$ & $39,9 \%$ & $46,8 \%$ \\
& Carvão & $0,0 \%$ & $2,0 \%$ & $0,6 \%$ \\
& Óleo Comb. & $0,0 \%$ & $1,4 \%$ & $0,3 \%$ \\
& Diesel & $0,0 \%$ & $0,0 \%$ & $0,0 \%$ \\
\hline Eólica & Eólica & $0,0 \%$ & $0,7 \%$ & $1,4 \%$ \\
\hline & Total & $100 \%$ & $100 \%$ & $100 \%$ \\
\cline { 2 - 5 } & & & & \\
\end{tabular}

A geração hidrelétrica e termelétrica a gás natural mantém seus níveis de participação em relação ao caso de referência sem geração eólica, com pequenas diferenças entre cada caso. Estas duas fontes operam na base, contribuindo com a geração de mais de $97 \%$ da energia requerida pelo sistema.

Por outro lado, o contrário acontece com a geração térmica a carvão, óleo combustível e diesel que tiveram uma menor participação, sendo deslocadas pela geração eólica, como é apresentado na figura 52.

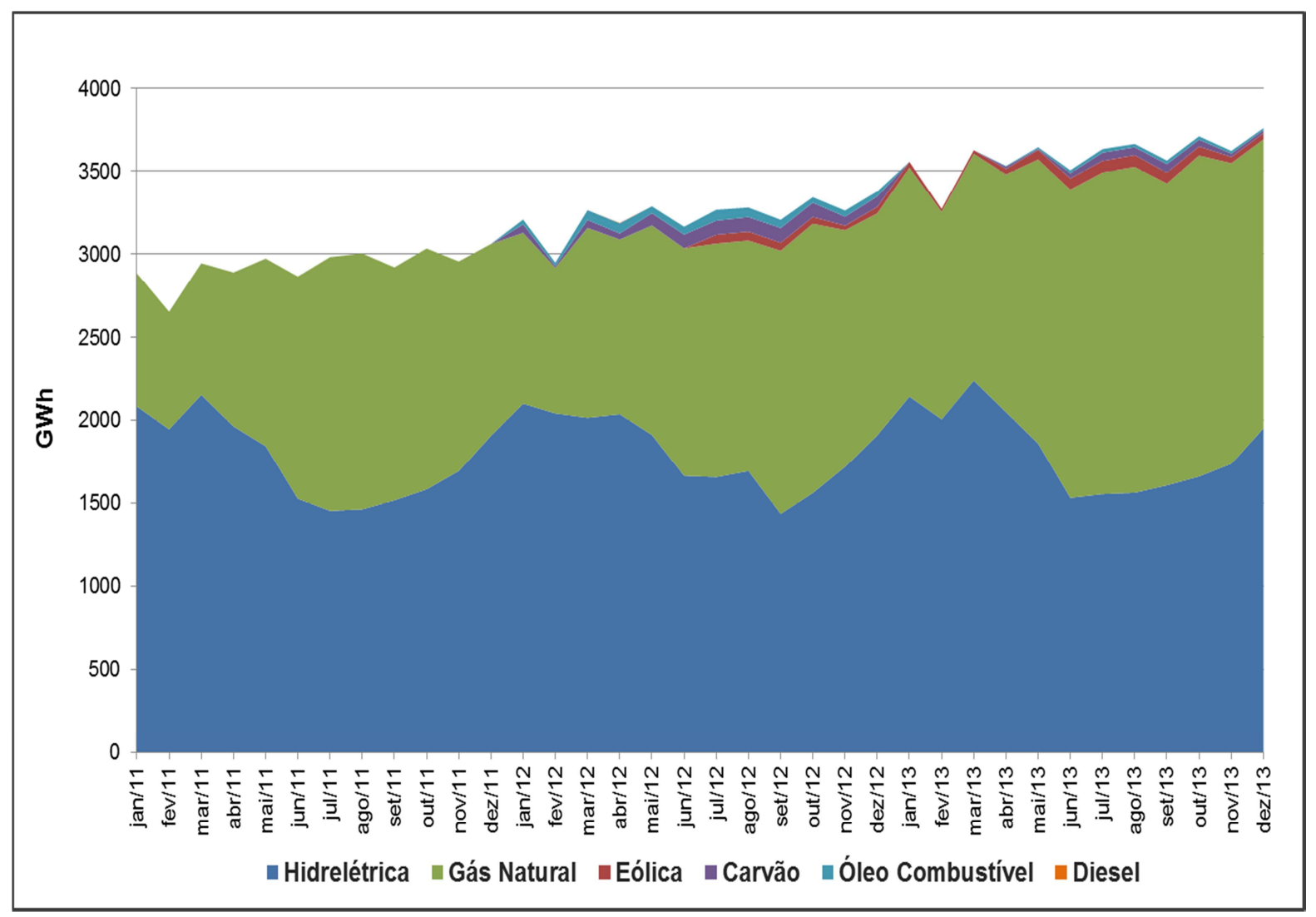

Figura 52 - Produção de energia por tipo de fonte no curto prazo. 


\subsubsection{Impacto no Custo Marginal de Operação (CMO)}

A partir dos resultados obtidos da simulação foi realizada a comparação dos custos marginais de operação entre os casos de estudo com e sem inserção de energia eólica, mantendo a equivalência dos sistemas nos mesmos níveis de garantia física e características para ambos os casos.

Os resultados apresentaram a diminuição do custo marginal de operação (CMO) a partir da entrada em operação da energia eólica, comparados ao caso de referência sem eólicas, como é apresentando na figura 53.

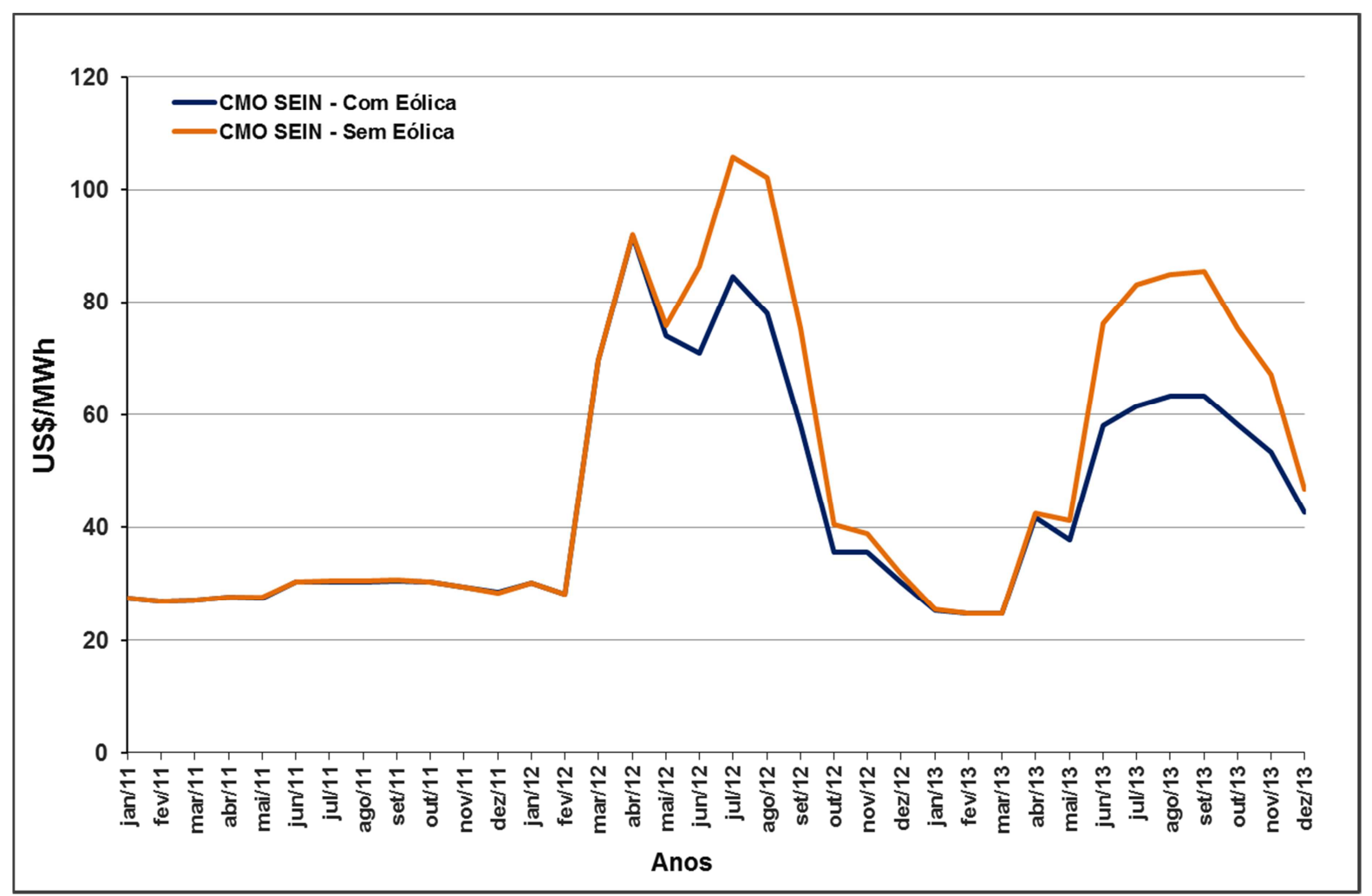

Figura 53 - Custo marginal de operação no curto prazo.

A queda do custo marginal médio anual do SEIN em 2012, gerado pela inserção da geração eólica, apresenta um valor $12 \%$ menor em relação ao caso da operação sem geração eólica, chegando a 18\%, em 2013, como é mostrado na figura 54 a seguir. 


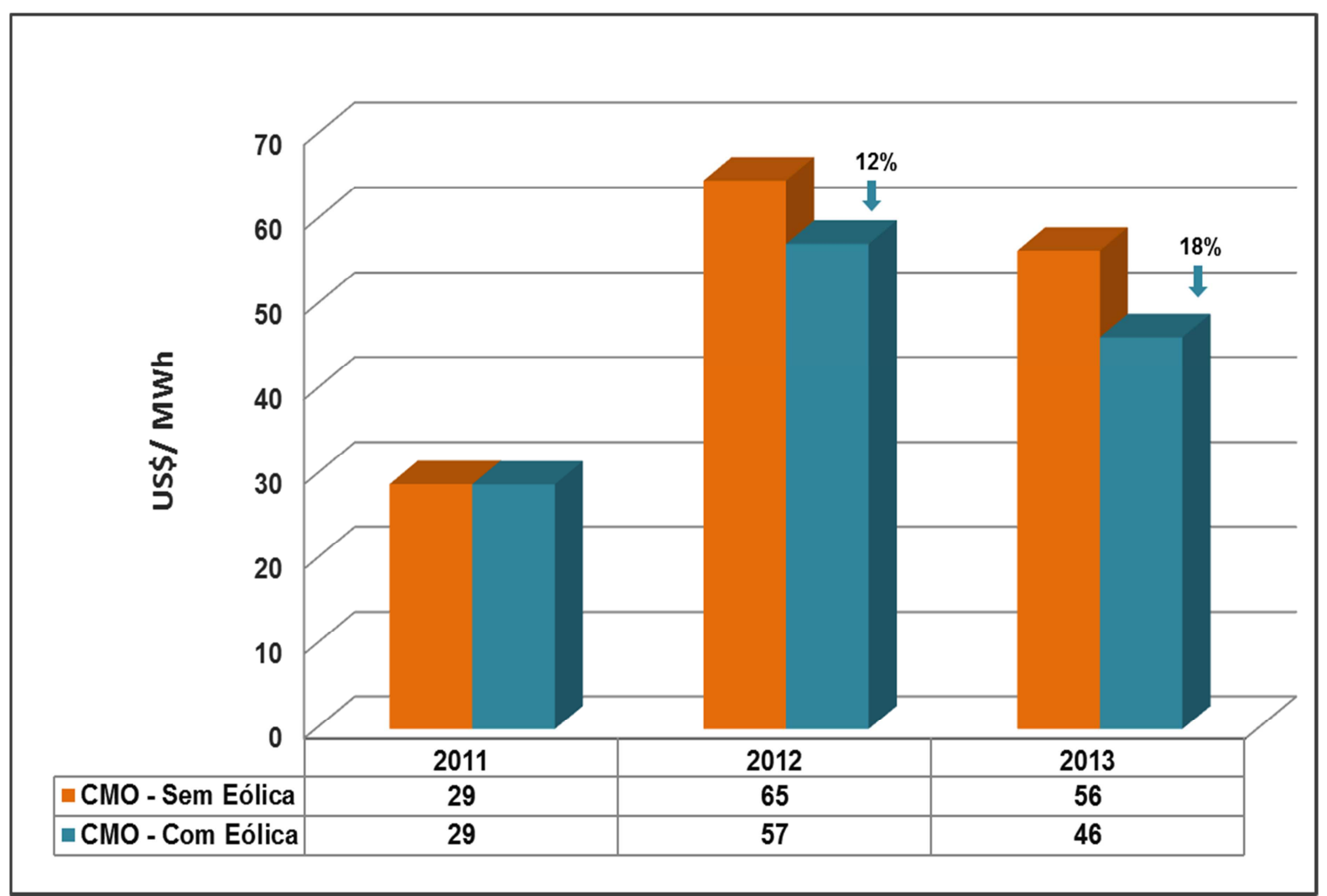

Figura 54 - Custo marginal médio anual no curto prazo.

A queda do custo marginal de operação (CMO) é originada pelo menor custo de operação das usinas eólicas em relação às térmicas de maior custo, como as usinas a diesel, óleo combustível e carvão, que deixaram de despachar no sistema, permitindo a geração de energia a menores custos médios anuais.

\subsubsection{Impacto no Custo de Operação}

A operação do mercado hidrotérmico peruano avaliado com base nas duas hipóteses propostas na metodologia do presente estudo, com e sem participação de geração eólica, apresenta resultados favoráveis à geração eólica, permitindo diminuir os custos de operação do sistema, como é apresentado na figura 55. 


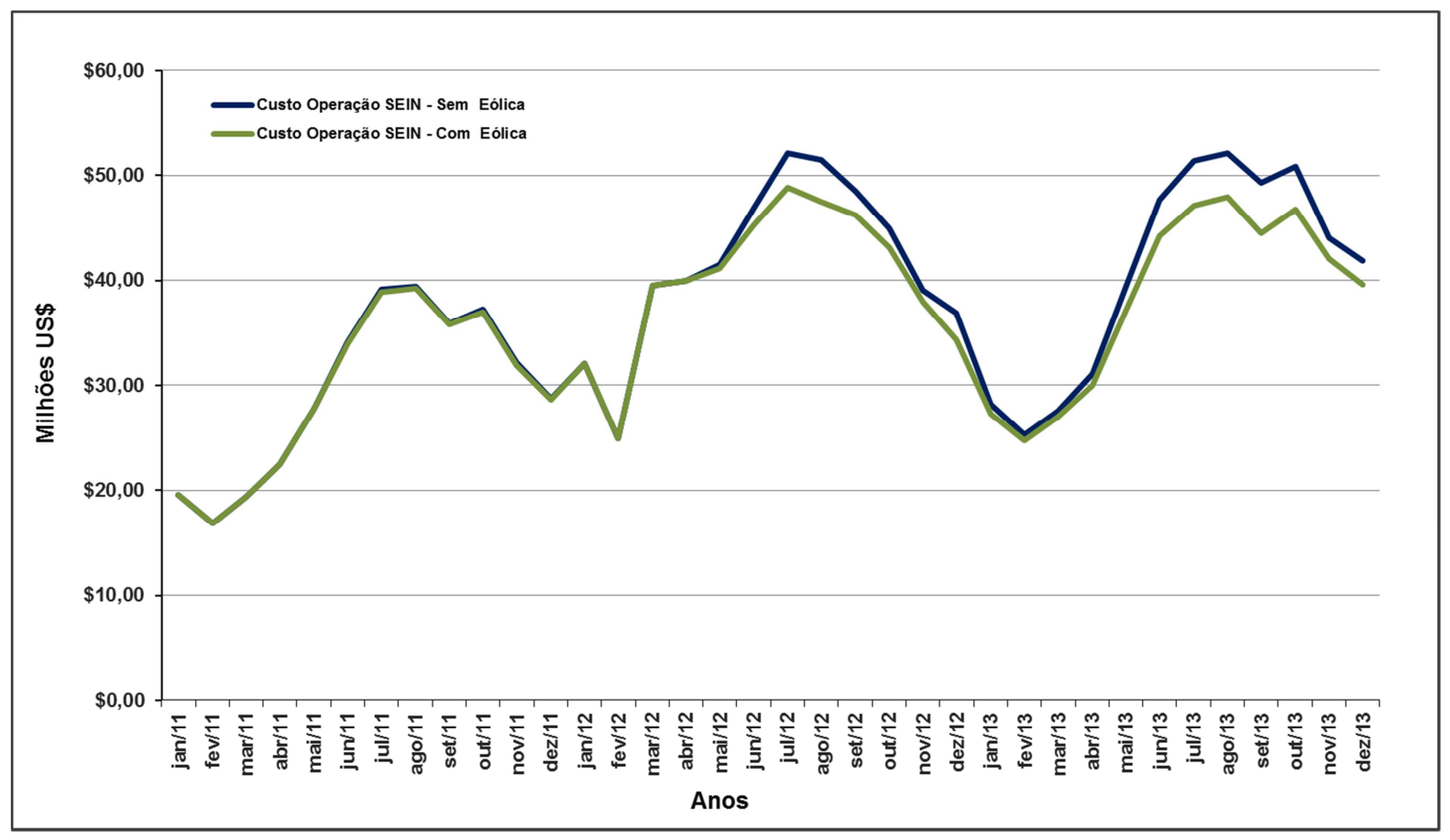

Figura 55 - Evolução do custo de operação no curto prazo.

O menor custo de operação do SEIN gerado pela inserção da geração eólica permite ao sistema diminuir as despesas em torno de 17 milhões de dólares em 2012 e até US\$ 30 milhões em 2013, o que representa uma queda de $3 \%$ e 6\%, respectivamente, como é apresentado na figura 56 , a seguir.

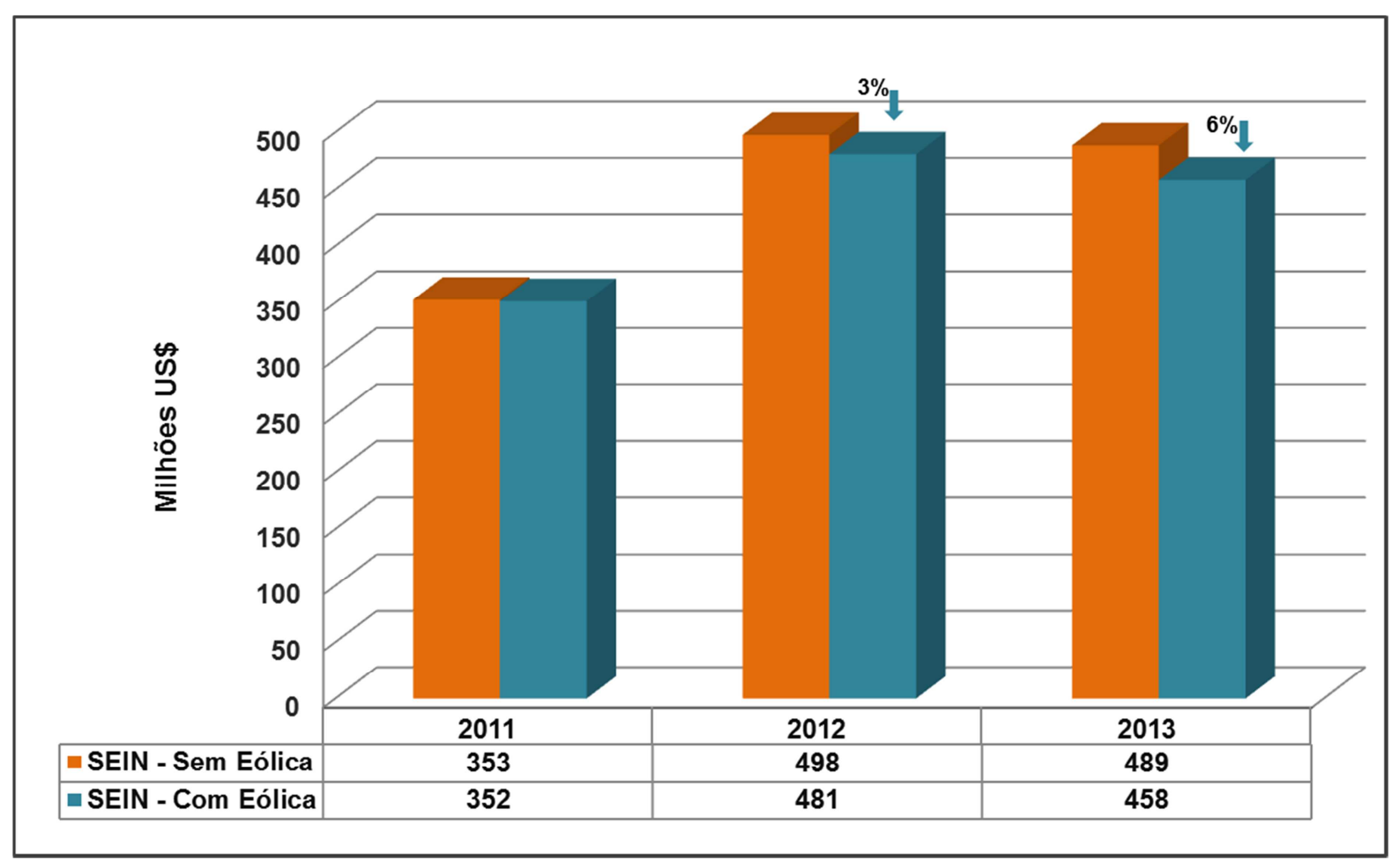

Figura 56 - Custo de operação no curto prazo. 


\subsubsection{Impacto na Geração Termelétrica}

Os resultados das simulações apresentam deslocamento na geração térmica, principalmente para as usinas que têm o maior custo variável de combustível, isto é, aquelas que operam com diesel, óleo combustível e carvão, sendo deslocadas em $100 \%$, 39\% e 30\%, respectivamente, no despacho do SEIN em 2013, como é apresentado no quadro 20.

Quadro 20 - Deslocamento de geração térmica no curto prazo.

\begin{tabular}{|r|l|r|r|r|r|r|r|}
\hline \multicolumn{2}{|c|}{ Fonte } & \multicolumn{2}{|c|}{2011} & \multicolumn{2}{c|}{2012} & \multicolumn{2}{c|}{2013} \\
\cline { 2 - 8 } & \multicolumn{2}{|c|}{ GWh } & $\%$ & GWh & \multicolumn{1}{c|}{$\%$} & GWh & \multicolumn{1}{c|}{$\%$} \\
\hline Hidrelétrica & Hidro & 0 & $0 \%$ & 0 & $0 \%$ & 27 & $0 \%$ \\
\hline \multirow{5}{*}{ Termelétrica } & Gás Natural & 0 & $0 \%$ & 166 & $1 \%$ & 332 & $2 \%$ \\
& Carvão & 0 & $0 \%$ & 15 & $2 \%$ & 122 & $30 \%$ \\
& Óleo Comb. & 0 & $0 \%$ & 82 & $13 \%$ & 91 & $39 \%$ \\
& Diesel & 0 & $0 \%$ & 1 & $40 \%$ & 3 & $100 \%$ \\
\hline
\end{tabular}

Existe deslocamento da geração termelétrica a gás natural, embora pequeno em termos porcentuais, comparado ao total, em quantidade de energia, é bastante considerável, em torno de 332 GWh em 2013, o que não gera grande impacto nos custos de operação do sistema, pelo fato da geração a gás natural ter o custo de combustível baixo.

Por outro lado, o contrário acontece com a geração térmica, com custos de combustíveis mais caros, como o diesel, óleo combustível e carvão que impactam fortemente no custo final. A seguir, é apresentado na figura 57, o deslocamento das térmicas com maior custo variável de combustível do SEIN. 


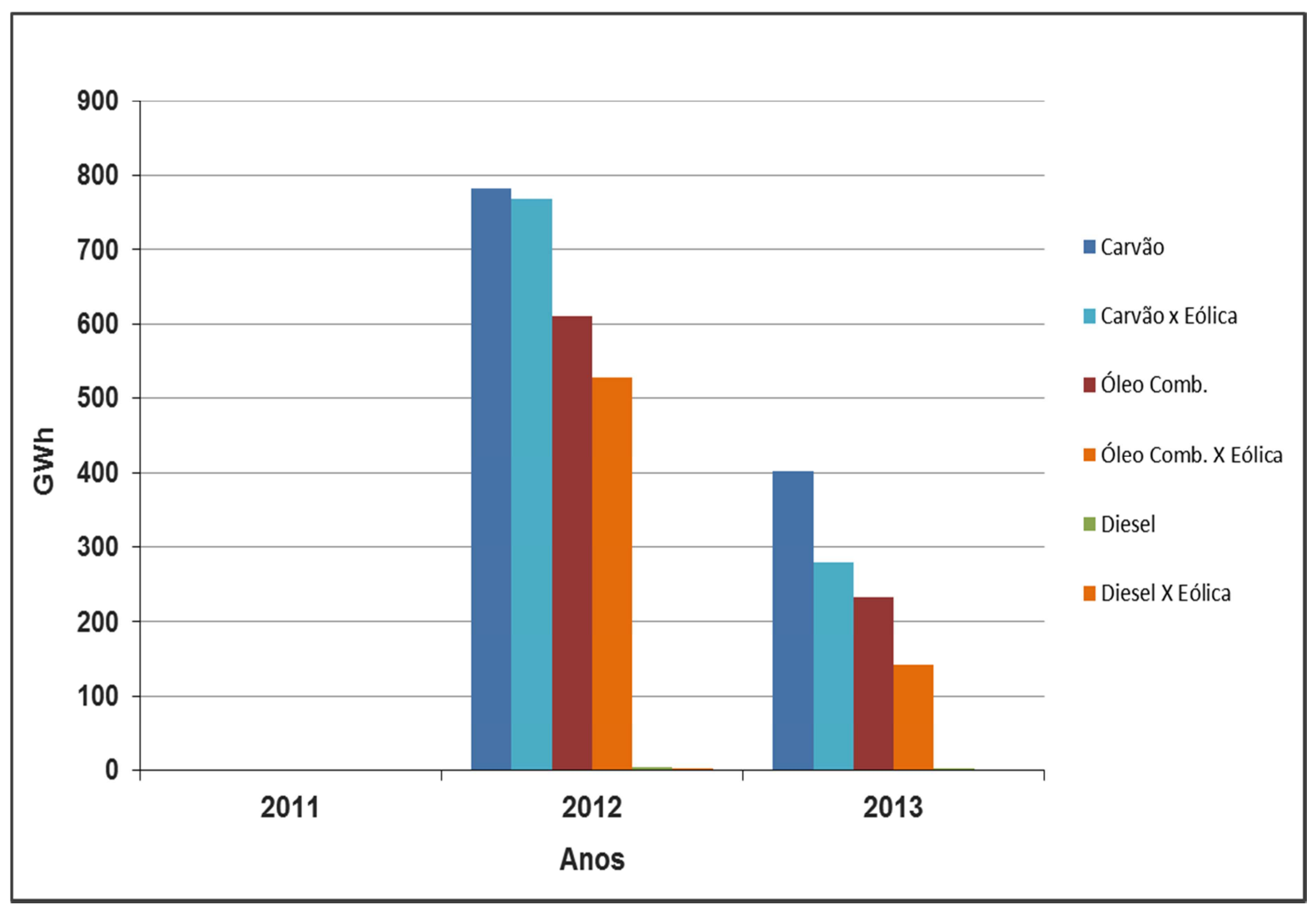

Figura 57 - Deslocamento da geração térmica no curto prazo.

\subsubsection{Complementaridade Hídrica - Eólica}

A complementaridade entre a geração hidrelétrica e eólica foi verificada nos resultados da simulação, o que é coerente pelas características sazonais destas fontes, tendo maior geração eólica nos períodos secos onde a geração hidrelétrica decresce entre os meses de maio a novembro. Nos meses chuvosos, de dezembro a abril, a geração hidrelétrica é alta e a presença do vento é baixa, como é apresentado na figura 58. 


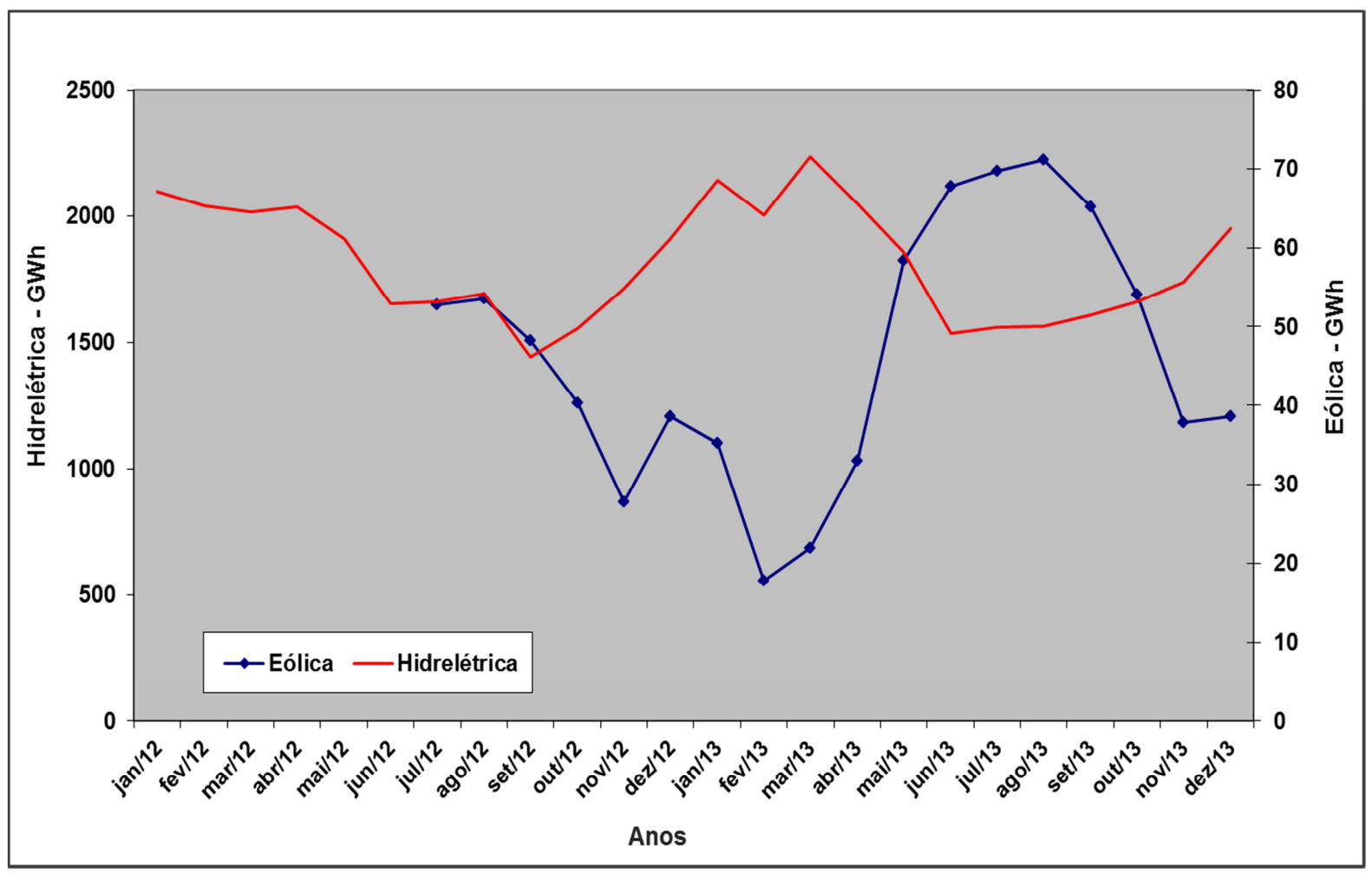

Figura 58 - Complementaridade hídrica - eólica no curto prazo.

\subsubsection{Expansão da Geração Termelétrica a Gás Natural}

Para o atendimento da demanda de curto prazo do SEIN observa-se o incremento no despacho das usinas hidrelétricas e termelétricas a gás natural, com maior expansão da geração termelétrica a gás natural, resultando no deslocamento de despacho de usinas térmicas que utilizam combustíveis de maior custo como o diesel, óleo combustível e carvão, originado pela disponibilidade do recurso e seu baixo custo no sistema.

No curto prazo a participação da geração termelétrica a gás natural aumentará de 40,2\%, em 2012, para 47,6\%, em 2013, em relação ao total de energia gerada no SEIN, como é apresentado no quadro 21. Os resultados foram obtidos sem geração eólica e guardam semelhança com os resultados do estudo de caso com geração eólica, apresentados anteriormente no quadro 19. 
Quadro 21 - Participação da termelétrica a gás natural no curto prazo.

\begin{tabular}{|r|l|r|r|r|}
\hline \multicolumn{2}{|c|}{ Fonte } & \multicolumn{1}{c|}{$\mathbf{2 0 1 1}$} & \multicolumn{1}{|c|}{$\mathbf{2 0 1 2}$} & \multicolumn{1}{c|}{2013} \\
\hline Hidrelétrica & Hidro & $60,0 \%$ & $56,1 \%$ & $50,9 \%$ \\
\hline \multirow{4}{*}{ Termelétrica } & Gás Natural & $40,0 \%$ & $40,3 \%$ & $47,6 \%$ \\
\cline { 2 - 5 } & Carvão & $0,0 \%$ & $2,0 \%$ & $0,9 \%$ \\
& Óleo Comb. & $0,0 \%$ & $1,6 \%$ & $0,5 \%$ \\
& Diesel & $0,0 \%$ & $0,0 \%$ & $0,0 \%$ \\
\hline \multirow{2yyyy}{*}{} & Total & $100 \%$ & $100 \%$ & $100 \%$ \\
\cline { 2 - 5 } & & &
\end{tabular}

O resultado mostra que a geração termelétrica a gás natural no curto prazo até 2013 terá um crescimento considerável no atendimento da demanda crescente do mercado elétrico peruano junto à geração hidrelétrica.

A partir de 2013 haverá um equilíbrio entre a participação da geração termelétrica a gás natural e a hidrelétrica, com a entrada em operação comercial de novas usinas em ciclo combinado e ciclos simples.

\subsection{RESULTADOS NO LONGO PRAZO (2014 - 2020)}

Neste período avaliamos os impactos da inserção de $65 \mathrm{MW}$ médios de energia eólica por ano a partir de 2014, totalizando $520 \mathrm{MW}$ médios em 2020. As simulações foram realizadas para os dois casos de estudo, com e sem inserção de geração eólica. Os resultados obtidos mostram indicadores que nos permitiram avaliar e determinar o impacto da inserção sustentada da energia eólica no cenário de longo prazo, além de avaliar a expansão das termelétricas a gás natural.

\subsubsection{Expansão de Referência sem Energia Eólica}

A simulação da expansão do SEIN sem geração eólica foi realizada tendo em conta a programação da oferta e demanda prevista no cenário futuro de 
longo prazo excluindo unicamente a geração eólica. Os resultados do despacho de energia são apresentados na figura 59 .

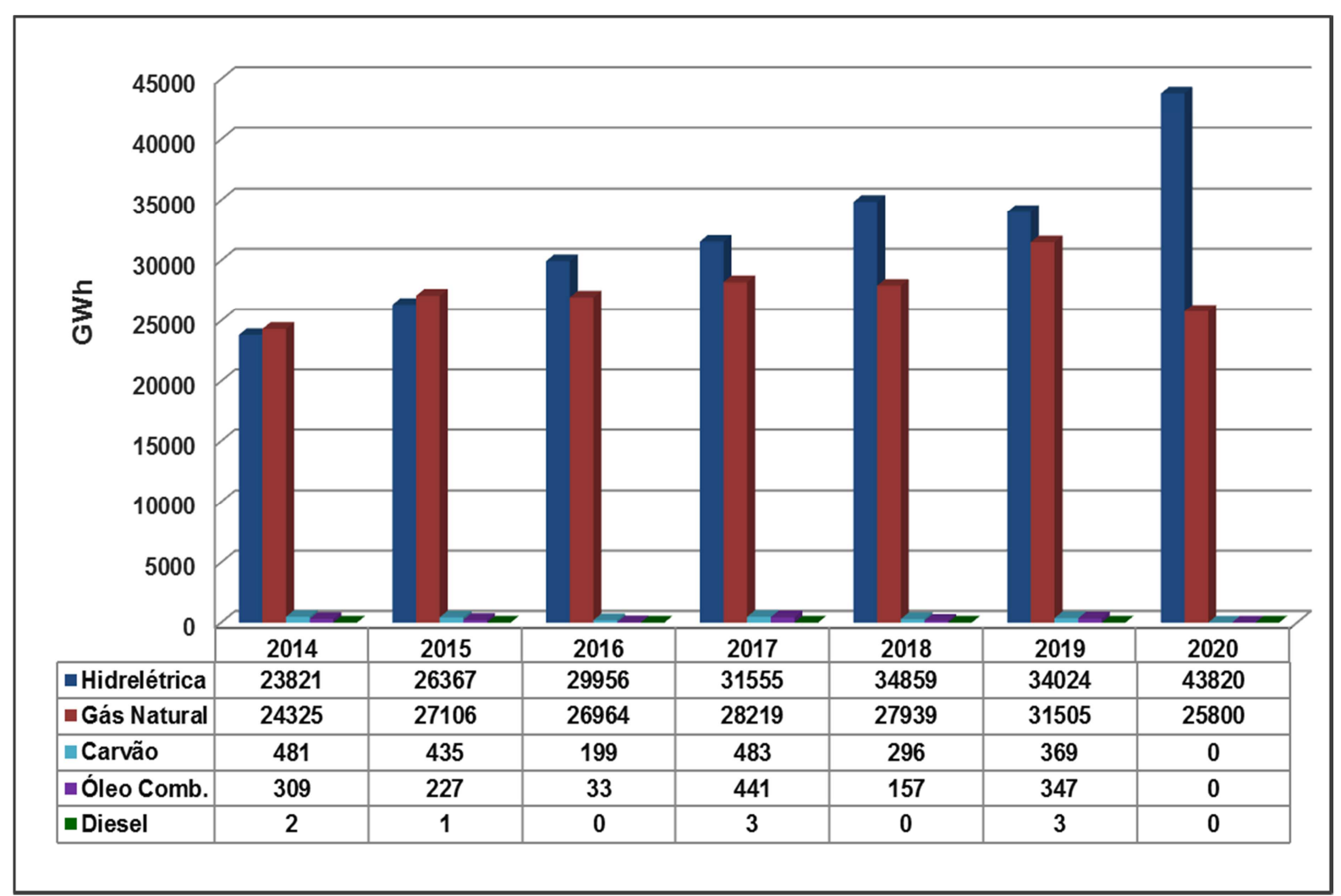

Figura 59 - Energia sem geração eólica no longo prazo.

A demanda crescente no longo prazo é suprida principalmente pela geração hidrelétrica e termelétrica a gás natural, com crescimento equilibrado destas fontes; a produção conjunta das duas fontes atinge $98 \%$ da produção média de energia do SEIN, como é apresentado no quadro 22.

Quadro 22 - Participação de energia por tipo de fonte no longo prazo (\%).

\begin{tabular}{|c|c|c|c|c|c|c|c|c|}
\hline \multicolumn{2}{|c|}{ Fonte } & 2014 & 2015 & 2016 & 2017 & 2018 & 2019 & 2020 \\
\hline Hidrelétrica & Hidro & $49 \%$ & $49 \%$ & $52 \%$ & $52 \%$ & $55 \%$ & $51 \%$ & $63 \%$ \\
\hline \multirow{5}{*}{ Termelétrica } & Gás & $50 \%$ & $50 \%$ & $47 \%$ & $46 \%$ & $44 \%$ & $48 \%$ & $37 \%$ \\
\hline & Cañ̃o & $1 \%$ & $1 \%$ & $0 \%$ & $1 \%$ & $0 \%$ & $1 \%$ & $0 \%$ \\
\hline & Óleo Comb. & $1 \%$ & $0 \%$ & $0 \%$ & $1 \%$ & $0 \%$ & $1 \%$ & $0 \%$ \\
\hline & Diesel & $0 \%$ & $0 \%$ & $0 \%$ & $0 \%$ & $0 \%$ & $0 \%$ & $0 \%$ \\
\hline & Total & $100 \%$ & $100 \%$ & $100 \%$ & $100 \%$ & $100 \%$ & $100 \%$ & $100 \%$ \\
\hline
\end{tabular}


A participação da geração termelétrica a carvão e óleo combustível tem uma produção mínima menor que 1\%. Em 2016 e 2020 esta produção é bem menor devido ao ingresso em operação comercial de novas hidrelétricas. A geração diesel tem sua participação considerada como reserva, como é mostrado na figura 60 .

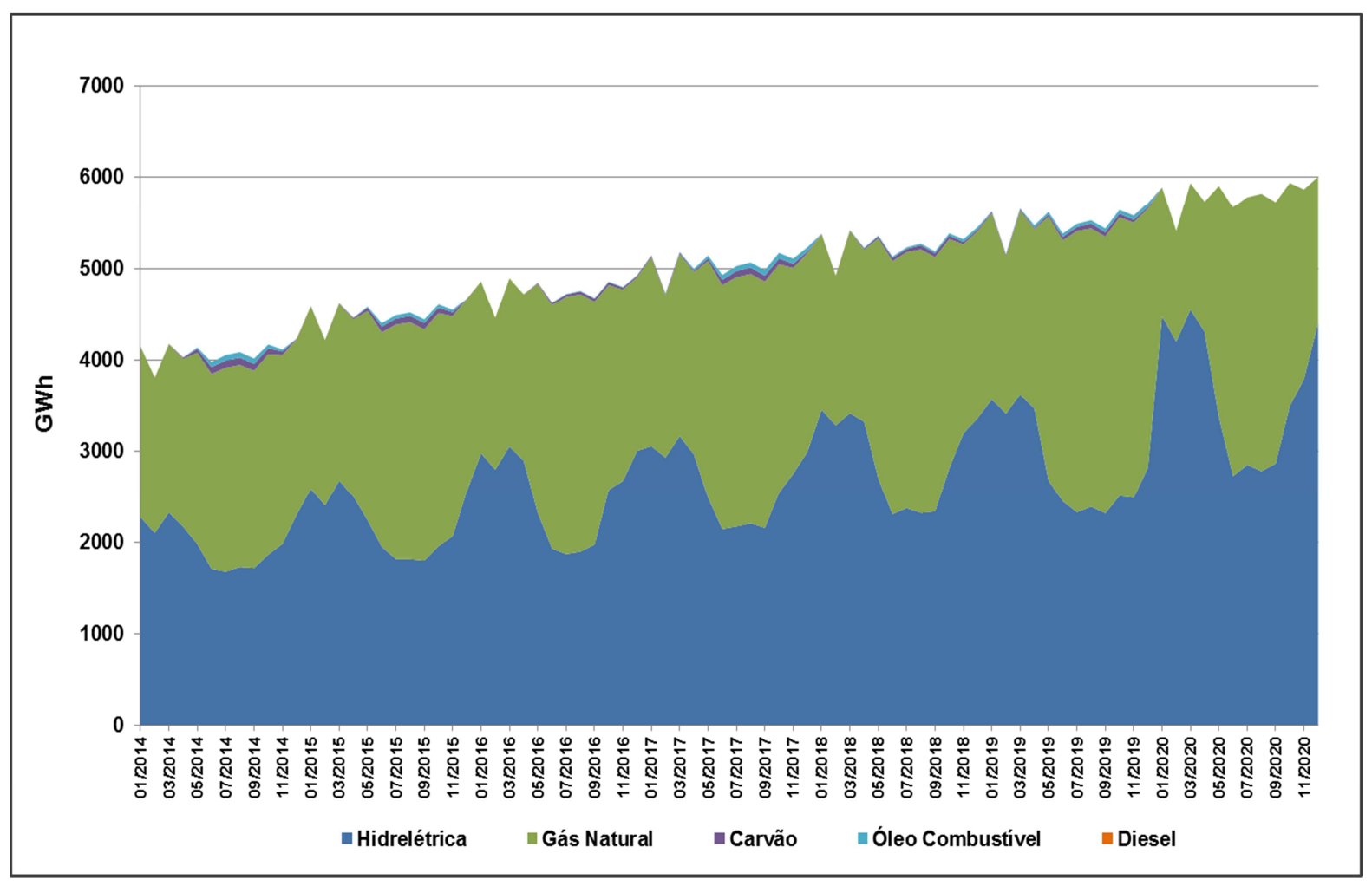

Figura 60 - Produção de energia por tipo de fonte no longo prazo.

\subsubsection{Expansão com Inserção de Energia Eólica}

Os resultados da operação econômica do SEIN no cenário de longo prazo, incluindo a geração eólica, mostram a produção crescente desta fonte a cada ano, atingindo em 2020 uma produção de 4592 GWh de energia, equivalente a 7\% da produção total. No caso da geração hidrelétrica, mantém sua participação, atingindo mais de $50 \%$ da produção total a partir de 2016 até 2020. No entanto, em 2014 e 2015, a geração termelétrica a gás natural passa a ser a fonte com maior participação na produção de energia, como é mostrado no quadro 23 , reduzindo a participação a partir de 2016, quando a hidrelétrica passa a ser novamente a fonte com participação majoritária. 
Quadro 23 - Produção de energia por tipo de fonte no longo prazo (GWh).

\begin{tabular}{|l|l|r|r|r|r|r|r|r|}
\hline \multicolumn{2}{|c|}{ Fonte } & 2014 & 2015 & 2016 & 2017 & 2018 & 2019 & 2020 \\
\hline Hidrelétrica & Hidro & 23802 & 26277 & 29859 & 31456 & 34623 & 33741 & 43820 \\
\hline \multirow{4}{*}{ Termelétrica } & Gás Natural & 23855 & 26124 & 24975 & 26264 & 25153 & 28377 & 21208 \\
& Carvão & 133 & 21 & 23 & 97 & 53 & 98 & 0 \\
& Óleo Comb. & 0 & 0 & 0 & 31 & 0 & 44 & 0 \\
& Diesel & 0 & 0 & 0 & 0 & 0 & 0 & 0 \\
\hline Eólica & Eólica & 1141 & 1712 & 2296 & 2853 & 3424 & 3994 & 4592 \\
\hline
\end{tabular}

Enquanto à produção térmica a carvão é limitada a uma quantidade mínima, inclusive sendo nula em 2020, a termelétrica a óleo combustível apresenta participação só no ano 2019, com uma produção pequena. A geração térmica a diesel é nula em todo o cenário de longo prazo atuando só como reserva do sistema.

A geração hidrelétrica mantém seu nível de participação em relação ao caso de referência sem geração eólica tendo uma diferença mínima de variação na produção; o contrário acontece com a geração térmica a gás natural que diminui sua participação de 49\% em 2014 a 30\% em 2020, em função do ingresso em 2018, 2019 e 2020 de maior quantidade de novas usinas hidrelétricas e da geração eólica, como é apresentado no quadro 24.

Quadro 24 - Participação de energia por tipo de fonte no longo prazo (GWh).

\begin{tabular}{|l|l|r|r|r|r|r|r|r|}
\hline \multicolumn{2}{|c|}{ Fonte } & $\mathbf{2 0 1 4}$ & $\mathbf{2 0 1 5}$ & $\mathbf{2 0 1 6}$ & $\mathbf{2 0 1 7}$ & $\mathbf{2 0 1 8}$ & $\mathbf{2 0 1 9}$ & $\mathbf{2 0 2 0}$ \\
\hline Hidrelétrica & Hidro & $49 \%$ & $49 \%$ & $52 \%$ & $52 \%$ & $55 \%$ & $51 \%$ & $63 \%$ \\
\hline \multirow{5}{*}{ Termelétrica } & Gás Natural & $49 \%$ & $48 \%$ & $44 \%$ & $43 \%$ & $40 \%$ & $43 \%$ & $30 \%$ \\
& Carvão & $0 \%$ & $0 \%$ & $0 \%$ & $0 \%$ & $0 \%$ & $0 \%$ & $0 \%$ \\
& Óleo Comb. & $0 \%$ & $0 \%$ & $0 \%$ & $0 \%$ & $0 \%$ & $0 \%$ & $0 \%$ \\
& Diesel & $0 \%$ & $0 \%$ & $0 \%$ & $0 \%$ & $0 \%$ & $0 \%$ & $0 \%$ \\
\hline Eólica & Eólica & $2 \%$ & $3 \%$ & $4 \%$ & $5 \%$ & $5 \%$ & $6 \%$ & $7 \%$ \\
\hline
\end{tabular}

A evolução da produção de energia com a inserção da geração eólica e a participação de cada fonte no suprimento total da demanda média no cenário de longo prazo é apresentada na figura 61. 


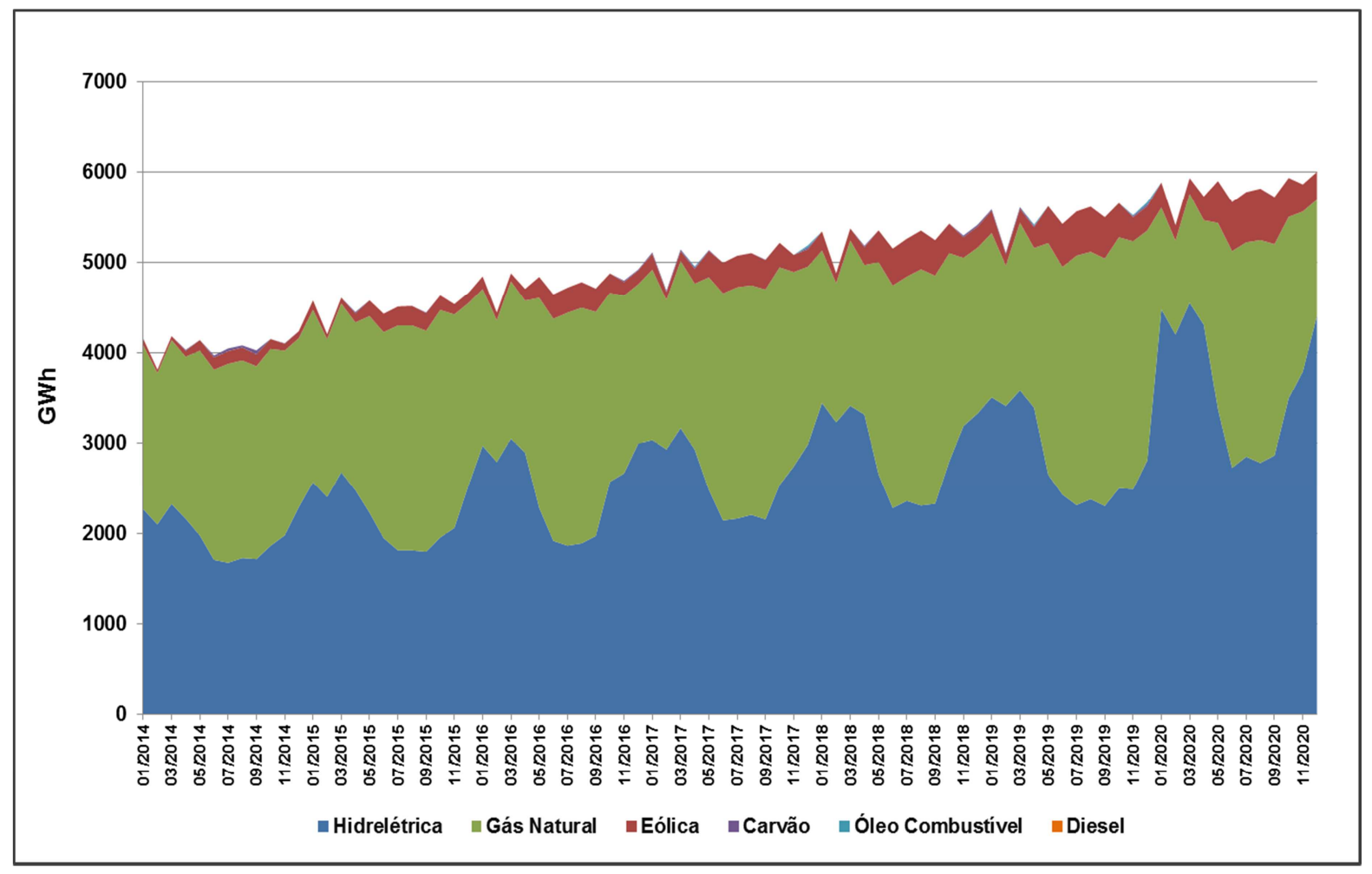

Figura 61 - Produção de energia por tipo de fonte no longo prazo.

\subsubsection{Impacto no Custo Marginal de Operação (CMO)}

Comparando os custos marginais de operação obtidos dos estudos de caso com e sem inserção de energia eólica no cenário de longo prazo, é determinado o impacto no custo de operação do SEIN com a inserção de energia eólica no sistema hidrotérmico peruano.

Os resultados mostram uma diminuição no custo marginal de operação (CMO) em torno de um valor médio de $18 \%$ entre 2014 e 2020, com valores extremos de custo anual médio de $23 \%$ em 2015 e $11 \%$ em 2019, estes valores mostram o impacto positivo da participação da geração eólica na operação do SEIN, como é apresentando na figura 62. 


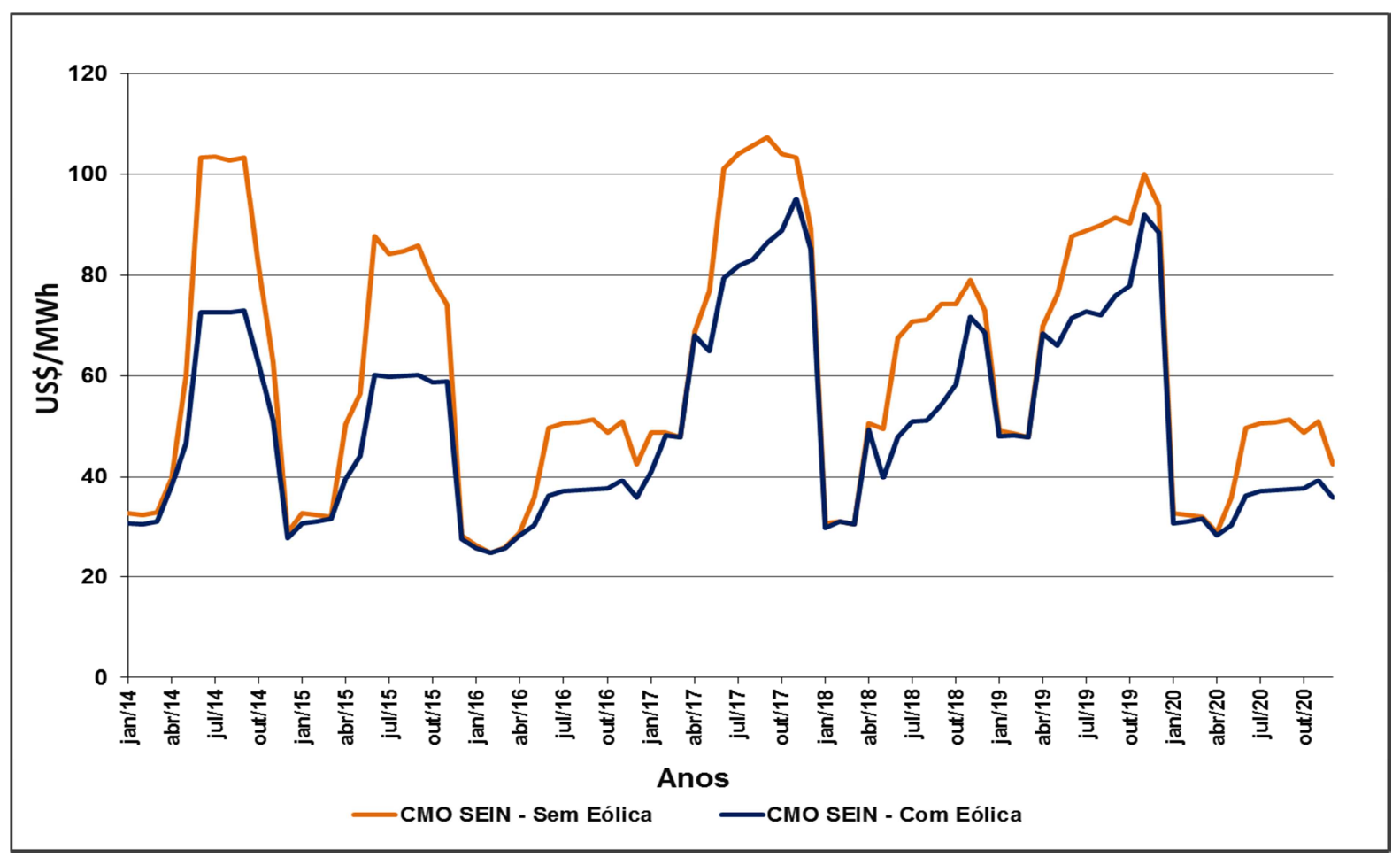

Figura 62 - Custo marginal de operação no longo prazo.

Os menores custos marginais anuais médios do SEIN obtidos com a inserção da geração eólica mostram valores mínimos e máximos de 33 e 72 US\$/MWh em 2016 e 2017, respectivamente, como é mostrado na figura 63 a seguir.

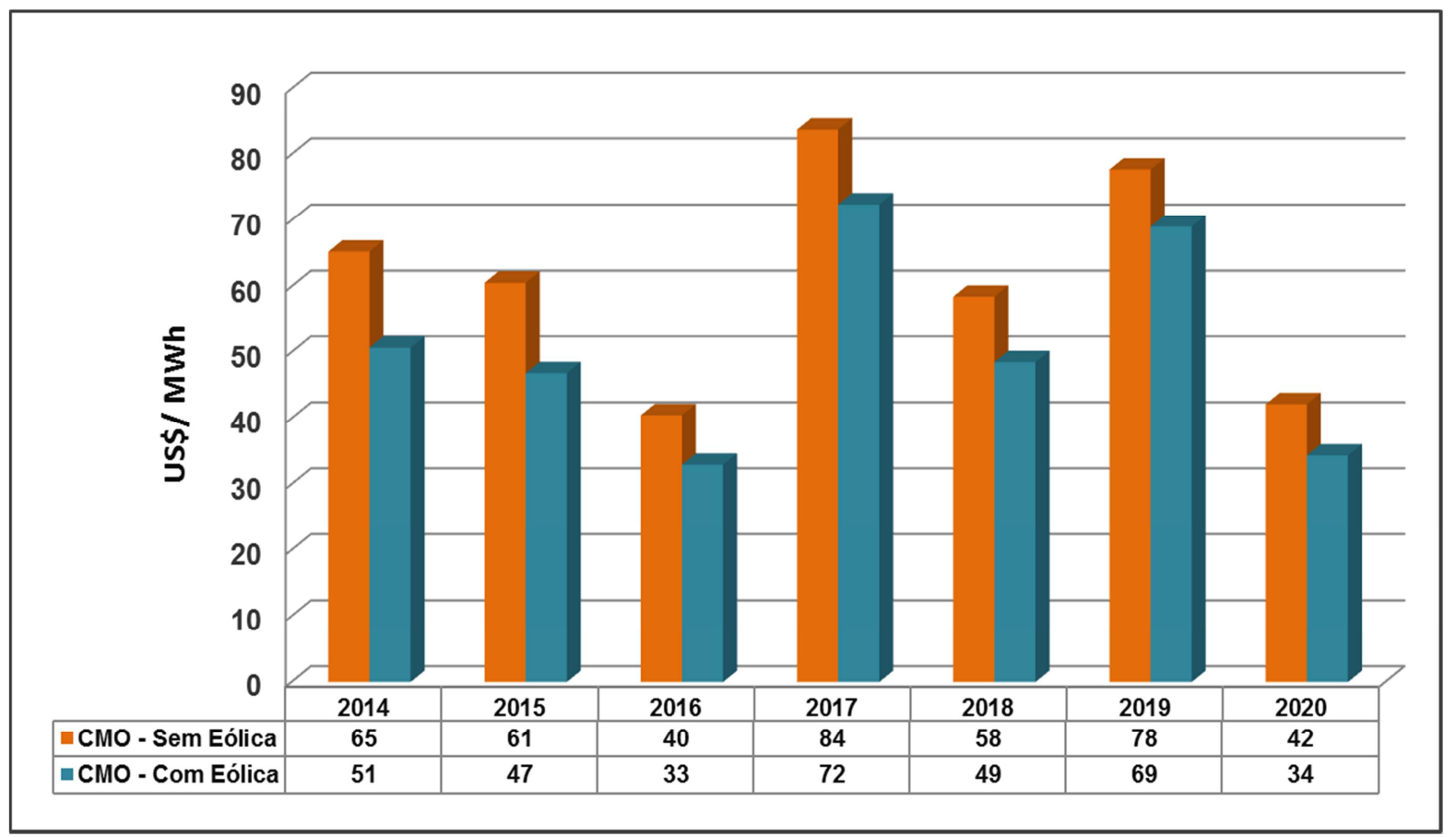

Figura 63 - Custo marginal médio anual do SEIN no longo prazo. 


\subsubsection{Impacto no Custo de Operação}

Um dos indicadores considerados mais importantes neste trabalho, para a avaliação do impacto econômico da inserção da geração eólica no sistema hidrotérmico peruano, é o custo de operação do sistema. Da comparação dos resultados da simulação dos casos com e sem geração eólica do SEIN, conseguiuse determinar os valores deste impacto e sua evolução no cenário de longo prazo.

Os resultados são favoráveis à inserção da geração eólica no SEIN permitindo uma diminuição dos custos de operação do sistema como é apresentado na figura 64 .

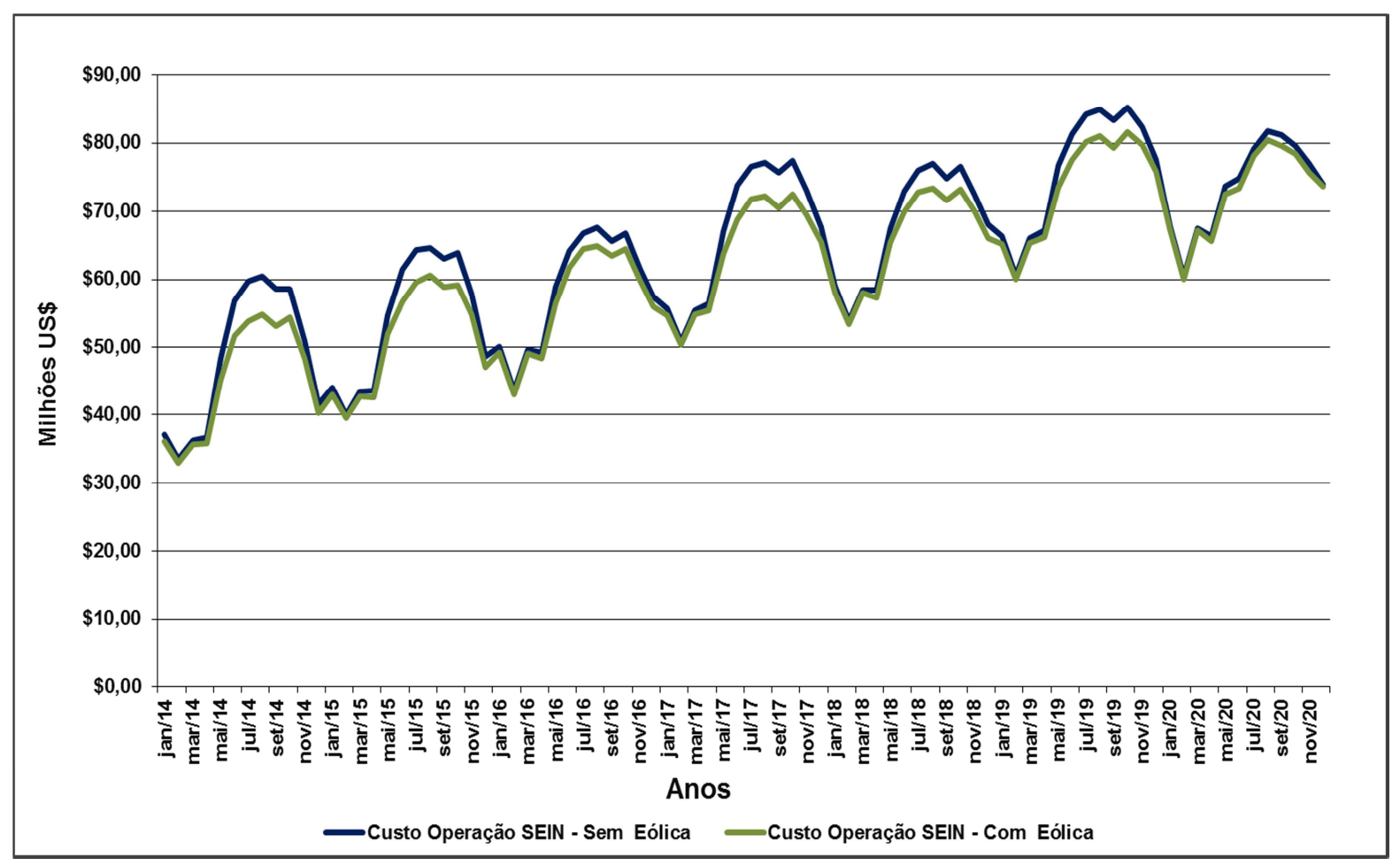

Figura 64 - Evolução do custo de operação no longo prazo.

O impacto da inserção da energia eólica na diminuição dos custos de operação do SEIN no período entre 2014 e 2020 atingiu a soma de 194 milhões de dólares, com redução anual média de US\$28 milhões no mesmo período, o que representa uma queda média anual de $4 \%$. Isto sinaliza a atratividade de se ter um ingresso de maiores quantidades desta fonte renovável de energia no sistema elétrico peruano, como é mostrado na figura 65. 


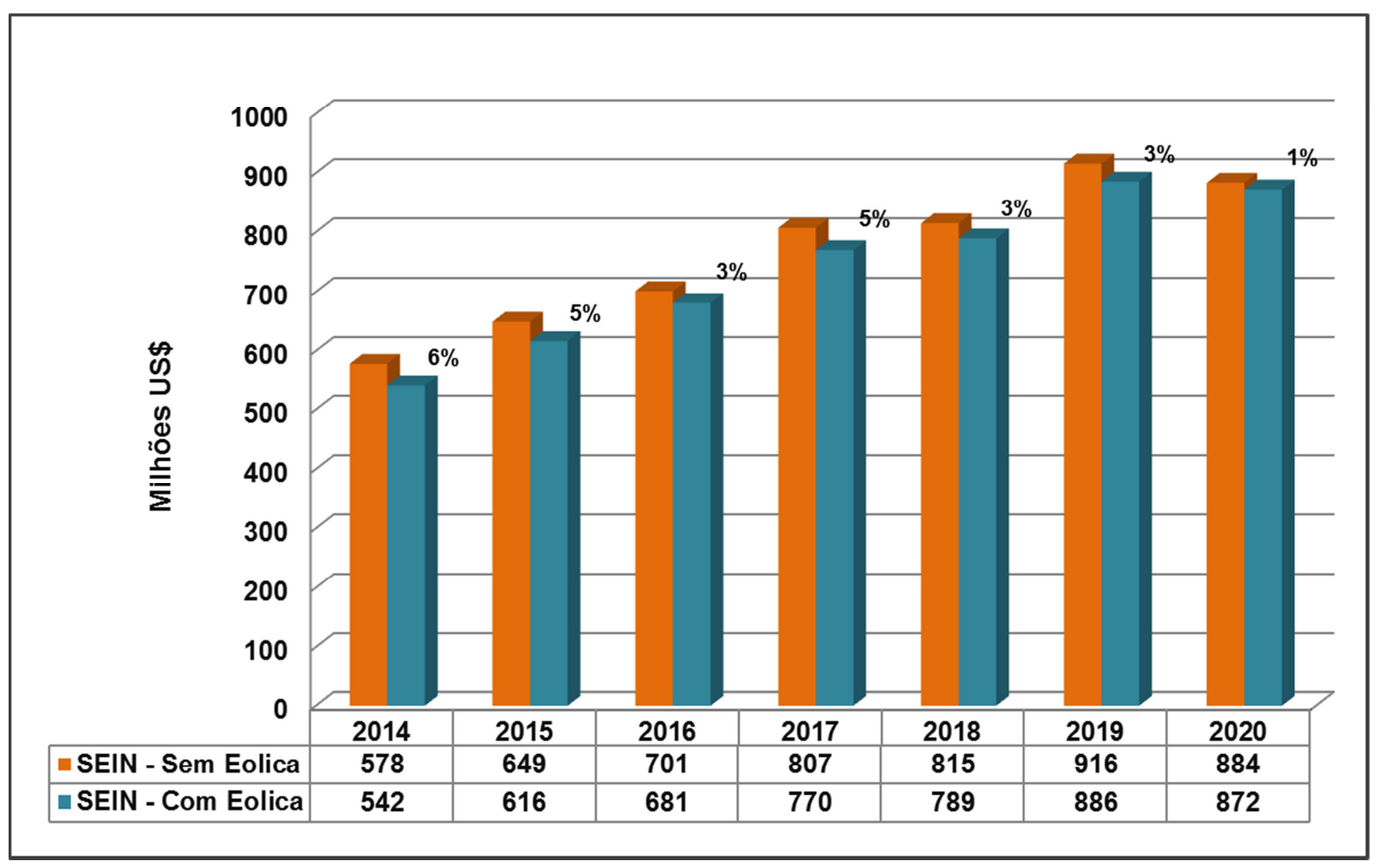

Figura 65 - Custo de operação no longo prazo.

\subsubsection{Impacto na Geração Termelétrica}

O impacto gerado no deslocamento da geração térmica pela eólica mostra resultados de geração evitada total de $100 \%$ com diesel, este atuando só como reserva no SEIN. A geração com óleo combustível, carvão, e gás natural teve uma redução anual média de despacho entre 2014 e 2020 de $97 \%$, 82\%, e 8\%, respectivamente, como é apresentado no quadro 25.

Quadro 25 - Deslocamento de geração térmica no longo prazo.

\begin{tabular}{|c|c|c|c|c|c|c|c|c|c|c|c|c|c|c|c|}
\hline \multirow{2}{*}{\multicolumn{2}{|c|}{ Fonte }} & \multicolumn{2}{|c|}{2014} & \multicolumn{2}{|c|}{2015} & \multicolumn{2}{|c|}{2016} & \multicolumn{2}{|c|}{2017} & \multicolumn{2}{|c|}{2018} & \multicolumn{2}{|c|}{2019} & \multicolumn{2}{|c|}{2020} \\
\hline & & GWh & $\%$ & GWh & $\%$ & GWh & $\%$ & GWh & $\%$ & GWh & $\%$ & GWh & $\%$ & GWh & $\%$ \\
\hline Hidrelétrica & Hidro & 20 & $0 \%$ & 90 & $0 \%$ & 97 & $0 \%$ & 99 & $0 \%$ & 236 & $1 \%$ & 283 & $1 \%$ & 0 & $0 \%$ \\
\hline \multirow{5}{*}{ Termelétrica } & Gás Natural & 470 & $2 \%$ & 982 & $4 \%$ & 1989 & $7 \%$ & 1955 & $7 \%$ & 2786 & $10 \%$ & 3127 & $10 \%$ & 4592 & $18 \%$ \\
\hline & Carvão & 348 & $72 \%$ & 414 & $95 \%$ & 176 & $88 \%$ & 385 & $80 \%$ & 243 & $82 \%$ & 271 & $74 \%$ & 0 & $0 \%$ \\
\hline & Óleo Comb. & 309 & $100 \%$ & 227 & $100 \%$ & 33 & $100 \%$ & 409 & $93 \%$ & 157 & $100 \%$ & 303 & $87 \%$ & 0 & $0 \%$ \\
\hline & Diesel & 2 & $100 \%$ & 1 & $100 \%$ & 0 & $0 \%$ & 3 & $100 \%$ & 0 & $0 \%$ & 3 & $100 \%$ & 0 & $0 \%$ \\
\hline & Total & \multicolumn{2}{|c|}{1149} & \multicolumn{2}{|c|}{1713} & \multicolumn{2}{|c|}{2295} & \multicolumn{2}{|c|}{2852} & \multicolumn{2}{|c|}{3422} & \multicolumn{2}{|c|}{3987} & \multicolumn{2}{|c|}{$\frac{1}{4592}$} \\
\hline
\end{tabular}


A menor participação no despacho das usinas térmicas está relacionada com o alto custo do combustível e sua disponibilidade. A seguir é apresentado na figura 66 o deslocamento das térmicas com maior custo variável de combustível.

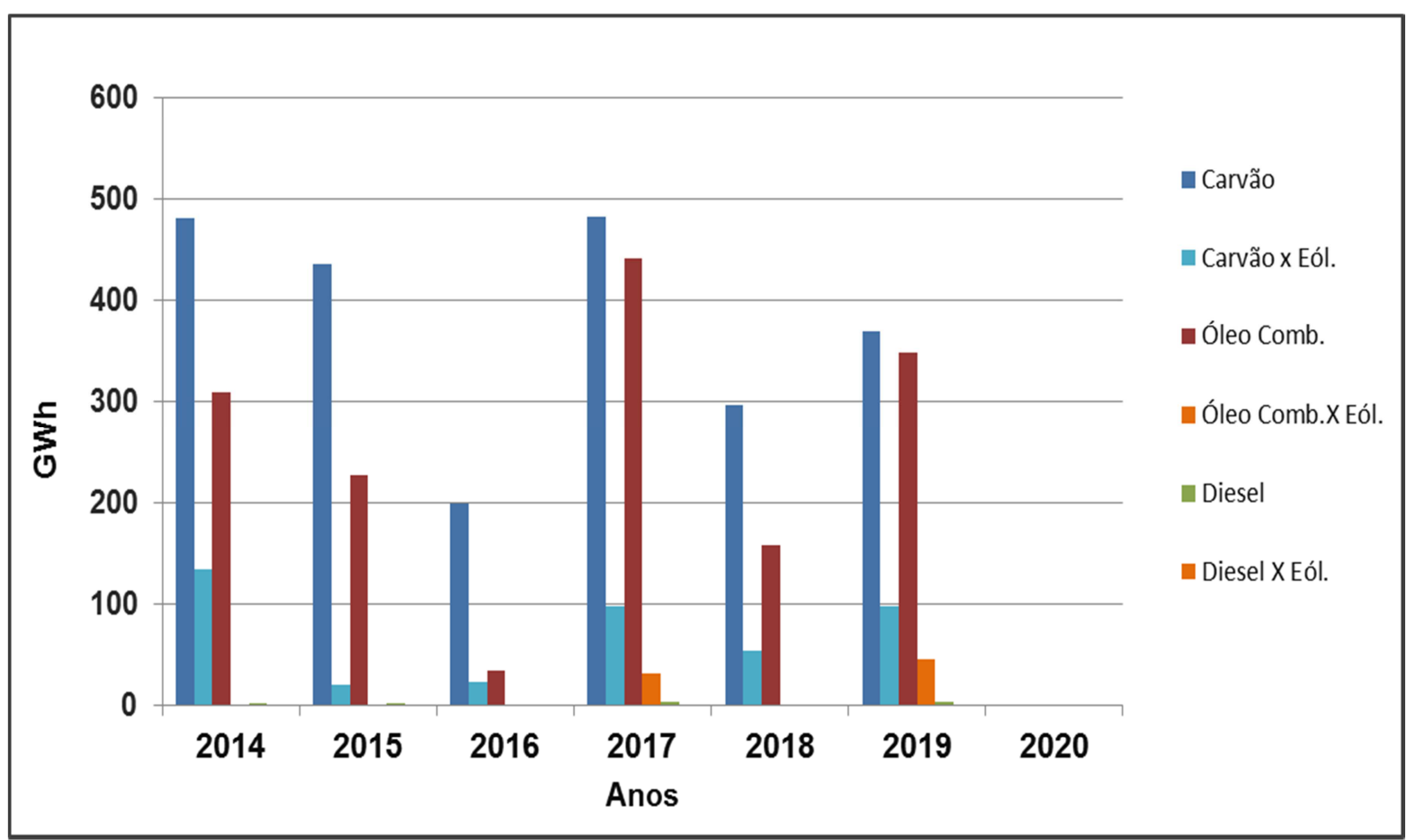

Figura 66 - Deslocamento da geração térmica no longo prazo.

\subsubsection{Complementaridade Hídrica - Eólica}

Os resultados das simulações no longo prazo apresentados na figura 67 confirmam a complementaridade existente entre o recurso hídrico e eólico no SEIN, originado pela variação sazonal dos ventos e as hidrologias que se complementam. A característica complementar destes apresenta vantagens para o sistema hidrotérmico peruano impactando positivamente na produção de usinas e nos custos de operação do sistema. 


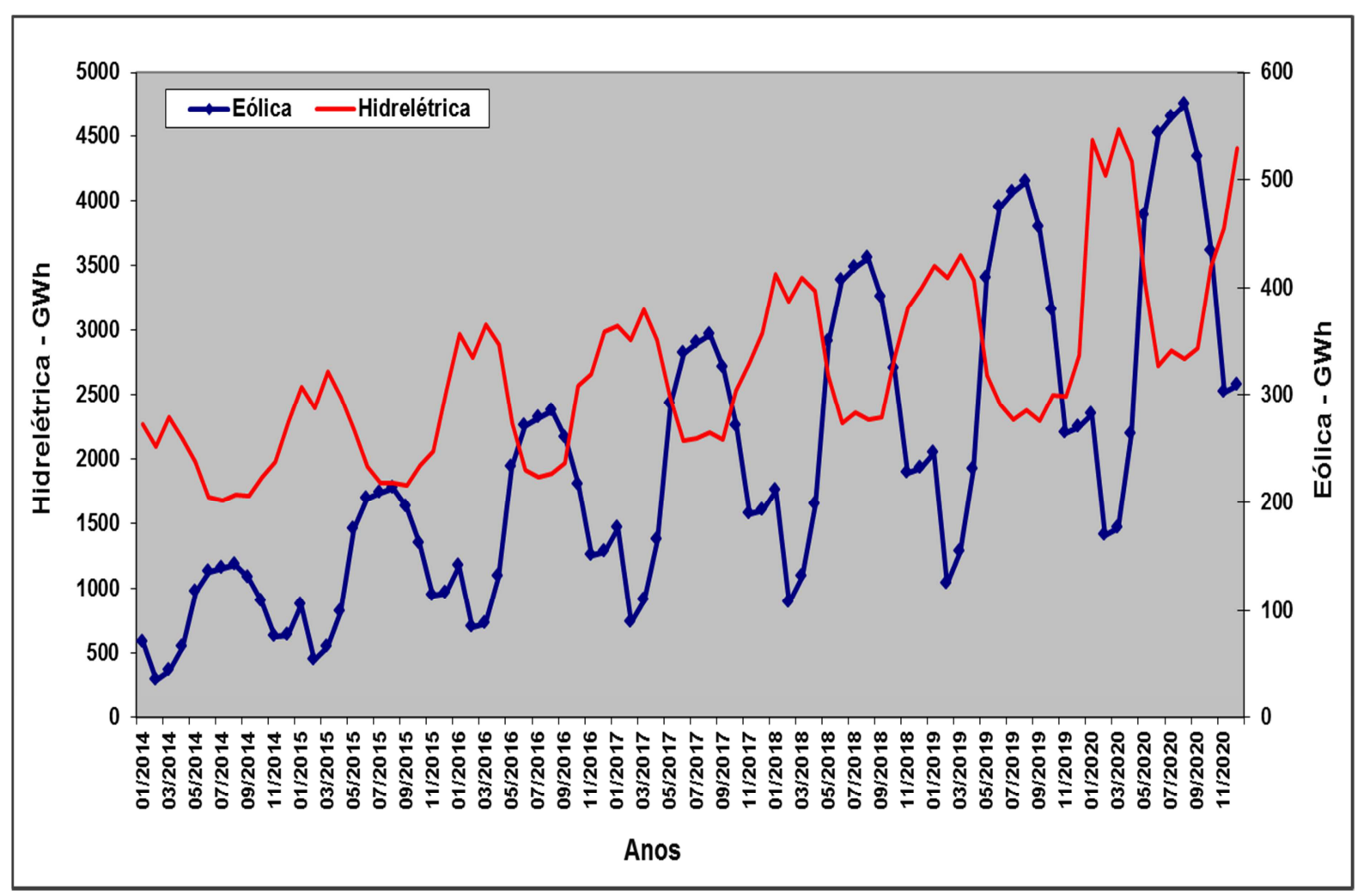

Figura 67 - Complementaridade hídrica - eólica no longo prazo.

\subsubsection{Expansão da Geração Termelétrica a Gás Natural}

A expansão da geração termelétrica no longo prazo, entre 2014 e 2020, apresenta um crescimento considerável no primeiro momento entre 2014 e 2015 com a entrada em operação comercial de novas usinas em ciclo combinado e ciclo simples usando gás natural de Camisea.

Já, para o final do período em 2020, a produção térmica a gás natural decresce numa quantidade considerável em relação a 2019, em função da entrada em operação comercial de novas hidrelétricas que deslocam a geração térmica a gás natural, como é apresentado no quadro 26. 
Quadro 26 - Produção do SEIN por tipo de fonte no longo prazo (GWh).

\begin{tabular}{|c|c|c|c|c|c|c|c|c|}
\hline \multicolumn{2}{|c|}{ Fonte } & 2014 & 2015 & 2016 & 2017 & 2018 & 2019 & 2020 \\
\hline \begin{tabular}{|l|} 
Hidrelétrica \\
\end{tabular} & Hidro & 23821 & 26367 & 29956 & 31555 & 34859 & 34024 & 43820 \\
\hline \multirow{5}{*}{ Termelétrice } & Gás Natural & 24325 & 27106 & 26964 & 28219 & 27939 & 31505 & 25800 \\
\hline & Carvão & 481 & 435 & 199 & 483 & 296 & 369 & 0 \\
\hline & Óleo Comb. & 309 & 227 & 33 & 441 & 157 & 347 & 0 \\
\hline & Diesel & 2 & 1 & 0 & 3 & 0 & 3 & 0 \\
\hline & Total & 48939 & 54135 & 57152 & 60701 & 63251 & 66248 & 69621 \\
\hline
\end{tabular}

\subsubsection{Proposta para a Inserção da Energia Eólica no SEIN}

Os dois primeiros leilões de energia (RER) realizados no setor elétrico peruano viabilizaram a instalação dos primeiros parques eólicos no Peru para 0 atendimento da demanda de curto prazo.

O leilão de energia, portanto, é uma das formas de garantir a competitividade nos custos de geração do sistema, possibilitando uma maior participação de fontes renováveis de energia, com destaque a eólica.

Existe a alternativa dos leilões por reserva ou por disponibilidade que possam ser utilizados para favorecer a inserção da energia eólica. Também a construção de redes coletoras que possam eliminar as restrições na transmissão de energia gerada pelos futuros parques eólicos, o que incrementaria a segurança e confiabilidade destas na operação do SEIN.

O benefício com a receita advinda da venda de créditos de carbono em países em desenvolvimento como o Peru, também constitui-se em um mecanismo que vem favorecer a maior participação da geração eólica no SEIN.

\subsection{EXPANSÃO COM EXPORTAÇÃO DE 50\% DE UHEs AMAZÔNIA}

Como parte complementar do presente trabalho foi realizado a simulação da expansão do SEIN com 50\% de exportação de energia ao Brasil, 
comparado ao caso sem exportação, com base na geração das usinas hidrelétricas da Amazônia, que, segundo o Ministério de Energia e Minas do Peru, estão planejadas para entrarem em operação comercial a partir de janeiro de 2020, o mesmo horizonte que foi levado em conta na simulação, pelo que decidiu-se adotar a comparação dos resultados da simulação nos dois últimos anos 2019 e 2020, como é mostrado na figura 68. A simulação da exportação no modelo foi realizada com aumento da carga e incremento da oferta correspondente para fazer a comparação de sistemas equivalentes.

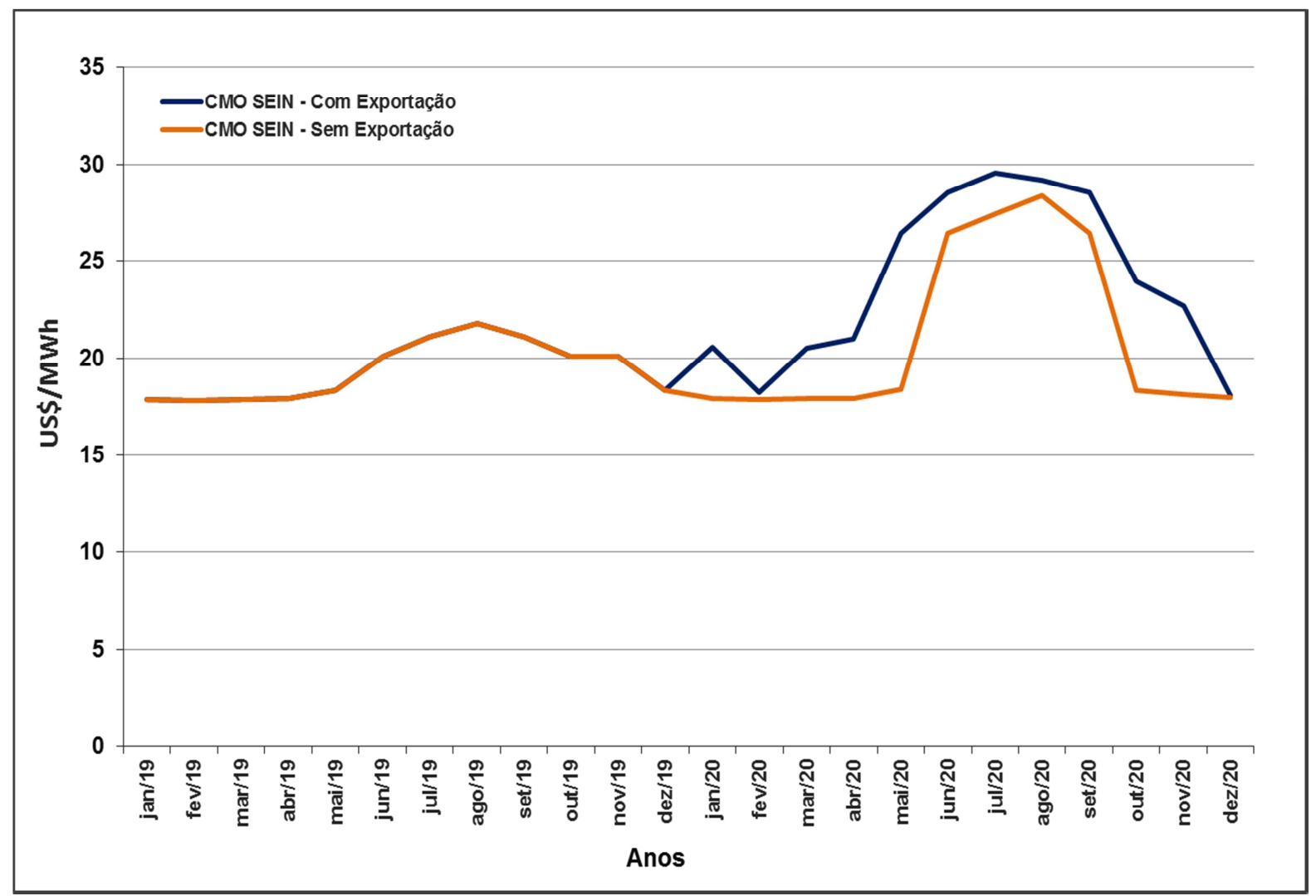

Figura 68 - Custo marginal de operação do SEIN.

A análise dos resultados das simulações com base no custo marginal de operação (CMO) mostra uma diferença nos custos marginais do sistema apresentando valores maiores com a exportação, em relação ao caso adverso sem exportação, como é mostrado na figura 69. 


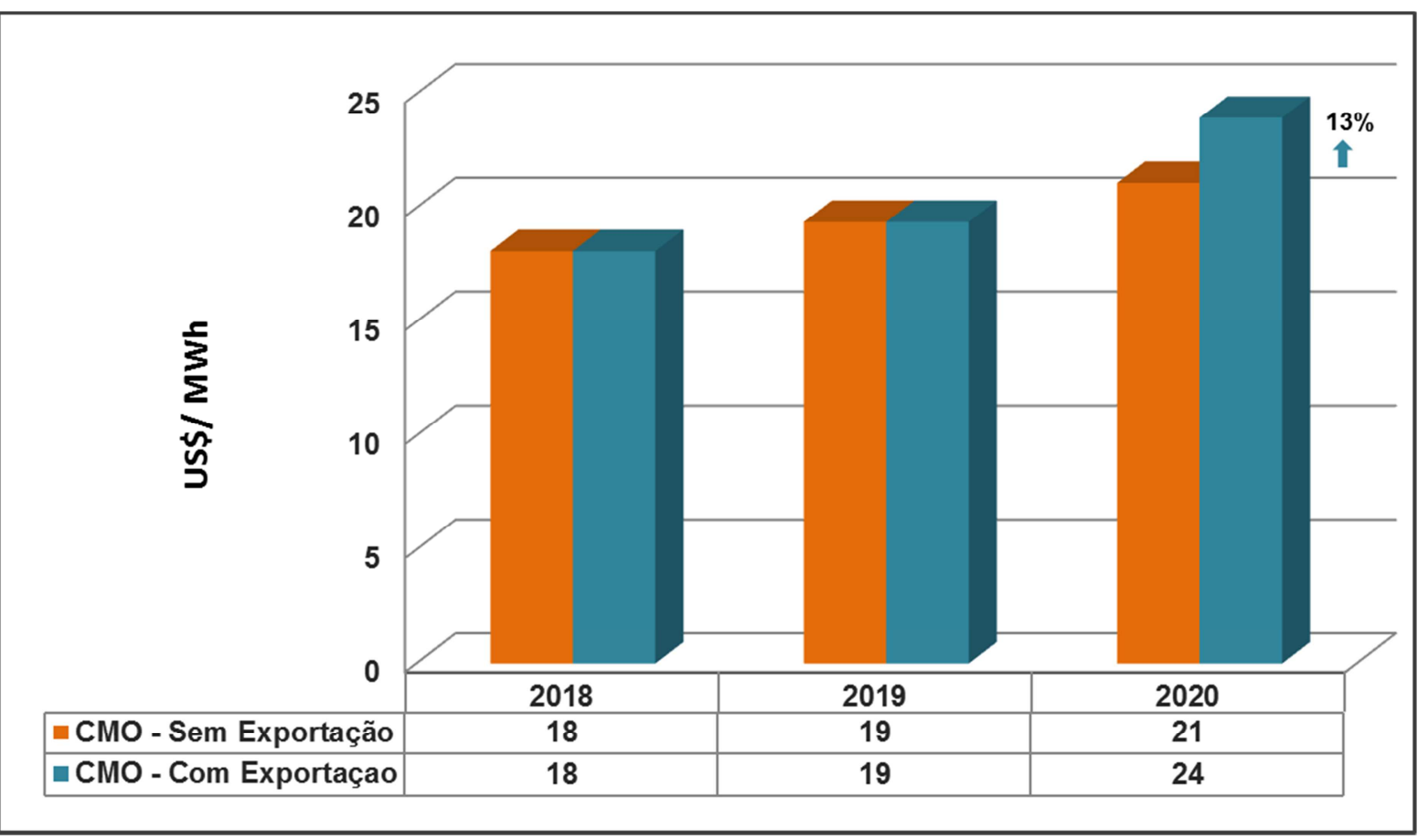

Figura 69 - Custo marginal de operação com e sem exportação SEIN.

Os valores anuais médios do custo marginal de operação do SEIN indicam valores baixos entre 18 e 24 US\$/MWh. Outro indicador importante é o custo de operação do sistema que apresenta valores maiores para o caso da exportação das usinas da Amazônia, incrementando o custo de operação mensal média em US\$ 34 milhões durante o ano 2020, como é apresentado na figura 70.

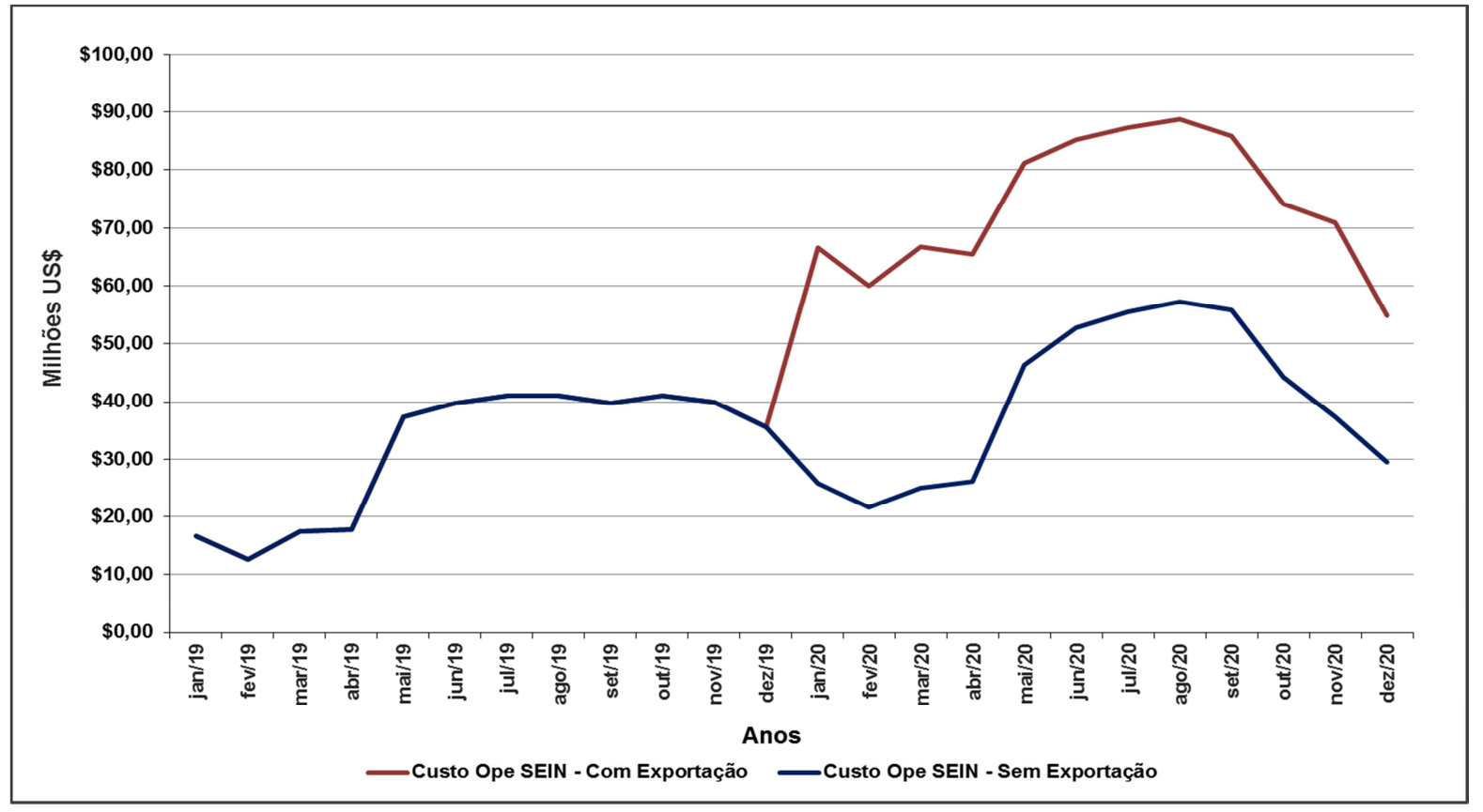

Figura 70 - Custo de operação com e sem exportação SEIN. 


\section{CONCLUSÕES}

O crescimento da participação da energia eólica na matriz elétrica mundial nos últimos anos é considerável, apresentando altos índices de expansão em países como a China, EUA, entre outros, sendo a fonte renovável de maior desenvolvimento tecnológico e atratividade econômica, principalmente pelas reduções que apresentam os custos de sua implantação.

O gás natural sem duvida é uma fonte energética que aproveitado de forma eficiente na geração termelétrica oferece vantagens no atendimento da demanda elétrica dos países que possuem reservas deste combustível, influindo favoravelmente na complementariedade a outras fontes como a hidrelétrica e eólica, permanecendo no longo prazo como uma das fontes de geração mais importantes da matriz elétrica mundial.

A evolução do setor elétrico peruano apresenta uma estrutura que promove a competição em segmentos da geração e comercialização incentivando a eficiência econômica pelo livre mercado, mantendo a transmissão e distribuição como monopólio natural, tendo uma agencia de regulação, operação centralizada do SEIN e planejamento indicativo centralizado da expansão da geração e transmissão, que Ihe-permitiu crescer consideravelmente nos últimos anos e acompanhar de forma adequada a demanda do mercado.

O setor elétrico peruano, produto do desenvolvimento de sua economia, vem apresentando crescimento nos últimos anos em sua demanda, em torno de $8 \%$ ao ano, permitindo, portanto a expansão da oferta na mesma proporção. Em 2010 foi realizado o primeiro leilão de energia renovável (RER) com participação da geração eólica para o atendimento da demanda no cenário de curto prazo, o que viabilizou a inserção dos primeiros parques eólicos no Peru, permitindo desta forma a diversificação da matriz elétrica.

Atualmente, o sistema elétrico peruano conta com forte participação da geração hidrelétrica e termelétrica a gás natural, atendendo quase a totalidade da demanda do SEIN, além disso, a expansão hidrotérmica da oferta de energia vem tentando cobri-la no curto e longo prazo.

Com a inserção da geração eólica, prevista para 2012 surgiram novos 
desafios e oportunidades na operação econômica do sistema, produzindo impactos nos custos marginais, no custo total de operação do sistema, no deslocamento da geração térmica com combustíveis caros, e mudança no perfil de despacho de energia no SEIN. Além da possibilidade de aproveitar a característica complementar da geração hídrica e eólica.

O impacto gerado pela inserção de energia eólica no sistema elétrico peruano avaliado no curto e longo prazo através do custo marginal de operação (CMO) do SEIN apresenta ganhos favoráveis com redução média de $18 \%$ ao ano, comparado à operação sem inserção de geração eólica.

Já no custo de operação do sistema, a inserção da energia eólica no curto prazo, em 2013, permite a redução dos custos em 30 milhões de dólares anuais o que equivale a uma redução nos custos de $6 \%$. Do mesmo modo, no longo prazo, entre 2014 e 2020, a redução anual média dos custos operativos do SEIN tem uma queda de US\$28 milhões, o que representa em termos porcentuais uma redução de $4 \%$ ao ano sobre o total.

Evidenciou-se no cenário de curto prazo o deslocamento no despacho da geração termelétrica que utiliza combustíveis com custos variáveis caros, como o diesel, óleo combustível e carvão numa proporção de 100\%, 39\% e 30\%, respectivamente, originados pela inserção de energia eólica.

Por outro lado, no cenário de longo prazo, o deslocamento da geração térmica a diesel é total, com atuação só como reserva do sistema. No entanto, a geração com óleo combustível e carvão é deslocada em uma média anual de $97 \%$ e $82 \%$, respectivamente. Quanto à geração termelétrica a gás natural evitada encontrou-se uma proporção menor, em termos porcentuais, mais significativas em relação às quantidades deslocadas das outras fontes, representando $8 \%$ em termos de média anual.

Foi verificada a complementariedade existente entre a energia hidrelétrica e eólica. As variações sazonais das hidrologias e os melhores ventos acontecem em períodos complementares, tendo maior produção eólica no período de secas, entre os meses de maio a novembro, período onde a geração hidrelétrica decresce. O contrário acontece nos meses chuvosos, de dezembro a abril, onde a presença dos ventos decresce diminuindo a geração eólica.

O perfil de produção no curto e longo prazo manteve a geração hidrelétrica na base da carga, complementado com a geração termelétrica a gás 
natural, alcançando entre as duas fontes uma média maior que 95\% da produção do SEIN, com uma participação reduzida do carvão e óleo combustível, deixando as térmicas a diesel como reserva do sistema. No entanto, a inserção de energia eólica no longo prazo, com adição de maior oferta, desloca inclusive à geração termelétrica a gás natural, isto pelo fato de operar na base da carga com um custo variável de combustível igual a zero, mesmo que nas simulações a geração eólica é representada de forma simples e otimista, sem considerar as incertezas no fator de capacidade mensal de cada usina.

A expansão da geração termelétrica a gás natural com a entrada de novas usinas em ciclo combinado e ciclos simples no SEIN permite uma maior participação desta fonte na produção de energia, impactando favoravelmente na manutenção dos baixos custos de operação do sistema, despachando mais nos meses secos onde a produção hídrica é baixa.

Verificou-se então a competitividade existente a partir dos custos baixos do gás natural e sua disponibilidade no setor que permitem a operação desta fonte na base do sistema junto com a geração hidrelétrica.

A integração elétrica de Peru e Brasil mediante a construção de usinas hidrelétricas localizadas na Amazônia peruana e a linha de transmissão que permita a interligação dos dois países é importante e estratégico no objetivo da integração elétrica Sul-americana, isto pela localização geográfica destes entre os dois blocos econômicos do continente a Comunidade Andina de Nações (CAN) e o Mercosul.

A possibilidade de exportação da energia excedente ao Brasil, pela oferta adicional de energia no Peru, através do convenio bilateral de integração energética, encontra-se num período inicial de implementação dos procedimentos legais e regulatórios, paralelamente vem sendo levado a etapa inicial de elaboração de estudos de viabilidade dos projetos hidrelétricos. Neste ponto é necessário então propor o estudo mais meticuloso dos impactos da interligação elétrica de Peru e Brasil no SEIN, que possa levar em conta as características reais dos fluxos de oferta e demanda de energia entre os sistemas elétricos e mostre de forma mais completa e exata seus impactos.

O desenvolvimento do estudo permitiu observar a possibilidade da realização de trabalhos futuros com a finalidade de gerar uma visão mais completa e profunda dos impactos da inserção eólica no sistema elétrico peruano referente a parte operativa, avaliando os impactos gerados na operação da rede do SEIN, além 
disso, integrado com projetos de geração eólica.

A avaliação dos impactos da geração eólica nos custos finais, ou seja, nas tarifas ao consumidor, decorrentes no caso dos contratos RER, garantidos com uma prima que é assumida por todos os consumidores, torna-se assunto importante para estudos futuros.

Outro aspecto que merece especial atenção é a possibilidade da integração dos sistemas elétricos peruano-brasileiro no contexto da expansão de hidrelétricas da Amazônia peruana e sua exportação para o Brasil, levando em conta a interação da energia eólica neste contexto futuro, posto que no presente trabalho avaliou-se de forma complementar este aspecto e que precisa de uma avaliação mais precisa e aprofundada. 


\section{REFERÊNCIAS BIBLIOGRÁFICAS}

ABEEólica. Associação Brasileira de Energia Eólica. Notícias. Online. 2011. Disponível em:<http://www.abeeolica.org.br/site/zpublisher/materias/Noticias.asp?id $=19714>$. Acesso em: 05 out 2011 .

ACOSTA, E. Q. La reforma del sector electricidad y el servicio universal en el Perú (1992-2007). Lima: Relatório, Fundación CIDOB, 2008. Disponível em:<http://www.osinerg.gob.pe/newweb/uploads/Estudios_Economicos/La\%20refor ma\%20del\%20sector\%20electricidad.pdf>. Acesso em: 03 jun 2011.

ANDINA. Agencia de Noticias. Perú alcanzará cobertura eléctrica de $94 \%$ en el 2011. Online. 2010. Disponível em:<http://www.andina.com.pe/espanol/Noticia.aspx? id=N9kjEAlmAGA=>. Acesso em: 02 mar 2010.

ARISTONDO, F. M. Análisis de las facilidades y barreras para la inversión en centrales hidroeléctricas: Una revisión de la agenda pendiente. Lima: Revista de la Competencia y la Propiedad Intelectual № 8, 2009.

BARCO, D. R. Energias renovables. Apresentação. $4^{\circ}$ Congreso de energias renovables y biocombustibles (IV COBER). Lima: Banco Central de Reserva del Perú (BCRP), 2010. Disponível em:<http://energiaslimpias.files.wordpress.com /2010/10/404-daniel-barco-las-energias-renovables-en-la-generacion-electrica-en-elperu.pdf>. Acesso em: 15 jun. 2011.

BBVA. Banco Continental - Sector electricidad. Observatorio sectorial. Lima: BBVA Banco Continental, 2008. Disponível em:<http://www.bbvaresearch.com/KETD /fbin/mult/ESAPE_080903_ObserSectorial_76_tcm346-176691.pdf?ts=1082011>. Acesso em: 24 jun 2010.

BELTRÁN, N. J. C. Análise do comportamento da demanda com a inserção do gás natural das jazidas de Camisea na matriz energética peruana. Dissertação (Mestrado) - Programa Interunidades de Pós-Graduação em Energia da Universidade de São Paulo, São Paulo, 2004. 111 p.

BOHORQUEZ, W. O. I. Análise termoenergetica, econômica e ambiental da repotenciação e conversão de UTEs com ciclo rankine para ciclo combinado utilizando turbinas a gás. Dissertação (Mestrado) - Programa de Pós-Graduação em Engenharia da Energia, Universidade Federal de Itajubá, Itajubá, 2007. 203 p. Disponível em:< http://200.131.128.3/phl/pdf/0031979.pdf>. Acesso em: 18 jun 2010. 
BRANCO, F. P. Análise termoeconômica de uma usina termelétrica a gás natural operando em ciclo aberto e em ciclo combinado. Dissertação (Mestrado em Engenharia) - Faculdade de Engenharia.Universidade Estadual Paulista. Ilha Solteira, 2005.

BRASIL. EPE. Empresa de Pesquisa Energética. Nota Técnica PRE 01/2009-r0 Proposta para a expansão da geração eólica no Brasil. Rio de Janeiro: Relatório, 2009.

CAMISEA. Empresa exploradora de gás natural no Peru. Lima. Projeto Camisea. Disponível em:<http://www.camisea.pluspetrol.com.pe/>. Acesso em: 12 de out 2010.

CAMPODÓNICO, H. S. Las reformas estructurales del sector eléctrico peruano y las características de la inversión 1992 - 2000. Lima: Relatório CEPAL, 1999. Disponível em:<http://www.eclac.org/publicaciones/xml/7/4547/lcl1209e.pdf>.Acesso em: 15 jun 2010.

CAMPODÓNICO, H. S. Perú la política energética logros y metas para los próximos años. Bahia: I Encontro Latino - Americano de Economia da Energia, DESCO, 2008. 9 -10p.

COES. Comité de Operación Economica del Sistema Interconectado Nacional. Estadistica de operaciones 2010. Lima : Coes-Sinac, Relatorio Anual, 2011. p 133. Disponível em:< http://www.coes.org.pe/wcoes/coes/estadistica/estadanual.aspx>. Acesso em: 24 jun 2011.

COES. Comité de Operación Economica del Sistema Interconectado Nacional. Informe de diagnostico de las condiciones operativas del SEIN periodo 2013 2022. Lima : Relatorio, Dirección de Planificación de Transmisión, 2011a.

CTE. Comisión de Tarifas de Energia. Nuevo modelo tarifario del sistema interconectado nacional. Lima : Comisión de Tarifas de Energia, 2000. Ano 4 : Vol. $N^{\circ}$ 3. Dissponível em:<http://www2.osinerg.gob.pe/Pu blicaciones/pdf/Informativo/ INFO0403.pdf>. Acesso em: 10 jun 2011.

DA COSTA R. A.; CASOTTI B. P.; De AZEVEDO R. L. S. Um panorama da indústria de bens de capital relacionados à energia eólica. Rio de Janeiro : Relatório, BNDES Setorial, 2009. n. 29, p 229-278 p. 
DE LA CRUZ, R.; GARCÍA, R. La problemática de la actividad de transmisión de energía en el Perú. Lima: Economia y Sociedad, No. 54, CIES, 2004. Disponível em:<http://www.gestiopolis.com/canales5/eco/consorcio/eys54/archivos/54-problema s-energeticos-en-el-peru.pdf>. Acesso em: 10 de julho, 2011.

DUTRA R. M. Energia eólica estado da arte e princípios físicos. Apresentação: Curso de Tecnologia da Energia no PPE/COPPE/UFRJ. CEPEL. Rio de Janeiro, 2010. Disponivel em:<http://www.cresesb.cepel.br/>. Acesso em: 15 nov 2010.

DUTRA R. M. Energia eólica princípios e tecnologia. Tutorial, CRESESB. Rio de Janeiro, 2009. Disponível em:<http://www.cresesb.cepel.br/>. Acesso em: 20 dez 2010.

DUTRA R. M. Propostas de políticas específicas para energia eólica no brasil após a primeira fase do PROINFA. Tese (Doutorado Ciências em Planejamento Energético) - Programas de Pós-Graduação de Engenharia, Universidade Federal do Rio de Janeiro, Rio de Janeiro, 2007. 415 p. Disponível em:<http://www.cresesb.cepel.br/>. Acesso em: 15 de nov. 2010.

DUTRA R. M. Viabilidade técnico-econômica da energia eólica. Dissertação (Mestrado Ciências em Planejamento Energético) - Programas de Pós-Graduação de Engenharia, Universidade Federal do Rio de Janeiro, 2001. 309 p. Disponível em:<http://www.cresesb.cepel.br/>. Acesso em: 15 de nov. 2010.

EDEGEL. Centrales térmicas de Edegel. Lima: Apresentação: Seminario Termoeléctricas Perú 2007 Presente y Futuro, 2007.

EIA. Energy Information Administration. International energy Outlook 2010. Online. 2010. Disponível em:<http://www.eia.doe.gov/neic/speeches/howard 052510.pdf>. Acesso em: 01 Jun 2010.

ELETROSUL. Interligação pode reduzir valor da conta de luz. Online. Gestor digital de informações, 2009. Disponivel em:<http://www.eletrosul.gov.br/gdi/gdi/ index.php?pg=cl_abre\&cd=hfleff3 BUdig >. Acesso em: 05 jun 2010.

ESC. Electrical System Consultants. Determinación de la capacidad máxima de generación eólica en el SEIN. Lima: Relatorio COES, 2009. Disponível em:<http://biblioteca.uns.edu.pe/saladocentes/archivoz/curzoz/ESC_090810_91_IF_ Maxima_Gen_Eolica_Rev_1.pdf>.Acesso em: 25 out 2010. 
EVANS, J. I. Benefits of wind power curtailment in a hydro-dominated electric generation system. Thesis (Master) Of Applied Science B.Sc. - Civil Engineering, The University Of British Columbia, Vancouver - Canada, 2004. 96 p.

FADIGAS, E. A. F. A. Identificação de locais e opções tecnológicas para implantação de termoelétricas no sistema elétrico brasileiro: Contribuição à metodologia e aplicação ao caso do gás natural. Tese (Doutorado em Engenharia) - Escola Politécnica da Universidade de São Paulo, São Paulo, 1998.

FERNANDINI, E. B.; MARIÑO, G. R.; MOTTA, V. C. Propuesta estratégica para el desarrollo de la energia eólica en el peru. Tesis (Maestria) - Universidad Católica del Peru, Lima, 2007. 251p.

FERREIRA, H. T. Energia eólica: barreiras a sua participação no setor elétrico brasileiro. Dissertação (Mestrado) - Programa Interunidades de Pós-Graduação em Energia IEE, Universidade de São Paulo, São Paulo, 2008. 97 p.

FILHO, J. M. A. Uma visão integrada do planejamento da expansão e da operação energética do sistema eletrico brasileiro. Tese (Doutorado) - Escola Politécnica, Universidade de São Paulo, São Paulo, 2006. 167 p.

FLORES, S. A.; MENDOZA, M. M. A.; ROSALES, E A. F. Despacho economico de un sistema termoeléctrico a corto plazo. Tese (Graduación) - Escuela Superior de Ingeniería Mecánica y Eléctrica, Instituto Politecnico Nacional, Mexico DF, 2008. 61 p.

FONAM. Fondo Nacional del Ambiente. Promoción de la participación pública y privada en proyectos de Energía Renovable y Fortalecimiento de la capacidad de FONAM. Lima: Relatório, FONAM. Lima, 2006. Disponível em:<http://www. fonamperu.org/general/energia/documentos/promox.pdf>. Acesso em: 22 ago 2010.

FREITEZ, A.; ALCALA, E.;TOLEDO, J.; JIMENEZ, J.D. Expected mid term optimal operational planning of the venezuelan interconnected power system. IEEE Xplore Digital Library, 2006, 5 p.

GUEDES, D. F.; CAVALCANTI, E J. Análise energética do impacto da geração eólica com atraso em obras do sistema elétrico brasileiro. In: III Simpósio Brasileiro de Sistemas Elétricos da Universidade Federal do Pará. Belem: Resumos dos trabalhos, UFPA, 2010. Disponível em:<http://www.labplan.ufsc.br/congressos/ III\%20SBSE\%20-\%202010/ PDF/SBSE2010-0160.PDF>. Acesso em: 24 ago 2010. 
GUENA, A. M. O. Avaliação ambiental de diferentes formas de geração de energia elétrica. Dissertação (Mestrado) - IPEN Instituto de Pesquisas Energéticas e Nucleares, Autarquia Associada à Universidade de São Paulo, São Paulo, 2007. $133 \mathrm{p}$.

GWEC. Global Wind Energy Council. Global wind 2009 report. 2010. Disponível em:<http://www.gwec.net/fileadmin/documents/Publications/Global_Wind_2007_repo rt/GWEC_Global_Wind_2009_Report_LOWRES_15th.\%20Apr..pdf>. Acesso em: 12 nov 2010.

GWEC. Global Wind Energy Council. Global wind estatistics 2010. 2011a. Disponível em:<http://www.gwec.net/fileadmin/documents/Publications/GWEC_PR stats_02-02-2011_final.pdf>. Acesso em: 02 fev 2011.

GWEC. Global Wind Energy Council. Global wind energy outlook 2010. 2011b. Disponível em:<http://www.gwec.net/fileadmin/documents/Publications/ GWEO\% 202010\%20final.pdf>. Acesso em: 02 fev 2011.

HERRERA, C.D.; NOVOA, A.P.; HORN, M.M. Matriz energética en el Perú y contribución de las energías renovables. Lima: Relatório Friedrich Eberto Stiftung, 2010. Disponível em:<http://www.fes.org.pe/Matriz\% 20Energetica\% 20Peru.pdf>. Acesso em: 24 jun 2010.

HOFFMANN B. S. O ciclo combinado com gaseificação integrada e a captura de CO2: uma solução para mitigar as emissões de $\mathrm{CO} 2 \mathrm{em}$ termeletricas a carvão em larga escala no curto prazo?. Dissertação (Mestrado em Planejamento Enegético) - Programa de Pós-Graduação em Planejamento Energético da Universidade Federal de Rio de Janeiro, Rio de Janeiro, 2010.

HOLTTINEN, H. The impact of large scale wind power production on the Nordic electricity system. 2004. 82p. Dissertation (for the degree of Doctor of Science) Technology to Department of Engineering Physics and Mathematics, University of Technology, Otamedia - Espoo - Finland, 2004.

HUAYLLAS T. E. D. C. Análise comparativa de modelos para fixação de tarifas de transmissão e de previsão de mercado de energia de alguns paises sul americanos. Dissertação (Mestrado) - Escola Politécnica, Universidade de São Paulo, São Paulo, 2008. 
JANUÁRIO, A. C. V. O mercado de energia elétrica de fontes incentivadas: proposta para sua expansão e implicações na câmara de comercialização de energia elétrica. Dissertação (Mestrado) - Escola Politécnica, Universidade de São Paulo, São Paulo, 2007. 121 p.

JASKULSKI, Í. W. Contribuições ao estudo de conexão de geração eólica à rede elétrica. Dissertação (Mestrado) - Programa de Pós-Graduação em Engenharia Elétrica, Universidade Federal de Santa Maria, Santa Maria - RS, 2007. 99 p.

JIMÉNEZ, L. A. F. Modelos avanzados para la predicción a corto plazo de la producción eléctrica en parques eólicos. Tesis (Doctoral) - Universidad de La Rioja, La Rioja - España, 2008. 310 p.

LOPES, J. E. G. Modelo de planejamento da operação de sistemas hidrotérmicos de produção de energia elétrica. Tese (Doutorado) - Escola Politecnica, Universidade de São Paulo, São Paulo, 2007. 127 p.

LOPES, J. E. G. Otimização de sistemas hidroenergéticos. Dissertação (Mestrado) - Escola Politécnica, Universidade de São Paulo, São Paulo, 2001. 85 p.

LORA, E. E. S.; NASCIMENTO, M. A. R. Geração termelétrica: planejamento, projeto e operação. Rio de Janeiro: Interciencia, 2004.

LOURENÇO, S. R. Gás natural: perspectivas e utilização. Dissertação (Mestrado) Faculdade de Engenharia Mecânica, da Universidade Estadual de Campinas, Campinas, 2003. 106 p.

LUYO, J. E. Modelado de la interconexión de los mercados de gas y electricidad en el perú. Lima, 2008. Disponível em: http://csdinstitute.org/Publish/Modelling_of_the_interconnected_gas_and_electricity_markets_i n_Peru.pdf. Acesso em: 10 mai 2010.

LUYO, J. E. Oportunidad de cambio de la matriz energética para el desarrollo sostenible en Perú. Lima, 2009. Disponível em:< http://www.eumed.net/rev/delos/ 06/ jel.pdf>. Acesso em: 10 mai 2010.

MACROINVEST. Empresa Consultora. Determinación del precio a ser tomado en cuenta por energy europes.r.l. y acciona s. a. através de generalimas.a. en la oferta sobre las acciones comunes con derecho a voto emitidas por empresa eléctrica de piura. Lima : Relatório Final, 2008. 
MELLO, O. D. Despacho integrado da geração termelétrica e da produção e transmissão de gás natural. Tese (Doutorado) - Faculdade de Engenharia Elétrica e de Computação, Universidade Estadual de Campinas, Campinas SP, 2006. 107 p. Disponível em:<http://cutter.unicamp.br/document/?code=vtls000391284>. Acesso em: 01 jun 2010.

MEM - OSINERG. Comisión Mixta. Libro blanco: proyecto de ley para asegurar el desarrollo eficiente de la generación eléctrica. Lima : Relatório Comisión MEMOSINERG, 2005.

MORENO, M. PAZ Comech. Análisis y ensayo de sistemas eólicos ante huecos de tensión. Tesis (Doctoral) - Departamento de Ingeniería Eléctrica, Universidad de Zaragoza, Zaragoza - España, 2007. 329 p.

NADIRA, R; MERRILL, H; PINHEIRO, A. Modelo para la planificación y expansión de los sistemas de transmisión. Lima: OSINERGMIN- Informe Final, Segunda Versão, 2007.

NREL. National Renewable Energy Laboratory. Informação Online. 2011. Disponível em:<http://www.nrel.gov/analysis/lcoe_documentation.html>. Acesso em: 28 jul 2011.

ORTIZ, M. A. M. Inversión para el futuro próximo termoeléctrica a gas natural. Tesis Pre-Grado (Ingenieria Industrial) - Facultad de Ciências e Ingeniería, Pontificia Universidad Católica del Perú, Lima, 2005. 142 p.

OSINERG. Organismo Supervisor de la Inversión en Energía. La industria del gas natural en el perú. Lima: Documento de Trabajo $N^{\circ} 1$, Oficina de Estudios Económicos OSINERG, 2004.

OSINERG. Organismo Supervisor de la Inversión en Energía. Manual técnico: metodologia del modelo Perseo. Lima: Manual Osinerg, 2006a.

OSINERG. Organismo Supervisor de la Inversión en Energía. Manual técnico: uso del modelo Perseo. Lima : Manual Osinerg, 2006b.

OSINERG. Organismo Supervisor de la Inversión en Energía. Reformas estructurales en el sector eléctrico peruano. Lima: Relatório Oficina de Estudios Económicos OSINERG, 2005. 
OSINERGMIN. Organismo Supervisor de la Inversión en Energía y Mineria. Boletin anual 2010: operación del sector eléctrico. Lima: Relatório, 2011a. Disponível em:<http://www2.osinerg.gob.pe/gart.htm>. Acesso em: 30 Jul 2011.

OSINERGMIN. Organismo Supervisor de la Inversión en Energía y Mineria. Boletin informativo de gas natural 2010 II. Lima: Relatório Osinergmin, 2011b. Disponível em:<http://gasnatural.osinerg.gob.pe/contenidos/ciudadania/publicaciones_osinergmi n.html>. Acesso em: 30 Mai 2011.

OSINERGMIN. Organismo Supervisor de la Inversión en Energía y Mineria. Gas natural online. 2010a. Disponível em:<http://www2.osinerg.gob.pe/Pagina\%20 Osinergmin/Gas\%20Natural/index.html>. Acesso em: 14 ago 2010.

OSINERGMIN. Organismo Supervisor de la Inversión en Energía y Mineria. EI informativo: régimen remunerativo de generación RER. Lima: Relatório Osinergmin - Gart, 2010b. Disponível em:<http://www2.osinerg.gob.pe/Publicacio nes/pdf/Informativo/INFO-A14N04.pdf>. Acesso em: 25 de mai 2011.

OSINERGMIN. Organismo Supervisor de la Inversión en Energía y Mineria. Impacto de la GRP de Camisea en el sector electrico peruano. Lima: Relatório Osinergmin - GART, 2009. Disponível em:<http://www2.osinerg.gob.pe/Pagina\%20 Osinergmin/Gas\%20Natural/Contenido/PAGINA\%20WEB/pdf/Folleto005/untitled1/fil es/Impacto\%20de\%20la\%20GRP.pdf>. Accesso em: 15 mai 2011.

OSINERGMIN. Organismo Supervisor de la Inversión en Energía y Mineria. Regulación del gas natural en el Perú: estado del arte al 2008. Lima: Relatório Osinergmin-Gart, 2008. Disponível em:<http://www2.osinerg.gob.pe/Infotec/Gas Natural/pdf/Regulacion_Gas_Natural_Peru.pdf>. Acesso em: 15 jul 2011.

PARO, A. de C. Estudo da Contribuição do gás natural no setor elétrico - uma análise de cenários de sua expansão nos setores de geração termelétrica, cogeração e residencial. Dissertação (Mestrado) - Escola Politécnica da Universidade de São Paulo, São Paulo, 2005. 101 p.

PEREIRA, R. H.; BRAGA, S. L.; BRAGA C. V. M.. Substituição parcial do óleo diesel pelo gás natural em motores - atratividade da tecnologia e sua avaliação experimental. Departamento de Engenharia Mecânica, Pontifícia Universidade Católica do Rio de Janeiro, Rio de Janeiro, 2003. Disponível em:<http://www.workoutenergy.com.br/publicacao_vencontro/trabalhos_tecnicos/do wnload/ricardo_hernandez.pdf>. Acesso em: 25 mai 2010. 
PERU MINISTERIO DE ENERGIA Y MINAS. Dirección General de Electricidad. Acuerdo entre el gobierno de la república federativa del Brasil y el gobierno de la república del perú para el suministro de electricidad al Perú y exportación de excedentes al brasil. Online. 2010b. Disponivel em:<http://www.minem.gob.pe/>. Acesso em: 25 jul 2010.

PERU MINISTERIO DE ENERGIA Y MINAS. Dirección General de Electricidad. Atlas eólico del Perú. Lima: Dirección General de Electrificación Rural, 2008. Disponível em:<http://dger.minem.gob.pe/atlaseolico/PeruViento.html>. Acesso em: 12 jul 2010.

PERU MINISTERIO DE ENERGIA Y MINAS. Dirección General de Electricidad. Estadística eléctrica 2009 - 2010* Generación - Transmisión. Lima: Relatório DGE, 2011a. Disponível em:<http://www.minem.gob.pe/>. Acesso em: 10 ago 2011.

PERU MINISTERIO DE ENERGIA Y MINAS. Dirección General de Electricidad. Estadistica eléctrica 2009 - 2010 distribución. Lima: Relatório DGE, 2011b. Disponível em:<http://www.minem.gob.pe/>. Acesso em: 10 ago 2011.

PERU MINISTERIO DE ENERGIA Y MINAS. Dirección General de Electricidad. Sector eléctrico 2010: Documento Promotor. Lima: Relatório DGE, 2010a. 36 p.

PERU MINISTERIO DE ENERGIA Y MINAS. Dirección General de Electricidad. Estadística Eléctrica 2008-2009 Generación - Transmisión. Lima: Relatório DGE, 2010c. Disponível em:< http://www.minem.gob.pe /novedadesSector.php?idSector =6>. Acesso em: 05 jun 2010 .

PERU MINISTERIO DE ENERGIA Y MINAS. Dirección General de Electricidad. Plan referencial de electricidad 2008 - 2017. Lima: Relatorio DGE, 2009a. Disponível em:<http://www.minem.gob.pe/sector.php?idSector=6\#>. Acesso em: 12 abr 2010.

PERU MINISTERIO DE ENERGIA Y MINAS. Dirección General de Electricidad. Evolución de indicadores del mercado eléctrico 1995 - 2009. Lima: Relatório DGE, 2009b. Disponível em:<http://www.minem.gob.pe/novedadesSector.php?id Sector=6>. Acesso em: 05 jun 2010.

PETROMONT. Avances en el aprovechamiento de la energia eolica en el Perú y su potencial para la generación de eléctricidad aislada y conectada a la red. Apresentação. 1er. Seminario de Energia Eólica en el Perú. Lima, 2008. Disponível em:<http://www.itdg.org.pe/publicaciones/preseolica/foley.pdf>. Acesso em: 24 ago 2010. 
PINTO, J. A. et al. Desafios e soluções para a integração de 7500 MW de potência eólica na rede portuguesa. Decimo Tercer Encuentro Regional Iberoamericano de Cigré, 2009, 8 p.

PORRUA, $F$. et al. Wind power insertion through energy auctions in Brazil. Artigo. IEEE Xplore, 2010. 8p. Disponivel em:<http://ieeexplore.iee.org/stamp/ stamp.jsp?tp=\&arnumber=558975>. Acesso em: 10 ago 2010.

PORTELLA J. R. Viabilidade da captação da energia eólica nos oceanos (captação offshore). Monografia - Departamento de Engenharia, Universidade Federal de Lavras, Lavras - MG, 2007. 20 p.

PSR. Abeeólica. Inserção da energia eólica desafios e oportunidades. Rio de Janeiro: Relatorio, 2009. 78 p.

QUINGATUÑA, C. F. G. Estabilidad y amortiguamiento de oscilaciones en sistemas eléctricos con alta penetración eólica. Tese (Doctoral) - Departamento de Ingenieria Eléctrica, Electrónica y Automática, Universidad Carlos III de Madrid, Leganés/Getafe - España, 2009. 192 p.

REP. Red de Energia del Perú. Tejedores de luz: Homenaje a los forjadores de la transmisión eléctrica en el perú. Lima, 2007. Disponivel em:<http://www.minem.gob.pe /minem/archivos/file/institucional/publicaciones/biblio teca/tejedores.html>. Acesso em 18 de mai 2010.

REYES, R. P. Regulación y funcionamiento del sector de la energía en el perú. Lima: Relatório OSINERG, 2005. Disponivel em:< http://www.ariae.org/ download/sistemas_energeticos/peru.pdf>. Acesso em: 14 abr 2010.

ROCHA D. Q.; CALFA L. F. F. Análise da estrutura de formação de preços no mercado de gás natural. TCC - Escola Politécnica da Universidade Federal de Rio de Janeiro. Departamento de Engenharia Industrial, Rio de Janeiro, 2003. Disponível em:<www.petroleo.ufrj.br/lorde/?q=file/30/download/30 . Acesso em: 15 de jun 2011.

ROSAS, P. Dynamic influences of wind power on the power system. Thesis (Submitted) - Ørsted Institute, Section of Electric Power Engineering Technical University of Denmark, Dinamarca, 2003. 152 p. 
SALES, W. S. Planejamento da reserva operativa de sistemas de geração com elevada penetração de energia eólica. Tese (Doutorado) -Programa de PósGraduação em Engenharia Elétrica, Universidade Federal de Itajubá, Itajubá - MG, 2009. $161 \mathrm{p}$.

SALES, W. S. Planejamento de sistemas de geração com elevada penetração de energia eólica. Dissertação (Mestrado) - Programa de Pós-Graduação em Engenharia Elétrica, Universidade Federal de Itajubá, Itajubá - MG, 2006. 135 p.

SALLES, A. C. N. Metodologias de análise de risco para avaliação financeira de projetos de geração eólica. Dissertação (Mestrado) - Programas de PósGraduação de Engenharia, Universidade Federal do Rio de Janeiro, Rio de Janeiro, 2004. 83 p.

SARANGO D. J.; VELÁSQUEZ T. B. Uso de series sintéticas de caudales mensuales en el cálculo del costo marginal de energía del sistema eléctrico interconectado nacional del Perú. Lima: Revista de Investigación de Física, 2009. Vol. 12. 59 - 69 p. Disponível em:<http://fisica.unmsm.edu.pe/images/a/a5/Rif 12_1_59-69.pdf>. Acesso em: 05 out. 2010.

SERRA, J. V. Inambari: la urgencia de una discusión seria y nacional. Lima: ProNaturaleza, 2010. Vol. 1. Disponivel em:<http://www.pronaturaleza.org/archivos/ pdf/inambari_02dic_vf.pdf>. Acesso em: 10 fev 2011.

SILVA, K. F. D. Controle e integração de centrais eólicas à rede elétrica com geradores de indução duplamente alimentados. Tese (Doutorado) - Escola Politécnica, Universidade de São Paulo, São Paulo, 2006. 240p.

SOUZA, H. D. Análise de preços de energia elétrica em sistemas hidrotérmicos. Dissertação (Mestrado) - Comissão de pós-graduação da Faculdade de Engenharia Civil, Arquitetura e Urbanismo, Universidade Estadual de Campinas, Campinas - SP. 2008. $143 \mathrm{p}$.

SOWITEC. Energias Renovables de Perú S.A. Industria del viento en Perú. Apresentação, IV Congreso de Energias Renovables y Biocombustibles. Lima, 2010. Disponivel em:<http://energiaslimpias.wordpress.com/2010/10/18/iv-cober-acceso-alas-presentaciones/>. Acesso em: 15 dez 2010.

Tech4CDM. La energía eólica en perú. Lima; Relatório, 2009. Disponível em:< http://www.tech4cdm.com/uploads/documentos/documentos_La_Energia_Eolica_en _Peru_13aed1f1.pdf>. Acesso em: 24 mai. 2010. 
VALVERDE, G. B. Sistema de información para una bolsa de energía en el sector eléctrico y financiero peruano. Tesis Pre-Grado (Titulo de Ingeniería Informática) - Facultad de Ciencias e Ingeniería, Pontificia Universidad Católica del Perú, Lima, 2006. 103 p.

VITERBO, J. C. Geração de energia elétrica a partir da fonte eólica offshore. Dissertação (Mestrado) - Escola Politécnica, Universidade de São Paulo, São Paulo, 2008. $167 \mathrm{p}$.

WALSH PERÚ S.A. EIA parque eólico marcona y línea de transmisión. Lima: Relatório, 2010. Disponível em:< http://www.minem.gob.pe/minem/archivos/file/ DGGAE/ARCHIVOS/estudios/>. Acesso em: 15 jan 2010.

ZAMALLOA, G. A. C. Avaliação de alternativas tecnológicas (GNL e GTL) para a viabilização de jazidas de gás natural remotas em países em desenvolvimento estudo de caso: jazida de Camisea no Perú. Tese (Doutorado) - Programa Interunidades de Pós-Graduação em Energia, Universidade de São Paulo, São Paulo, 2004. 211 p.

ZAMBON, R. C. Planejamento da operação de sistemas hidrotérmicos de grande porte. Tese (Doutorado) - Escola Politécnica da Universidade de São Paulo. Departamento de Engenharia Hidráulica e Sanitária, São Paulo, 2008. 104 p. 


\section{ANEXO A: Metodologia do Modelo Perseo}

\section{Formulação Matemática do Despacho Térmico}

A formulação típica do despacho económico considera o déficit como uma usina adicional de geração térmica com um alto custo de operação (custo de falha). Em programação lineal, geralmente usa-se o seguinte modelo:

$$
z=\operatorname{Min} \sum_{j=1}^{N_{J}}\left[\sum_{t=1}^{N_{T}}\left(\begin{array}{cl}
c o_{j, t} & \left.g t_{j, t}\right)
\end{array}\right]\right.
$$

s/a

$\sum_{j=1}^{N_{J}} g t_{j, t}=d_{t} \quad t=1, \ldots, T$
$g t_{j, t} \leq \overline{g t}_{j, t}$
$j=1, \ldots, N_{J}$
$t=1, \ldots, T$
$\pi \frac{c p}{g t_{j, t}}$

Onde:

j índice das usinas de geração térmica.

$\mathrm{t} \quad$ índice das etapas.

$\mathrm{N}_{\mathrm{J}} \quad$ número de usinas de geração térmica.

$\mathrm{N}_{\mathrm{T}} \quad$ número de etapas do horizonte de estudo.

$\mathrm{CO}_{\mathrm{j}, \mathrm{t}}$ custo de operação da j-ésima usina térmica na etapa t.

gt $_{j, t} \quad$ geração da j-esma usina térmica na etapa $t$.

$\overline{g t}_{j, t} \quad$ capacidade disponível de geração da j-esma usina térmica na etapa t.

$d_{t} \quad$ demanda do mercado de energia na etapa $t$. 
Além disso:

$\pi_{d_{t}}^{c p} \quad$ multiplicador dual que expressa a sensibilidade do custo de produção à variação da demanda na etapa t.

$\pi \frac{c p}{g t_{j, t}} \quad$ multiplicador dual que expressa a sensibilidade do custo de produção à variação da capacidade disponível de geração da j-ésima usina térmica.

Estas sensibilidades representam os custos marginais de curto prazo e utilizam-se na elaboração das estruturas tarifarias dos sistemas eléctricos.

A solução do Despacho Térmico e consequentemente a derivação das sensibilidades associadas ao problema matemático é simples e pelo geral não requer de processos sofisticados de optimização. $O$ método mais conhecido é o denominado "Ordem de Mérito" ou "Lista de Prioridade", que consiste em despachar as usinas térmicas por custo crescente de operação até completar atender a demanda total do mercado.

\section{Formulação Determinística do despacho Hidrotérmico}

\subsection{Função Objetivo}

O problema da operação óptima determinística de curto prazo enfoca a evolução do sistema ao longo do tempo; considera conhecidas as variações mensais das disponibilidades hidrológicas e das demandas de energia eléctrica do sistema. A operação procura minimizar o custo de produção de energia elétrica para todo o horizonte de estudo; o qual se compõe normalmente dos custos de geração térmica e eventuais custos de déficit.

Se o déficit se modela como um gerador termoeléctrico fictício com um custo de operação elevado. Então, a função objetivo, em forma matemática, esta dada pela seguinte expressão: 


$$
\operatorname{Min} \sum_{j=1}^{N_{J}}\left[\sum_{t=1}^{N_{T}}\left(C O_{j, t} g t_{j, t}\right)\right]
$$

\subsection{Restrições Operativas}

A seguir descrevem-se o conjunto de restrições operativas de curto prazo:

2.2.1 Cobertura da Demanda (Balanço de Energia)

O balanço de energia no ponto onde se concentra a oferta com a demanda, esta dado por:

$$
\sum_{j=1}^{N_{J}} g t_{j, t}+\sum_{i=1}^{N_{I}} g h_{i, t}=d_{t} \quad t=1, \ldots, T
$$

Onde:

i índice das usinas de geração hidrelétrica.

$N_{l} \quad$ número de usinas de geração hidrelétrica.

$g h_{i, t}$ geração da i-esma usina hidrelétrica na etapa $t$, dado por:

$$
g h_{i, t}=\rho_{i} q_{i, t}
$$

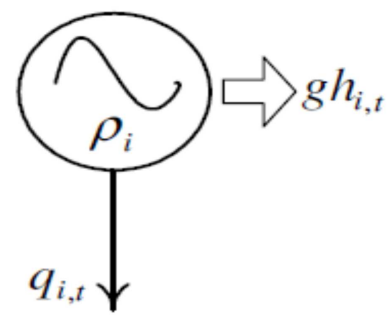

Onde:

$\rho_{i} \quad$ rendimento da turbina (coeficiente de vazão turbinado/energia gerada). 
$q_{i, t} \quad$ volume turbinado na i-esma usina hidrelétrica durante a etapa t.

Cabe notar que a expressão (2) assume duas simplificações:

i) Existência de uma turbina por usina: está simplificação é adoptada neste trabalho por simplicidade de maneira de facilitar o entendimento do leitor. Na prática, no entanto, podem existir mais de uma turbina por usina.

ii) Rendimento constante: $\mathrm{Na}$ prática, o rendimento de uma usina pode variar significativamente com o total da água armazenada e com a altura do canal de fuga. Apesar de que estas variações sejam importantes para a avaliação da evolução horária do embalse, pelo geral não são significativas em estudos com períodos mensais.

Finalmente, combinando as expressões (1) e (2), obtém-se:

$$
\sum_{j=1}^{N_{J}} g t_{j, t}+\sum_{i=1}^{N_{I}} \rho_{i} q_{i, t}=d_{t} \quad t=1, \ldots, N_{T}
$$

\subsubsection{Limites de geração}

As gerações hidrelétricas e termelétricas estão restringidas por valores máximos, enquanto a geração hidráulica pode estar adicionalmente restringida por mínimos:

$$
\begin{aligned}
q_{i, t} & \leq \bar{q}_{i, t} \\
q_{i, t} & \geq \underline{q}_{i, t} \\
g t_{j, t} & \leq \overline{g t}_{j, t}
\end{aligned}
$$




\subsubsection{Equações de Conservação da Água}

As equações de conservação da água representam o balanço hídrico em cada ponto do sistema, isto é, o total de água que entra em cada ponto (elemento da bacia hidrográfica) deve ser igual ao total de água de saída.

Este balanço depende do elemento do sistema hidráulico, no entanto é possível reduzir os casos a dois básicos, a partir dos quais se podem derivar todos os outros.

\section{a) Balanço em Embalses}

O volume final do embalse na etapa t é igual ao volume inicial (final da etapa anterior), mais as entradas de água (volumes incrementais afluentes e volumes provenientes das usinas águas acima), menos as perdas por evaporação, e os volumes turbinados e vertidos no próprio embalse.

$$
\begin{gathered}
v_{i, t+1}=v_{i, t}+a_{i, t+1}+\sum_{l \in M_{i}}\left(q_{l}+s_{l}\right)-q_{i}-s_{i}-e_{i, t+1} \\
e_{i, t+1}=\varepsilon v_{i, t}
\end{gathered}
$$

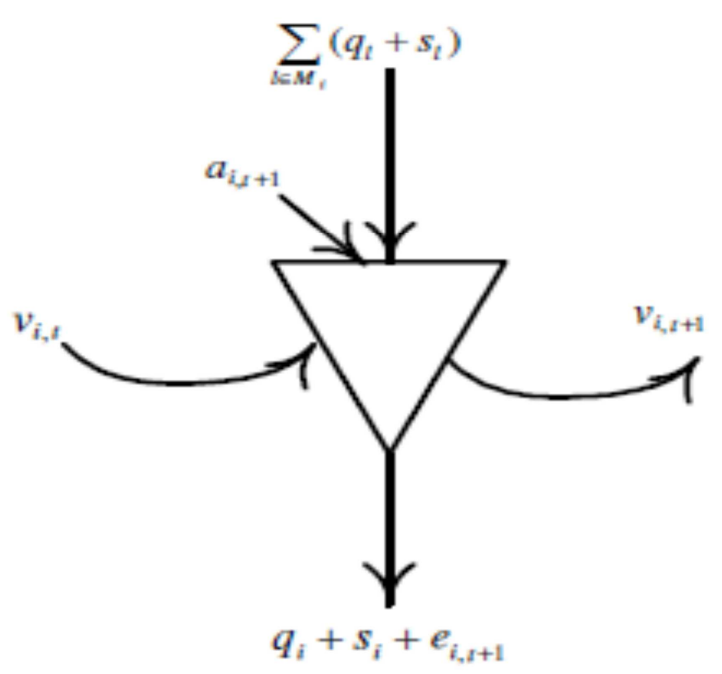


Onde:

$v_{i, t} \quad$ volume de água armazenado no embalse da i-esma usina ao início da etapa $\mathrm{t}$ (igual ao volume armazenado na etapa t-1).

$a_{i, t} \quad$ volume de água afluente ao embalse da i-ésima usina durante a etapa t.

$s_{i, t} \quad$ volume de água vertido pela i-ésima usina durante a etapa $\mathrm{t}$.

$M_{i} \quad$ conjunto de usinas águas acima da i-ésima usina.

$e_{i, t} \quad$ volume de água evaporada no embalse da i-ésima usina na etapa t.

$\varepsilon \quad$ porcentagem de evaporação respeito do volume armazenado no embalse.

\section{b) Balanço em Reservatórios}

O reservatório assume-se são do tipo que brindam regulação diária, de modo que sua operação esta referida só aos blocos horários que constituem cada etapa, pelo que o volume final do reservatório ao igual que o inicial na etapa té nulo. Dentro da etapa o volume do reservatório no bloco k é igual ao volume inicial (final do bloco posterior), mais as entradas de água (vazões incrementais afluentes e vazões provenientes das usinas águas acima), menos os volumes turbinados e vertidos no próprio reservatório durante cada bloco horário. Deve ficar claro que a finalidade de incluir os reservatórios dentro da formulação é de fazer a modelagem com maior detalhe a disponibilidade de água por parte das usinas hidrelétricas ao nível dos blocos horários de demanda da cada etapa.

$$
v_{i, t, k-1}=v_{i, t, k}+a_{i, t}+\sum_{l \in M_{i}}\left(q_{l}+s_{l}\right)-q_{i}-s_{i, t, k-1}
$$



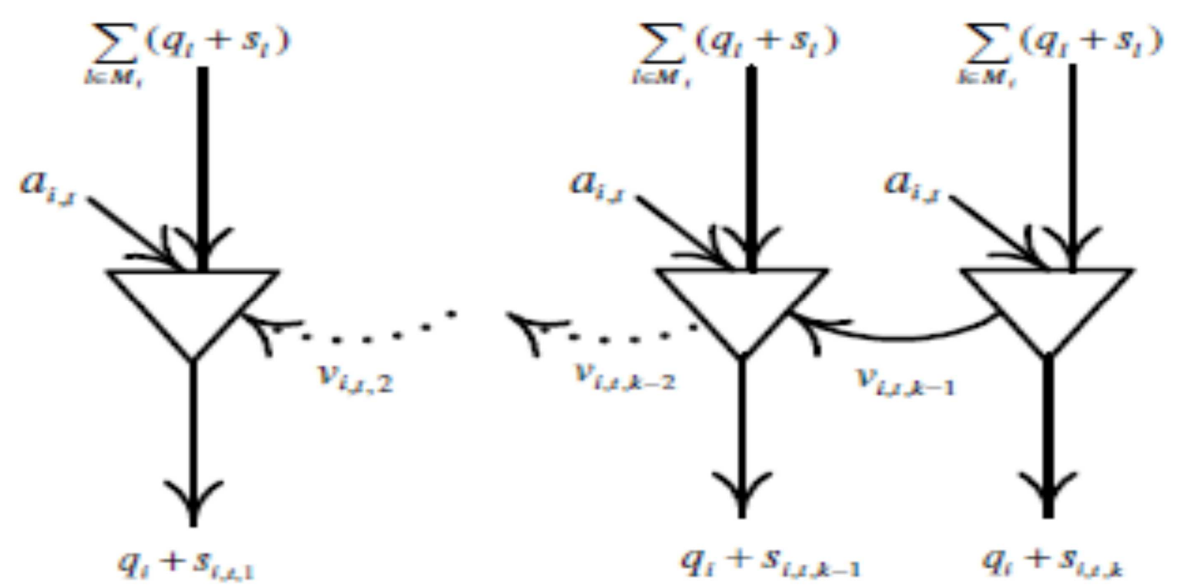

Onde:

$v_{i, t, k} \quad$ volume de água armazenado no reservatório da i-esma usina ao início durante a etapa t no bloco $\mathrm{k}$.

$a_{i, t} \quad$ volume de água afluente ao embalse da i-ésima usina durante a etapa t.

$s_{i, t, k} \quad$ volume de água vertido pela i-ésima usina durante o bloco $\mathrm{k}$ da etapa $\mathrm{t}$.

$M_{i} \quad$ conjunto de usinas águas acima da i-ésima usina.

2.2.4 Limites Operativos dos Embalses

Os volumes dos embalses têm limites físicos, mínimos $\underline{v}_{i, t} \mathrm{e}$ máximos $\bar{v}_{i, t}$ :

$$
\begin{aligned}
& v_{i, t} \geq \underline{v}_{i, t} \\
& v_{i, t} \leq \bar{v}_{i, t}
\end{aligned}
$$

2.2.5 Limites Operativos dos Reservatórios

Os volumes dos reservatórios têm limites físicos máximos $\bar{v}_{i}$ :

$$
v_{i, t, k} \leq \bar{v}_{i}
$$


2.2.6 Limites Operativos das Vazões Reguladas

Os volumes regulados aqui representados por $r_{i, t}$; onde:

$$
r_{i, t}=q_{i, t} \text { ou } r_{i, t}=s_{i, t}
$$

Estão restringidas por valores mínimos (por exemplo, em casos de restrições de irrigação, navegação ou recreação):

$$
r_{i, t} \geq \underline{r}_{i, t}
$$

Ou limites máximos (por exemplo, em casos de grandes avenidas):

$$
r_{i, t} \leq \bar{r}_{i, t}
$$

\section{Formulação Matemática da Optimização Determinística}

O problema da operação ótima determinística está composto pela função objetivo e das restrições operativas.

$\operatorname{Min} \sum_{j=1}^{N_{J}}\left[\sum_{t=1}^{N_{T}}\left(\operatorname{CO}_{j, t} g t_{j, t}\right)\right]$

s/a

$\sum_{j=1}^{N_{J}} g t_{j, t}+\sum_{i=1}^{N_{I}} \rho_{i} q_{i, t}=d_{t}$

$g t_{j, t} \leq \overline{g t}_{j, t}$ $\pi \frac{c p}{g t_{j, t}}$

$v_{i, t+1}-v_{i, t}-\sum_{l \in M_{i}}\left(q_{l}+s_{l}\right)+q_{i}+s_{i}=a_{i, t+1}-e_{i, t+1}$ $\pi_{a_{i, t}}^{c p}$

$v_{i, t, k-1}-v_{i, t, k}-\sum_{l \in M_{i}}\left(q_{l}+s_{l}\right)+q_{i}+s_{i}=a_{i, t}$ 


$$
\begin{array}{lll}
v_{i, t} & \leq \bar{v}_{i, t} & \pi_{\bar{v}_{i, t}}^{c p} \\
v_{i, t} \geq \underline{v}_{i, t} & \\
v_{i, t, k} & \leq \bar{v}_{i} \\
q_{i, t} & \leq \bar{q}_{i, t} & \\
q_{i, t} & \geq \underline{q}_{i, t} & \pi_{\bar{q}_{i, t}}^{c p} \\
r_{i, t} \leq \bar{r}_{i, t} & \\
r_{i, t} \geq \underline{r}_{i, t} & \\
\forall & i=1, \ldots, N_{I} ; \quad j=1, \ldots, N_{J} ; \quad t=1, \ldots, N_{T}
\end{array}
$$

\section{Incorporação da Rede de Transmissão}

O intercâmbio de energia entre as regiões, representadas por barras equivalentes, se modela através do seguinte conjunto de restrições:

\subsection{Balanço de Energia}

$$
\begin{gathered}
\sum_{j \in k} g t_{j, t}+\sum_{i \in k} \rho_{i} q_{i, t}+\sum_{m \in \Omega(k)}\left(\left(1-0.5 \gamma_{m k, t}\right) f_{m k, t}-\left(1+0.5 \gamma_{k m, t}\right) f_{k m, t}\right)=d_{k, t} \\
\forall \quad k=1, \ldots, N_{K} ; \quad t=1, \ldots, N_{T}
\end{gathered}
$$

Onde:

$\mathrm{K} \quad$ índice das barras elétricas equivalentes.

$N_{K} \quad$ número total de barras equivalentes no sistema. 
$\Omega_{\mathrm{k}} \quad$ conjunto de linhas de transmissão conectadas à barra equivalente $\mathrm{k}$.

$f_{m k, t} \quad$ fluxo de energia da barra equivalente $\mathrm{m}$ para a barra equivalente $\mathrm{k}$ na etapa $\mathrm{t}$

$\gamma_{m k, t}$ coeficiente de perdas de fluxo de transmissão de $\mathrm{m}$ para $\mathrm{k}$ durante a etapa $\mathrm{t}$, expressado em \% do fluxo atual.

$d_{k, t} \quad$ demanda de energia na barra equivalente $\mathrm{k}$ durante a etapa $\mathrm{t}$.

4.2 Limites de Intercâmbio

Os intercâmbios de energia entre as regiões estão limitados em valores máximos e mínimos:

$$
\begin{gathered}
f_{m k, t} \leq \bar{f}_{m k} \\
\forall \quad k=1, \ldots, N_{K} ; t=1, \ldots, N_{T} ; m \in \Omega_{k}
\end{gathered}
$$

Onde $\bar{f}_{m k}$ é a capacidade permitida de transporte da linha de transmissão que une as barras equivalentes $m$ e $k$.

\section{Modelo de Optimização incluindo as Restrições da Rede de Transmissão}

$\operatorname{Min} \sum_{j=1}^{N_{J}}\left[\sum_{t=1}^{N_{T}}\left(C O_{j, t} g t_{j, t}\right)\right]$

s/a

$\sum_{j \in k} g t_{j, t}+\sum_{i \in k} \rho_{i} q_{i, t}+\sum_{m \in \Omega(k)}\left(\left(1-0.5 \gamma_{m k, t}\right) f_{m k, t}-\left(1+0.5 \gamma_{k m, t}\right) f_{k m, t}\right)=d_{k, t} \quad \pi_{d_{k, t, s}}^{c p}$

$g t_{j, t} \leq \overline{g t}_{j, t}$ 


$$
\begin{aligned}
& f_{m k, t} \leq \bar{f}_{m k} \\
& \pi_{f_{m k, t, s}}^{c p} \\
& v_{i, t+1}-v_{i, t}-\sum_{l \in M i}\left(q_{l}+s_{l}\right)+q_{i}+s_{i}=a_{i, t}-e_{i, t} \\
& v_{i, t, k-1}-v_{i, t, k}-\sum_{l \in M i}\left(q_{l}+s_{l}\right)+q_{i}+s_{i}=a_{i, t} \\
& v_{i, t} \leq \bar{v}_{i, t} \\
& v_{i, t} \geq \underline{v}_{i, t} \\
& v_{i, t, k} \leq \bar{v}_{i} \\
& q_{i, t} \leq \bar{q}_{i, t} \\
& \pi_{q_{i, t, s}}^{c p} \\
& q_{i, t} \geq \underline{q_{i, t}} \\
& r_{i, t} \leq \bar{r}_{i, t} \\
& r_{i, t} \geq \underline{r}_{i, t} \\
& f_{m k, t}=f_{m k}\left(\theta_{m}, \theta_{k}\right) \geq 0 \\
& \forall \quad k=1, \ldots, N_{K} ; \quad i=1, \ldots, N_{I} ; \quad j=1, \ldots, N_{J} ; \quad t=1, \ldots, N_{T}
\end{aligned}
$$

\section{Modelo Matemático Estocástico}

O modelo matemático de operação de sistemas hidrotérmicos para uma sequência hidrológica $s$, pode-se representar através do modelo recursivo em programação dinâmica estocástica, mostrado na seguinte equação para um entendimento mais claro do conjunto:

$\alpha_{t}\left(v_{t}, A_{t-1}\right)=E_{A t \mid A t+1}\left\{\operatorname{Min}\left[\sum_{j=1}^{N_{J}} c o_{j} g t_{j, t}+\alpha_{t+1}\left(v_{t+1}, A_{t}\right)\right]\right\}$

$s / a$ 


$$
\begin{array}{lc}
\sum_{j \in k} g t_{j, t}+\sum_{i \in k} \rho_{i} q_{i, t}+\sum_{m \in \Omega(k)}\left(\left(1-0.5 \gamma_{m k, t}\right) f_{m k, t}-\left(1+0.5 \gamma_{k m, t}\right) f_{k m, t}\right)=d_{k, t} & \pi_{d_{k, t, s}}^{c p} \\
g t_{j, t} \leq \overline{g t}_{j, t} & \pi_{g t_{j, t, s}}^{c p} \\
f_{m k, t} \leq \bar{f}_{m k} & \pi_{f_{m k, t, s}}^{c p} \\
v_{i, t+1}-v_{i, t}-\sum_{l \in M i}\left(q_{l}+s_{l}\right)+q_{i}+s_{i}=a_{i, t}-e_{i, t} & \pi_{a_{i, t, s}}^{c p} \\
v_{i, t, k-1}-v_{i, t, k}-\sum_{l \in M i}\left(q_{l}+s_{l}\right)+q_{i}+s_{i}=a_{i, t} & \\
v_{i, t} \leq \bar{v}_{i, t} & \\
v_{i, t} \geq \underline{v}_{i, t} & \pi_{v_{i, t, s}}^{c p} \\
v_{i, t, k} \leq \bar{v}_{i} & \\
q_{i, t} \leq \bar{q}_{i, t} & \\
q_{i, t} \geq \underline{q}_{i, t} & \\
r_{i, t} \leq \bar{r}_{i, t} & \\
r_{i, t} \geq \underline{r}_{i, t} & \\
f_{m k, t}=f_{m k}\left(\theta_{m}, \theta_{k}\right) \geq 0 & \pi_{q_{i, t, t, s}}^{c p} \\
\forall \quad k=1, \ldots, N_{K} ; \quad i=1, \ldots, N_{I} ; j=1, \ldots, N_{J} ; t=1, \ldots, N_{T} & \\
\forall \quad t &
\end{array}
$$

Onde:

$\mathrm{K} \quad$ índice das barras elétricas equivalentes.

$N_{K} \quad$ número total de barras equivalentes no sistema.

$\Omega_{\mathrm{k}} \quad$ conjunto de linhas de transmissão conectadas à barra equivalente $\mathrm{k}$.

$f_{m k, t} \quad$ fluxo de energia da barra equivalente $m$ para a barra equivalente $\mathrm{k}$ na etapa $\mathrm{t}$

$\gamma_{m k, t}$ coeficiente de perdas de fluxo de transmissão de m para $\mathrm{k}$ durante a etapa $\mathrm{t}$, expressado em \% do fluxo atual.

$d_{k, t} \quad$ demanda de energia na barra equivalente $\mathrm{k}$ durante a etapa t.

$\bar{v}_{i, t} \quad$ volume do embalse mínimo. 
$\underline{v}_{i, t} \quad$ volume do embalse máximo.

$\bar{v}_{i} \quad$ volume máximo nos reservatórios diários.

$q_{i, t} \quad$ volume turbinado na i-ésima usina hidrelétrica durante a etapa t.

$\bar{q}_{i, t} \quad$ volume turbinado máximo.

$q_{i, t} \quad$ volume turbinado mínimo.

$r_{i, t} \quad$ vazões reguladas.

$\underline{r}_{i, t} \quad$ vazões reguladas mínimas de irrigação, navegação ou recreação.

$\bar{r}_{i, t} \quad$ vazões reguladas máximos caso das grandes estações chuvosas. 